CYRO ALBUQUERQUE NETO

MODELO INTEGRADO DOS SISTEMAS TÉRMICO E RESPIRATÓRIO DO CORPO HUMANO 

CYRO ALBUQUERQUE NETO

\title{
MODELO INTEGRADO DOS SISTEMAS TÉRMICO E RESPIRATÓRIO DO CORPO HUMANO
}

\author{
Tese apresentada à Escola Politécnica \\ da Universidade de São Paulo \\ para obtenção do título \\ de Doutor em Engenharia
}



CYRO ALBUQUERQUE NETO

\title{
MODELO INTEGRADO DOS SISTEMAS TÉRMICO E RESPIRATÓRIO DO CORPO HUMANO
}

\author{
Tese apresentada à Escola Politécnica \\ da Universidade de São Paulo \\ para obtenção do título \\ de Doutor em Engenharia \\ Área de Concentração: \\ Engenharia Mecânica \\ Orientador: \\ Prof. Dr. Jurandir Itizo Yanagihara
}


Este exemplar foi revisado e alterado em relação à versão original, sob responsabilidade única do autor e com a anuência de seu orientador.

São Paulo, de dezembro de 2010.

Assinatura do autor

Assinatura do orientador

FICHA CATALOGRÁFICA

Albuquerque Neto, Cyro

Modelo integrado dos sistemas térmico e respiratório do corpo humano / C. Albuquerque Neto. -- ed.rev. -- São Paulo, 2010.

186 p.

Tese (Doutorado) - Escola Politécnica da Universidade de São Paulo. Departamento de Engenharia Mecânica.

1. Transferência de calor 2. Massa (Transferência) 3. Bioengenharia 4. Sistema respiratório 5. Corpo humano (Modelagem matemática) I. Universidade de São Paulo. Escola Politécnica. Departamento de Engenharia Mecânica II. t. 


\section{Agradecimentos}

Ao Jurandir Itizo Yanagihara, pela orientação. Ao Maurício Silva Ferreira e ao Fábio Turri, autores das principais referências deste trabalho. Ao Fernando Fernandes Chaves e ao Leandro de Moraes, pela otimização do programa computacional. À Fundação de Amparo à Pesquisa do Estado de São Paulo (FAPESP), pelo suporte ao projeto. 



\section{Resumo}

O objetivo deste trabalho é o desenvolvimento de um modelo matemático dos sistemas térmico e respiratório humanos que permita, a partir das condições do ambiente e do nível de atividade física, determinar a distribuição da temperatura e das concentrações de oxigênio e dióxido de carbono ao longo do corpo. No modelo representou-se o corpo humano dividido em quinze segmentos: cabeça, pescoço, tronco, braços, antebraços, mãos, coxas, pernas e pés. Cada segmento contém um compartimento arterial e um compartimento venoso, os quais representam os grandes vasos. O sangue nos pequenos vasos foi considerado juntamente com os tecidos - músculo, gordura, pele, osso, cérebro, pulmão, coração e vísceras. Os gases - $\mathrm{O}_{2}$ e $\mathrm{CO}_{2}$ - são transportados pelo sangue e armazenados nos tecidos, dissolvidos e reagidos quimicamente. Nos tecidos ocorre metabolismo, que consome oxigênio e produz dióxido de carbono e calor. A pele troca calor com o ambiente por condução, convecção, radiação e evaporação. O trato respiratório o faz pela ventilação, por convecção e evaporação. Nos pulmões ocorre transferência de massa, por difusão entre um compartimento alveolar e diversos compartimentos capilares pulmonares. Para modelar o transporte de massa e o transporte de calor nos tecidos foram usadas duas formas distintas. No caso da transferência de massa, os tecidos foram representados por compartimentos nos segmentos modelados. No caso da transferência de calor, foram representados por camadas nos segmentos, sendo que estes ora têm a geometria de um cilindro (seção transversal circular), ora a de um paralelogramo - no caso das mãos e dos pés. O sistema regulador do corpo humano foi divido em quatro formas de atuação: metabolismo, circulação, ventilação e sudorese. O metabolismo varia com o calafrio (que depende da temperatura corporal) e a atividade física; a circulação depende da concentração dos gases no corpo, da temperatura e do metabolismo; a ventilação, da concentração dos gases; a sudorese, da temperatura. Para solucionar as equações diferenciais do modelo foram usados métodos numéricos implícitos. As equações diferenciais parciais foram discretizadas pelo método dos volumes finitos. Comparações com trabalhos experimentais encontrados na literatura mostraram que o modelo é adequado para representar variações climáticas, exposições a quantidades reduzidas de oxigênio e elevadas de dióxido de carbono, e situações de exercício físico. Outros resultados gerados pelo modelo demonstraram que acidentes de descompressão tornam-se mais severos quando associados à queda da temperatura ambiente, por causa do aumento do consumo de $\mathrm{O}_{2}$ pelo calafrio. Este também aumenta o risco de uma intoxicação por $\mathrm{CO}_{2}$, devido ao aumento da sua produção. O modelo mostrou-se ainda capaz de prever diversas interações entre os sistemas térmico e respiratório, como a diminuição da temperatura corpórea pelo aumento da ventilação (que depende das concentrações de $\mathrm{O}_{2}$ e $\mathrm{CO}_{2}$ ), ou a diminuição da pressão parcial dos gases nos segmentos mais extremos, em consequência do efeito da temperatura na capacidade do sangue de transportá-los. 
Palavras-chave: Bioengenharia. Modelagem matemática. Biotransferência de calor. Sistema respiratório. 


\section{Abstract}

The aim of this work is the development of a mathematical model of the human body respiratory and thermal systems. The model allows the determination of the temperature, oxygen and carbon dioxide distributions, depending on the ambient conditions and the physical activity level. The human body was divided into 15 segments: head, neck, trunk, arms, forearms, hands, thighs, legs and feet. Each segment contains an arterial and a venous compartment, representing the large vessels. The blood in the small vessels is considered together with the tissues - muscle, fat, skin, bone, brain, lung, heart and viscera. The gases $-\mathrm{O}_{2}$ and $\mathrm{CO}_{2}$ - are transported by the blood and stored by the tissues dissolved and chemically reacted. Metabolism takes place in the tissues, where oxygen is consumed generating carbon dioxide and heat. The skin exchanges heat with the environment by conduction, convection, radiation and evaporation. The respiratory tract exchanges heat by convection and evaporation. In the lungs, mass transfer happens by diffusion between an alveolar compartment and several pulmonary capillaries compartments. Two different forms were used to model the transport of mass and heat in the tissues. For the mass transfer, the tissues were represented by compartments inside the segments. For the heat transfer, the tissues were represented by layers inside the segments, which have the geometry of a cylinder (circular cross-section) or a parallelogram - hands and feet. The regulatory systems were divided into four mechanisms: metabolism, circulation, ventilation and sweating. The metabolism is modified by the shivering (which depends on the body temperature) and the physical activity; the circulation depends on the body gas concentrations, the temperature and the metabolism; the ventilation depends on the gas concentrations; the sweating depends on the temperature. Implicit methods were used to solve the differential equations. The discretization of the partial differential equations was obtained applying the finite volume method. Comparisons with experimental works found in literature show that the model is suitable to represent the exposure to cold and warm ambients, to low amounts of oxygen, to carbon dioxide, and physical activity. Other results of the developed model show that decompression accidents become more severe when associated to low ambient temperatures, because of the increase in the $\mathrm{O}_{2}$ consumption by shivering. The shivering also increases the danger of a $\mathrm{CO}_{2}$ intoxication, due to the increase of its production. The model showed as well the capacity to represent the several interactions between the thermal and respiratory systems, as the decrease of the body temperature because of the increase in the ventilation (which depends on the $\mathrm{O}_{2}$ and $\mathrm{CO}_{2}$ concentrations), or the decrease of the $\mathrm{O}_{2}$ and $\mathrm{CO}_{2}$ partial pressures in the more extreme segments, consequence of the temperature effect on their blood transport capacity.

Keywords: Bioengineering. Mathematical model. Bioheat transfer. Respiratory system. 



\section{Lista de Abreviaturas e Siglas}

BTPS body temperature and pressure saturated

$\mathrm{CSF}$ líquido cefalorraquidiano

EDO equação diferencial ordinária

EDP equação diferencial parcial

HVD hypoxic ventilatory decline

MVF método dos volumes finitos

PSP post-stimulus potentiation

SI sistema internacional de unidades

STPD standard temperature and pressure dry 



\section{Lista de Símbolos}

\section{Variáveis}

\section{Letras minúsculas}

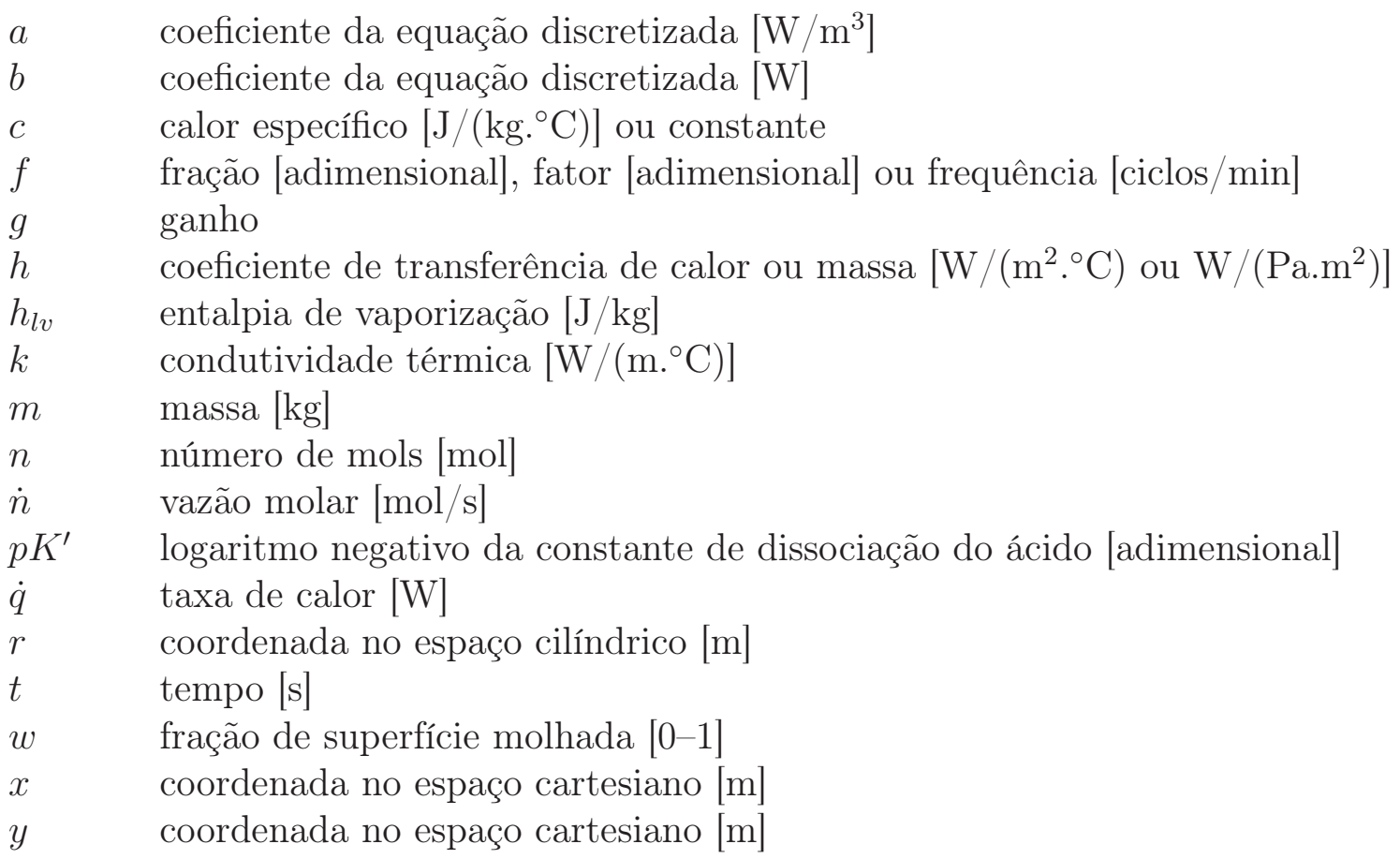

\section{Letras maiúsculas}

$\begin{array}{ll}A & \text { área }\left[\mathrm{m}^{3}\right] \\ B E & \text { excesso de base }[\mathrm{mEq} / \mathrm{L}] \\ C & \text { concentração }\left[\mathrm{mol} / \mathrm{m}^{3} \text { ou ml } /(100 \mathrm{ml})\right] \\ D & \text { coeficiente de difusão }\left[\mathrm{m}^{2} / \mathrm{s} \mathrm{ou} \mathrm{m} \mathrm{m}^{2} /(\mathrm{Pa} . \mathrm{s})\right] \\ H & \text { coeficiente de transferência de calor }\left[\mathrm{W} /{ }^{\circ} \mathrm{C}\right] \\ I & \text { isolamento }[\mathrm{clo}] \\ {\left[\mathrm{HCO}_{3}^{-}\right]} & \text {concentração de íon bicarbonato }[\mathrm{mmol} / \mathrm{L}] \\ {[H b]} & \text { concentração de hemoglobina }[\mathrm{g} /(100 \mathrm{ml})] \\ L & \text { comprimento }[\mathrm{m}] \\ {[M b]} & \text { concentração de mioglobina }\left[\mathrm{kg} / \mathrm{m}^{3}\right] \\ N & \text { número total ou capacidade máxima }\end{array}$




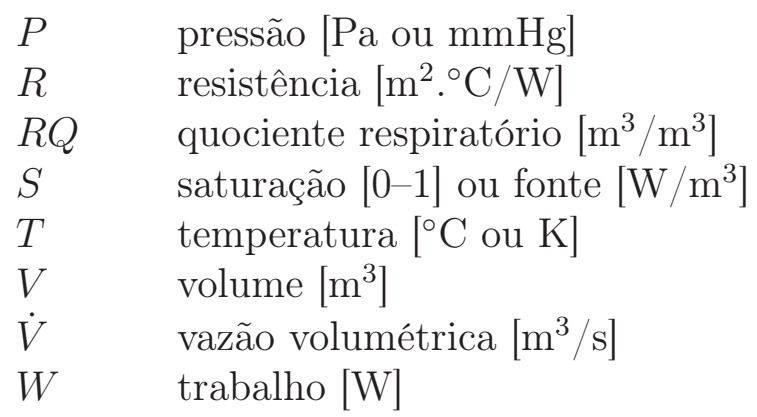

\section{Letras gregas}

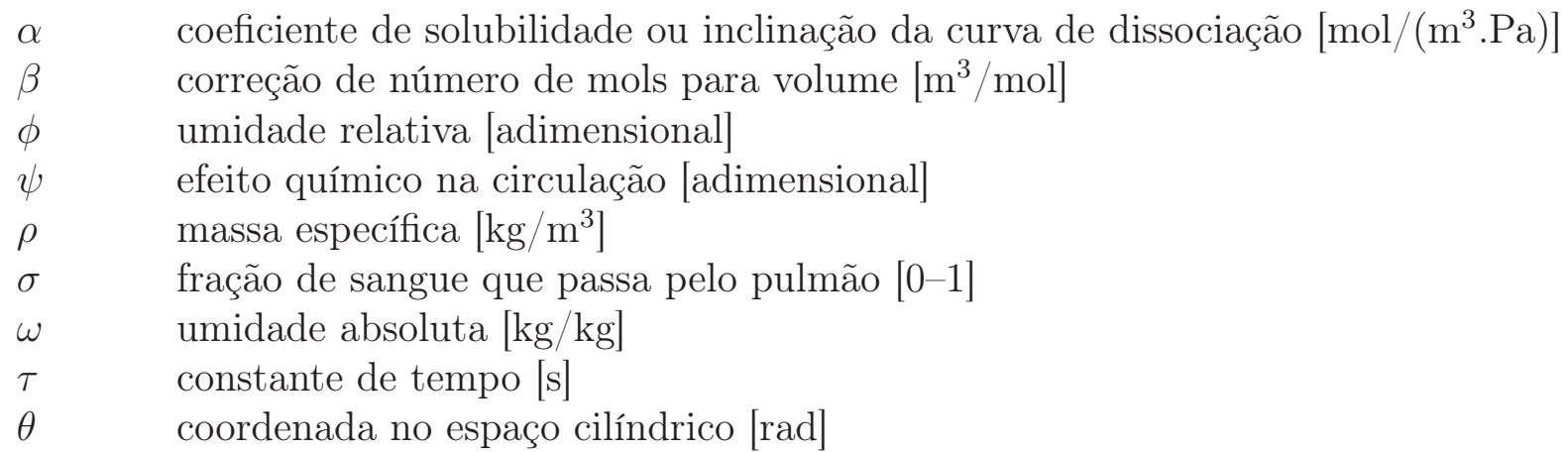

\section{Subscritos}

\section{Letras minúsculas}

$\begin{array}{ll}0 & \text { basal } \\ a & \text { ar ambiente } \\ a l & \text { camada de ar } \\ a r & \text { arterial } \\ a t & \text { atividade física } \\ a v & \text { entre arterial e venoso } \\ b a r & \text { barométrica } \\ b l & \text { sangue } \\ c & \text { convecção } \\ c h & \text { químico } \\ c l & \text { roupa } \\ c o r & \text { corrigido } \\ c p & \text { capilar pulmonar } \\ d & \text { atraso } \\ e & \text { face leste ou evaporação } \\ f & \text { fronteira ou tecido da roupa } \\ f c & \text { fator químico } \\ g & \text { gás } \\ h y & \text { hipotálamo }\end{array}$




$\begin{array}{ll}i & \text { interno } \\ \text { in } & \text { inspirado } \\ m e t & \text { metabolismo } \\ m & \text { tecido muscular } \\ n & \text { face norte } \\ o & \text { operativa } \\ p l & \text { plasma } \\ r & \text { radiação } \\ r e & \text { respiração } \\ r t & \text { trato respiratório } \\ s & \text { face sul } \\ s h & \text { calafrio } \\ s k & \text { pele } \\ s p & \text { segmento posterior } \\ s t a t & \text { estático } \\ s v & \text { pequenos vasos } \\ t & \text { tecido } \\ t h & \text { térmico } \\ v e & \text { venoso } \\ w & \text { água ou face oeste }\end{array}$

Letras maiúsculas

$\begin{array}{ll}A & \text { alveolar } \\ C & \text { central } \\ D & \text { espaço morto } \\ E & \text { expiração ou leste } \\ H b & \text { hemoglobina } \\ I & \text { inspiração } \\ L & \text { pulmão } \\ M b & \text { mioglobina } \\ N & \text { norte } \\ P & \text { periférico ou centro da célula } \\ S & \text { sul } \\ T & \text { corrente } \\ W & \text { oeste }\end{array}$

\section{Sobrescritos}

Letras minúsculas

$\begin{array}{ll}\text { in } & \text { entrada } \\ \text { out } & \text { saida } \\ \text { ref } & \text { referência }\end{array}$




\section{Símbolos}

média

por unidade de tempo

por unidade de volume

por unidade de área 


\section{Sumário}

1 Introdução $\quad 21$

1.1 Modelos . . . . . . . . . . . . . . . . . . . . 22

1.2 Objetivo . . . . . . . . . . . . . . . . . . . 22

1.3 Estrutura da tese . . . . . . . . . . . . . . . . . . 23

2 Revisão da Literatura $\quad 25$

2.1 Modelos do sistema respiratório . . . . . . . . . . . . . . 25

2.1.1 Primeiros modelos da ventilação . . . . . . . . . . . . . 25

2.1.2 Modelos multicompartimentais . . . . . . . . . . . 26

2.1.3 Controle cardiovascular . . . . . . . . . . . . . . . . . . . . . . . 29

2.1.4 O modelo de Albuquerque-Neto, Yanagihara e Turri (2008) . . . . . 30

2.2 Modelos do sistema térmico . . . . . . . . . . . . . . . . . . . 31

2.2.1 Biotransferência de calor . . . . . . . . . . . . . . . . . 31

2.2.2 Modelos completos . . . . . . . . . . . . . . . . . . 32

2.2 .3 Controladores . . . . . . . . . . . . . . . . . . . 36

2.2.4 O modelo de Ferreira e Yanagihara (2009) . . . . . . . . . . . . 37

2.3 Modelos integrados . . . . . . . . . . . . . . . . . . . 40

2.3.1 O modelo de Downey e Seagrave (2000) . . . . . . . . . . . . . . . 40

2.3.2 O modelo de Ji e Liu (2002) . . . . . . . . . . . . . . . . . 40

2.3.3 O modelo de Gaohua e Kimura (2008) . . . . . . . . . . . . . . . . 41

3 Fenômenos de Transporte no Sangue 43

3.1 Normas e unidades dos gases . . . . . . . . . . . . . . . . . . . 43

3.2 Oxigênio . . . . . . . . . . . . . . . . . . . . . . . 45

3.3 Dióxido de carbono . . . . . . . . . . . . . . . . . . . . . . . . 48

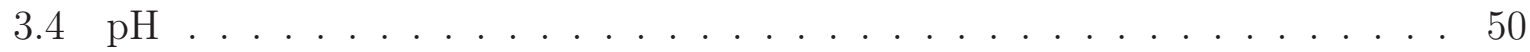


3.5 Circulação . . . . . . . . . . . . . . . . . . . . . . 51

3.6 Transferência de calor . . . . . . . . . . . . . . . . . . . 52

4 Fenômenos de Transporte nos Tecidos 55

4.1 Metabolismo . . . . . . . . . . . . . . . . . . . 55

4.2 Oxigênio . . . . . . . . . . . . . . . . . . . . . . . 59

4.2 .1 Tecidos musculares . . . . . . . . . . . . . . . . . . . 60

4.3 Dióxido de carbono . . . . . . . . . . . . . . . . . . . 61

4.4 Transferência entre pele e ambiente . . . . . . . . . . . . . . . . . . 62

5 Fenômenos de Transporte no Pulmão $\quad 69$

5.1 Mecanismos .............................. 69

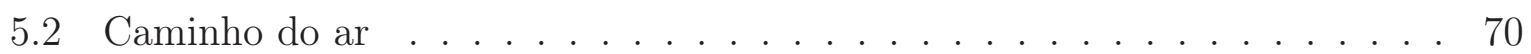

5.2.1 Propriedades termodinâmicas do ar . . . . . . . . . . . 70

5.3 Gases atmosféricos . . . . . . . . . . . . . . . . . . . 71

5.4 Ventilação alveolar . . . . . . . . . . . . . . . . . . . . . . . 72

5.5 Volume minuto respiratório . . . . . . . . . . . . . 73

5.6 Difusão pulmonar . . . . . . . . . . . . . . . . . . . . . . . 73

5.6.1 Membrana respiratória . . . . . . . . . . . . . . . . 73

5.6 .2 Uniformidade dos gases . . . . . . . . . . . . . . . . 75

5.6 .3 Capacidade de difusão . . . . . . . . . . . . . . . . 75

6 Modelagem da Transferência de Calor e Massa $\quad 79$

6.1 Geometria do corpo humano . . . . . . . . . . . . . . . . . . . . . 79

6.2 Camadas . . . . . . . . . . . . . . . . . . . . 80

6.3 Circulação . . . . . . . . . . . . . . . . . . . . . 83

6.4 Metodologia de modelagem . . . . . . . . . . . . . . . . . 84

6.5 Modelagem dos grandes vasos . . . . . . . . . . . . . . . . . . 86

6.5.1 Transferência de calor no compartimento arterial . . . . . . . . . 87

6.5.2 Transferência de calor no compartimento venoso . . . . . . . . . . . 89

6.5.3 Transferência de massa no compartimento arterial . . . . . . . . . . 91

6.5.4 Transferência de massa no compartimento venoso . . . . . . . . . . 92

6.6 Modelagem dos pequenos vasos e tecidos . . . . . . . . . . . . . 93

6.6.1 Transferência de calor . . . . . . . . . . . . . . . . . 93 
6.6.2 Transferência de massa . . . . . . . . . . . . . . . . . . 96

6.7 Modelagem da transferência de massa no pulmão . . . . . . . . . . . . . 100

6.7 .1 Inspiração . . . . . . . . . . . . . . . . . . . . . . . . . . . 101

6.7 .2 Compartimento alveolar . . . . . . . . . . . . . . . . . 101

6.7.3 Compartimentos capilares pulmonares . . . . . . . . . . . 103

6.8 Modelagem da transferência de calor no trato respiratório . . . . . . . . . . 104

7 Modelagem do Sistema Regulador $\quad 111$

7.1 Sinais . . . . . . . . . . . . . . . . . . . 112

7.1 .1 Sinais térmicos . . . . . . . . . . . . . . . . . 112

7.1 .2 Sinais químicos . . . . . . . . . . . . . . . . 113

7.1 .3 Sinais musculares . . . . . . . . . . . . . . . . 114

7.2 Metabolismo . . . . . . . . . . . . . . . . . . 114

7.2 .1 Calafrio . . . . . . . . . . . . . . . . 115

7.2 .2 Atividade física . . . . . . . . . . . . . . 116

7.3 Circulação . . . . . . . . . . . . . . . . . . . . . 117

7.3 .1 Fator químico . . . . . . . . . . . . . . . . . . . 118

7.3.2 Fator térmico . . . . . . . . . . . . . . . . . . . 119

7.3.3 Efeito do metabolismo . . . . . . . . . . . . . . . . . 121

7.4 Ventilação . . . . . . . . . . . . . . . . . . . . . . . . 122

7.5 Sudorese . . . . . . . . . . . . . . . . . . . . . 123

8 Solução do Modelo $\quad 125$

8.1 Discretização da equação de condução de calor . . . . . . . . . . . . . 126

8.1.1 Geração da malha . . . . . . . . . . . . . . . . . . . 127

8.1.2 Forma da equação discretizada . . . . . . . . . . . . . . . . . . 127

8.1 .3 Fonte . . . . . . . . . . . . . . . . . . 128

8.1.4 Propriedades geométricas . . . . . . . . . . . . . . . 128

8.1.5 Fronteira . . . . . . . . . . . . . . . . . . . 129

8.1.6 Coeficientes da equação discretizada . . . . . . . . . . . . . . . . . 129

8.1.7 Condutividade na interface . . . . . . . . . . . . . . . . 132

8.2 Implementação computacional . . . . . . . . . . . . . . . . . . . . . 132

8.2.1 Modelagem de objetos . . . . . . . . . . . . . . . 133 
9.1 Comparação com dados experimentais da literatura . . . . . . . . . . . 136

9.1.1 Respiração em situação normal . . . . . . . . . . . . . . . 136

9.1.2 Variações da temperatura ambiente . . . . . . . . . . . . . . . . 137

9.1.3 Exposição a ambiente frio . . . . . . . . . . . . . . . . . 140

9.1.4 Exposição a ambiente quente . . . . . . . . . . . . . . . 143

9.1.5 Exposição a grandes altitudes . . . . . . . . . . . . . . 146

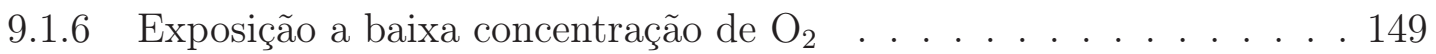

9.1 .7 Exposição ao $\mathrm{CO}_{2} \ldots \ldots$. . . . . . . . . . . . . . . 151

9.1.8 Respiração durante exercício físico . . . . . . . . . . . . . . . . 152

9.1 .9 Termorregulação durante exercício físico . . . . . . . . . . . . 156

9.2 Alterações no corpo humano em diferentes temperaturas ambientes . . . . 158

9.3 Acidentes de descompressão . . . . . . . . . . . . . . . . . 163

9.4 Intoxicação por $\mathrm{CO}_{2} \ldots \ldots \ldots \ldots \ldots$. . . . . . . . . . . . . . . . . . . . .

9.5 Exercício físico . . . . . . . . . . . . . . . . . . . 170

$\begin{array}{ll}10 \text { Conclusão } & 175\end{array}$

$\begin{array}{ll}\text { Referências } & 177\end{array}$ 


\section{Capítulo 1}

\section{Introdução}

O corpo humano é uma máquina complexa, formada por mecanismos que interagem entre si. Para o estudo destes, a Fisiologia o dividiu em sistemas, dependendo da função de cada mecanismo. Este trabalho trata de dois sistemas diretamente relacionados à atividade metabólica: o sistema respiratório e o sistema térmico.

A função principal do sistema respiratório é transportar o oxigênio $\left(\mathrm{O}_{2}\right)$ do ar externo até os tecidos, e remover o dióxido de carbono $\left(\mathrm{CO}_{2}\right)$ dos tecidos para o ambiente. Os tecidos utilizam o $\mathrm{O}_{2}$ e geram, como produto, $\mathrm{CO}_{2}$ e calor. A função do sistema térmico é manter a temperatura corporal interna dentro de limites aceitáveis.

São diversas as interações que ocorrem entre os processos do sistema respiratório e do sistema térmico. O metabolismo, a circulação sanguínea e a ventilação pulmonar são exemplos de mecanismos diretamente ligados aos dois sistemas.

No estudo de sistemas biológicos, a modelagem matemática vem sendo cada vez mais utilizada. Tem vantagens em relação aos métodos experimentais. Pode ser utilizada em situações em que a realização de um experimento não seria possível como, por exemplo, na existência de riscos de saúde para um indivíduo.

Modelos matemáticos do corpo humano podem ser empíricos, apresentando consistência na situação em que o experimento foi realizado. Também podem ter base fisiológica, descrevendo os mecanismos do corpo humano de forma simplificada com parâmetros reais. Os resultados experimentais são, neste caso, utilizados para calibração, validação e representação de mecanismos complexos.

Na Engenharia, conceitos de modelagem são amplamente utilizados. O presente trabalho aplica conceitos referentes a transferência de calor, transferência de massa e teoria de controle para a representação do corpo humano. 


\section{$1.1 \quad$ Modelos}

Desde meados do século XX, vários modelos teóricos do sistema respiratório e do sistema térmico do corpo humano foram desenvolvidos. No primeiro modelo do sistema respiratório, Grodins et al. (1954) representaram o corpo humano por compartimentos, com o objetivo de estudar a regulação do $\mathrm{CO}_{2}$. No primeiro modelo do sistema térmico, Wissler (1961) representou o corpo humano por segmentos com geração interna de calor, circulação de sangue e transferência de calor com o ambiente. Desde então, outros modelos específicos de cada um destes sistemas foram desenvolvidos. Já modelos que incluem ambos os sistemas começaram a ser desenvolvidos recentemente e são escassos.

O presente trabalho tem como base o modelo do sistema respiratório de AlbuquerqueNeto, Yanagihara e Turri (2008) e o modelo do sistema térmico de Ferreira e Yanagihara (2009). Ambos são modelos recentes, que consideram diversos aspectos importantes desenvolvidos ao longo da história.

No modelo do sistema respiratório de Albuquerque-Neto, Yanagihara e Turri (2008), o corpo humano foi representado por compartimentos sanguíneos (arterial, venoso, capilares pulmonares e teciduais), compartimentos teciduais (muscular e não muscular) e por um compartimento alveolar. As equações geradas a partir de balanços de massa determinam a concentração de $\mathrm{O}_{2}, \mathrm{CO}_{2}$ e $\mathrm{CO}$ em cada compartimento ao longo do tempo. O modelo tem como entrada a concentração dos gases no ambiente e o nível de atividade física.

No modelo do sistema térmico de Ferreira e Yanagihara (2009), o corpo humano foi dividido em quinze segmentos - cabeça, pescoço, tronco, braços, antebraços, mãos, coxas, pernas e pés. Os segmentos são cilindros com seção transversal elíptica. São formados por camadas que representam os tecidos (pele, gordura, osso, músculo, cérebro, pulmão, coração e vísceras) e compartimentos sanguíneos (arterial e venoso). A solução da equação de condução de calor, aplicada aos tecidos, permite o cálculo da distribuição de temperatura no corpo ao longo do tempo, dependendo das condições ambientais e da atividade física.

\subsection{Objetivo}

O objetivo principal deste trabalho é o desenvolvimento de um modelo matemático com bases fisiológicas da integração entre o sistema respiratório e o sistema térmico do corpo humano. O modelo deve representar os processos de transferência de calor, $\mathrm{O}_{2}$ e $\mathrm{CO}_{2}$, e os mecanismos que os controlam. Para isto, objetivos mais específicos precisam ser cumpridos. 
$\mathrm{Na}$ primeira parte do trabalho, a transferência de calor e massa em todo o corpo humano deve ser modelada matematicamente. A segunda parte trata da modelagem do sistema regulador. O próximo passo do trabalho é a solução das equações que compõem o modelo. A solução depende da aplicação de métodos numéricos e da implementação computacional.

Os resultados do modelo devem representar situações diversas, como variações climáticas, variação da quantidade de $\mathrm{O}_{2}$ ou $\mathrm{CO}_{2}$ no ambiente, e realização de atividade física.

\subsection{Estrutura da tese}

O texto aqui apresentado pode ser dividido em cinco partes principais:

- Revisão da literatura - o Capítulo 2 apresenta modelos do sistema respiratório, modelos do sistema térmico e de ambos os sistemas integrados.

- Conceitos fisiológicos - os Capítulos 3, 4 e 5 descrevem como ocorre o transporte de calor, $\mathrm{O}_{2}$ e $\mathrm{CO}_{2}$ no sangue, tecidos e pulmão. Estes conceitos são importantes para a compreensão da modelagem.

- Desenvolvimento do modelo - o Capítulo 6 mostra o desenvolvimento da parte de transferência de calor e massa do modelo; o Capítulo 7 mostra o desenvolvimento do sistema regulador.

- Solução - o Capítulo 8 mostra a metodologia usada para solucionar as equações que descrevem o modelo.

- Resultados - o Capítulo 9 apresenta comparações dos resultados do modelo com dados experimentais e análises de algumas aplicações. 



\section{Capítulo 2}

\section{Revisão da Literatura}

Os poucos modelos matemáticos encontrados que integram o sistema respiratório com o sistema térmico do corpo humano são recentes. Já os modelos específicos de cada um destes sistemas começaram a ser desenvolvidos em meados do século passado. Estes últimos são numerosos, no entanto ainda apresentam questões não resolvidas. A busca por modelos que representem a regulação dos sistemas respiratório e térmico continua sendo escopo de pesquisas recentes.

Esta revisão da literatura foi dividida em três partes principais. As duas primeiras partes apresentam modelos específicos do sistema respiratório e do sistema térmico. Nessas partes são apresentados os trabalhos com contexto histórico, os mais utilizados, os recentes e, com maiores detalhes, os que foram usados como referência para o presente trabalho. Na última parte são discutidos os modelos que integram os dois sistemas.

\subsection{Modelos do sistema respiratório}

A modelagem do sistema respiratório teve seu desenvolvimento focado no estudo do controle respiratório. Devido à complexidade dos mecanismos químicos envolvidos, ainda não é totalmente compreendida.

Dois trabalhos auxiliaram esta revisão. Um deles é uma revisão detalhada dos modelos de controle da ventilação feita por Khoo e Yamashiro (1989). O outro é a linha do tempo da modelagem do sistema respiratório de Kappel e Batzel (2003).

\subsubsection{Primeiros modelos da ventilação}

Os primeiros estudos sobre o controle da ventilação ocorreram no fim do século XIX e início do século XX. Um trabalho de grande importância foi o de Haldane e Priestley (1905). Ao analisarem a variação da porcentagem de $\mathrm{CO}_{2}$ alveolar no homem em várias 
situações, concluíram que o excesso de $\mathrm{CO}_{2}$ aumenta a atividade do centro respiratório. Foram feitos experimentos com variações da pressão atmosférica, frequência respiratória, porcentagem de $\mathrm{CO}_{2}$ e $\mathrm{O}_{2}$ inspirado e trabalho muscular. Observaram aumento da ventilação quando o $\mathrm{O}_{2}$ na atmosfera é inferior a $13 \%$; pequeno aumento do $\mathrm{CO}_{2}$ alveolar durante trabalho muscular com grande aumento da ventilação; e também que, em condições normais, a resposta do centro respiratório depende exclusivamente do $\mathrm{CO}_{2}$.

Os primeiros modelos de controle respiratório são em regime permanente. Um dos trabalhos pioneiros mais importante é o de Gray (1946), conhecido como a "teoria do fator múltiplo". Gray (1946) uniu as teorias da época e criou uma equação em que a ventilação é determinada a partir da soma dos efeitos da pressão parcial de $\mathrm{O}_{2}\left(P_{\mathrm{O}_{2}}\right)$, da pressão parcial de $\mathrm{CO}_{2}\left(P_{\mathrm{O}_{2}}\right)$ e do $\mathrm{pH}$.

Os modelos das décadas seguintes concordam que o efeito do $\mathrm{CO}_{2}$ na ventilação é linear. No caso do $\mathrm{O}_{2}$, consideraram que o efeito é multiplicado por uma parcela do efeito do $\mathrm{CO}_{2}$. Havia três principais propostas, que levam a resultados similares. São usadas até os dias de hoje para obter a ventilação em regime permanente. Na primeira delas, proposta por Lloyd, Jukes e Cunningham (1958), o efeito do $\mathrm{O}_{2}$ é hiperbólico. Kronenberg et al. (1972) consideraram que o efeito do $\mathrm{O}_{2}$ é exponencial. Na proposta de Rebuck e Woodley (1975), a dessaturação da hemoglobina representa o efeito do $\mathrm{O}_{2}$, ao invés da $P_{\mathrm{O}_{2}}$. Severinghaus (1976) propôs uma padronização destes modelos, junto com uma metodologia para determinar os coeficientes das equações usando no mínimo cinco pontos medidos. As equações a seguir mostram estas três propostas (hiperbólica, exponencial e dessaturação), com os coeficientes obtidos de um exemplo de Severinghaus (1976):

$$
\begin{aligned}
& \dot{V}_{I}=2\left(P_{C O_{2}, a r}-34,9\right)\left[1+15,8 /\left(P_{O_{2}, a r}-26,2\right)\right]-6,1 \\
& \dot{V}_{I}=2\left(P_{C O_{2}, a r}-34,9\right)\left[1+10,5 e^{\left(-0,055 P_{O_{2}, a r}\right)}\right]-6,1 \\
& \dot{V}_{I}=2\left(P_{C O_{2}, a r}-34,9\right)\left[1+4,7\left(1-S_{O_{2}, a r}\right)\right]-6,1
\end{aligned}
$$

sendo: $\dot{V}_{I}=$ ventilação inspirada $[\mathrm{L} / \mathrm{min}]$;

$P_{\mathrm{CO}_{2}, a r}=$ pressão parcial de $\mathrm{CO}_{2}$ no sangue arterial [mmHg];

$P_{O_{2}, a r}=$ pressão parcial de $\mathrm{O}_{2}$ no sangue arterial $[\mathrm{mmHg}]$;

$S_{\mathrm{O}_{2}, a r}=$ saturação de $\mathrm{O}_{2}$ no sangue arterial [0-1].

\subsubsection{Modelos multicompartimentais}

O primeiro modelo dinâmico do sistema respiratório foi desenvolvido por Grodins et al. (1954). Teve como objetivo o estudo da resposta da ventilação à inalação de $\mathrm{CO}_{2}$. O sistema respiratório foi composto por dois compartimentos, um representando os tecidos e 
outro o pulmão, conectados pela circulação de sangue arterial e venoso. Foram elaboradas equações descrevendo a variação da concentração de $\mathrm{CO}_{2}$ nos compartimentos, a partir de balanços de massa. A pressão parcial de $\mathrm{CO}_{2}$ no pulmão e no tecido foram consideradas iguais, relacionadas linearmente com a respectiva concentração. O controle foi feito por realimentação da concentração de $\mathrm{CO}_{2}$ nos tecidos. Conseguiram resultados satisfatórios ao compará-los com dados experimentais, mesmo com a simplicidade do modelo (Figura 2.1). A divisão do corpo humano em compartimentos é a principal metodologia utilizada na modelagem do sistema respiratório até os dias de hoje. Conhecida por modelagem multicompartimental, é amplamente empregada para modelar sistemas biológicos.

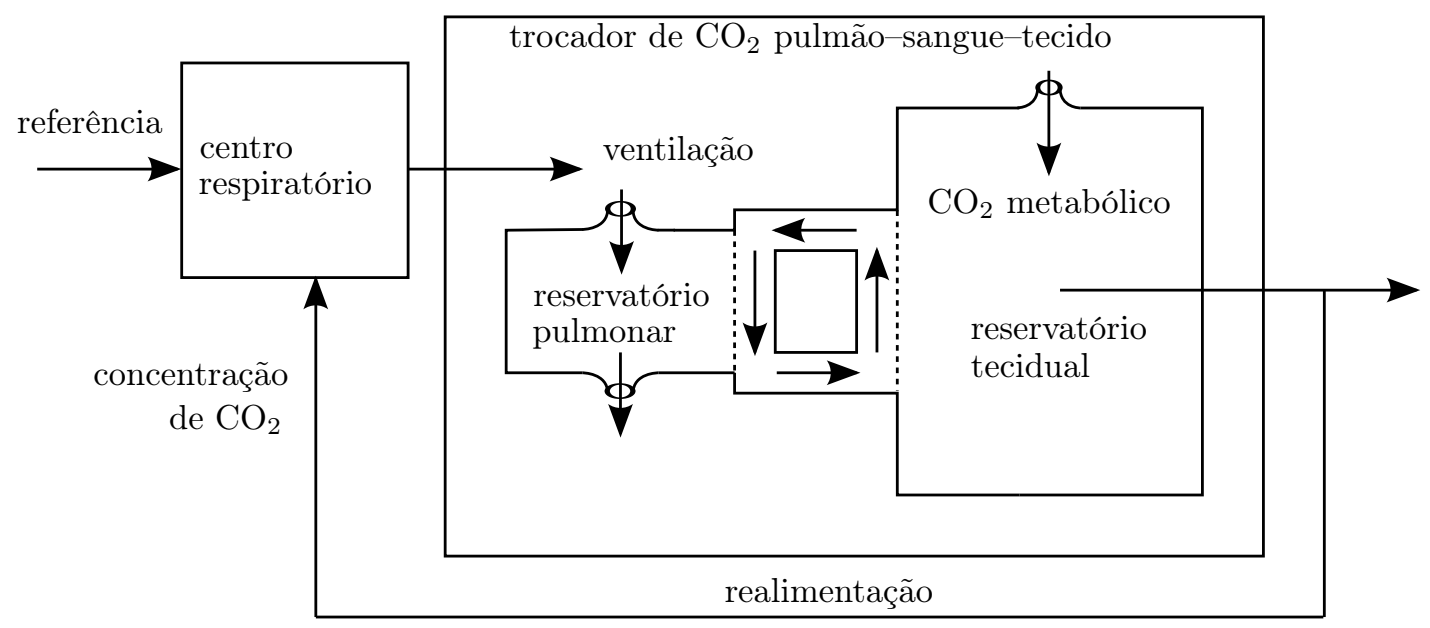

Figura 2.1 - Modelo do sistema respiratório de Grodins et al. (1954) [redesenhado]

Nos anos seguintes, surgiram modelos do sistema respiratório com maior número de detalhes. Horgan e Lange (1965) acrescentaram o oxigênio, consideraram o cérebro separado dos outros tecidos, e incluíram atrasos entre o pulmão e o controlador. Desse modo, foi possível a elaboração do controle da ventilação a partir de entradas mais realistas, separando a parte central da periférica e considerando a pressão parcial de $\mathrm{O}_{2}$. Utilizaram o controle da ventilação proposto por Gray (1946). Aplicaram seu modelo para o sistema respiratório de gatos. Verificaram que os resultados do modelo para variação na pressão parcial de $\mathrm{CO}_{2}$ têm a mesma forma de resultados experimentais.

Nos anos seguintes, surgiram outros modelos com novas características, ainda usando o controle da ventilação de Gray (1946). Milhorn Jr. et al. (1965) acrescentaram o controle da vazão de sangue no cérebro, em função da pressão parcial de $\mathrm{O}_{2}$ e $\mathrm{CO}_{2}$ no sangue arterial. Grodins, Buell e Bart (1967) acrescentaram equações de transporte dos gases no sangue mais elaboradas e débito cardíaco variável. O controle cardíaco desses trabalhos foi obtido por interpolação de dados experimentais.

Longobardo, Cherniack e Fishman (1966) desenvolveram um modelo do sistema respiratório considerando que os efeitos do $\mathrm{CO}_{2}$ e $\mathrm{O}_{2}$ na ventilação são multiplicativos, e que o efeito do $\mathrm{O}_{2}$ é hiperbólico. Aplicaram seu modelo para o estudo da respiração de 


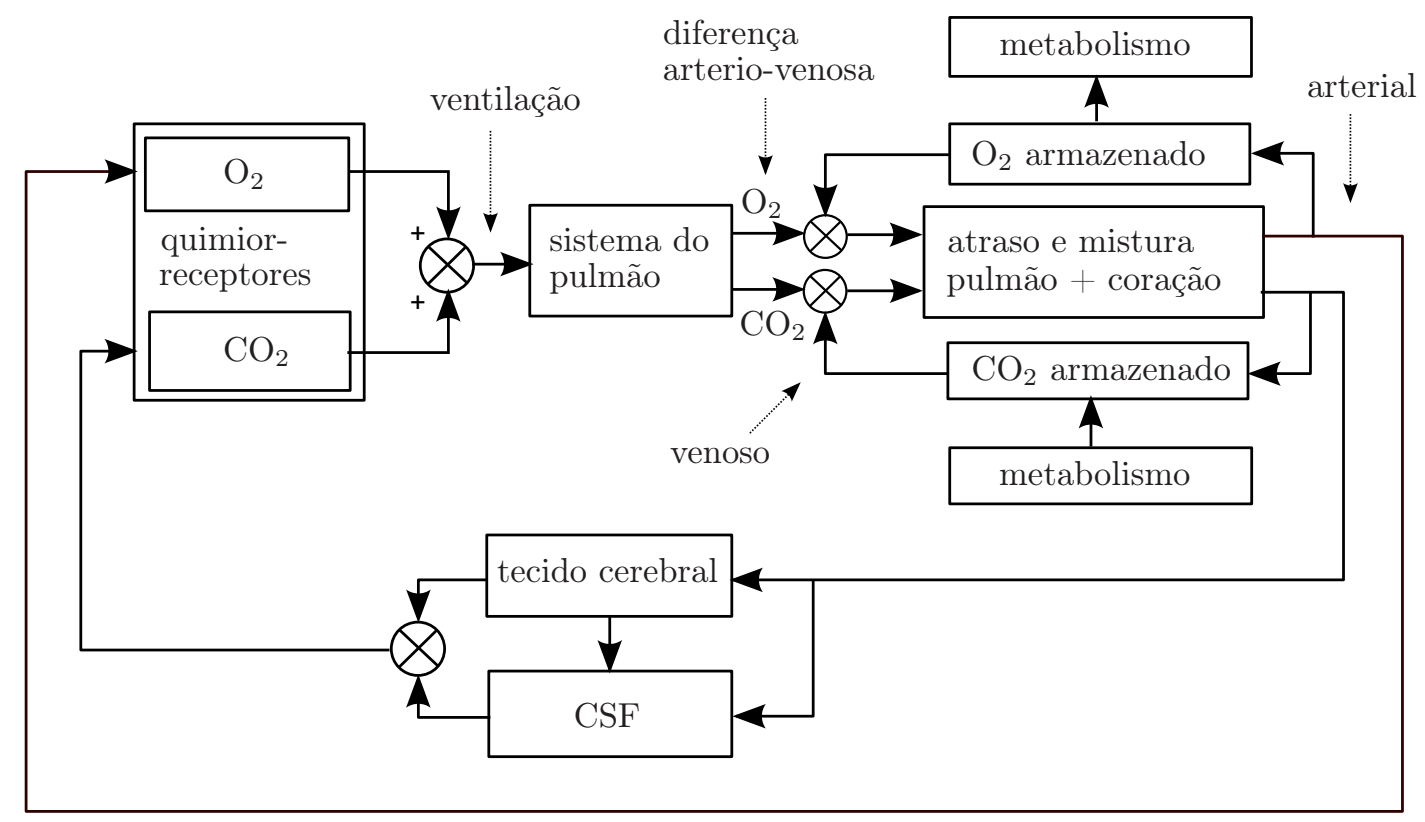

Figura 2.2 - Modelo do sistema respiratório de Horgan e Lange (1965) [redesenhado]

Cheyne-Stokes ${ }^{1}$. Também com esta mesma aplicação, Khoo et al. (1982) desenvolveram um modelo mais elaborado, incluindo análise de estabilidade do controle da ventilação. Consideraram que a fração da ventilação que independe do efeito do $\mathrm{O}_{2}$ está relacionada com a parte central (cérebro). A outra fração está relacionada com a parte periférica (outros tecidos). O efeito do $\mathrm{O}_{2}$ foi considerado exponencial.

Na maioria dos modelos, a difusão pulmonar não é considerada. Neste caso, os gases presentes nos alvéolos estão em equilíbrio com o sangue. Warner e Seagrave (1970) consideraram a difusão do $\mathrm{O}_{2}$ e do $\mathrm{CO}_{2}$ através da membrana pulmonar. Esta difusão ocorre entre um compartimento representando o espaço alveolar e diversos compartimentos em série, representando os capilares pulmonares.

A busca por um modelo do sistema respiratório que mais se aproxime da resposta do corpo humano continua sendo alvo de pesquisas recentes. Chiari, Avanzolini e Ursino (1997) desenvolveram um modelo com três compartimentos (pulmão, cérebro e tecidos) com controladores dinâmicos da ventilação e da vazão de sangue. Ambos controladores têm atrasos de tempo para considerar o transporte do sangue arterial e a dinâmica dos neurônios. Este mesmo grupo de pesquisa desenvolveu outros trabalhos sobre modelagem do sistema respiratório. Ursino e Magosso (2002) fizeram um modelo específico da resposta dos quimiorreceptores às alterações das pressões parciais de $\mathrm{O}_{2}$ e $\mathrm{CO}_{2}$. Modelos mais completos da ventilação e circulação foram desenvolvidos e aplicados para hipercapnia (URSINO; MAGOSSO; AVANZOLINI, 2001a) e hipoxia (URSINO; MAGOSSO; AVANZOLINI, 2001b). Estes dois últimos trabalhos incluem a diminuição da ventilação

\footnotetext{
${ }^{1}$ A respiração de Cheyne Stokes, também conhecida por respiração periódica, é uma série de respiração forçada com períodos sem respiração.
} 
quando a hipoxia é mantida, conhecida por HVD (hypoxic ventilatory decline). Reproduzir e analisar a HVD foram os principais objetivos dos modelos de Liang, Bascom e Robbins (1997) e Zhou, Saidel e Cabrera (2007). Também foi incluída no modelo de Longobardo, Evangelisti e Cherniack (2002), junto com duas outras características: PSP (post-stimulus potentiation) - estímulo que faz com que a ventilação diminua lentamente após um período de hipoxia - e fator de alerta.

Outros modelos recentes têm diferentes características e aplicações. Batzel e Tran (2000) consideraram atrasos de tempo variáveis para estudar a respiração de CheyneStokes em crianças. Yamashiro (2007), também para estudar a respiração de CheyneStokes, sugeriram o uso de controle não-linear da ventilação. O modelo de Lu et al. (2002), com atrasos de tempo variáveis, foi aplicado para o estudo de apnéia. Topor, Pawlicki e Remmers (2004) analisaram a sensibilidade e estabilidade de seu modelo em situações de hipoxia e hipercapnia. Duffin (2005) analisou o efeito dos distúrbios ácidobásicos na ventilação. O modelo de Wolf e Garner (2007) e o modelo de Qiu e Bai (2001) foram desenvolvidos para estudar o efeito da altitude no sistema respiratório.

Modelos do sistema respiratório com bases fisiológicas também foram aplicados para verificar o comportamento do gás monóxido de carbono (CO) no corpo humano. Os mais completos são os de Sharan e Selvakumar (1999), Bruce e Bruce (2003), Stuhmiller e Stuhmiller (2005) e Albuquerque-Neto, Yanagihara e Turri (2008)². Este último é a principal referência no desenvolvimento da parte respiratória do presente trabalho.

\subsubsection{Controle cardiovascular}

A maioria dos modelos encontrados do efeito do $\mathrm{O}_{2}$ e do $\mathrm{CO}_{2}$ na circulação sanguínea fazem parte de modelos completos do sistema respiratório. No modelo de Milhorn Jr. et al. (1965) e de Grodins, Buell e Bart (1967), as relações entre o débito cardíaco e as pressões parciais de $\mathrm{O}_{2}$ e $\mathrm{CO}_{2}$ são obtidas a partir de equações polinomiais. Ambos os modelos separam a vazão em central e periférica.

Outros exemplos são encontrados em modelos recentes do sistema respiratório. Longobardo, Evangelisti e Cherniack (2002) consideraram que a vazão de sangue no cérebro é proporcional à $P_{\mathrm{CO}_{2}}$ e ao inverso da saturação de $\mathrm{O}_{2}$ arterial. Zhou, Saidel e Cabrera (2007) consideraram que o débito cardíaco é proporcional à $P_{C_{2}}$ e à dessaturação de $\mathrm{O}_{2}$. Para o cérebro, consideraram que o efeito do $\mathrm{CO}_{2}$ na vazão é exponencial.

Ursino, Magosso e Avanzolini (2001a), Topor, Pawlicki e Remmers (2004) e Wolf e Garner (2007) usaram equações com formas mais complexas para obter as relações entre

\footnotetext{
${ }^{2}$ detalhado na dissertação de mestrado de Albuquerque-Neto (2005)
} 
as variáveis do sangue arterial e a vazão de sangue central e periférica. Eles também acrescentaram atrasos em seus modelos da circulação, concedendo assim um caráter dinâmico.

O modelo de Fincham e Tehrani (1983) é um exemplo de modelo que não faz parte de modelos completos do sistema respiratório. Usaram polinômios de Chebyshev para representar a vazão de sangue central e periférica em função da $P_{\mathrm{O}_{2}}$ arterial, da $P_{\mathrm{CO}_{2}}$ arterial e do metabolismo.

\subsubsection{O modelo de Albuquerque-Neto, Yanagihara e Turri (2008)}

No modelo de Albuquerque-Neto, Yanagihara e Turri (2008), o corpo humano foi dividido em cinco compartimentos, além dos que representam os capilares pulmonares (Figura 2.3). A composição dos gases nos compartimentos foi descrita por equações diferenciais ordinárias representando a variação no tempo, uma para cada compartimento e uma para cada gás.

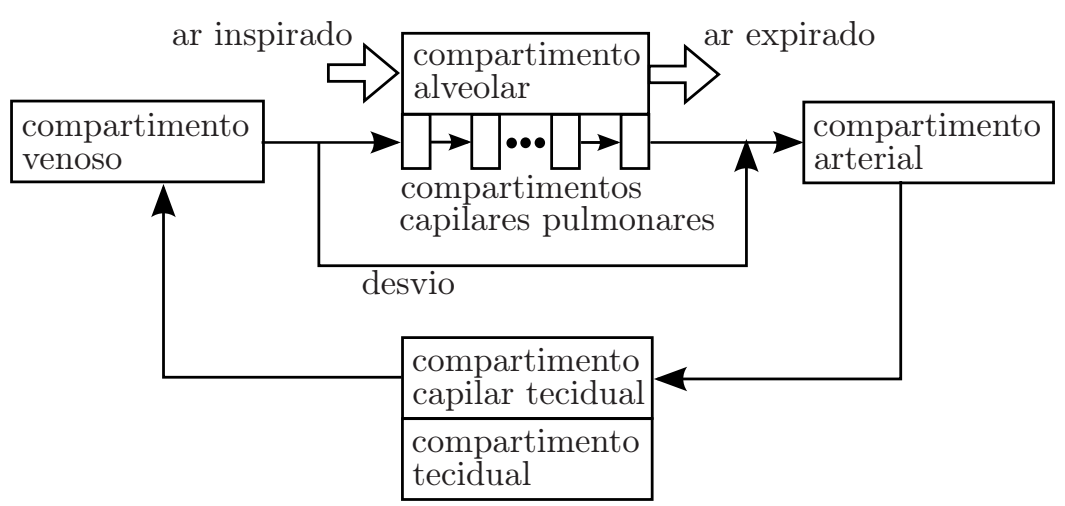

Figura 2.3 - Modelo do sistema respiratório de Albuquerque-Neto, Yanagihara e Turri (2008)

O compartimento que liga o corpo humano ao ar externo é o compartimento alveolar. A entrada de ar é resultado da inspiração após ser umidificado pelo espaço morto. O ar expirado representa a saída que, por ser uniforme, possui a mesma composição do ar nos alvéolos. Outro processo existente no compartimento é a transferência de gases por difusão com os compartimentos capilares pulmonares através da membrana respiratória.

Os capilares pulmonares são representados por diversos compartimentos em série. Por cada compartimento percorre o sangue não desviado do pulmão. Sangue venoso entra no primeiro compartimento. Depois, o sangue segue para os próximos capilares pulmonares realizando transferência dos gases com o compartimento alveolar. Saindo dos capilares pulmonares, o sangue se junta com a parte desviada do pulmão e segue para o compartimento arterial.

O próximo compartimento pelo qual o sangue passa é o compartimento capilar tecidual. Ao passar por este compartimento, o sangue realiza troca de gases com o compar- 
timento tecidual, onde ocorre o metabolismo. O mecanismo de difusão tecidual, por ser demasiado complexo, foi simplificado considerando a pressão parcial dos gases nos capilares teciduais sendo a mesma dos tecidos. O compartimento tecidual é separado em dois volumes, um representando os tecidos não musculares, onde os gases estão dissolvidos, e outro representando os tecidos musculares, onde os gases $\mathrm{O}_{2}$ e CO encontram-se, além de dissolvidos, ligados à proteína mioglobina.

O último compartimento pelo qual o sangue passa é o compartimento venoso. Saindo do compartimento venoso, o sangue retorna ao pulmão.

Os gases $\mathrm{O}_{2}, \mathrm{CO}_{2}$ e $\mathrm{CO}$ são transportados pelo sangue tanto dissolvidos fisicamente como reagidos quimicamente. Nos tecidos os gases estão dissolvidos e, no caso do $\mathrm{O}_{2}$ e do $\mathrm{CO}$, também ligados à proteína mioglobina. Para a representação destes mecanismos de transporte, foram usadas relações encontradas na literatura.

Para solucionar o modelo foi desenvolvido um programa de computador na linguagem $\mathrm{C}++$. As equações em regime permanente e as relações de transporte dos gases foram resolvidas utilizando o método das aproximações sucessivas. Em regime transitório, utilizou-se o método de Euler explícito.

\subsection{Modelos do sistema térmico}

Modelos do sistema térmico começaram a ser desenvolvidos em meados do século passado. Costumam ser divididos em duas partes principais: modelo passivo e modelo do sistema termorregulador. O modelo passivo contém a definição da geometria do corpo humano e os balanços de energia e massa entre ambiente, sangue e tecidos. O sistema termorregulador contém três principais mecanismos: sudorese, calafrio e mecanismo vasomotor.

\subsubsection{Biotransferência de calor}

A primeira tentativa de aplicar a equação de transferência de calor aos tecidos do corpo humano foi feita por Pennes (1948). Além da condução, a equação de Pennes (1948) inclui termos que representam a geração metabólica de calor e o transporte de calor pelo sangue presente nos pequenos vasos. Seu trabalho foi aplicado para o antebraço, que foi representado por um cilindro com seção transversal circular. Medições com termopares foram realizadas, na superfície e nos tecidos internos, e comparadas com o modelo teórico. A importância do artigo de Pennes (1948) levou-o a ser revisto recentemente por Wissler (1998). Sua equação, conhecida por bio-heat equation, é referência dos modelos do sistema 
térmico do corpo humano até os dias de hoje. Em regime permanente e considerando só a variação radial, conforme usada por Pennes (1948), é igual a:

$$
-k_{t}\left(\frac{\mathrm{d}^{2} T_{t}}{\mathrm{~d} r^{2}}+\frac{1}{r} \frac{\mathrm{d} T_{t}}{\mathrm{~d} r}\right)=\hat{\dot{V}}_{s v} \rho_{b l} c_{b l}\left(T_{a r}-T_{t}\right)+\hat{\dot{q}}_{t}
$$

sendo: $k_{t}=$ condutividade térmica do tecido $\left[\mathrm{W} /\left(\mathrm{kg} .{ }^{\circ} \mathrm{C}\right)\right]$;

$T_{t}=$ temperatura do tecido $\left[{ }^{\circ} \mathrm{C}\right]$;

$r=$ coordenada cilíndrica $[\mathrm{m}]$;

$\hat{\dot{V}}_{s v}=$ vazão de sangue no tecido $\left[\mathrm{m}^{3} /\left(\mathrm{m}^{3} \cdot \mathrm{s}\right)\right]$;

$\rho_{b l}=$ massa específica do sangue $\left[\mathrm{kg} / \mathrm{m}^{3}\right]$;

$c_{b l}=$ calor específico do sangue $\left[\mathrm{J} /\left(\mathrm{kg} .{ }^{\circ} \mathrm{C}\right)\right]$;

$T_{a r}=$ temperatura do sangue arterial total $\left[{ }^{\circ} \mathrm{C}\right]$;

$\hat{\dot{q}}_{t}=$ geração interna de calor $\left[\mathrm{W} / \mathrm{m}^{3}\right]$.

\subsubsection{Modelos completos}

O primeiro modelo da parte passiva do sistema térmico com divisão do corpo em segmentos foi o de Wissler (1961) (Figura 2.4a). Os seis segmentos considerados têm forma cilíndrica. Circulação de sangue arterial e venoso ocorre entre eles. Os tecidos internos de cada segmento são homogêneos e isotrópicos. Wissler (1961) incluiu os seguintes mecanismos de transferência de calor:

- geração metabólica de calor;

- condução radial de calor nos tecidos;

- convecção de calor pela perfusão de sangue;

- perda de calor na superfície por radiação, convecção e evaporação;

- perda de calor através do trato respiratório;

- troca de calor contra-corrente entre grandes artérias e veias.

Estes mecanismos foram incluídos nos modelos subsequentes do sistema térmico mais completos.

O primeiro modelo de Wissler considerava que o sistema estava em regime permanente. Dando sequência, Wissler (1964) desenvolveu um modelo em regime transitório, com quinze segmentos (Figura 2.4b). Foram consideradas as mesmas características de transporte de calor do modelo anterior, com o acréscimo de:

- baixa condutividade na camada superficial de gordura e pele;

- geração de calor por calafrio. 
As equações do modelo foram discretizadas com o método das diferenças finitas. Resultados da temperatura interna (retal) durante exercício seguido de descanso são similares à solução analítica e experimental.

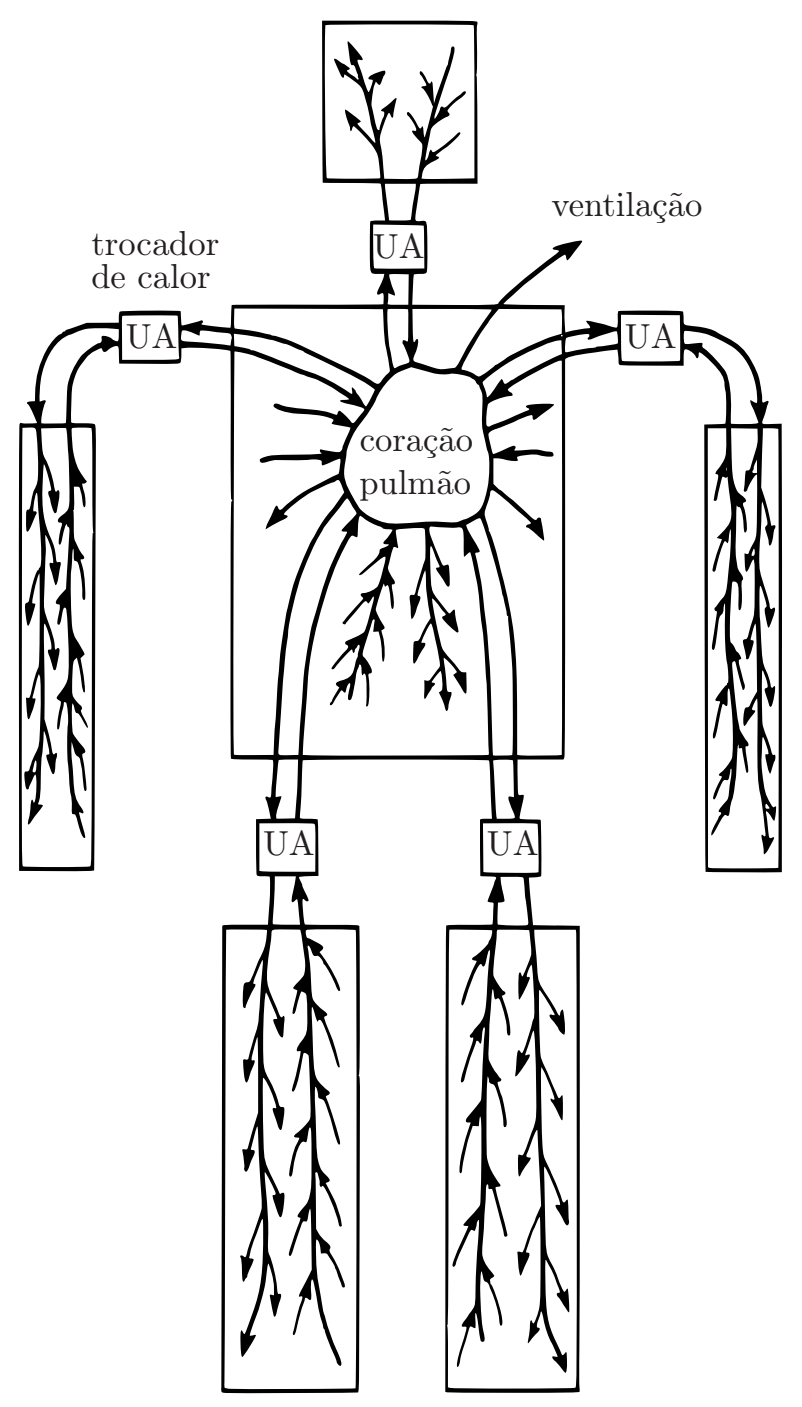

(a)

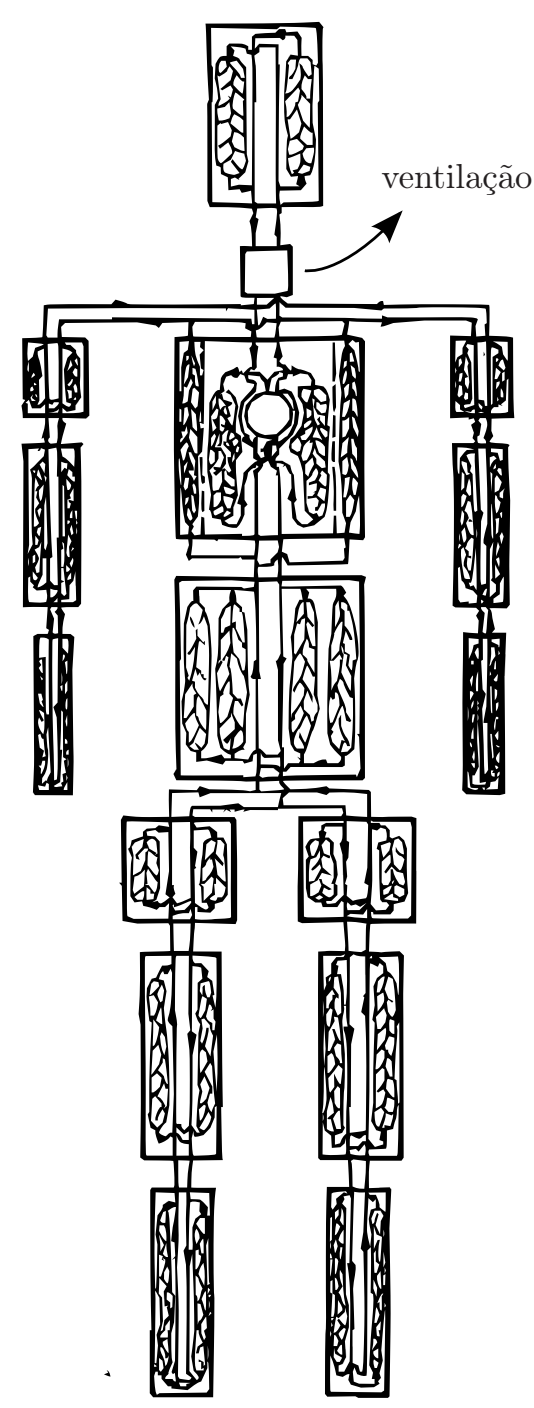

(b)

Figura 2.4 - Modelo do sistema térmico de Wissler em regime permanente (WISSLER, 1961) (a) e em regime transitório (WISSLER, 1964) (b)

Modelos simplificados, em que o corpo humano é representado por um só cilindro, também foram desenvolvidos. Exemplos são os trabalhos de Fanger (1970), de Gagge, Stolwijk e Nishi (1971) e de Ferreira (1997). O modelo de Fanger (1970) é bastante utilizado na área de conforto térmico. Detalhes incluídos em seu modelo, como os relativos à transferência de calor com o ambiente, são usados em modelos mais completos até os dias de hoje. Além do desenvolvimento do modelo, Fanger (1970) produziu uma metodologia amplamente utilizada na análise de conforto térmico em ambiente fechados.

Dentre os modelos com divisão do corpo em vários compartimentos, um trabalho muito importante é o de Stolwijk e Hardy (1966a). Além de ser muito utilizado, serviu 
como base para o desenvolvimento de outros modelos, principalmente quando se trata do sistema de controle. Stolwijk e Hardy (1966a) dividiram o corpo humano em três cilindros: cabeça, tronco e extremidades (Figura 2.5). Cada cilindro tem duas ou mais camadas concêntricas. Ocorre transferência de calor por condução entre as camadas e por convecção entre as camadas e um compartimento sanguíneo central. As camadas de pele trocam calor com o ambiente por condução, convecção, radiação e evaporação. O modelo de Stolwijk e Hardy (1966a) foi validado por diversos pesquisadores, ao comparar suas respostas com dados experimentais (KONZ et al., 1977; HANCOCK, 1980).

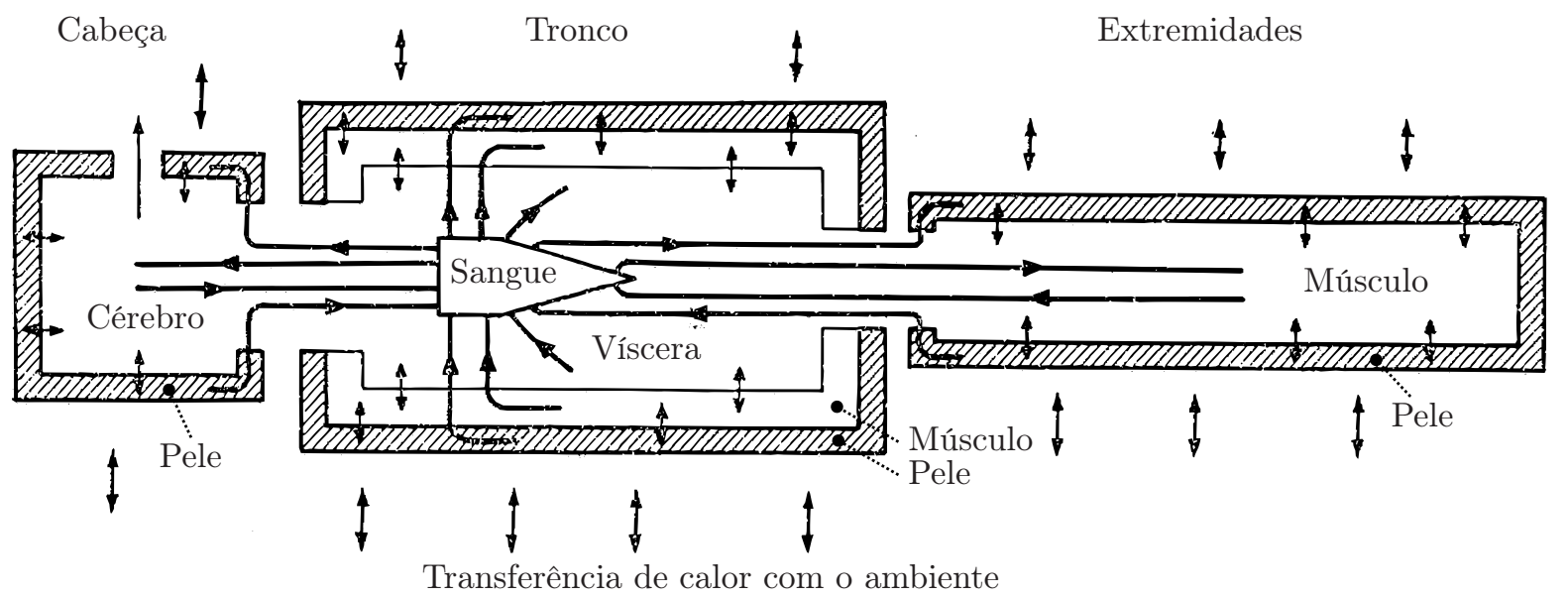

Figura 2.5 - Modelo do sistema térmico de Stolwijk e Hardy (1966a) [modificado]

Desde essa época, diversos modelos foram desenvolvidos para diferentes aplicações. Quase todos têm como base os trabalhos de Wissler (1964) e Stolwijk e Hardy (1966a). Hsu, Hwang e Fan (1973) modificaram o modelo de Wissler (1964) para estudar a minimização dos esforços de controle de dispositivos de resfriamento e aquecimento, como os encontrados em trajes espaciais.

O modelo de Miller e Seagrave (1974) tem quinze segmentos cilíndricos. O cérebro e o abdômen têm três camadas de tecidos e os outros membros duas. Foi aplicado para imersão em água e validado com experimentos em que a temperatura da água variava entre 28 e $39^{\circ} \mathrm{C}$. O único controlador considerado foi a vazão de sangue na pele, já que não há evaporação na pele, nem calafrio.

Gordon, Roemer e Horvath (1976) desenvolveram um modelo com quatorze segmentos. Acima do tronco, consideraram segmentos separados para a face, teste, pescoço e cabeça. Foi aplicado para exposição a ambientes frios e comparado com dados experimentais com variação da temperatura do ambiente de $28^{\circ} \mathrm{C}$ para $4,7^{\circ} \mathrm{C}$. Outro modelo aplicado para exposição ao frio foi elaborado por Tikuisis, Gonzalez e Pandolf (1988), com o corpo imerso em água. Seus resultados também foram comparados com dados experimentais. 
O modelo de Smith e Twizell (1982) uniu as principais características do modelo de Wissler (1964) e do modelo de Stolwijk e Hardy (1966a), ou seja, a distribuição de temperatura e o sistema de controle.

A hipertermia localizada é reconhecida como sendo útil no tratamento de câncer. Alguns modelos são focados neste estudo, como Charny, Hagmann e Lavin (1987). O estudo de queimaduras, assim como seu tratamento, foi o objetivo do modelo de Gardner e Martin (1994).

Ao invés de utilizarem formas geométricas simples, Werner e Buse (1988) consideraram uma geometria tridimensional detalhada, elaborada a partir de um modelo anatômico do corpo humano. Seus resultados mostram a variação da temperatura em diversos tecidos e órgãos do corpo para um ambiente neutro. Fizeram um levantamento dos valores das propriedades físicas dos tecidos e órgãos encontrados na literatura, utilizado em modelos recentes.

Alguns modelos são focados no estudo da transferência de calor entre vasos sanguíneos e tecidos. Nestes modelos, revistos por Arkin, Xu e Holmes (1994), foram propostas modificações no termo da perfusão de sangue da equação de Pennes (1948). Um exemplo é o modelo de Chen e Holmes (1980), que analisou a relação entre o equilíbrio térmico do sangue com o tecido e o diâmetro dos vasos.

Modelos completos do sistema térmico do corpo humano continuaram a ser desenvolvidos nos últimos anos. Fiala, Lomas e Stohrer (1999) desenvolveram um modelo passivo detalhado do corpo humano. Consideraram quinze segmentos, sendo a cabeça esférica e os outros cilíndricos (cabeça, face, pescoço, ombros, tórax, abdômen, braços, mãos, pernas e pés). Dando sequência, Fiala, Lomas e Stohrer (2001) desenvolveram equações de controle a partir de regressões de dados experimentais. O modelo de Fiala, Lomas e Stohrer (1999) foi modifico por Severens et al. (2007) e aplicado para determinar a temperatura de um paciente durante operação cardíaca.

Muitos dos modelos recentes são modificações do modelo de Stolwijk e Hardy (1966a). No modelo de Huizenga, Zhang e Arens (2001), conhecido como UC Berkeley Comfort Model, o modelo de Stolwijk e Hardy (1966a) recebeu diversas melhorias: possibilidade de usar inúmeros segmentos; transferência de calor contracorrente entre sangue arterial e venoso; e resistência da roupa. O modelo tem como objetivo analisar conforto térmico e, para isto, também teve melhorias na representação das trocas térmicas por convecção e radiação com o ambiente. Outra melhoria do modelo de Stolwijk e Hardy (1966a) com aplicação para conforto térmico foi feita por Yi et al. (2004). Incluíram um modelo elaborado da dinâmica da temperatura e vapor-d'água nas roupas, podendo estas ter várias camadas. Ying et al. (2004) desenvolveram um modelo para analisar a distribuição de temperatura em crianças durante os primeiros anos de vida. Além do modelo de 
Stolwijk e Hardy (1966a), também tiveram como base o modelo de Gagge, Stolwijk e Nishi (1971).

Salloum, Ghaddar e Ghali (2007) fizeram um modelo, também tendo como base o modelo de Stolwijk e Hardy (1966a), com uma representação detalhada do sistema circulatório. Usaram um modelo anatômico da distribuição dos vasos, com dimensões e segmentações realistas. Melhorias deste modelo foram feitas por Al-Othmani, Ghaddar e Ghali (2008), para que assim fosse possível a simulação de condições assimétricas.

Ferreira e Yanagihara $(2009)^{3}$ observaram que alguns membros do corpo humano, como as mãos e os pés, estão longe de terem seção transversal circular. Sendo assim, desenvolveram um modelo completo do sistema termorregulador em que os segmentos do corpo humano são cilindros com seção transversal elíptica. Este modelo é a principal referência da parte térmica do presente trabalho. Será descrito a seguir com mais detalhes.

\subsubsection{Controladores}

Os três controladores diretamente relacionados com o sistema térmico (vazão de sangue na pele, calafrio e sudorese) foram pauta de alguns estudos. Têm como princípio relacionar a diferença entre a temperatura atual e uma temperatura de referência (erro), multiplicado por um ganho proporcional. Estas temperaturas representam a temperatura interna (hipotálamo, esôfago, reto ou tímpano) e a temperatura média da pele. Os coeficientes são determinados a partir de dados experimentais. Alguns modelos consideram que os erros estão multiplicados. Outros os consideram somados. Outros modelos consideram ainda configurações polinomiais ou exponenciais. Efeitos locais da temperatura da pele também fazem parte de alguns modelos.

Os modelos de controladores do sistema térmico incluem limites de atuação. Alguns consideram que os erros não podem ser negativos ou não podem ser positivos. Outros limitam o valor da resposta do controlador.

O modelo do sistema térmico de Stolwijk e Hardy (1966a) inclui controladores para os três mecanismos. Também inclui variação da vazão de sangue nos músculos, sendo esta proporcional a variação do metabolismo por calafrio e atividade física. A vazão de sangue na pele, calor perdido por evaporação e geração de calor por calafrio são iguais a:

$$
\begin{aligned}
\dot{V}_{b l, s k} & =10,6+36\left(T_{h y}-36,6\right)\left(\bar{T}_{s k}-34,1\right)+0,93\left(\bar{T}_{s k}-34,1\right) \\
\dot{q}_{e} & =68\left(T_{h y}-36,6\right)\left(\bar{T}_{s k}-34,1\right)+200\left(T_{h y}-36,6\right)\left(\bar{T}_{m}-35,88\right) \\
\Delta \dot{q}_{m} & =60\left(T_{h y}-36,6\right)\left(\bar{T}_{s k}-34,1\right)
\end{aligned}
$$

\footnotetext{
${ }^{3}$ detalhado na tese de doutorado de Ferreira (2001).
} 
sendo: $\dot{V}_{b l, s k}=$ vazão de sangue na pele $[\mathrm{L} / \mathrm{h}]$;

$\dot{q}_{e}=$ calor perdido pela evaporação $[\mathrm{kcal} / \mathrm{h}]$;

$\bar{T}_{m}=$ temperatura atual média do músculo $\left[{ }^{\circ} \mathrm{C}\right]$;

$\Delta \dot{q}_{m}=$ calor gerado no músculo por calafrio $[\mathrm{kcal} / \mathrm{h}]$.

Exemplos de modelos específicos do mecanismo vasomotor são os modelos de Savage e Brengelmann (1996), com o efeito dos erros somados (da temperatura interna e da temperatura média da pele); e o modelo recente de Wissler (2008), com erros da temperatura interna, da pele média e local e do nível de atividade física multiplicados.

Entre os modelos específicos do aumento da geração metabólica de calor devido ao calafrio, tem-se o modelo de Hammel et al. (1963), em que o erro da temperatura média da pele é multiplicado pelo inverso da temperatura do hipotálamo. O modelo de Nadel et al. (1970) considera que o erro da temperatura interna e o da temperatura média da pele são multiplicados e somados com mais um termo da temperatura média na pele. Hayward, Eckerson e Collis (1977) consideram que o efeito desses erros no calafrio é multiplicativo. No modelo de Tikuisis e Giesbrecht (1999), o erro da temperatura média da pele contém também um termo quadrático.

Modelos específicos para a sudorese seguem esses mesmos princípios. Um exemplo é o modelo de Nadel, Bullard e Stolwijk (1971), em que a geração de suor está relacionada com a soma dos erros da temperatura interna e da temperatura média da pele, esta última multiplicada pela exponencial do erro da temperatura da pele local.

Os três mecanismos de controle do sistema térmico foram representados pela mesma equação por Wyss et al. (1974), com coeficientes diferentes. A resposta de controle é, neste caso, função do erro da temperatura interna somada com o erro da temperatura média da pele e a sua taxa de variação.

A hipótese dos controladores do sistema térmico serem relacionados com uma temperatura de referência gera discussões nos dias de hoje. Os principais motivos desta discussão são os casos de febre e anapirexia. Duas hipóteses estão sendo discutidas. Uma é que o corpo humano regula a temperatura, e a referência é variável. Outra é que a regulação térmica do corpo é função do balanço de calor (CABANAC, 2006).

\subsubsection{O modelo de Ferreira e Yanagihara (2009)}

No modelo do sistema térmico de Ferreira e Yanagihara (2009), representado na Figura 2.6, o corpo humano foi dividido em 15 segmentos (cabeça, pescoço, tronco, braços, antebraços, mãos, coxas, pernas e pés). 


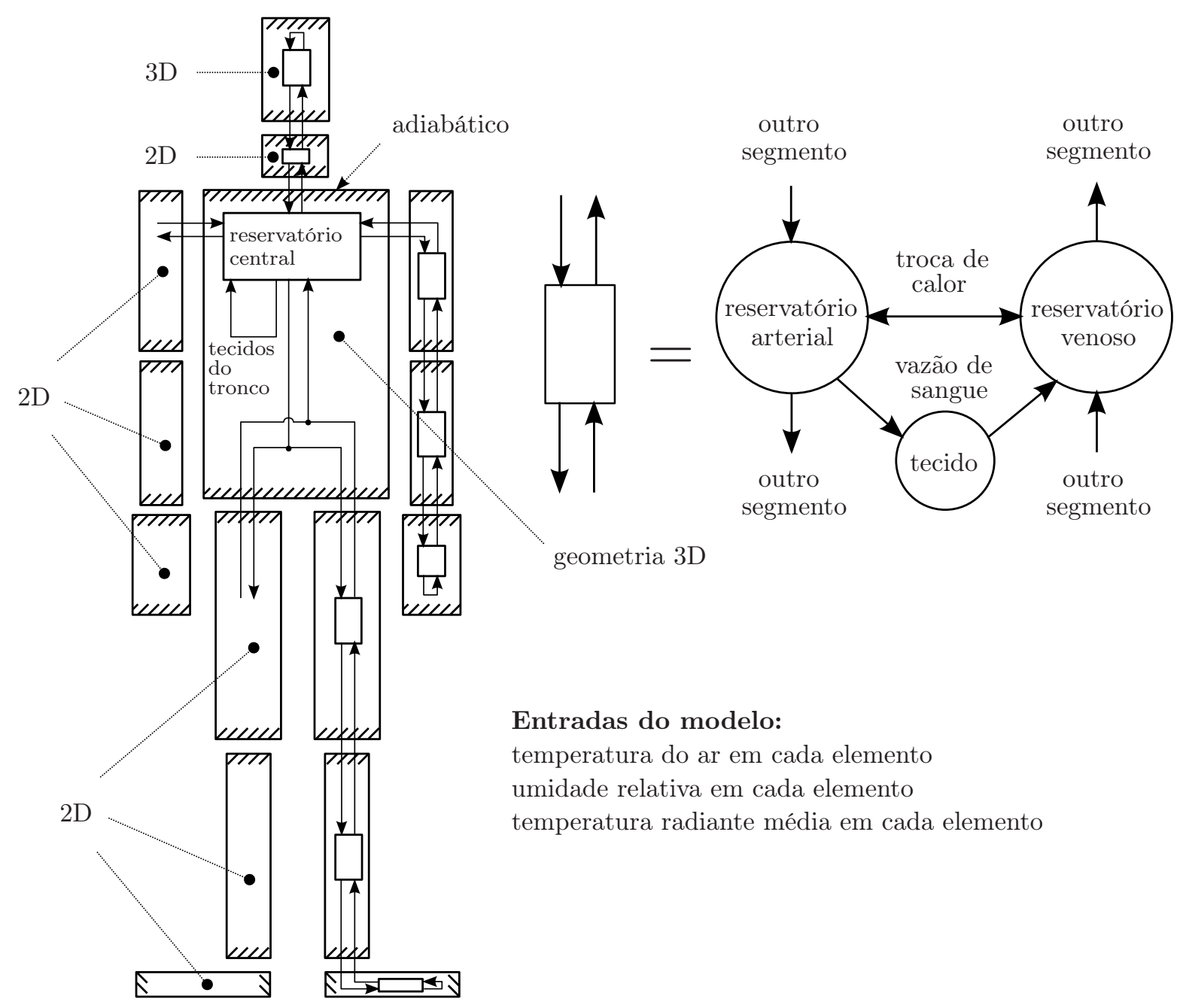

Figura 2.6 - Modelo do sistema térmico de Ferreira e Yanagihara (2009) [redesenhado]

Os segmentos com seção transversal elíptica são formados por camadas que representam os tecidos e órgãos. Foram considerados pele, gordura, músculo, osso, coração, pulmões e vísceras. A distribuição das camadas nos segmentos pode ser tridimensional, bidimensional ou unidimensional. A Figura 2.7 mostra a distribuição das camadas nas seções transversais dos segmentos.

Para a transferência de calor nos tecidos, Ferreira e Yanagihara (2009) utilizaram a equação de condução de calor de Pennes (1948), transformada para um elaborado sistema de coordenadas elíptico.

Com o ambiente, há transferência de calor por convecção, radiação, evaporação e respiração. A roupa foi considerada como uma resistência térmica adicional.

Para o cálculo da evaporação, utilizaram uma analogia entre transferência de calor e massa. O calor transferido na respiração é obtido a partir do metabolismo, pois esse altera a ventilação pulmonar. 


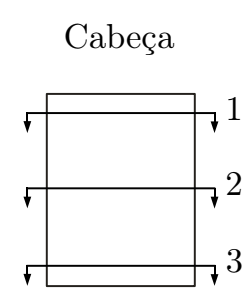

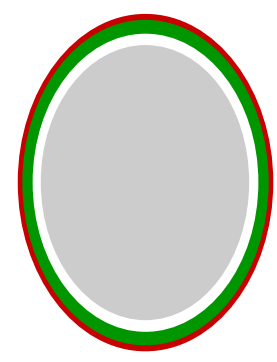

1

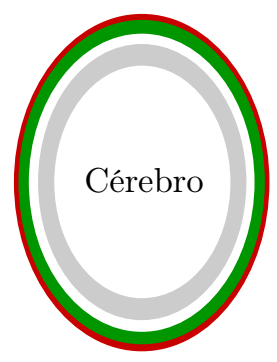

2

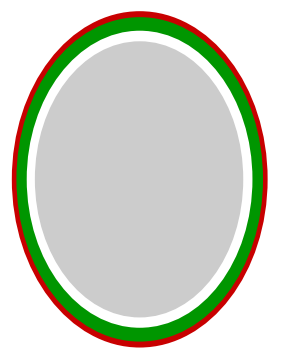

3

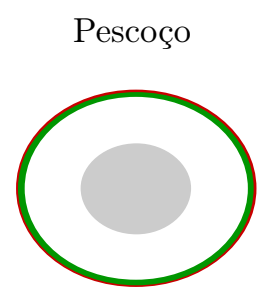

Tronco

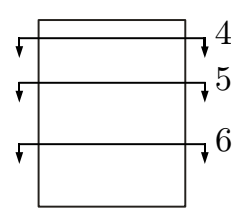

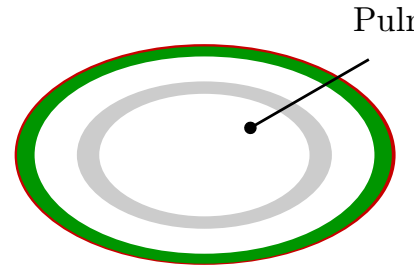

4

Pulmão

Coração

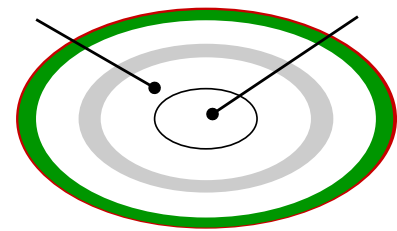

5

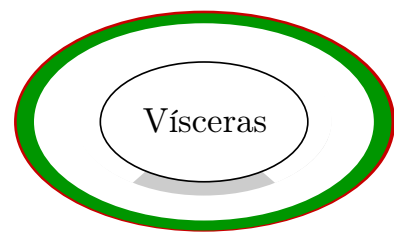

6
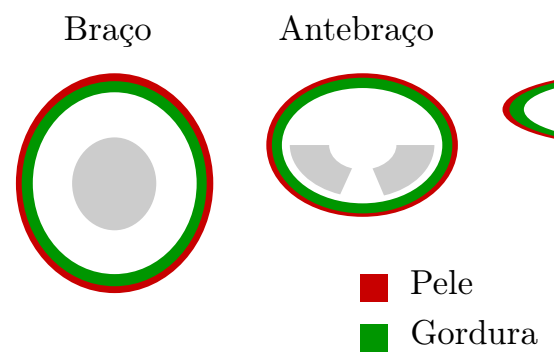

Mão

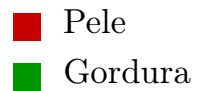

Músculo

Osso
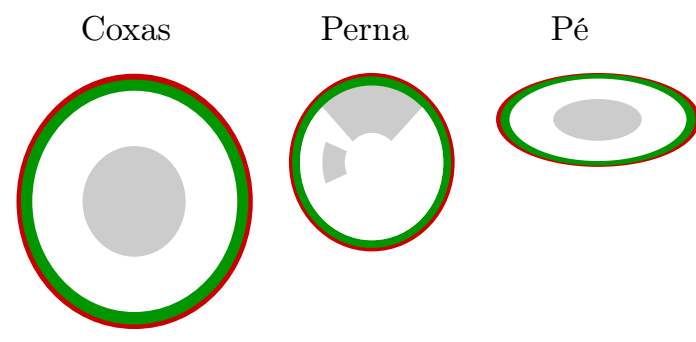

Figura 2.7 - Cortes transversais mostrando as distribuições das camadas do modelo do sistema térmico de Ferreira e Yanagihara (2009) [redesenhado]

O transporte de calor pelo sangue é dividido em duas partes: pequenos e grandes vasos. O sangue, ao passar pelos pequenos vasos, chega ao equilíbrio térmico com os tecidos. Os grandes vasos são representados, em cada segmento, por um reservatório de sangue arterial e outro de sangue venoso; com exceção do tronco, que só tem um reservatório central.

Os três principais mecanismos de regulação térmica foram considerados por Ferreira e Yanagihara (2009). Estes mecanismos respondem aos sinais de temperatura da pele e do hipotálamo. Para representá-los, foram utilizados modelos de controladores existentes na literatura. Para o mecanismo vasomotor utilizou-se o modelo proposto por Savage e Brengelmann (1996). Para a sudorese, o modelo de Nadel, Bullard e Stolwijk (1971). O modelo do calor gerado pelos calafrios é semelhante ao proposto por Gordon, Roemer e Horvath (1976).

Para a solução do modelo foi implementado um programa orientado a objetos na linguagem $\mathrm{C}++$. As equações diferenciais parciais foram discretizadas usando o método dos volumes finitos. 


\subsection{Modelos integrados}

Modelos que consideram as interações existentes entre temperatura e concentrações de oxigênio ou dióxido de carbono são recentes. Downey e Seagrave (2000) desenvolveram um modelo para estudar as trocas de água no corpo humano. Ji e Liu (2002) e Gaohua e Kimura (2008) aplicaram seus modelos para o estudo de hipotermia no cérebro. Estes três modelos serão descritos nas seções a seguir.

\subsubsection{O modelo de Downey e Seagrave (2000)}

No modelo de Downey e Seagrave (2000), o corpo humano foi dividido por compartimentos representando o pulmão, a parte central, os músculos e a pele (Figura 2.8). As equações que descrevem a variação das concentrações dos gases em cada compartimento foram obtidas a partir de balanços de massa. As equações para a variação de temperatura foram obtidas por balanços de energia, considerando pulmão e parte central como um mesmo compartimento. O modelo inclui equações de transporte dos gases no sangue, considerando os efeitos da temperatura. Também inclui relações entre consumo e geração dos gases e calor pelo metabolismo. O metabolismo nos músculos aumenta no caso de exercício físico. O compartimento da pele tem perda de calor para o ambiente. Calor também é perdido pela ventilação pulmonar. As variáveis controladas em função de outras variáveis do sistema são a vazão de sangue na pele e no músculo, a ventilação e a taxa de suor.

Downey e Seagrave (2000) calcularam a variação da água no corpo por um balanço entre água ingerida, água perdida pela urina, água perdida na evaporação do suor e água desperdiçada (suor que acaba não evaporando). Resultados do modelo foram comparados com resultados experimentais em exposição a ambientes quentes com e sem reposição de água.

\subsubsection{O modelo de Ji e Liu (2002)}

Ji e Liu (2002) desenvolveram um modelo do cérebro, considerando a transferência de calor, do oxigênio e a variação da viscosidade do sangue. Tiveram como objetivo estudar a vantagem da hipotermia durante ressuscitação do cérebro, que diminui o consumo de $\mathrm{O}_{2}$, contra o aumento da viscosidade do sangue na hipotermia, que diminui a vazão de sangue e a distribuição de $\mathrm{O}_{2}$. 


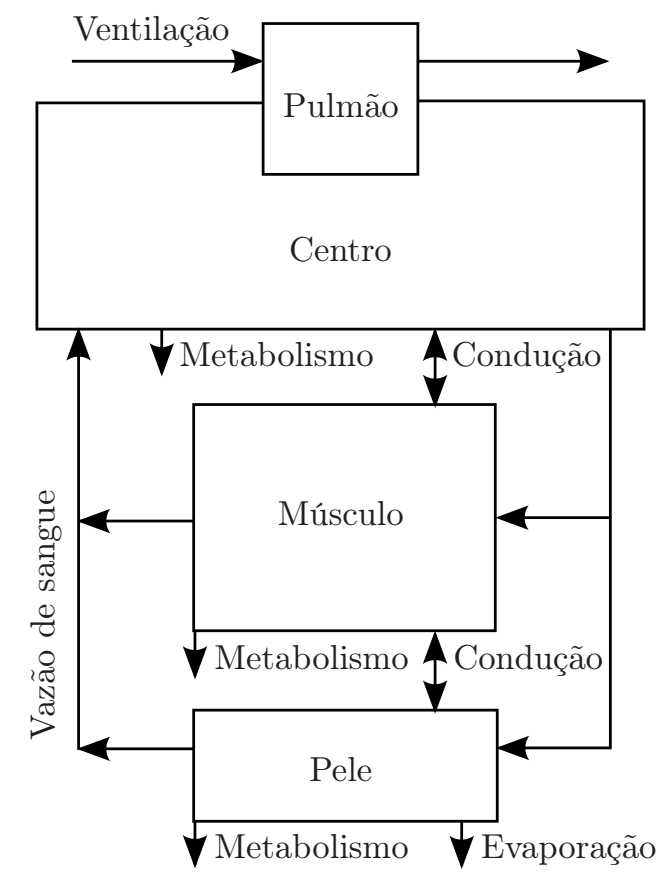

(a)

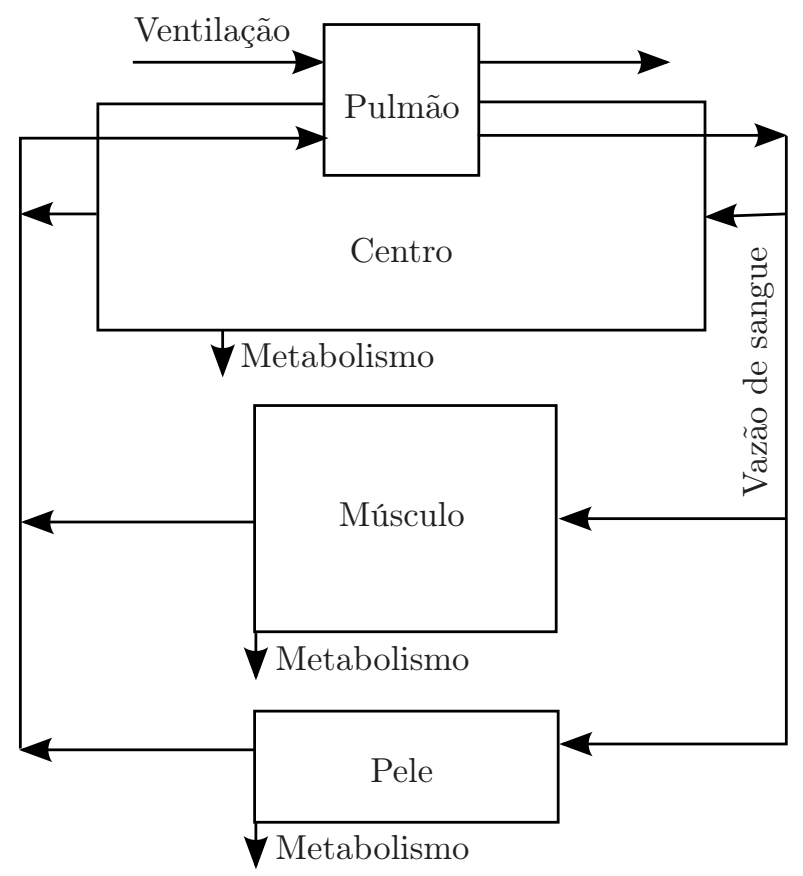

(b)

Figura 2.8 - Modelo do sistema térmico (a) e respiratório (b) de Downey e Seagrave (2000) [redesenhado]

Para determinar a distribuição de temperatura, a cabeça foi representada por uma esfera homogênea. A equação de Pennes (1948) foi aplicada considerando variação radial. A diminuição do consumo de $\mathrm{O}_{2}$ com a temperatura é representada pelo efeito $Q_{10}$.

Já para determinar a distribuição de $\mathrm{O}_{2}$, o cérebro foi representado por um compartimento. Os vasos sanguíneos foram representados por diversos compartimentos dispostos em série, com difusão com o cérebro e entre pares de artérias e veias (Figura 2.9). Equações de transporte são consideradas para representar o transporte do $\mathrm{O}_{2}$ no sangue. No cérebro, o $\mathrm{O}_{2}$ está dissolvido. Ji e Liu (2002) consideraram que o coeficiente de viscosidade do sangue varia com a temperatura, resultando na variação da vazão de sangue.

Seus resultados, usando dados de carneiros, mostraram que o efeito da diminuição da vazão de sangue não é significativo.

\subsubsection{O modelo de Gaohua e Kimura (2008)}

Gaohua e Kimura (2008) desenvolveram um modelo com o objetivo de discutir como deve ser o manejo da respiração durante um tratamento do cérebro com hipotermia. O corpo humano foi divido em diversos compartimentos, representando os lugares em que o sangue e os tecidos estão presentes (Figura 2.10). Entre sangue e tecido, ocorre difusão de $\mathrm{O}_{2}$ e $\mathrm{CO}_{2}$. O modelo também inclui a cobertura de resfriamento e o ventilador mecânico, ambos usados no tratamento. Em cada compartimento, balanços de massa e energia permitem calcular a pressão parcial de $\mathrm{O}_{2}$ e $\mathrm{CO}_{2}$ e a temperatura. Dois mecanismos de 


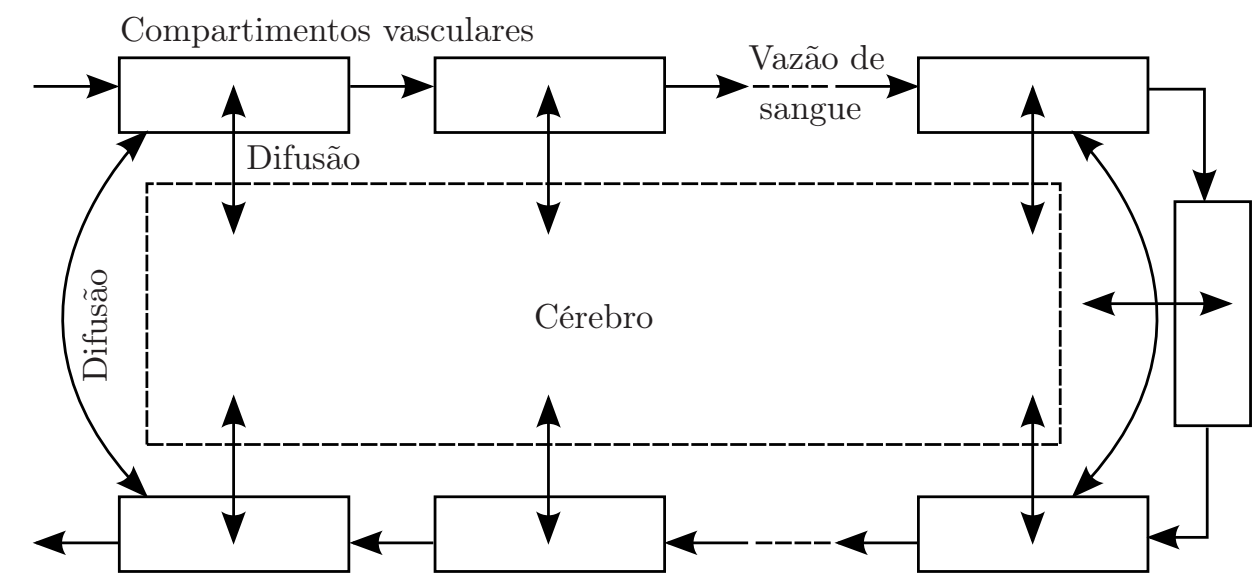

Figura 2.9 - Modelo do transporte de $\mathrm{O}_{2}$ no cérebro de Ji e Liu (2002) [redesenhado]

transferência de massa são diretamente relacionados com a temperatura: o metabolismo (efeito $Q_{10}$ ) e as equações de transporte dos gases no sangue.

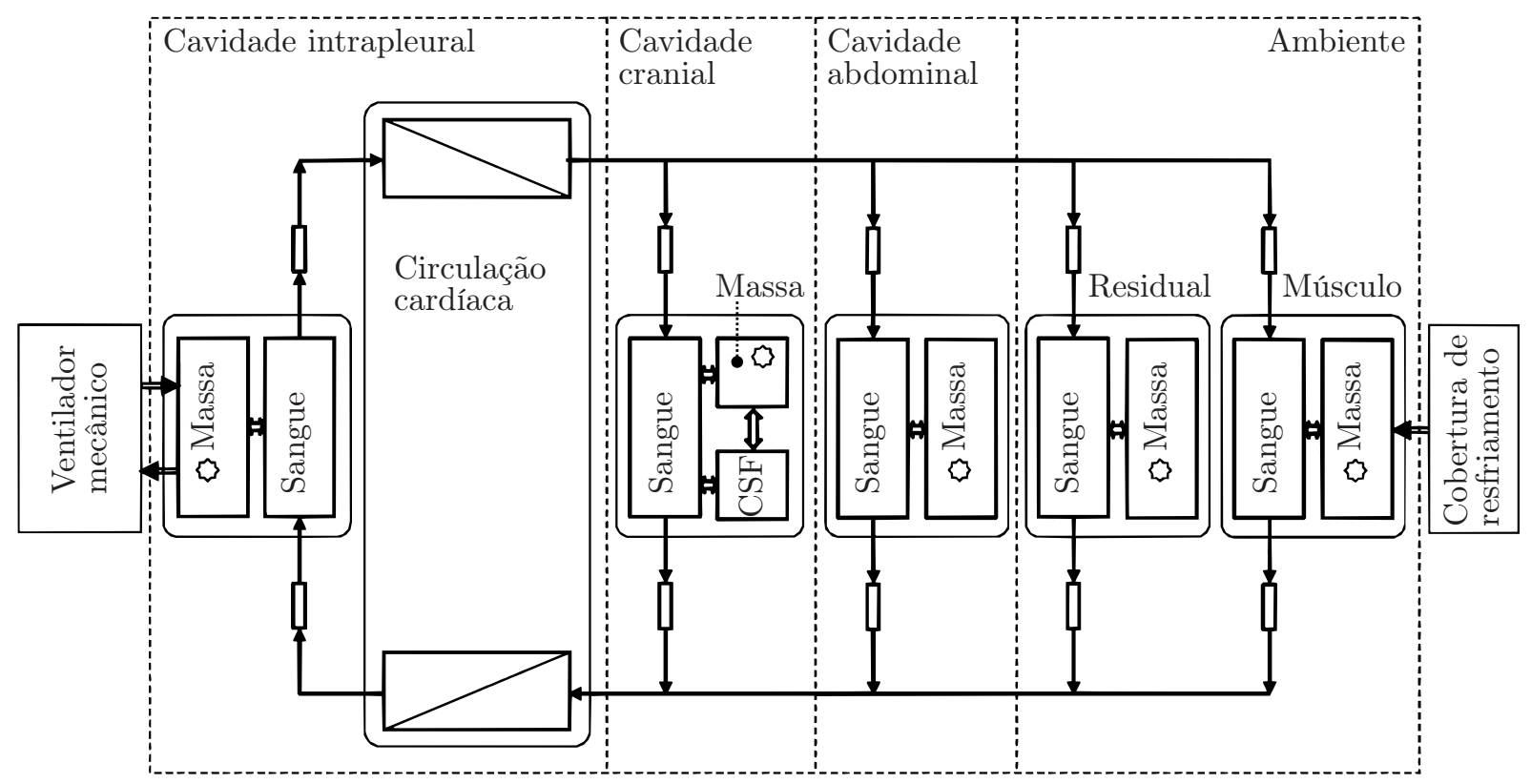

Figura 2.10 - Modelo do sistema respiratório e térmico Gaohua e Kimura (2008) [modificado]

O modelo de Gaohua e Kimura (2008) foi validado em situações de hipoxia e hipercapnia, usando um modelo de controle da ventilação. Concluíram que a ventilação mecânica durante o tratamento deve ser controlada em função do resfriamento, para que assim a oxigenação do cérebro se mantenha estável. Fizeram também uma proposta de metodologia de controle para o ventilador. 


\section{Capítulo 3}

\section{Fenômenos de Transporte no Sangue}

O sangue é composto de uma fase líquida (plasma) e componentes corpusculares (glóbulos vermelhos e células brancas) (Figura 3.1). O oxigênio $\left(\mathrm{O}_{2}\right)$ é transportado pelo sangue quase que totalmente reagido nos glóbulos vermelhos com a hemoglobina ( 99\%). O dióxido de carbono $\left(\mathrm{CO}_{2}\right)$ é carregado na forma de íons bicarbonato ( $\left.\sim 70 \%\right)$, dissolvido $(\sim 10 \%)$ e reagido nos glóbulos vermelhos $(\sim 20 \%)$. Além do transporte dos gases, o sangue é o principal meio responsável pela distribuição de calor no corpo humano.

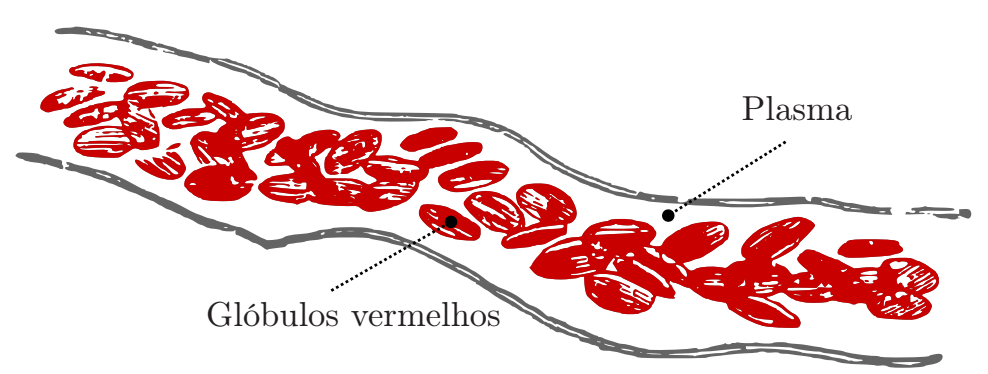

Figura 3.1 - Representação do sangue em um pequeno vaso [modificado de Halliburton (1914)]

Nas próximas seções, será discutido como ocorre o transporte dos gases no sangue, a circulação e a transferência de calor. Os livros de Davenport (1973) e Guyton e Hall (2006) e os capítulos de Lambertsen (1974d) e Roughton (1964) serviram como base para as descrições dos conceitos fisiológicos deste capítulo.

\subsection{Normas e unidades dos gases}

Os volumes dos gases dependem da pressão e da temperatura em que eles se encontram. Os dados utilizados na Fisiologia seguem duas normas, BTPS e STPD (ALTMAN; GIBSON JR.; WANG, 1958). BTPS significa "Body Temperature and Pressure Saturated", ou seja, temperatura corpórea e pressão parcial de vapor-d'água saturada. A temperatura corpórea é $37^{\circ} \mathrm{C}$ e a pressão é igual a pressão barométrica $\left(P_{b a r}\right)$ menos a pressão de 
vapor-d'água a $37^{\circ} \mathrm{C}$, que é igual a $47 \mathrm{mmHg}$ (6281 Pa) (ASHRAE, 2005). Essa norma é utilizada para a ventilação pulmonar e para os volumes dos gases no pulmão.

Já STPD significa "Standard Temperature and Pressure Dry", ou seja, temperatura padrão e pressão padrão seca. A temperatura padrão é $0{ }^{\circ} \mathrm{C}$ e a pressão ao nível do mar. Essa norma é utilizada para o consumo e geração dos gases no metabolismo e também para expressar os volumes dos gases no sangue e nos tecidos.

Para corrigir um volume entre as duas normas utiliza-se a seguinte relação (ALTMAN; GIBSON JR.; WANG, 1958):

$$
V_{B T P S} \frac{P_{b a r}-47}{273,15+37}=V_{S T P D} \frac{760}{273,15}
$$

sendo: $V_{B T P S}=$ volume em BTPS;

$V_{S T P D}=$ volume em STPD;

$P_{b a r}=$ pressão barométrica $[\mathrm{mmHg}]$.

Para evitar o uso de correções ao longo da modelagem, optou-se no presente trabalho pela utilização da norma STPD para todos os volumes. Quando algum volume for representado em BTPS, será logo indicado.

O uso de concentração volumétrica para os gases é comum na Fisiologia. A fim de manter consistência nos balanços de massa, as concentrações presentes no modelo serão representadas pela relação entre número de mols do gás e o volume de sangue ou tecido. Concentrações volumétricas serão utilizadas somente nas equações obtidas de trabalhos de outros pesquisadores. As concentrações volumétricas no sangue ou tecido são normalmente expressas na norma STPD. Nesta norma, um mol de $\mathrm{O}_{2}$ ocupa 22,4 L, enquanto um mol de $\mathrm{CO}_{2}$ ocupa 22,26 L (DAVENPORT, 1973).

A pressão parcial de um gás é muito utilizada para representar os processos difusivos. Também é muito utilizada para representar a quantidade dos gases no sangue, tecidos ou pulmão, sendo mais comum que as concentrações. Na Fisiologia, costuma-se utilizar a unidade mmHg. Embora não esteja de acordo com o Sistema Internacional de Unidades (SI), esta unidade será utilizada na representação de valores dos parâmetros encontrados na literatura. Também será utilizada na apresentação dos resultados. O motivo desta escolha é o uso desta unidade em quase todos trabalhos encontrados nesta área. Quando estes valores estiverem ao longo do texto, o equivalente em SI será apresentado. Nas partes do trabalho onde o desenvolvimento do modelo matemático é descrito, unidades em SI serão adotadas. Para converter um mmHg para Pa, multiplica-se o valor por 133,32. 


\subsection{Oxigênio}

$\mathrm{O}_{2}$ é carregado dissolvido e reagido quimicamente pelo sangue. A quantidade de $\mathrm{O}_{2}$ dissolvido no sangue é diretamente proporcional a pressão parcial de $\mathrm{O}_{2}\left(P_{O_{2}, b l}\right)$. Essa relação depende do coeficiente de solubilidade do $\mathrm{O}_{2}$ no sangue $\left(\alpha_{\mathrm{O}_{2}, b l}\right)$, que é igual a $2,93 \times 10^{-5} \mathrm{ml} /(\mathrm{ml} \cdot \mathrm{mmHg})$ ou $9,83 \times 10^{-6} \mathrm{~mol} /\left(\mathrm{m}^{3} \cdot \mathrm{Pa}\right)$ na temperatura corpórea de $37{ }^{\circ} \mathrm{C}$ e pressão ao nível do mar (ALTMAN; GIBSON JR.; WANG, 1958). A Lei de Henry descreve essa relação segundo a seguinte equação (caso o $\mathrm{O}_{2}$ estivesse somente dissolvido):

$$
C_{O_{2}, b l}=\alpha_{O_{2}, b l} P_{O_{2}, b l}
$$

sendo: $C_{O_{2}, b l}=$ concentração de $\mathrm{O}_{2}$ no sangue $\left[\mathrm{mol} / \mathrm{m}^{3}\right]$;

$\alpha_{\mathrm{O}_{2}, b l}=$ coeficiente de solubilidade do $\mathrm{O}_{2}$ no sangue $\left[\mathrm{mol} /\left(\mathrm{m}^{3} . \mathrm{Pa}\right)\right]$;

$P_{\mathrm{O}_{2}, b l}=$ pressão parcial de $\mathrm{O}_{2}$ no sangue $[\mathrm{Pa}]$.

Segundo medições de Hedley-Whyte e Laver (1964), a relação entre a solubilidade do $\mathrm{O}_{2}$ no sangue e a solubilidade do $\mathrm{O}_{2}$ na água se mantém constante entre 24,5 e $38^{\circ} \mathrm{C}$. A temperatura do sangue, em condições normais, está dentro dessa faixa. Desse modo, a variação da solubilidade do sangue em função da temperatura pode ser calculada a partir da variação da solubilidade da água, segundo a seguinte equação (THOMAS, 1972):

$$
\frac{\alpha_{O_{2}, b l}}{\alpha_{O_{2}, b l\left(37^{\circ} \mathrm{C}\right)}}=\frac{\alpha_{w, b l}}{\alpha_{w, b l\left(37^{\circ} \mathrm{C}\right)}}=1+\log \frac{T_{b l}}{37}+0,00012\left(T_{b l}-37\right)^{2}
$$

sendo: $\alpha_{\mathrm{O}_{2}, b l\left(37^{\circ} \mathrm{C}\right)}=$ coeficiente de solubilidade do $\mathrm{O}_{2}$ no sangue a $37^{\circ} \mathrm{C}\left[\mathrm{mol} /\left(\mathrm{m}^{3} . \mathrm{Pa}\right)\right]$;

$\alpha_{\mathrm{O}_{2}, w}=$ coeficiente de solubilidade do $\mathrm{O}_{2}$ na água $\left[\mathrm{mol} /\left(\mathrm{m}^{3} . \mathrm{Pa}\right)\right]$;

$\alpha_{O_{2}, w\left(37^{\circ} \mathrm{C}\right)}=$ coeficiente de solubilidade do $\mathrm{O}_{2}$ na água a $37^{\circ} \mathrm{C}\left[\mathrm{mol} /\left(\mathrm{m}^{3} . \mathrm{Pa}\right)\right]$;

$T_{b l}=$ temperatura do sangue $\left[{ }^{\circ} \mathrm{C}\right]$.

A maior parte do $\mathrm{O}_{2}$ é carregada pelo sangue reagido quimicamente com a proteína hemoglobina, formando um composto chamado de oxihemoglobina, representado por $\mathrm{O}_{2} \mathrm{Hb}$. Existe no sangue uma capacidade máxima do $\mathrm{O}_{2}$ se ligar com a hemoglobina. O percentual de $\mathrm{O}_{2}$ ligado com a hemoglobina é a saturação de $\mathrm{O}_{2}$.

$\mathrm{O}_{2}$ se liga quimicamente com a hemoglobina através de um átomo de ferro ferroso $\left(\mathrm{Fe}^{++}\right)$. Esta ligação reversível ocorre dependendo da pressão parcial de $\mathrm{O}_{2}\left(P_{\mathrm{O}_{2}}\right)$ do sangue e é chamada de oxigenação. Cada molécula de hemoglobina contém quatro átomos de ferro, podendo se ligar a quatro moléculas de $\mathrm{O}_{2}$. A reação da hemoglobina com o $\mathrm{O}_{2}$ costuma ser escrita da seguinte maneira:

$$
\mathrm{Hb}_{4}+4 \mathrm{O}_{2} \longleftrightarrow \mathrm{Hb}_{4}\left(\mathrm{O}_{2}\right)_{4}
$$


A hemoglobina é formada por uma molécula de globina, seu maior componente, e quatro grupos hemáticos, cada um contendo um átomo de ferro. A globina é formada por quatro cadeias polipeptídicas. Cada uma se liga simetricamente a um grupo hemático através de um átomo de nitrogênio. A globina contém os elementos que fornecem ao ferro a capacidade de oxigenação.

A relação entre a quantidade máxima de $\mathrm{O}_{2}$ com a hemoglobina é de $1,34 \mathrm{ml} / \mathrm{g}$ (GUYTON; HALL, 2006). A concentração de hemoglobina no sangue [Hb] de uma pessoa normal é de 15,4 g/(100 ml) (ALTMAN; GIBSON JR.; WANG, 1958). A capacidade máxima da hemoglobina carregar $\mathrm{O}_{2}\left(N_{H b}\right)-\mathrm{em} \mathrm{ml} /(100 \mathrm{ml})$ - é igual a $1,34[H b]$.

A concentração total de $\mathrm{O}_{2}$ no sangue pode ser escrita como:

$$
C_{O_{2}, b l}=\alpha_{O_{2}, b l} P_{O_{2}, b l}+N_{H b} S_{O_{2}, b l}
$$

sendo: $N_{H b}=$ capacidade máxima da hemoglobina carregar $\mathrm{O}_{2}\left[\mathrm{~mol} / \mathrm{m}^{3}\right]$;

$S_{O_{2}, b l}=$ saturação da hemoglobina por $\mathrm{O}_{2}[0-1]$.

Um conceito que será muito utilizado nesse trabalho é o da curva de dissociação, que relaciona a saturação de $\mathrm{O}_{2} \mathrm{Hb}$ com a pressão parcial de $\mathrm{O}_{2}\left(P_{O_{2}}\right)$. Varia em função da temperatura, da quantidade de $\mathrm{CO}_{2}$ e do pH. Na Figura 3.2 há uma representação desta curva, variando em função da temperatura.

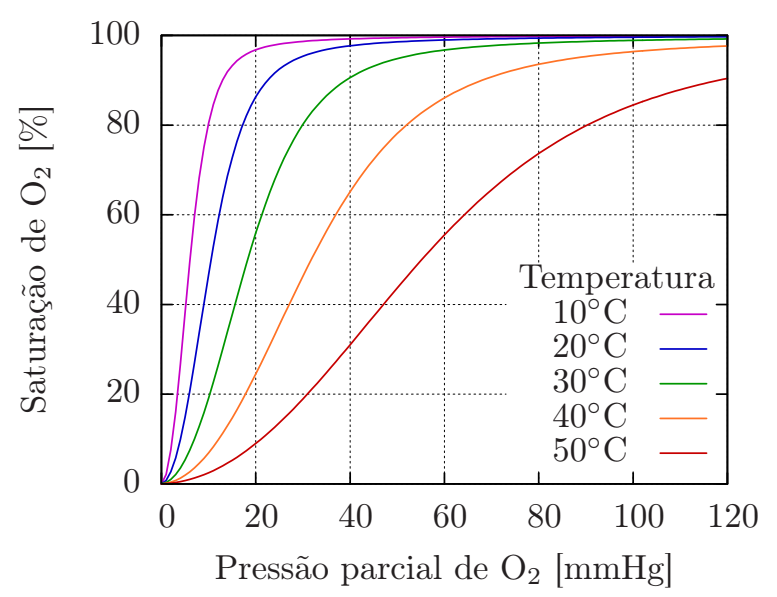

Figura 3.2 - Curvas de dissociação de $\mathrm{O}_{2}$ para diferentes temperaturas [modelo de Thomas (1972)]

A curva tem essa forma porque a afinidade da hemoglobina pelo $\mathrm{O}_{2}$ aumenta conforme aumenta a oxigenação. A ligação de um átomo de $\mathrm{O}_{2}$ com um átomo de ferro facilita a reação do $\mathrm{O}_{2}$ com os outros átomos de ferro de uma molécula de hemoglobina. A oxihemoglobina tem 300 vezes mais afinidade com o $\mathrm{O}_{2}$ do que a forma desoxigenada. A inclinação acentuada da curva para $P_{O_{2}}$ menor que $60 \mathrm{mmHg}$ é importante para que nos tecidos o $\mathrm{O}_{2}$ seja liberado com pequenas variações de $P_{O_{2}}$. 
A influência da $P_{\mathrm{CO}_{2}}$ na curva de dissociação de $\mathrm{O}_{2}$ é conhecido por "efeito Bohr". A curva se desvia para a direita em resposta a aumentos de $\mathrm{CO}_{2}$ e para a esquerda quando este diminui. Como nos tecidos a $P_{\mathrm{CO}_{2}}$ é mais elevada para uma certa $P_{\mathrm{O}_{2}}$, quantidades maiores de $\mathrm{O}_{2}$ serão fornecidas. Já na parte superior da curva a $P_{\mathrm{CO}_{2}}$ não causa influência significativa, correspondendo à passagem de sangue no fim dos capilares pulmonares. O efeito do pH na curva de dissociação é contrário ao efeito da variação da $P_{\mathrm{CO}_{2}}$ e temperatura, conforme aumenta o $\mathrm{pH}$ a curva se desloca para a esquerda (Figura 3.3).

(a)
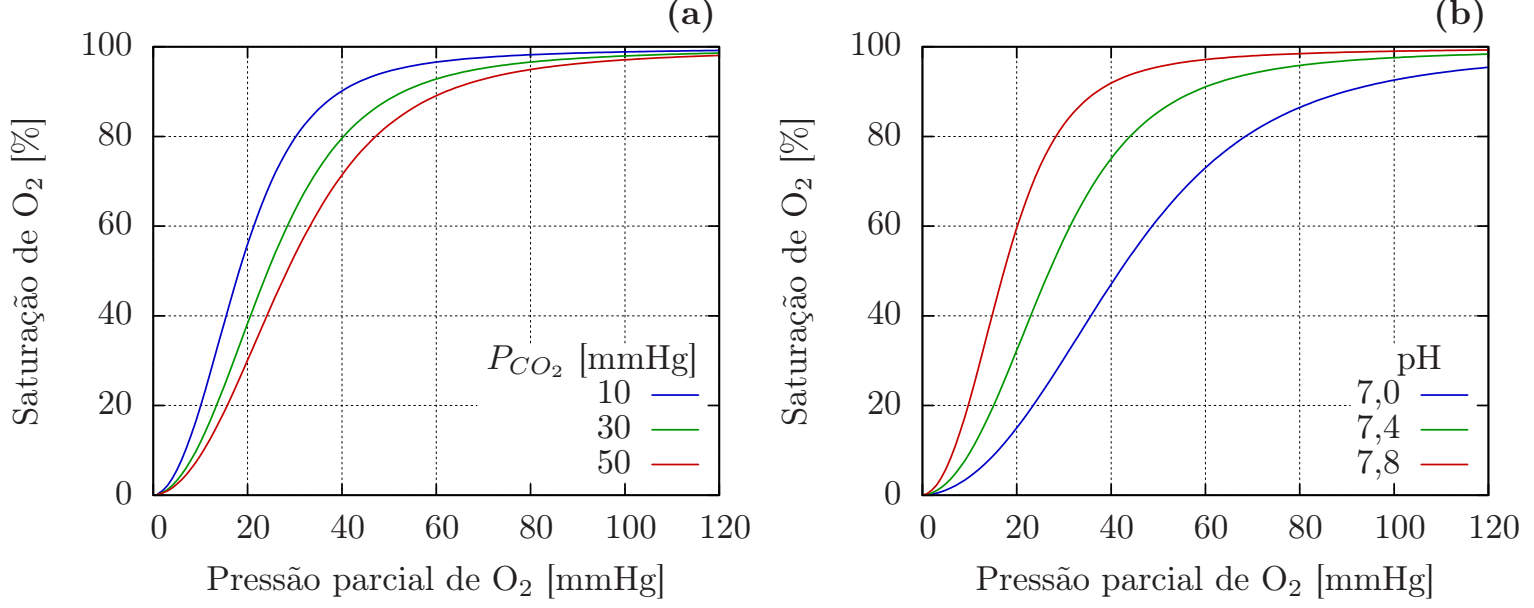

Figura 3.3 - Variação da pressão parcial de $\mathrm{CO}_{2}$ (a) e do $\mathrm{pH}(\mathrm{b})$ na curva de dissociação de $\mathrm{O}_{2}$

Para a representação da curva de dissociação, duas clássicas equações são amplamente utilizadas. Ambas têm como base o balanço de massa da reação entre $\mathrm{O}_{2}$ e hemoglobina. A primeira e mais simples é a equação de Hill (1910), que depende de dois coeficientes: o número de átomos de ferro e a constante de equilíbrio da reação. A outra é a equação de Adair (1925), que considera quatro reações, desde a forma desoxigenada da hemoglobina até as quatro possíveis ligações com $\mathrm{O}_{2}$. Neste caso, a equação depende das quatro constantes de equilíbrio das reações.

A equação proposta por Kelman (1966) oferece uma boa representação da curva de dissociação para valores de $P_{\mathrm{CO}_{2}}$ maiores que $10 \mathrm{mmHg}$. É similar à equação de Adair, porém utiliza sete coeficientes ajustados segundo dados empíricos de Severinghaus (1966), para $T=37^{\circ} \mathrm{C}, \mathrm{pH}=7,40$ e $P_{\mathrm{CO}_{2}}=40 \mathrm{mmHg}$. Thomas (1972) reajustou os coeficientes dessa equação e obteve uma representação melhor dos mesmos dados experimentais para toda a curva. No presente trabalho, a equação de Kelman (1966) com os coeficientes de Thomas (1972) será usada para a representação da curva de dissociação. Essa escolha tem como base a pesquisa realizada por Turri (2006).

Para corrigir a curva de dissociação para condições diferentes das quais foi elaborada, deve-se primeiro corrigir a $P_{\mathrm{O}_{2}}$ que será usada como entrada da equação para o cálculo 
da saturação de $\mathrm{O}_{2}$ (KELMAN, 1966; THOMAS, 1972). As correções propostas por Severinghaus (1966), a partir de revisões de dados experimentais, serão utilizadas. A $P_{O_{2}}$ é corrigida em função do $\mathrm{pH}$, da temperatura $(T)$ e do excesso de base $(B E)$. A relação entre a $P_{\mathrm{CO}_{2}}$ e esses parâmetros será descrita na próxima seção.

Desse modo, a saturação de $\mathrm{O}_{2}$ pode ser obtida, em função de $P_{\mathrm{O}_{2}}, \mathrm{pH}$, temperatura e excesso de base, a partir das seguintes equações:

$$
\begin{aligned}
P_{c o r} & =P_{O_{2}, b l} \times 10^{\left[0,48(p H-7,4)-0,024\left(T_{b l}-37\right)-0,0013 B E\right]} \\
S_{O_{2}, b l} & =\frac{P_{c o r}^{4}-15 P_{c o r}^{3}+2045 P_{c o r}^{2}+2000 P_{c o r}}{P_{c o r}^{4}-15 P_{c o r}^{3}+2400 P_{c o r}^{2}-31100 P_{c o r}+2,4 \times 10^{6}}
\end{aligned}
$$

sendo: $P_{\text {cor }}=$ pressão parcial de $\mathrm{O}_{2}$ corrigida $[\mathrm{mmHg}]$;

$B E=$ excesso de base $[\mathrm{mEq} / \mathrm{L}]$.

O excesso de base $(B E)$ é o valor da quantidade de ácido ou base que teria que ser acrescida para levar um litro de sangue aos valores de $\mathrm{pH}=7,4, P_{\mathrm{CO}_{2}}=40 \mathrm{mmHg}$ e $T=37^{\circ} \mathrm{C}$. Em condições padrões é igual a $0 \mathrm{mEq} / \mathrm{L}$, com variação entre $-2,3$ e 2,3 mEq/L. É representado pela seguinte equação, a $38^{\circ} \mathrm{C}$ (SIGGAARD-ANDERSEN, 1966):

$$
B E=(1-0,0143[H b])\left[\left[H C O_{3}^{-}\right]-(9,5+1,63[H b])(7,40-p H)-24,0\right]
$$

sendo: $[H b]=$ concentração de hemoglobina no sangue $[\mathrm{g} /(100 \mathrm{ml})]$;

$\left[\mathrm{HCO}_{3}^{-}\right]=$concentração de íon bicarbonato $[\mathrm{mmol} / \mathrm{L}]$.

\subsection{Dióxido de carbono}

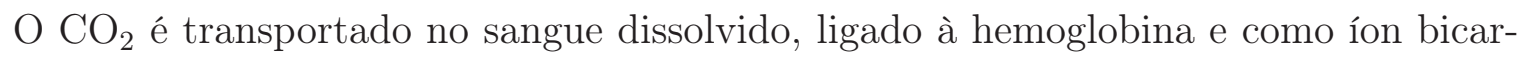
bonato. Aproximadamente $7 \%$ do $\mathrm{CO}_{2}$ no sangue encontra-se dissolvido. $\mathrm{O} \mathrm{CO}_{2}$ se liga à proteína hemoglobina formando o composto carbamino $\left(\mathrm{CO}_{2} \mathrm{Hb}\right)$. Esta ligação ocorre na parte globina da molécula de hemoglobina, não ocupando o lugar das ligações com o átomo de ferro do $\mathrm{O}_{2}$. A quantidade de $\mathrm{CO}_{2} \mathrm{Hb}$ depende da saturação da hemoglobina por $\mathrm{O}_{2}$. Aproximadamente $20 \%$ do $\mathrm{CO}_{2}$ é transportado no sangue dessa forma.

A maior parte do $\mathrm{CO}_{2}$ (aproximadamente 70\%) é transportada na forma de íon bicarbonato após reagir com a água. Ele é formado nas hemácias com a ajuda da enzima anidrase carbônica (AC), que acelera a reação cerca de 5000 vezes, segundo a seguinte reação:

$$
\mathrm{H}_{2} \mathrm{O}+\mathrm{CO}_{2} \stackrel{\mathrm{AC}}{\longleftrightarrow} \mathrm{H}_{2} \mathrm{CO}_{3} \longleftrightarrow \mathrm{H}^{+}+\mathrm{HCO}_{3}^{-}
$$


A determinação da concentração total de $\mathrm{CO}_{2}$ no sangue a partir da saturação de $\mathrm{O}_{2}$ $\left(S_{\mathrm{O}_{2}, b l}\right), P_{\mathrm{CO}_{2}}$ e temperatura $(T)$ tem como base a pesquisa realizada por Turri (2006).

O primeiro passo para a determinação da concentração total de $\mathrm{CO}_{2}$ é calcular a concentração de $\mathrm{CO}_{2}$ no plasma. Para isso, é usada a equação Handerson-Hasselbalch (ROUGHTON, 1964; DOUGLAS; JONES; REED, 1988). Além do $\mathrm{pH}$ e $P_{\mathrm{CO}_{2}}$, a equação tem duas outras variáveis. Uma delas é o coeficiente de absorção do $\mathrm{CO}_{2}$ no plasma, representado por $\alpha_{C O_{2}, p l}$. A outra é o $p K^{\prime}$, que é igual a $-\log K^{\prime}$, sendo $K^{\prime}$ a constante de dissociação do ácido, isto é, sua tendência para dar origens a íons hidrogênio livres (LAMBERTSEN, 1974d).

$$
C_{C O_{2}, p l}=\alpha_{C O_{2}, p l} P_{C O_{2}, b l}\left[1+10^{\left(p H-p K^{\prime}\right)}\right]
$$

sendo: $C_{C O_{2}, p l}=$ concentração de $\mathrm{CO}_{2}$ no plasma $[\mathrm{mmol} /(100 \mathrm{ml})]$;

$\alpha_{C O_{2}, p l}=$ coeficiente de absorção do $\mathrm{CO}_{2}$ no plasma $[\mathrm{mmol} /(100 \mathrm{ml} . \mathrm{mmHg})]$;

$P_{\mathrm{CO}_{2}, b l}=$ pressão parcial de $\mathrm{CO}_{2}$ no sangue $[\mathrm{mmHg}]$;

$p K^{\prime}=$ logaritmo negativo da constante de dissociação do ácido [adimensional].

O coeficiente de absorção do $\mathrm{CO}_{2}$ no plasma $\left(\alpha_{C O_{2}, p l}\right)$ e o logaritmo negativo da constante de dissociação do ácido $\left(p K^{\prime}\right)$ variam em função da temperatura e do $\mathrm{pH}$, segundo as seguintes equações (DOUGLAS; JONES; REED, 1988):

$$
\begin{aligned}
\alpha_{C O_{2}, p l} & =0,0307+0,00057\left(37-T_{b l}\right)+0,00002\left(37-T_{b l}\right)^{2} \\
p K^{\prime} & =6,086+0,042(7,4-p H)+\left(38-T_{b l}\right)[0,00472+0,00139(7,4-p H)]
\end{aligned}
$$

A relação entre a concentração de $\mathrm{CO}_{2}$ no plasma e a concentração total de $\mathrm{CO}_{2}$ no sangue é descrita em função da concentração de hemoglobina ([Hb]), pH e saturação de $\mathrm{O}_{2}$ $\left(S_{O_{2}, b l}\right)$. Douglas, Jones e Reed (1988) propuseram a seguinte equação, com os coeficientes ajustados a partir de dados experimentais:

$$
C_{C O_{2}, b l}=C_{C O_{2}, p l}\left[1-\frac{2,89 \times 10^{-5}[\mathrm{Hb}]}{\left(3,352-0,456 S_{\mathrm{O}_{2}, b l}\right)(8,142-p H)}\right]
$$

sendo: $C_{C O_{2}, b l}=$ concentração de $\mathrm{CO}_{2}$ no sangue $[\mathrm{mmol} /(100 \mathrm{ml})]$.

A Figura 3.4 mostra a variação da concentração de $\mathrm{CO}_{2}$ em função da variação de $P_{\mathrm{CO}_{2}}$ para variação da temperatura e da saturação de $\mathrm{O}_{2}$, segundo o equacionamento apresentado. 
(a)
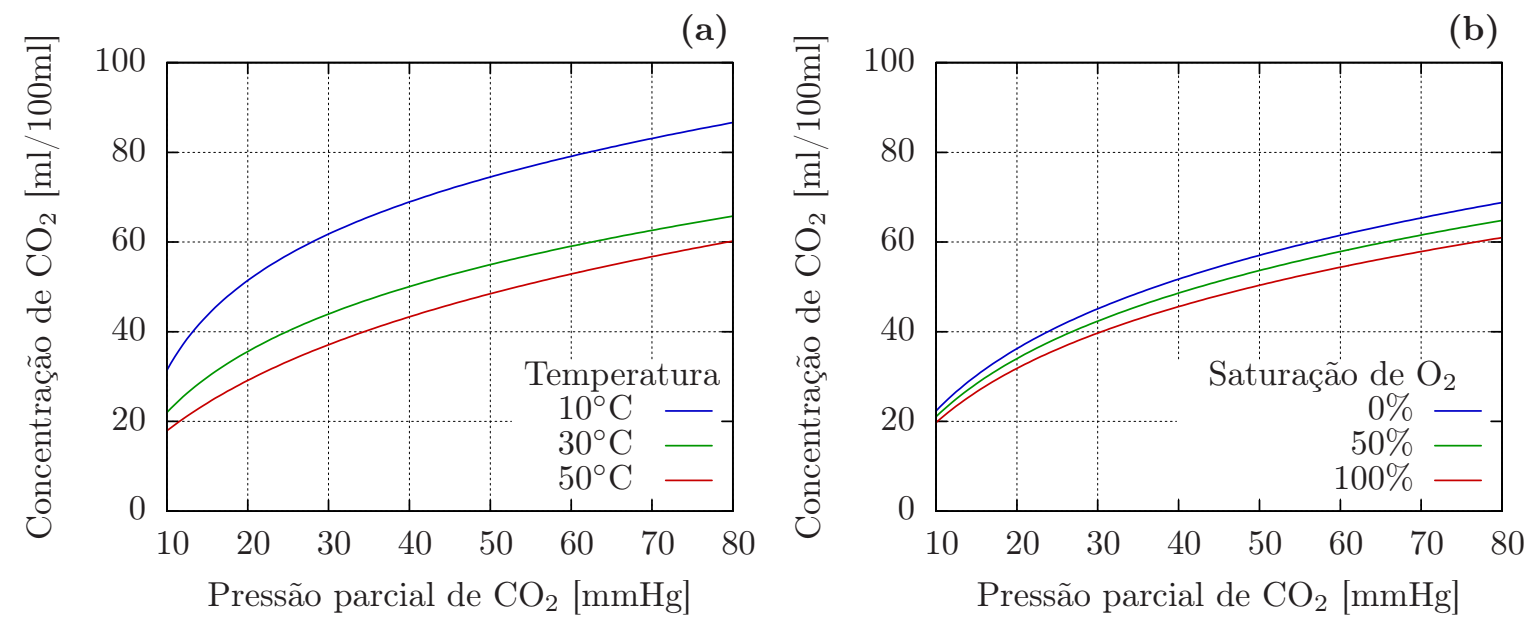

Figura 3.4 - Curvas de dissociação do $\mathrm{CO}_{2}$ no sangue com variação da temperatura (a) e da saturação de $\mathrm{O}_{2}(\mathrm{~b})$

\section{$3.4 \mathrm{pH}$}

Para obter o pH em função da pressão parcial $\mathrm{CO}_{2}$ e da saturação de $\mathrm{O}_{2}$, considera-se que a concentração de íon bicarbonato $\left(\left[\mathrm{HCO}_{3}^{-}\right]\right)$da eq.(3.7), que define o excesso de base, é igual à concentração de $\mathrm{CO}_{2}$ no plasma $\left(C_{C O_{2}, p l}\right)$ da eq.(3.8) (TURRI, 2006).

A equação que define o excesso de base, eq.(3.7), foi feita para temperatura igual a $38{ }^{\circ} \mathrm{C}$. Portanto, utilizando essa equação, todo o cálculo do pH deve ser feito nesta temperatura. A pressão parcial de $\mathrm{CO}_{2}$ é primeiro corrigida pela seguinte equação (SIGGAARDANDERSEN, 1966):

$$
P_{C O_{2}, b l\left(38^{\circ} \mathrm{C}\right)}=P_{C O_{2}, b l} 10^{0,021\left(38-T_{b l}\right)}
$$

sendo: $P_{C O_{2}, b l\left(38^{\circ} \mathrm{C}\right)}=$ pressão parcial de $\mathrm{CO}_{2}$ no sangue a $38^{\circ} \mathrm{C}[\mathrm{mmHg}]$.

No passo seguinte, o $\mathrm{pH}$ a $38^{\circ} \mathrm{C}$ é calculado iterativamente pela igualdade entre $\left[\mathrm{HCO}_{3}^{-}\right]$e $\mathrm{C}_{\mathrm{CO}_{2}, p l}$. Neste cálculo deve se usar a $\mathrm{P}_{\mathrm{CO}_{2}, 38}$ e todos os coeficientes que determinam a $C_{C_{2}, p l}$ a $38^{\circ} \mathrm{C}$. O pH calculado é em seguida corrigido para a temperatura do sangue pela seguinte equação (SIGGAARD-ANDERSEN, 1966):

$$
p H=p H_{\left(38^{\circ} \mathrm{C}\right)}+0,0147\left(38-T_{b l}\right)
$$

sendo: $p H_{\left(38^{\circ} \mathrm{C}\right)}=\mathrm{pH}$ a $38^{\circ} \mathrm{C}$

A determinação do pH inclui ainda o efeito da desoxigenação do sangue. Este efeito é considerado somando o termo $0,003[H b]\left(1-S_{O_{2}}\right)$ ao pH calculado (KELMAN, 1968). 


\subsection{Circulação}

O coração é o órgão responsável pela circulação do sangue. É formado por duas bombas. Uma faz o sangue ir para o pulmão (circulação pulmonar) e a outra bombeia o sangue do pulmão para os outros tecidos do corpo humano (circulação sistêmica).

As artérias transportam o sangue para os tecidos com elevada pressão. O último vaso antes de chegar nos capilares teciduais são as arteríolas. Sua constrição e dilatação regulam a vazão de sangue nos capilares, conforme as necessidades dos tecidos.

Através das finas paredes dos capilares teciduais ocorre a troca de substâncias entre o sangue e os tecidos. Dos capilares, o sangue segue pelas vênulas até as veias. Além de transportar o sangue de volta para o coração, as veias servem como um reservatório adicional de sangue para o corpo humano.

A Figura 3.5 mostra a distribuição de sangue nas diversas partes do sistema circulatório.

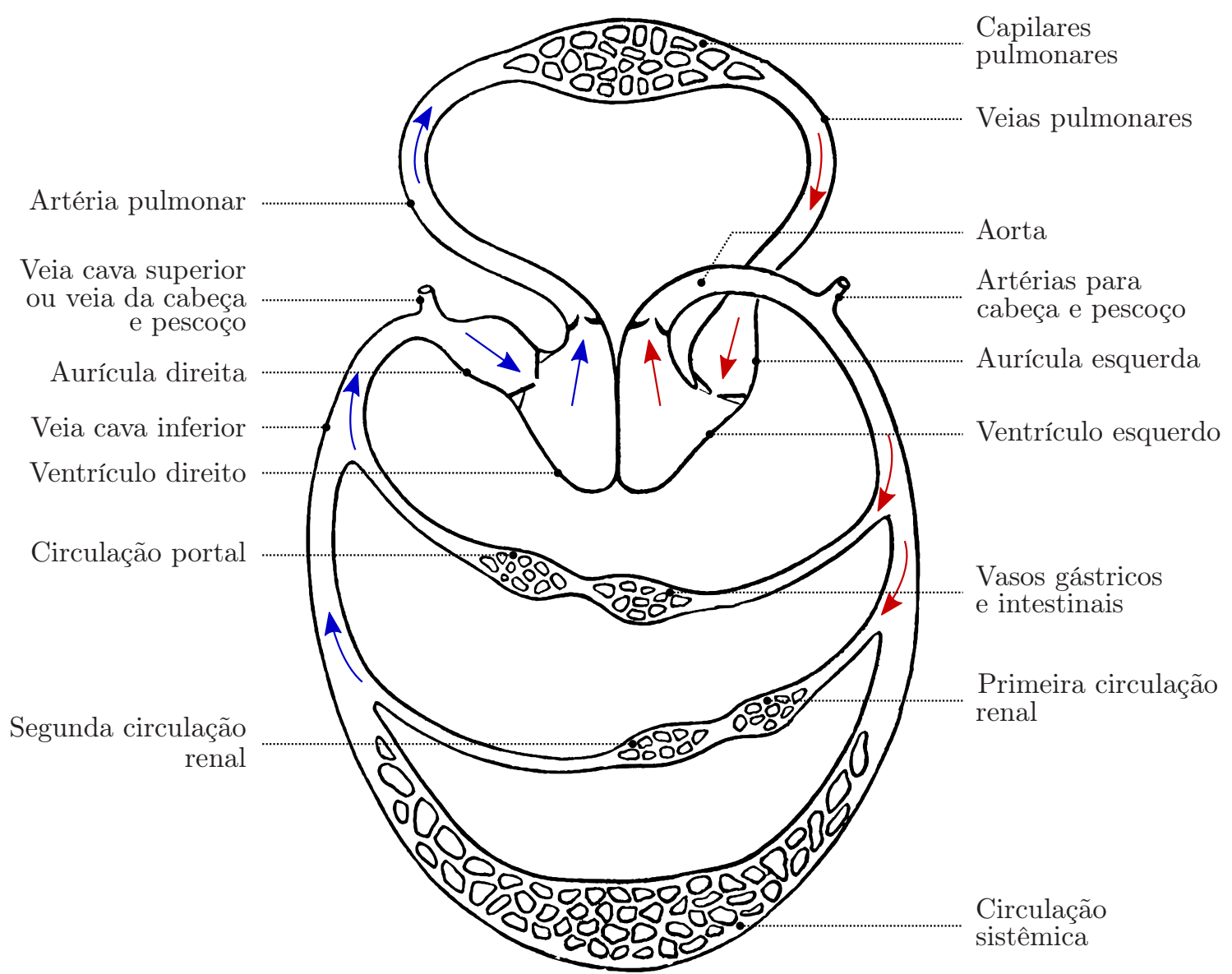

Figura 3.5 - Circulação [adaptado de Halliburton (1914)]

A vazão de sangue pela circulação sistêmica é conhecida por débito cardíaco, representada por $\dot{V}_{b l}$. Para um homem jovem em repouso, o débito cardíaco é aproximadamente 
$5600 \mathrm{ml} / \mathrm{min}$. Já em mulheres é aproximadamente $4900 \mathrm{ml} / \mathrm{min}$. Em situações de exercício físico, esse valor pode chegar a $35000 \mathrm{ml} / \mathrm{min}$ (GUYTON; HALL, 2006). A Tabela 3.1 mostra a distribuição da vazão de sangue para os órgãos e tecidos nas condições basais.

Tabela 3.1 - Vazão de sangue basal nos órgãos e tecidos [adaptado de Guyton e Hall (2006)]

\begin{tabular}{lrr}
\hline & {$[\%]$} & {$[\mathrm{ml} / \mathrm{min}]$} \\
\hline Cérebro & 14 & 700 \\
Coração & 4 & 200 \\
Brônquios & 2 & 100 \\
Rins & 22 & 1100 \\
Fígado & 27 & 1350 \\
Músculo & 15 & 750 \\
Osso & 5 & 250 \\
Pele (Frio) & 6 & 300 \\
Outros tecidos & 5 & 250 \\
\hline
\end{tabular}

Alguns tecidos têm características específicas em relação ao controle da vazão de sangue. A vazão de sangue nos músculos pode aumentar mais que 20 vezes em condições de exercício físico. No cérebro, a vazão de sangue é regulada pela concentração de dióxido de carbono. Quando em excesso aumenta a acidez diminuindo a função neuronal. Na pele, a vazão de sangue tem outra função além da nutrição, que é a regulação da temperatura corporal. Pode variar de $50 \mathrm{ml} / \mathrm{min}$ para a pele toda, quando as artérias estão contraídas, até $3000 \mathrm{ml} / \mathrm{min}$, quando dilatadas.

No pulmão, somente uma fração do débito cardíaco realiza trocas de gases com os alvéolos. Essa fração, representada por $\sigma$, é igual a 0,98 para indivíduos em situações normais (GUYTON; HALL, 2006). O sangue que chega nos pulmões, vindo dos tecidos, é o sangue venoso. A fração de sangue venoso que não realiza trocas de gases se junta com o sangue oxigenado pelo pulmão, formando o sangue arterial. Essa fração desviada do pulmão é conhecida na Fisiologia por "shunt". É composta por uma parte de sangue que não passa pelo pulmão, e outra que passa pelo pulmão através dos capilares pulmonares, mas não realiza troca de gases.

\subsection{Transferência de calor}

O sangue tem um papel importante na regulação da temperatura corpórea. Como irriga todos os tecidos do corpo, influi diretamente em suas temperaturas. É comum nos modelos do sistema térmico separar os vasos sanguíneos em pequenos e grandes vasos. Isso porque, no caso dos grandes vasos, a transferência de calor entre sangue e tecidos é pequena ao comparar com a que ocorre nos pequenos vasos. Nas arteríolas, capilares e vênulas a temperatura é praticamente igual a dos tecidos. Para a divisão do sangue 
em pequenos e grandes vasos, será utilizada a abordagem feita por Ferreira e Yanagihara (2009).

Uma questão importante da divisão em pequenos e grandes vasos é definir onde ela ocorre, ou seja, a partir de que diâmetro dos vasos começa a ocorrer influência significativa da temperatura. Chen e Holmes (1980) propuseram uma análise com base na ocorrência do equilíbrio térmico entre os pequenos vasos e os tecidos. Definiram um comprimento de equilíbrio da variação axial de temperatura para cada tipo de vaso. O equacionamento foi feito a partir da análise de um vaso com tecido ao redor. A Tabela 3.2 mostra, para cada tipo de vaso, o volume de sangue, o raio e o comprimento de equilíbrio. Chen e Holmes (1980) acrescentaram o grupo 5 para preencher uma lacuna existente entre os raios do ramo terminal e as arteríolas. O valor elevado do comprimento de equilíbrio nas grandes artérias e veias indica que o sangue nestes vasos não está em equilíbrio com os tecidos. O pequeno valor do comprimento de equilíbrio nos pequenos vasos indica que a temperatura do sangue é praticamente a mesma que os tecidos.

Tabela 3.2 - Propriedades dos vasos sanguíneos (CHEN; HOLMES, 1980)

\begin{tabular}{|c|c|c|c|c|}
\hline & Vaso & $\begin{array}{r}\text { Volume } \\
{[\%]}\end{array}$ & $\begin{array}{l}\text { Raio } \\
{[\mu \mathrm{m}]}\end{array}$ & $\begin{array}{l}\text { Comprimento de } \\
\text { equilíbrio }[\mathrm{m}]\end{array}$ \\
\hline 1 & Aorta & 3,30 & 5000 & 190 \\
\hline 2 & Grande artéria & 6,59 & 1500 & 4 \\
\hline 3 & Ramo arterial & 5,49 & 500 & 0,3 \\
\hline 4 & Ramo terminal & 0,55 & 300 & 0,08 \\
\hline 5 & & & 175 & 0,009 \\
\hline 6 & Arteríola & 2,75 & 10 & 0,000005 \\
\hline 7 & Capilar & 6,59 & 4 & 0,0000002 \\
\hline 8 & Vênula & 12,09 & 15 & 0,000002 \\
\hline 9 & Veia terminal & 3,30 & 750 & 0,1 \\
\hline 10 & Ramo venoso & 29,67 & 1200 & 0,3 \\
\hline 11 & Grande veia & 24,18 & 3000 & 5 \\
\hline 12 & Vena cava & 5,49 & 6250 & 190 \\
\hline
\end{tabular}

Ferreira e Yanagihara (2009) consideraram como pequenos vasos, onde a transferência de calor entre sangue e tecidos é significativa, os vasos do ramo terminal até a veia terminal (número 4 a 9). Os outros são os grandes vasos.

A maior parte da transferência dos gases oxigênio e dióxido de carbono entre o sangue e os tecidos ocorre nos capilares. Uma parcela menor dessa transferência ocorre também nas arteríolas e vênulas. Com a divisão proposta por Ferreira e Yanagihara (2009), tem-se que toda essa transferência ocorre nos pequenos vasos. 



\section{Capítulo 4}

\section{Fenômenos de Transporte nos Tecidos}

Neste capítulo serão descritos conceitos utilizados na representação do transporte do oxigênio, dióxido de carbono e calor nos tecidos do corpo humano.

A primeira seção trata do metabolismo nos tecidos, onde o oxigênio é consumido gerando dióxido de carbono e calor. Depois segue uma descrição do transporte do oxigênio e do dióxido de carbono nos tecidos, onde os gases estão dissolvidos, ligados à mioglobina no caso do $\mathrm{O}_{2}$ nos músculos, e como íon bicarbonato no caso do $\mathrm{CO}_{2}$.

A última seção descreve a metodologia usada para representar a transferência de calor e massa entre a pele e o ambiente.

Os conceitos fisiológicos apresentados têm como base o livro de Guyton e Hall (2006) e o capítulo de Brobeck (1974b).

\subsection{Metabolismo}

A geração de energia no corpo humano é realizada pela oxidação de alguns compostos com ligações entre carbono e hidrogênio. Estes compostos são os carboidratos, gorduras e algumas cadeias de ligação carbono-hidrogênio. Como produto dessa oxidação são gerados $\mathrm{CO}_{2}$ e $\mathrm{H}_{2} \mathrm{O}$. Este processo é conhecido por metabolismo.

A relação entre o volume de $\mathrm{CO}_{2}$ produzido e o volume de $\mathrm{O}_{2}$ consumido durante um certo intervalo de tempo é chamado de quociente respiratório $(R Q)$. Ele depende do tipo de substância que está sendo metabolizado. Como exemplo, pode-se citar a reação do metabolismo da glicose, que tem $R Q=1$, pois 6 moléculas de $\mathrm{CO}_{2}$ são produzidas a cada 6 moléculas de $\mathrm{O}_{2}$ reagidas:

$$
\mathrm{C}_{6} \mathrm{H}_{12} \mathrm{O}_{6}+6 \mathrm{O}_{2} \longrightarrow 6 \mathrm{CO}_{2}+6 \mathrm{H}_{2} \mathrm{O}+\text { energia }
$$


Para gorduras o valor de $R Q$ fica próximo de 0,7 e para as proteínas de 0,8. Já para todo o corpo humano, o valor de $R Q$ é aproximadamente 0,82. A Tabela 4.1 mostra, para sustâncias que são normalmente metabolizadas, a quantidade de $\mathrm{O}_{2}$ necessária para oxidar 1 g da substância, o $\mathrm{CO}_{2}$ e o calor produzido, e o quociente respiratório.

Tabela 4.1 - Trocas gasosas, produção de calor e quociente respiratório de compostos comumente metabolizados [modificado de Brobeck (1974b)]

\begin{tabular}{lrrrr}
\hline Substância & \multicolumn{3}{c}{ Oxidação de 1 g do material } & $R Q$ \\
\cline { 2 - 3 } & $\mathrm{O}_{2}$ necessário & $\mathrm{CO}_{2}$ produzido & Calor produzido & \\
& {$[\mathrm{ml}]$} & $8 \mathrm{ml}]$ & $4,29,3$ & \\
\hline Amido & 829,3 & 785,5 & 3,96 & 1,00 \\
Açúcar de cana & 785,5 & 746,2 & 3,74 & 1,00 \\
Dextrose & 746,2 & 745,9 & 3,62 & 1,00 \\
Ácido láctico & 745,9 & 1431,1 & 9,50 & 0,71 \\
Gordura animal & 2013,2 & 773,8 & 4,40 & 0,81 \\
Proteína & 956,9 & 1157,2 & 7,43 & 0,75 \\
Acetona & 1542,9 & 972,9 & 7,08 & 0,67 \\
Álcool etílico & 1459,5 & & & \\
\hline
\end{tabular}

A quantidade de energia produzida para uma certa quantidade de $\mathrm{O}_{2}$ depende do quociente respiratório, segundo a seguinte equação (ASHRAE, 2005):

$$
\frac{\dot{q}_{t}}{\dot{V}_{O_{2}, t}}=21(0,23 R Q+0,77)
$$

sendo: $\dot{q}_{t}=$ calor produzido no tecido $[\mathrm{W}]$;

$\dot{V}_{\mathrm{O}_{2}, t}=$ consumo de $\mathrm{O}_{2}$ no tecido $[\mathrm{ml} / \mathrm{s}, \mathrm{STPD}]$;

$R Q=$ quociente respiratório $[\mathrm{ml} / \mathrm{ml}, \mathrm{STPD}]$.

O consumo de oxigênio pelo corpo humano varia principalmente em função da atividade física do indivíduo. Para um homem normal em repouso, este valor varia entre 200 e $300 \mathrm{ml} \mathrm{O} 2 / \mathrm{min}$.

O metabolismo basal de um indivíduo costuma ser relacionado com sua área superficial. Deste modo, é possível considerar as variações de massa e altura. A área superficial pode ser calculada com a equação de DuBois e DuBois (1916), obtida a partir de medições do corpo humano com moldes:

$$
A_{b}=0,007184 m_{b}^{0,425} L_{b}^{0,725}
$$

sendo: $A_{b}=$ área superficial da pele $\left[\mathrm{m}^{2}\right]$;

$m_{b}=$ massa corporal [kg];

$L_{b}=$ altura corporal $[\mathrm{cm}]$. 
Além desses fatores, outros podem influir no metabolismo basal de um indivíduo. Entre eles: idade, sexo, nutrição, treinamento atlético, clima, altitude, sono, temperatura corporal, raça, menstruação e drogas. Esses fatores devem ser considerados nas medições do metabolismo do corpo humano, que podem ser feitas por medição direta (em um calorímetro), ou indireta (pela análise dos gases respiratórios). Os fatores mais influentes no metabolismo são a atividade muscular, a temperatura externa e a ingestão de alimento. A Tabela 4.2 mostra a variação do metabolismo basal em função da idade e sexo.

Tabela 4.2 - Metabolismo basal em função da idade e sexo [modificado de Brobeck (1974b)]

\begin{tabular}{lcc}
\hline Idade & \multicolumn{2}{c}{ Metabolismo Basal $\left[\mathrm{W} / \mathrm{m}^{2}\right]$} \\
\cline { 2 - 3 } [anos] & Homem & Mulher \\
\hline 14 a 16 & 53,5 & 50,0 \\
16 a 18 & 50,0 & 46,5 \\
18 a 20 & 47,7 & 44,2 \\
20 a 30 & 45,9 & 43,0 \\
30 a 40 & 45,9 & 42,4 \\
40 a 50 & 44,8 & 41,9 \\
50 a 60 & 43,6 & 40,7 \\
60 a 70 & 42,4 & 39,5 \\
70 a 80 & 41,3 & 38,4 \\
\hline
\end{tabular}

Sabendo o metabolismo e o $R Q$, o consumo de $\mathrm{O}_{2}$ e a geração de $\mathrm{CO}_{2}$ podem ser determinados a partir da eq.(4.1) e da eq.(4.2). Por exemplo, para um homem de 1,74 m, $70 \mathrm{~kg}$, entre 20 e 30 anos. Da eq.(4.2) tem-se que a área superficial é igual a 1,84 $\mathrm{m}^{2}$. Da Tabela 4.2 obtém-se que seu metabolismo basal é de $45,9 \mathrm{~W} / \mathrm{m}^{2}$, ou $84,5 \mathrm{~W}$ ao multiplicar pela área superficial. Considerando ainda que seu quociente respiratório é igual a 0,85, da eq.(4.1), tem-se que um litro de $\mathrm{O}_{2}$ gera 4,862 kcal de energia. Relacionando o metabolismo basal com esse valor obtém-se o consumo de $\mathrm{O}_{2}$ de $250 \mathrm{ml} / \mathrm{min}$, que corresponde a geração de $\mathrm{CO}_{2}$ de $213 \mathrm{ml} / \mathrm{min}$.

A taxa do metabolismo pela área superficial também é frequentemente expressada na unidade "met". É definida como a taxa do metabolismo pela área superficial de uma pessoa em atividade sedentária (sentada e quieta): 1 met $=58,1 \mathrm{~W} / \mathrm{m}^{2}$ (ASHRAE, 2005).

Durante a atividade física, o metabolismo e o consumo de $\mathrm{O}_{2}$ no corpo humano aumentam devido a uma maior necessidade de energia. Esse aumento ocorre principalmente nos tecidos musculares. A Tabela 4.3 mostra o metabolismo para diferentes níveis de atividade física.

A reação metabólica tem sua velocidade alterada quando ocorre variação da temperatura nos tecidos. A razão entre duas taxas de metabolismo com a diferença da temperatura de $10{ }^{\circ} \mathrm{C}$ costuma ser representada por " $Q_{10}$ " (HARDY; BARD, 1974), e o efeito da temperatura chamado de "efeito $Q_{10}$ ". Essa razão foi utilizada em alguns modelos de termorregulação, como em Gordon, Roemer e Horvath (1976), Werner e Reents (1980) e 
Tabela 4.3 - Geração de calor pelo metabolismo, típica para várias atividades físicas (ASHRAE, 2005; BROBECK, 1974a)

\begin{tabular}{|c|c|c|}
\hline & {$\left[\mathrm{W} / \mathrm{m}^{2}\right]$} & [met] \\
\hline $\begin{array}{l}\text { Descansando } \\
\text { - Dormindo } \\
\text { - Repousando na cama } \\
\text { - Sentado, quieto } \\
\text { - Em pé, relaxado }\end{array}$ & $\begin{array}{l}40 \\
50 \\
60 \\
70\end{array}$ & $\begin{array}{c}0,7 \\
0,85 \\
1,0 \\
1,2\end{array}$ \\
\hline $\begin{array}{l}\text { Andando (superfície plana) } \\
-3,2 \mathrm{~km} / \mathrm{h} \\
-4,3 \mathrm{~km} / \mathrm{h} \\
-6,4 \mathrm{~km} / \mathrm{h}\end{array}$ & $\begin{array}{l}115 \\
150 \\
220\end{array}$ & $\begin{array}{l}2,0 \\
2,6 \\
3,8\end{array}$ \\
\hline $\begin{array}{l}\text { Atividades de escritório } \\
\text { - Lendo, sentado } \\
\text { - Escrevendo } \\
\text { - Digitando }\end{array}$ & $\begin{array}{l}55 \\
60 \\
65\end{array}$ & $\begin{array}{l}1,0 \\
1,0 \\
1,1\end{array}$ \\
\hline $\begin{array}{l}\text { Dirigindo/Pilotando } \\
\text { - Carro } \\
\text { - Avião, rotina } \\
\text { - Avião, combate } \\
\text { - Veículo pesado }\end{array}$ & $\begin{array}{c}60-115 \\
70 \\
140 \\
185\end{array}$ & $\begin{array}{l}1,0-2,0 \\
1,2 \\
2,4 \\
3,2\end{array}$ \\
\hline $\begin{array}{l}\text { Atividades ocupacionais } \\
\text { - Cozinhando } \\
\text { - Limpeza doméstica } \\
\text { - Trabalho com máquinas, leve } \\
\text { - Trabalho com máquinas, pesado }\end{array}$ & $\begin{array}{c}95-115 \\
115-200 \\
115-140 \\
235\end{array}$ & $\begin{array}{l}1,6-2,0 \\
2,0-3,4 \\
2,0-2,4 \\
\quad 4,0\end{array}$ \\
\hline $\begin{array}{l}\text { Atividades de lazer } \\
\text { - Dançando, social } \\
\text { - Tênis, simples } \\
\text { - Basquete }\end{array}$ & $\begin{array}{l}140-255 \\
210-270 \\
290-440\end{array}$ & $\begin{array}{l}2,4-4,4 \\
3,6-4,0 \\
5,0-7,6\end{array}$ \\
\hline
\end{tabular}

Fiala, Lomas e Stohrer (1999). Consideraram que a taxa de metabolismo dobra quando a temperatura aumenta $10{ }^{\circ} \mathrm{C}$, ou cai pela metade quando a temperatura diminui $10{ }^{\circ} \mathrm{C}$. Desse modo, a taxa de metabolismo é corrigida pela temperatura com seguinte equação:

$$
\dot{q}_{t}=\dot{q}_{t, 0} 2^{\left(T_{t}-T_{t, 0}\right) / 10}
$$

sendo: $\dot{q}_{t, 0}=$ calor basal produzido no tecido [W];

$T_{t}=$ temperatura do tecido $\left[{ }^{\circ} \mathrm{C}\right]$;

$T_{t, 0}=$ temperatura basal do tecido $\left[{ }^{\circ} \mathrm{C}\right]$.

Embora a respiração anaeróbica não esteja incluída no presente trabalho, será considerado que o mínimo valor que a pressão parcial de $\mathrm{O}_{2}$ de um tecido pode chegar é igual a 7,4 mmHg. Abaixo desse valor há uma predominância da respiração anaeróbica, conforme pode ser observado nos experimentos de Bylund-Fellenius et al. (1981). A diminuição da respiração aeróbica será considerada do mesmo modo que Ursino, Magosso e Avanzolini 
(2001a). Consideraram que, quando a pressão parcial de $\mathrm{O}_{2}$ no tecido $\left(P_{\mathrm{O}_{2}, t}\right)$ está abaixo de um certo valor, o consumo de $\mathrm{O}_{2}$ e a geração de $\mathrm{CO}_{2}$ diminuem proporcionalmente à pressão parcial. Para determinar o consumo de $\mathrm{O}_{2}$ corrigido (abaixo do limite da $P_{O_{2}, t}$ de $7,4 \mathrm{mmHg}$ ), basta multiplicar seu valor por $P_{O_{2}, t} / 7,4$.

\subsection{Oxigênio}

Os tecidos trocam gases com o sangue quando este passa pelos pequenos vasos, através do processo de difusão (Figura 4.1).

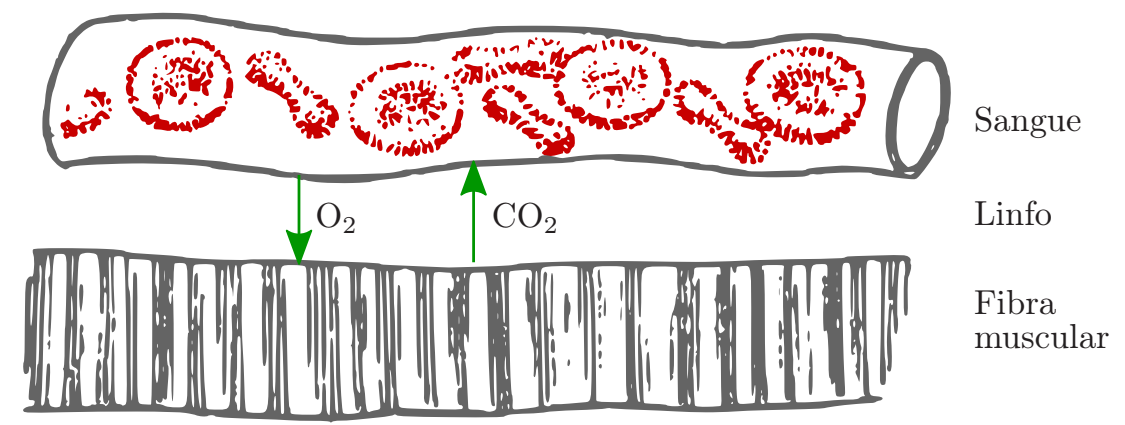

Figura 4.1 - Passagem dos gases entre sangue e tecido [adaptado de Halliburton (1914)]

O transporte de $\mathrm{O}_{2}$ nos tecidos musculares ocorre de forma diferente dos tecidos não musculares. Nos tecidos não musculares, o $\mathrm{O}_{2}$ está presente somente na forma dissolvida, ou seja, sua concentração é diretamente proporcional à $P_{O_{2}}$. Desse modo, a relação abaixo é válida para os tecidos não musculares:

$$
C_{O_{2}, t}=\alpha_{O_{2}, t} P_{O_{2}, t}
$$

sendo: $C_{O_{2}, t}=$ concentração do $\mathrm{O}_{2}$ nos tecidos $\left[\mathrm{mol} / \mathrm{m}^{3}\right]$;

$\alpha_{O_{2}, t}=$ coeficiente de solubilidade do $\mathrm{O}_{2}$ nos tecidos $\left[\mathrm{mol} /\left(\mathrm{m}^{3} . \mathrm{Pa}\right)\right]$;

$P_{O_{2}, t}=$ pressão parcial de $\mathrm{O}_{2}$ nos tecidos $[\mathrm{Pa}]$.

Os coeficientes de solubilidade do $\mathrm{O}_{2}$ nos tecidos são de difícil determinação. Uma alternativa é o uso do coeficiente de solubilidade do $\mathrm{O}_{2}$ na água. Este coeficiente é igual a $3,14 \times 10^{-5} \mathrm{ml} /(\mathrm{ml} . \mathrm{mmHg})$ ou $1,05 \times 10^{-5} \mathrm{~mol} /\left(\mathrm{m}^{3} . \mathrm{Pa}\right)$ a $37^{\circ} \mathrm{C}($ ALTMAN; GIBSON JR.; WANG, 1958).

Os tecidos de um homem de $70 \mathrm{~kg}$ têm aproximadamente $0,3 \mathrm{~L}$ de $\mathrm{O}_{2}$, valor pequeno quando comparado com 1,2 L de $\mathrm{O}_{2}$ presente no sangue (CHERNIACK; LONGOBARDO, 1970). 


\subsubsection{Tecidos musculares}

Nos tecidos musculares existe uma proteína chamada mioglobina que, assim como a hemoglobina no sangue, realiza a função de transporte de $\mathrm{O}_{2}$. Aproximadamente $80 \%$ dos tecidos do corpo humano são musculares.

A mioglobina é formada por uma cadeia polipeptídica e um grupo hemo, que se liga reversivelmente com uma molécula de $\mathrm{O}_{2}$ através de um átomo de ferro (a hemoglobina, presente no sangue, tem capacidade de carregar quatro moléculas de $\mathrm{O}_{2}$ ). $\mathrm{O}_{2}$ presente na mioglobina é liberado quando não há $\mathrm{O}_{2}$ suficiente no sangue para os músculos. A mioglobina pode ser considerada como uma reserva de $\mathrm{O}_{2}$ para os músculos, sendo utilizada em casos de exercício físico.

A capacidade máxima da mioglobina carregar $\mathrm{O}_{2}\left(N_{M b}\right)$ pode ser estimada a partir da capacidade da hemoglobina $(0,0446 \mathrm{~mol} / \mathrm{kg})$ vezes a razão das massas moleculares, 68000 para Hb e 17600 para Mb (BRUCE; BRUCE, 2003; GUYTON; HALL, 2006), dividido por quatro (relação entre as quantidades de moléculas de $\mathrm{O}_{2}$ que cada uma carrega). A concentração volumétrica média $([M b])$ da mioglobina nos músculos é igual a $5,3 \mathrm{~kg} / \mathrm{m}^{3}$ (COBURN; MAYERS, 1971). A capacidade máxima da mioglobina carregar $\mathrm{O}_{2}\left(N_{M b}\right)$ é igual a $\frac{0,0446}{4} \frac{68000}{17600}[M b]$.

De forma similar ao transporte de $\mathrm{O}_{2}$ pela hemoglobina, a quantidade de $\mathrm{O}_{2}$ carregada pela mioglobina é igual a capacidade máxima da mioglobina carregar $\mathrm{O}_{2}$ vezes a saturação de mioglobina $\left(S_{O_{2}, m}\right)$, variando de 0 a 1 , mais a parte dissolvida.

$$
C_{O_{2}, m}=\alpha_{O_{2}, t} P_{O_{2}, m}+N_{M b} S_{O_{2}, m}
$$

sendo: $C_{O_{2}, m}=$ concentração de $\mathrm{O}_{2}$ nos tecidos musculares $\left[\mathrm{mol} / \mathrm{m}^{3}\right]$;

$P_{O_{2}, m}=$ pressão parcial de $\mathrm{O}_{2}$ nos tecidos musculares $[\mathrm{Pa}]$;

$N_{M b}=$ capacidade máxima da mioglobina carregar $\mathrm{O}_{2}\left[\mathrm{~mol} / \mathrm{m}^{3}\right]$;

$S_{O_{2}, m}=$ saturação da mioglobina por $\mathrm{O}_{2}[0-1]$.

A saturação de mioglobina por $\mathrm{O}_{2}\left(S_{O_{2}, m}\right)$ varia em função da pressão parcial de $\mathrm{O}_{2}$ $\left(P_{O_{2}, m}\right)$ e é representada através da curva de dissociação da mioglobina. Uma equação utilizada para representar essa curva é a equação de Hill (HILL, 1910). Esta equação pode também ser utilizada para representar a curva de dissociação da hemoglobina, porém, o equacionamento apresentado na seção 3.2 é mais completo. Como a mioglobina é um monômero, só tendo um grupo hemo, a equação fica na seguinte forma simplificada (SCHENKMAN et al., 1997):

$$
S_{O_{2}, m}=\frac{P_{O_{2}, m}}{P_{O_{2}, m}+P_{50}}
$$


sendo: $P_{50}=P_{O_{2}}$ necessária para saturar metade das mioglobinas $[\mathrm{Pa}]$.

A $P_{50}$ foi determinada por Schenkman et al. (1997), usando espectroscopia, em função da temperatura e do $\mathrm{pH}$. Como as variações da $P_{50}$ em função do $\mathrm{pH}$ são muito pequenas ao compará-las com as variações da temperatura, não serão consideradas. Segundo suas medições, a $P_{50}$ para pH 6,5 e 7,5 à $37^{\circ} \mathrm{C}$, são iguais a 2,46 e 2,32 mmHg respectivamente. Já para as temperaturas de 10 e $40{ }^{\circ} \mathrm{C}$ com pH 7,40, são iguais a 0,17 e $3,11 \mathrm{mmHg}$. A $P_{50}$ pode então ser determinada em função da temperatura pela seguinte equação (em Pa):

$$
P_{50}=133,3 e^{\left(0,098 T_{t}-2,748\right)}
$$

sendo: $T_{t}=$ temperatura do tecido $\left[{ }^{\circ} \mathrm{C}\right]$.

A Figura 4.2 mostra a variação da saturação da mioglobina em relação a $P_{\mathrm{O}_{2}}$, para diversas temperaturas. Pela curva, pode-se verificar que as reservas de $\mathrm{O}_{2}$ da mioglobina são utilizadas principalmente quando a $P_{O_{2}}$ nos tecidos musculares está abaixo de 20 $\mathrm{mmHg}$.

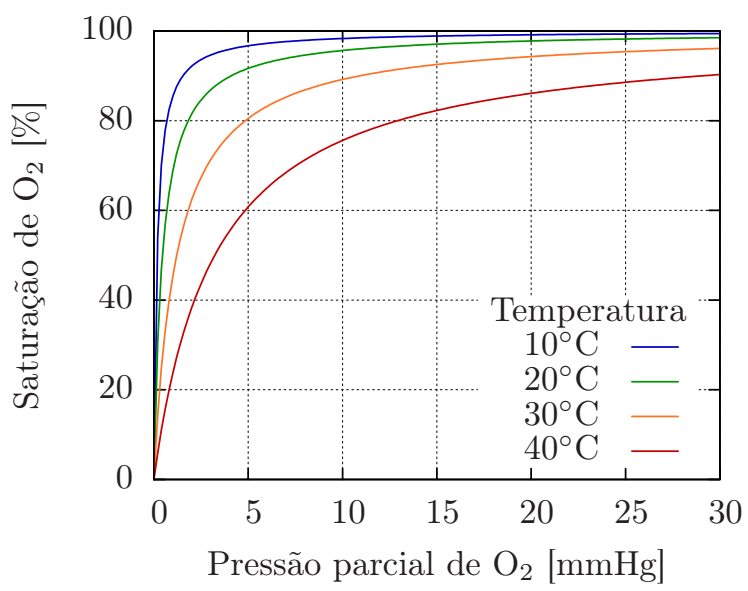

Figura 4.2 - Curva de dissociação do $\mathrm{O}_{2}$ na mioglobina para diferentes temperaturas [modelo de Schenkman et al. (1997)]

\subsection{Dióxido de carbono}

A maior parte do dióxido de carbono no corpo humano está armazenada nos tecidos. Para um homem de $70 \mathrm{~kg}$, são aproximadamente $120 \mathrm{~L}$ de $\mathrm{CO}_{2}$ (no sangue há 2,7 L). A maior parte do $\mathrm{CO}_{2}$ nos tecidos ( $90 \%$ ) está no osso, na forma de carbonato (CHERNIACK; LONGOBARDO, 1970). Como a vazão de sangue nos ossos é desprezível ao se comparar com a vazão dos outros tecidos, essa forma de armazenamento não será considerada. A outra parte do $\mathrm{CO}_{2}$ está dissolvida ou na forma de íon bicarbonato. 
O mecanismo de transporte do $\mathrm{CO}_{2}$ nos tecidos, dissolvido ou como íon bicarbonato, é complexo. Um método que costuma ser utilizado para representá-lo é agrupar essas duas formas de transporte e tratar por um único coeficiente, definido como a inclinação da curva de dissociação do $\mathrm{CO}_{2}$ no tecido (FARHI; RAHN, 1960). Desse modo, a relação entre a pressão parcial de $\mathrm{CO}_{2}$ e a concentração de $\mathrm{CO}_{2}$ é diretamente proporcional a esse coeficiente:

$$
C_{\mathrm{CO}_{2}, t}=\alpha_{C \mathrm{O}_{2}, t} P_{\mathrm{CO}_{2}, t}
$$

sendo: $C_{C O_{2}, t}$ é a concentração do $\mathrm{CO}_{2}$ nos tecidos $\left[\mathrm{mol} / \mathrm{m}^{3}\right]$;

$\alpha_{\mathrm{CO}_{2}, t}$ é a inclinação da curva de dissociação do $\mathrm{CO}_{2}$ no tecido $\left[\mathrm{mol} /\left(\mathrm{m}^{3} . \mathrm{Pa}\right)\right]$;

$P_{\mathrm{CO}_{2}, t}$ é a pressão parcial do $\mathrm{CO}_{2}$ nos tecidos [Pa].

As inclinações da curva de dissociação do $\mathrm{CO}_{2}$ em alguns tecidos foram determinadas por Farhi e Rahn (1960) a partir de dados de outros autores (Tabela 4.4). Esses valores são usados no presente trabalho.

Tabela 4.4 - Valores da inclinação da curva de dissociação do $\mathrm{CO}_{2}$ nos tecidos (FARHI; RAHN, 1960)

\begin{tabular}{lc}
\hline Tecido & {$[\mathrm{ml} /(\mathrm{kg} \cdot \mathrm{mmHg})]$} \\
\hline Cérebro & 2,9 \\
Coração & 2,4 \\
Músculo & 4,2 \\
Outros & 3,0 \\
\hline
\end{tabular}

\subsection{Transferência entre pele e ambiente}

A transferência de calor entre a pele e o ambiente ocorre, na ausência de vestimentas, por convecção, radiação e evaporação. A presença de vestimentas acrescenta as resistências dos tecidos e das camadas de ar. Estas ocorrem entre a pele e o tecido e entre os tecidos (caso haja mais que um). A Figura 4.3 mostra uma representação desses fluxos de calor. A seguir será descrita a metodologia para determinar a transferência de calor entre a pele e o ambiente, com base no livro do Fanger (1970), no manual da ASHRAE (2005) e nos artigos de McCullough, Jones e Huck (1985) e McCullough, Jones e Tamura (1989).

A transferência de calor por convecção é determinada pela multiplicação entre o coeficiente de transferência de calor por convecção $\left(h_{c}\right)$, a razão entre a área do corpo vestido e $\mathrm{nu}\left(f_{c l}\right)$, e a diferença entre a temperatura da roupa $\left(T_{c l}\right)$ e a temperatura do ar ambiente $\left(T_{a}\right)$ :

$$
\dot{q}_{c}=f_{c l} h_{c}\left(T_{c l}-T_{a}\right)
$$




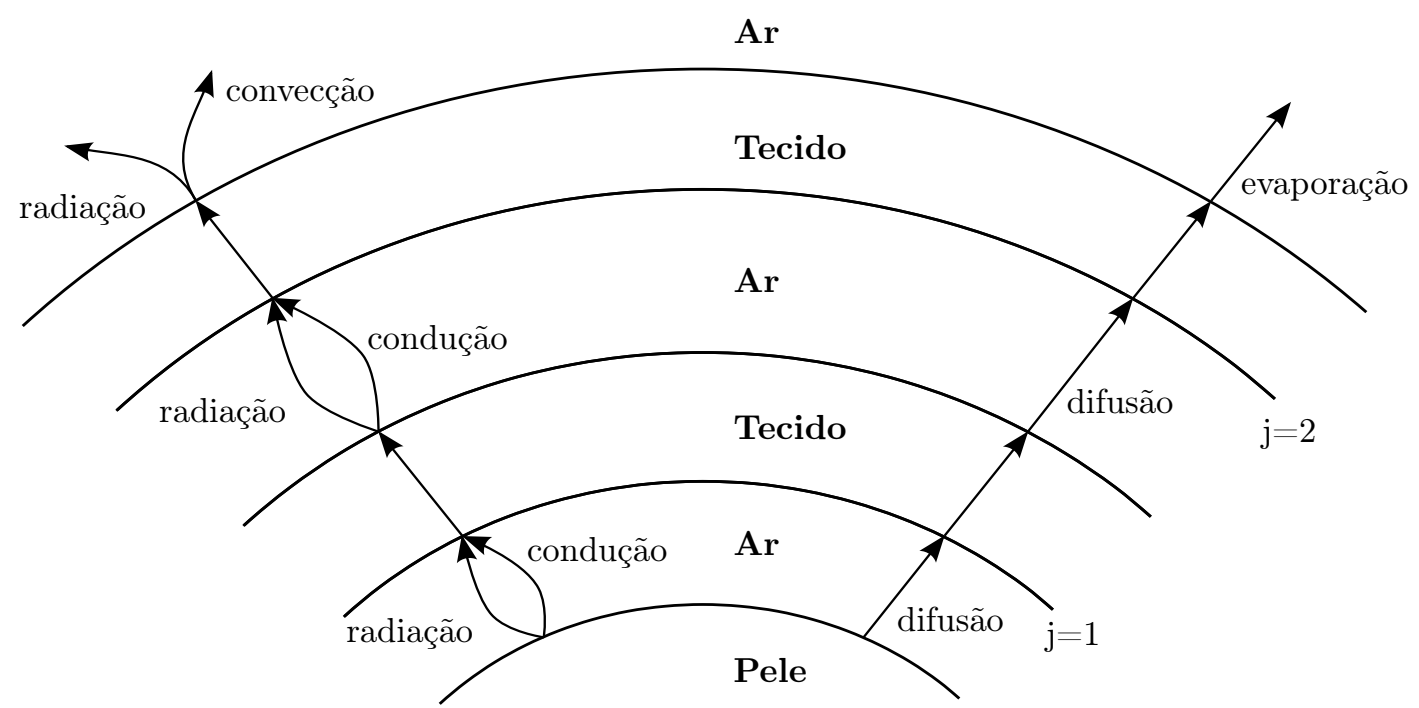

Figura 4.3 - Transferência de calor entre a pele e o ambiente considerando duas camadas de roupa [redesenhado de McCullough, Jones e Tamura (1989)]

sendo: $\dot{q}_{c}=$ calor transferido por convecção $\left[\mathrm{W} / \mathrm{m}^{2}\right]$;

$f_{c l}=$ razão entre área superficial do corpo vestido e nu [adimensional];

$h_{c}=$ coeficiente de transferência de calor por convecção $\left[\mathrm{W} /\left(\mathrm{m}^{2} .{ }^{\circ} \mathrm{C}\right)\right]$;

$T_{c l}=$ temperatura externa da roupa $\left[{ }^{\circ} \mathrm{C}\right]$;

$T_{a}=$ temperatura do ar ambiente $\left[{ }^{\circ} \mathrm{C}\right]$.

A transferência de calor por radiação é determinada de forma similar à convecção. É igual a multiplicação entre o coeficiente de transferência de calor por radiação linearizado $\left(h_{r}\right)$, a razão entre a área do corpo vestido e nu $\left(f_{c l}\right)$, e a diferença entre a temperatura da roupa e a temperatura radiante média $\left(\bar{T}_{r}\right)$ :

$$
\dot{q}_{r}=f_{c l} h_{r}\left(T_{c l}-\bar{T}_{r}\right)
$$

sendo: $\dot{q}_{r}=$ calor transferido por radiação $\left[\mathrm{W} / \mathrm{m}^{2}\right]$;

$h_{r}=$ coeficiente de transferência de calor por radiação $\left[\mathrm{W} /\left(\mathrm{m}^{2} \cdot{ }^{\circ} \mathrm{C}\right)\right]$;

$\bar{T}_{r}=$ temperatura radiante média $\left[{ }^{\circ} \mathrm{C}\right]$.

Essas equações costumam ser combinadas e expressas em função de uma temperatura operativa $\left(T_{o}\right)$ e um coeficiente de transferência de calor combinado $(h)$ :

$$
\begin{aligned}
\dot{q}_{c}+\dot{q}_{r} & =f_{c l} h\left(T_{c l}-T_{o}\right) \\
T_{o} & =\frac{h_{r} \bar{T}_{r}+h_{c} T_{a}}{h_{r}+h_{c}} \\
h & =h_{r}+h_{c}
\end{aligned}
$$

sendo: $h=$ coeficiente combinado de transferência de calor $\left[\mathrm{W} /\left(\mathrm{m}^{2} .{ }^{\circ} \mathrm{C}\right)\right]$; 
$T_{o}=$ temperatura operativa $\left[{ }^{\circ} \mathrm{C}\right]$.

A resistência à troca de calor entre a pele e a superfície externa da roupa inclui a resistência do tecido e da camada de ar entre a roupa e a pele. Ambas podem ser agrupadas e representadas por uma única resistência $\left(R_{c l}\right)$, conhecida por isolamento da roupa intrínseco ou básico. Também costuma ser representada por $I_{c l}$, com a unidade clo $\left(1,0\right.$ clo $\left.=0,155 \mathrm{~m}^{2} \cdot \mathrm{K} / \mathrm{W}\right)$.

Agrupando as resistências entre a pele e a superfície externa da roupa com os fluxos de calor entre a superfície externa da roupa e o ambiente, chega-se a seguinte equação:

$$
\dot{q}_{c}+\dot{q}_{r}=\frac{T_{s k}-T_{o}}{R_{c l}+\frac{1}{f_{c l} h}}
$$

sendo: $T_{s k}=$ temperatura da superfície da pele $\left[{ }^{\circ} \mathrm{C}\right]$;

$R_{c l}=$ resistência térmica da roupa $\left[\mathrm{m}^{2} \cdot{ }^{\circ} \mathrm{C} / \mathrm{W}\right]$.

A transferência de calor por evaporação pode ocorrer por difusão de água através da pele e por evaporação do suor resultante do sistema de controle. O cálculo da transferência de calor por evaporação é feito multiplicando a quantidade máxima de evaporação, quando a pele está saturada com água, pela fração de superfície molhada $(w)$, igual a 0,06 quando não há suor. De forma análoga à convecção, a determinação da quantidade de calor perdida por evaporação considera um coeficiente de transferência de calor $\left(h_{e}\right)$, a razão entre a área do corpo vestido e nu $\left(f_{c l}\right)$, a resistência à evaporação da roupa e da camada de ar entre a pele e a roupa $\left(R_{e, c l}\right)$, e a diferença entre a pressão parcial de vapor-d'água na superfície da pele $\left(P_{w, s k}\right)$ e no ambiente $\left(\phi_{a} P_{w, a}\right)$.

$$
\dot{q}_{e}=w \frac{P_{w, s k}-\phi_{a} P_{w, a}}{R_{e, c l}+\frac{1}{f_{c l} h_{e}}}
$$

sendo: $\dot{q}_{e}=$ calor transferido por evaporação $\left[\mathrm{W} / \mathrm{m}^{2}\right]$;

$w=$ fração de superfície molhada [0-1];

$P_{w, s k}=$ pressão de saturação do vapor-d'água na superfície da pele [Pa];

$\phi_{a}=$ umidade relativa do ar [0-1];

$P_{w, a}=$ pressão parcial do vapor-d'água no ar [Pa];

$R_{e, c l}=$ resistência à evaporação da roupa $\left[\mathrm{Pa} \cdot \mathrm{m}^{2} / \mathrm{W}\right]$;

$h_{e}=$ coeficiente de transferência de calor por evaporação $\left[\mathrm{W} /\left(\mathrm{Pa}^{2} \mathrm{~m}^{2}\right)\right]$.

Os coeficientes de transferência de calor por convecção (natural, velocidade do ar $<0,10 \mathrm{~m} / \mathrm{s}$ ) e radiação usados por Ferreira e Yanagihara (2009) foram obtidos de Dear 
et al. (1997), a partir de experimentos com um manequim feminino. As medições com o manequim em pé estão na Tabela 4.5 (também foram feitas medições com o manequim sentado). Os coeficientes de transferência de calor por evaporação $\left(h_{e}\right)$ para os diversos elementos do corpo foram determinados por Ferreira e Yanagihara (2009) a partir de uma analogia entre transferência de calor e massa com os coeficientes de transferência de calor por convecção $\left(h_{c}\right)$. Os resultados também estão na Tabela 4.5.

Tabela 4.5 - Coeficientes de transferência de calor por convecção, radiação (DEAR et al., 1997) e evaporação (FERREIRA; YANAGIHARA, 2009)

\begin{tabular}{lccc}
\hline Elemento & $\begin{array}{c}\text { Convecção }\left(h_{c}\right) \\
{\left[\mathrm{W} /\left(\mathrm{m}^{2} .{ }^{\circ} \mathrm{C}\right)\right]}\end{array}$ & $\begin{array}{c}\text { Radiação }\left(h_{r}\right) \\
{\left[\mathrm{W} /\left(\mathrm{m}^{2} \cdot{ }^{\circ} \mathrm{C}\right)\right]}\end{array}$ & $\begin{array}{c}\text { Evaporação }\left(h_{e}\right) \\
\left.\left[\mathrm{W} /\left(\mathrm{Pa}^{2}\right)^{2}\right)\right]\end{array}$ \\
\hline Cabeça & 3,6 & 4,1 & 0,059 \\
Pescoço & 3,6 & 4,1 & 0,059 \\
Tronco & 3,2 & 4,3 & 0,053 \\
Braço & 2,9 & 5,2 & 0,048 \\
Antebraço & 3,7 & 4,9 & 0,061 \\
Mão & 4,1 & 4,1 & 0,068 \\
Coxa & 4,1 & 4,3 & 0,068 \\
Perna & 4,1 & 5,3 & 0,068 \\
Pé & 5,1 & 3,9 & 0,084 \\
\hline Corpo todo & 3,4 & 4,5 & 0,056 \\
\hline
\end{tabular}

Os coeficientes de transferência de calor com o ambiente foram determinados para situações próximas do nível do mar. Para corrigi-los em outras altitudes, o coeficiente de transferência de calor por convecção $\left(h_{c}\right)$ deve ser multiplicado por $\left(P_{b a r} / 101325\right)^{0.55}$, e o coeficiente de calor por evaporação $\left(h_{e}\right)$ deve ser multiplicado por $\left(P_{b a r} / 101325\right)^{0.45}$, sendo que $P_{b a r}$ é a pressão barométrica (em Pa) (ASHRAE, 2005).

A determinação do isolamento intrínseco da roupa $\left(R_{c l}\right)$, da resistência intrínseca à evaporação $\left(R_{e, c l}\right)$ e da fração entre a área do corpo vestido e nu $\left(f_{c l}\right)$ foi feita a partir de dados obtidos por McCullough, Jones e Tamura (1989). Neste trabalho constam, para diferentes tecidos, suas espessuras $\left(l_{f}\right)$, isolamentos intrínsecos $\left(R_{f}\right)$ e resistências intrínsecas à evaporação $\left(R_{e, f}\right)$. Estes parâmetros não incluem a resistência do ar. Os dados para alguns tecidos estão na Tabela 4.6. A seguir serão descritos os passos realizados para determinar $R_{c l}, R_{e, c l}$ e $f_{c l}$ a partir desses dados.

A camada de ar entre pele e tecido ou entre tecidos tem isolamento térmico $\left(R_{a l}\right)$ igual a $0,043 \mathrm{~m}^{2} .{ }^{\circ} \mathrm{C} / \mathrm{W}$ e resistência à evaporação $\left(R_{e, a l}\right)$ igual a $0,0039 \mathrm{~m}^{2} . \mathrm{kPa} / \mathrm{W}(\mathrm{MCCUL}-$ LOUGH; JONES; TAMURA, 1989). A espessura da camada de ar $\left(l_{a l}\right)$ varia dependendo da roupa. Como esses valores não são fornecidos, será considerado um valor constante igual a 1,34 mm. Este foi calculado a partir da seguinte relação, com valores para o coefici- 
Tabela 4.6 - Dados dos tecidos das roupas (MCCULLOUGH; JONES; TAMURA, 1989)

\begin{tabular}{|c|c|c|c|c|}
\hline \multicolumn{2}{|c|}{ Código e descrição do tecido } & \multirow{2}{*}{$\begin{array}{c}\text { Espessura } \\
\left(l_{f}\right) \\
{[\mathrm{mm}]} \\
1,118\end{array}$} & \multirow{2}{*}{$\begin{array}{c}\begin{array}{c}\text { Isolamento } \\
\text { térmico }\left(R_{f}\right) \\
{\left[\mathrm{m}^{2} \cdot{ }^{\circ} \mathrm{C} / \mathrm{W}\right]}\end{array} \\
0,039\end{array}$} & \multirow{2}{*}{$\begin{array}{c}\begin{array}{c}\text { Resistência à } \\
\text { evaporação }\left(R_{e, f}\right) \\
{\left[\mathrm{m}^{2} . \mathrm{kPa} / \mathrm{W}\right]}\end{array} \\
0,0039\end{array}$} \\
\hline 01 & malha dupla, $65 \%$ poliéster, $35 \%$ algodão & & & \\
\hline 02 & tecido simples, $100 \%$ algodão & 0,965 & 0,025 & 0,0044 \\
\hline 03 & $\begin{array}{l}\text { malha canelada, } 80 \% \text { algodão, } 8 \% \text { acrílico } \\
7 \% \text { nylon, } 5 \% \text { elástico }\end{array}$ & 3,48 & 0,070 & 0,0076 \\
\hline 04 & tecido largo, $65 \%$ poliéster, $35 \%$ algodão & 0,533 & 0,025 & 0,0024 \\
\hline 05 & tecido de lã simples, $50 \%$ lã, $50 \%$ poliéster & 1,727 & 0,049 & 0,0055 \\
\hline 06 & veludo, $75 \%$ lã, $25 \%$ poliéster & 1,88 & 0,041 & 0,0065 \\
\hline 07 & popelina, $60 \%$ algodão, $40 \%$ poliéster & 0,787 & 0,070 & 0,0076 \\
\hline 08 & meta-aramida Nomex & 0,787 & 0,030 & 0,0035 \\
\hline 09 & meia atlética, malha canelada & 3,48 & 0,070 & 0,0076 \\
\hline 10 & meia social, malha canelada & 3,353 & 0,086 & 0,0083 \\
\hline 11 & tênis esportivo & 3,50 & 0,052 & 0,052 \\
\hline 12 & sapato de vinil & 2,7 & 0,041 & 0,079 \\
\hline 13 & bota de couro & 3,2 & 0,048 & 0,047 \\
\hline
\end{tabular}

ente de transferência de calor por radiação $\left(h_{r, a l}\right)$ igual a $4,94 \mathrm{~W} /\left(\mathrm{m}^{2}{ }^{\circ} \mathrm{C}\right)$ e condutividade térmica $\left(k_{a l}\right)$ igual a $24,51 \mathrm{~W} . \mathrm{mm} /\left(\mathrm{m}^{2} .{ }^{\circ} \mathrm{C}\right)(\mathrm{MCCULLOUGH} ; \mathrm{JONES} ; \mathrm{HUCK}, 1985)$ :

$$
R_{a l}=\frac{1}{h_{r, a l}+k_{a l} / l_{a l}}
$$

sendo: $R_{a l}=$ isolamento térmico da camada de $\operatorname{ar}\left[\mathrm{m}^{2} .{ }^{\circ} \mathrm{C} / \mathrm{W}\right]$;

$h_{r, a l}=$ coeficiente de transferência de calor por radiação da camada de ar $\left[\mathrm{W} /\left(\mathrm{m}^{2} .{ }^{\circ} \mathrm{C}\right)\right]$;

$k_{a l}=$ condutividade térmica da camada de ar $\left[\mathrm{W} \cdot \mathrm{mm} /\left(\mathrm{m}^{2} \cdot{ }^{\circ} \mathrm{C}\right)\right]$;

$l_{a l}=$ espessura da camada de ar $[\mathrm{mm}]$.

Para calcular o isolamento intrínseco e a resistência à evaporação da roupa, incluindo a camada de ar, é necessário considerar o aumento da circunferência. As seguintes relações foram sugeridas por McCullough, Jones e Tamura (1989), e validadas com seus dados experimentais:

$$
\begin{aligned}
R_{c l} & =\sum_{i=1}^{N_{c l}}\left[R_{a l} \frac{r_{(0)}}{r_{(i-1)}}+R_{f(i)} \frac{r_{(0)}}{r_{(i)}}\right] \\
R_{e, c l} & =\sum_{i=1}^{N_{c l}}\left[R_{e, a l} \frac{r_{(0)}}{r_{(i-1)}}+R_{e, f(i)} \frac{r_{(0)}}{r_{(i)}}\right]
\end{aligned}
$$

sendo: $N_{c l}$ é o número de tecidos;

$r_{(i)}=$ raio da superfície externa do tecido $i[\mathrm{~mm}]$;

$R_{f(i)}=$ isolamento térmico do tecido $i\left[\mathrm{~m}^{2} \cdot{ }^{\circ} \mathrm{C} / \mathrm{W}\right]$;

$R_{e, a l}=$ resistência à evaporação da camada de $\operatorname{ar}\left[\mathrm{m}^{2} \cdot \mathrm{kPa} / \mathrm{W}\right]$; 


$$
R_{e, f(i)}=\text { resistência à evaporação do tecido } i\left[\mathrm{~m}^{2} \cdot \mathrm{kPa} / \mathrm{W}\right] \text {. }
$$

Nessas relações, o primeiro raio $\left(r_{(0)}\right)$ é o raio da superfície da pele. O valor deste raio para cada segmento está na Tabela 6.3. No caso da mãos e dos pés, que têm seções transversais retangulares, foram calculados raios equivalentes a partir da igualdade entre perímetros. Para a determinação do próximo raio, soma-se ao raio anterior a espessura de uma camada de ar e do tecido em questão. A fração entre a área do corpo vestido e nu $\left(f_{c l}\right)$ é igual à relação entre o raio da superfície externa do último tecido $\left(r_{\left(N_{c l}\right)}\right)$ e o raio da superfície da pele $\left(r_{(0)}\right)$.

A Tabela 4.7 mostra as resistências calculadas segundo a metodologia descrita para cada segmento e três conjuntos diferentes de roupa. Peças de roupa que ocupam uma pequena fração do segmento, como roupas íntimas e cinto, foram desconsideradas. Nesta tabela também está indicado o código do tecido que foi acrescentado em cada segmento (da Tabela 4.6) e o tipo da roupa. Os segmentos que não estão na tabela são porque não estão vestidos. Nestes casos, as resistências são nulas e as superfícies externas são iguais a da pele $\left(f_{c l}=1,0\right)$.

Tabela 4.7 - Resistências dos conjuntos de roupa

\begin{tabular}{|c|c|c|c|c|c|}
\hline $\begin{array}{l}\text { Conjunto } \\
\text { de roupa }\end{array}$ & Segmento & $\begin{array}{l}\text { Tecido(s) } \\
\text { (código da } \\
\text { Tabela 4.6) }\end{array}$ & $\begin{array}{c}\text { Isolamento } \\
\text { térmico }\left(R_{c l}\right) \\
{\left[\mathrm{m}^{2} \cdot{ }^{\circ} \mathrm{C} / \mathrm{W}\right]}\end{array}$ & $\begin{array}{c}\text { Resistência à } \\
\text { evaporação }\left(R_{e, c l}\right) \\
{\left[\mathrm{m}^{2} \cdot \mathrm{kPa} / \mathrm{W}\right]}\end{array}$ & $\begin{array}{c}\text { Fração entre área } \\
\text { do corpo vestido } \\
\text { e nu }\left(f_{c l}\right)\end{array}$ \\
\hline \multirow[t]{4}{*}{$\operatorname{Verão~}^{a}$} & Tronco & 01 & 0,0813 & 0,00773 & 1,018 \\
\hline & Braço & 01 & 0,0799 & 0,00759 & 1,058 \\
\hline & Coxa & 02 & 0,0671 & 0,00814 & 1,037 \\
\hline & Pé & $09 / 11$ & 0,1876 & 0,05696 & 1,218 \\
\hline \multirow[t]{7}{*}{ Terno $^{b}$} & Pescoço & $04 / 05 / 04$ & 0,2161 & 0,02082 & 1,117 \\
\hline & Tronco & $04 / 05$ & 0,1574 & 0,01542 & 1,036 \\
\hline & Braço & $04 / 05$ & 0,1520 & 0,01486 & 1,116 \\
\hline & Antebraço & $04 / 05$ & 0,1501 & 0,01466 & 1,147 \\
\hline & Coxa & 06 & 0,0820 & 0,01008 & 1,052 \\
\hline & Perna & 06 & 0,0811 & 0,00995 & 1,075 \\
\hline & Pé & $10 / 12$ & 0,1935 & 0,08092 & 1,197 \\
\hline \multirow{6}{*}{$\begin{array}{l}\text { Macacão } \\
\text { industrial }^{c}\end{array}$} & Tronco & $01 / 08$ & 0,1574 & 0,01542 & 1,036 \\
\hline & Braço & $01 / 08$ & 0,1520 & 0,01486 & 1,116 \\
\hline & Antebraço & 08 & 0,1501 & 0,01466 & 1,147 \\
\hline & Coxa & $07 / 08$ & 0,0820 & 0,01008 & 1,052 \\
\hline & Perna & $07 / 08$ & 0,0811 & 0,00995 & 1,075 \\
\hline & Pé & $09 / 13$ & 0,1935 & 0,08092 & 1,197 \\
\hline
\end{tabular}

Peças de roupa: ${ }^{a}$ camiseta de manga curta, shorts, meias esportivas e tênis esportivo; ${ }^{b}$ camisa de manga comprida, paletó, gravata, calça, meias sociais e sapatos; ${ }^{c}$ camiseta de manga curta, calça, macacão de manga longa, meias esportivas e botas.

As áreas superficiais de alguns segmentos do presente modelo têm valores diferentes da geometria usada como referência (FERREIRA; YANAGIHARA, 2009). Para corrigir essas diferenças, um fator de correção para cada segmento deve ser multiplicado pelos 
coeficientes de transferência de calor $\left(h\right.$ e $\left.h_{e}\right)$. Já as resistências intrínsecas das roupas $\left(R_{c l}\right.$ e $\left.R_{e, c l}\right)$ devem ser divididas por esse fator. Os valores do fator para cada segmento estão na Tabela 6.1, na parte referente à descrição da geometria. 


\section{Capítulo 5}

\section{Fenômenos de Transporte no Pulmão}

Este capítulo descreve o transporte do oxigênio, dióxido de carbono e calor do ar ambiente até os pulmões. Primeiro serão descritos os mecanismos responsáveis pela ventilação. A segunda seção apresenta as propriedades termodinâmicas do ar usadas no trabalho. Depois segue uma breve discussão sobre os gases atmosféricos. Nas próximas seções, os conceitos sobre ventilação alveolar e volume minuto respiratório serão apresentados. A quinta seção trata da difusão pulmonar, que ocorre entre o gás presente nos alvéolos e o sangue nos capilares pulmonares através da membrana respiratória. As referências usadas na descrição dos conceitos fisiológicos são o livro de Guyton e Hall (2006) e os capítulos de Lambertsen (1974c) e Lambertsen (1974a).

\subsection{Mecanismos}

A ventilação pulmonar consiste de dois processos: a inspiração e a expiração. Ocorrem por dois mecanismos, o movimento do diafragma para cima e para baixo e a elevação e abaixamento das costelas. Em situação de repouso, o corpo humano utiliza quase que totalmente o movimento do diafragma. Durante a inspiração sua contração faz com que a parte inferior do pulmão seja tracionada e, durante a expiração, o diafragma simplesmente fica relaxado. As costelas são utilizadas quando uma maior ventilação pulmonar é necessária, como no caso de exercício físico.

$\mathrm{Na}$ inspiração o pulmão se expande fazendo com que a pressão pulmonar seja menor que a pressão atmosférica. Como há uma abertura entre o pulmão e o ar externo as pressões tendem a se igualar, entrando ar nos pulmões. Na expiração ocorre o oposto, o diafragma retorna a posição de repouso (arqueada para cima) fazendo com que o pulmão se contraia e eleve a pressão acima da atmosférica. Como as pressões no pulmão e atmosférica tendem a se igualar ocorre a expiração. Durante a inspiração, a pressão no pulmão fica aproximadamente $0,8 \mathrm{mmHg}$ menor que a atmosférica e durante a expiração, a pressão no pulmão fica aproximadamente $0,8 \mathrm{mmHg}$ maior que a atmosférica. Essa diferença de 
pressão faz com que aproximadamente meio litro de ar seja movido em cada processo. Esse volume é conhecido por volume corrente. A inspiração dura aproximadamente dois segundos e a expiração de dois a três segundos.

\subsection{Caminho do ar}

O ar percorre um certo caminho até chegar nos pulmões. A entrada de ar ocorre pelo nariz, quando a vazão de ar pelo nariz não é suficiente a boca também é utilizada. Seguindo, o ar passa pela faringe, laringe, traqueia, brônquios, bronquíolos até atingir os alvéolos, onde ocorre a troca de gases com o sangue. Uma representação desse caminho pode ser vista na Figura 5.1. A região por onde o ar passa que não ocorre troca gasosa, ou seja, do nariz até os bronquíolos, é conhecida como espaço morto. O volume do espaço morto $\left(V_{D}\right)$ para um homem jovem é de aproximadamente $150 \mathrm{ml}$.

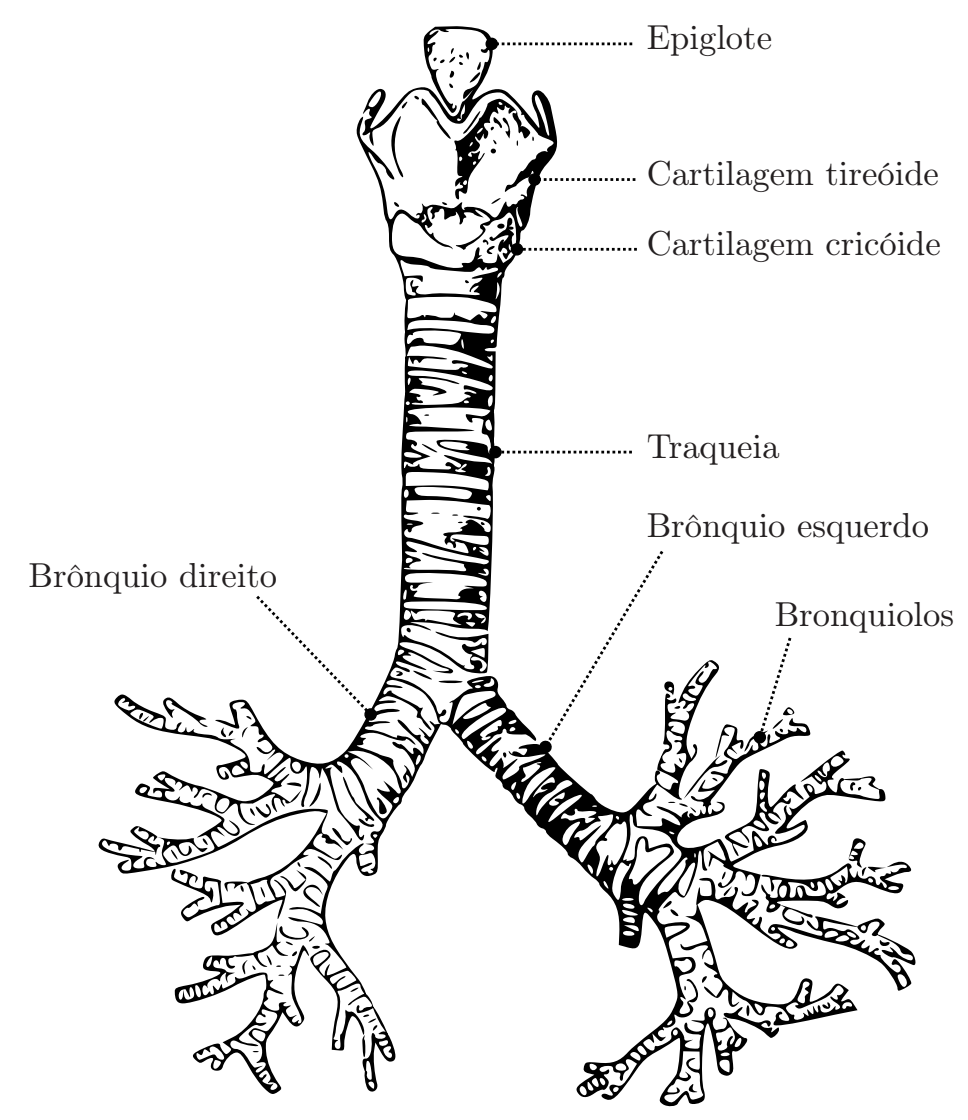

Figura 5.1 - Caminho do ar até os pulmões [adaptado de Gray (1918)]

\subsubsection{Propriedades termodinâmicas do ar}

Nesta seção serão apresentados valores e relações das propriedades termodinâmicas do ar usadas no presente trabalho. Estas propriedades são usadas principalmente nos 
processos pulmonares, por isto fazem parte deste capítulo. Entretanto, também são utilizadas na determinação da transferência de calor entre a superfície da pele e o ambiente (Seção 4.4).

A pressão de vapor-d'água pode ser determinada, em função da temperatura (0 a $200{ }^{\circ} \mathrm{C}$ ), a partir da seguinte equação (ASHRAE, 2005):

$$
\begin{aligned}
\ln P_{w}= & -5,8002206 \times 10^{3} / T+1,3914993-4,8640239 \times 10^{-2} T \\
& +4,1764768 \times 10^{-5} T^{2}-1,4452093 \times 10^{-8} T^{3}+6,5459673 \ln T
\end{aligned}
$$

sendo: $P_{w}=$ pressão de vapor-d'água $[\mathrm{Pa}]$;

$T=$ temperatura $[\mathrm{K}]$.

A umidade absoluta do ar ambiente é calculada pela seguinte relação (ASHRAE, 2005):

$$
\omega_{a}=0,62198 \frac{P_{w} \phi_{a}}{P_{b a r}-P_{w} \phi_{a}}
$$

sendo: $\omega_{a}=$ umidade absoluta do ar ambiente $[\mathrm{kg} / \mathrm{kg}]$;

$\phi_{a}=$ umidade relativa do ar ambiente [0-1];

$P_{b a r}=$ pressão barométrica $[\mathrm{Pa}]$.

A entalpia de vaporização da água $\left(h_{l v, w}\right)$ pode ser determinada em função da temperatura (dados da ASHRAE (2005) entre 0 e $50{ }^{\circ} \mathrm{C}$ ):

$$
h_{l v}=2500,89-2,3736 T
$$

sendo: $h_{l v}=$ entalpia de vaporização da água $[\mathrm{J} / \mathrm{kg}]$;

$T=$ temperatura, ${ }^{\circ} \mathrm{C}$.

O calor específico do ar $\left(c_{p, a}\right)$ foi considerado constante e igual a $1003,5 \mathrm{~kJ} /(\mathrm{kg} . \mathrm{K})$ (VAN WYLEN; SONNTAG; BORGNAKKE, 1998).

\subsection{Gases atmosféricos}

Os gases que fazem parte do metabolismo e os gases inertes mais envolvidos na troca respiratória estão presentes na atmosfera, com proporções segundo a Tabela 5.1. Os gases inertes, como o $\mathrm{N}_{2}$, são envolvidos de forma passiva na respiração, sendo utilizados como diluentes e veículos para o $\mathrm{O}_{2}$. Os processos metabólicos do corpo humano não ocorrem em equilíbrio com as proporções dos gases na atmosfera. $\mathrm{O} \mathrm{O}_{2}$ com a pressão parcial da 
Tabela 5.1 - Composição gasosa da atmosfera terrestre (LAMBERTSEN, 1974a)

\begin{tabular}{ll}
\hline Elemento & \% do ar seco \\
\hline Nitrogênio & 78,09 \\
Oxigênio & 20,94 \\
Argônio & 0,93 \\
Dióxido de Carbono & 0,03 \\
Neônio & 0,002 \\
Hélio & 0,0005 \\
Criptônio & 0,0001 \\
Hidrogênio & 0,00005 \\
Xenônio & 0,000008 \\
\hline
\end{tabular}

atmosfera ao nível do mar é tóxico para a maioria dos tecidos, enquanto a pressão parcial de $\mathrm{CO}_{2}$ é tão baixa que causaria alcalose nas células.

O gás presente nos alvéolos tem uma composição diferente da atmosférica, criando uma interface onde a troca de gás com o sangue seja possível. São três processos que alteram a composição do gás alveolar: a troca de gases com os capilares, a passagem de gás pela via respiratória e a umidificação.

\subsection{Ventilação alveolar}

Um conceito bastante utilizado nesse trabalho é o da ventilação alveolar, representada por $\dot{V}_{A}$, que é a vazão de ar úmido correspondente à renovação de ar da região próxima do sangue dos capilares. Nessa região incluem-se os alvéolos, os sacos alveolares, os ductos alveolares e os bronquíolos respiratórios.

A ventilação alveolar é igual a frequência respiratória $(f)$ vezes o volume de ar fresco que entra nos alvéolos na inspiração. A frequência respiratória é a frequência em que ocorre um ciclo de respiração, incluindo a inspiração seguida da expiração. O volume de ar fresco que chega nos alvéolos é igual à diferença entre o volume corrente $\left(V_{T}\right)$ e o volume do espaço morto $\left(V_{D}\right)$ pois, durante a inspiração, a parte de ar que fica no espaço morto não é utilizada para troca e, durante a expiração, o ar do espaço morto é o primeiro a ser expirado. A ventilação alveolar é representada por:

$$
\dot{V}_{A}=f\left(V_{T}-V_{D}\right)
$$

sendo: $\dot{V}_{A}=$ ventilação alveolar, $[\mathrm{ml} / \mathrm{min}]$;

$f=$ frequência respiratória, [ciclos $/ \mathrm{min}]$;

$V_{T}=$ volume corrente, $[\mathrm{ml}]$;

$V_{D}=$ volume do espaço morto $[\mathrm{ml}]$. 
Segundo medições de Fowler (1948), em 45 homens e 4 mulheres sentados e quietos, o volume corrente é igual a $651 \mathrm{ml}$, o volume do espaço morto $156 \mathrm{ml}$ e a frequência respiratória 15,6 ciclos/min. A ventilação alveolar é, nesse caso, igual a $7722 \mathrm{ml} / \mathrm{min}$.

O espaço alveolar tem um volume $\left(V_{A}\right)$ de $2180 \mathrm{ml}$ no final de uma expiração (LAMBERTSEN, 1974c). A cada ciclo respiratório somente $350 \mathrm{ml}$ de ar é renovado, ou seja, aproximadamente $15 \%$ do total. Isto faz com que o ar alveolar seja lentamente renovado, evitando que haja bruscas alterações em sua concentração.

\subsection{Volume minuto respiratório}

A vazão de ar conhecida por volume minuto respiratório é composta pela ventilação alveolar e a ventilação do espaço morto. É igual ao produto do volume corrente $\left(V_{T}\right)$ com a frequência respiratória ( $f$ ) (LAMBERTSEN, 1974a).

O volume minuto respiratório pode ser expirado ou inspirado. O primeiro é representado por $\dot{V}_{E}$. Este será usado no presente trabalho quando se tratar desta vazão.

A relação entre a ventilação alveolar e o volume minuto respiratório é a seguinte:

$$
\frac{\dot{V}_{A}}{\dot{V}_{E}}=\frac{V_{T}-V_{D}}{V_{T}}
$$

sendo: $\dot{V}_{E}=$ volume minuto respiratório $[\mathrm{ml} / \mathrm{min}]$.

\subsection{Difusão pulmonar}

\subsubsection{Membrana respiratória}

Nos pulmões existem cerca de 300 milhões de alvéolos com diâmetro médio de 0,28 mm. Em volta de suas paredes extremamente finas passa uma rede de capilares, fazendo com que os gases presentes nos alvéolos estejam próximos do sangue (Figura 5.2).

A composição das membranas existentes entre os gases e o sangue é conhecida por membrana respiratória (também conhecida por membrana pulmonar). As moléculas de $\mathrm{O}_{2}$ no espaço alveolar passam pela membrana alveolar, pelo espaço intersticial existente entre os alvéolos e os capilares e pela parede dos capilares. No sangue, parte do $\mathrm{O}_{2}$ permanece dissolvido no plasma e parte reage com a hemoglobina nos glóbulos vermelhos.

A espessura média da membrana respiratória é de aproximadamente 0,6 $\mu \mathrm{m}$ e a área total é de aproximadamente $70 \mathrm{~m}^{2}$ para um adulto normal. O volume de sangue nos 


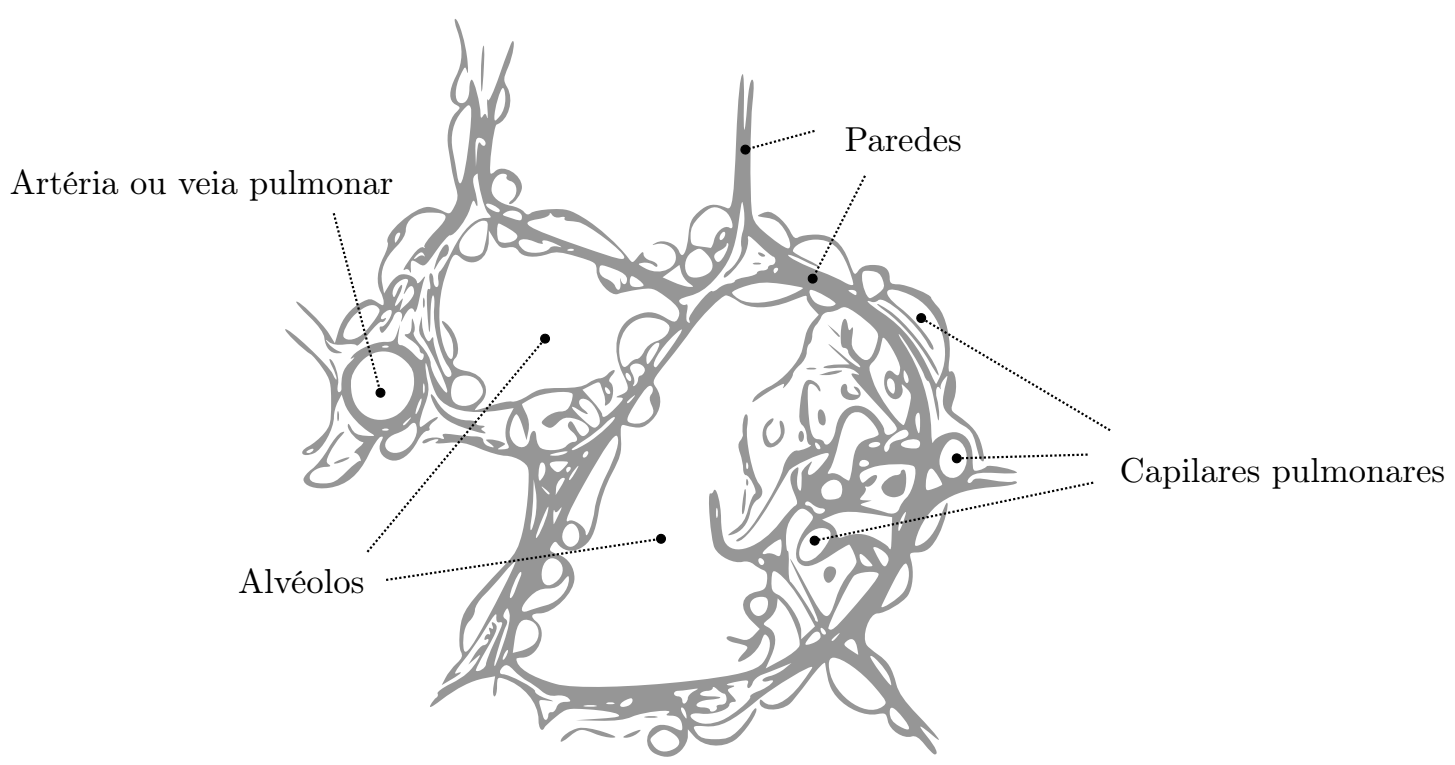

Figura 5.2 - Seção do pulmão de um gato mostrando os alvéolos e os vasos sanguíneos pulmonares [adaptado de Todd e Bowman (1850)]

capilares varia de 60 a $140 \mathrm{ml}$. Como a área de troca é grande comparada com o volume de sangue a troca de gases no pulmão ocorre com grande velocidade. A Tabela 5.2 mostra algumas dimensões e características da membrana respiratória.

Tabela 5.2 - Estimativas de dimensões da membrana respiratória (LAMBERTSEN, 1974a)

\begin{tabular}{ll}
\hline Membrana & Dimensões \\
\hline Número de alvéolos & $300 \times 10^{6}$ \\
Diâmetro alveolar & $280 \mu \mathrm{m}$ \\
Área alveolar total & $70 \mathrm{~m}^{2}$ \\
Espessura da membrana & $0,36 \mu \mathrm{m}-2,5 \mu \mathrm{m}$ \\
Comprimento capilar & $10,3 \mu \mathrm{m}$ \\
Volume capilar & $60 \mathrm{ml}-140 \mathrm{ml}$ \\
Tempo de trânsito sanguíneo & \\
- Repouso & $0,75 \mathrm{~s}$ \\
- Exercício & $0,34 \mathrm{~s}$ \\
\hline
\end{tabular}

Os capilares têm diâmetro médio muito pequeno $(\sim 5 \mu \mathrm{m})$, com isso as hemácias passam uma de cada vez e em contato com a parede dos capilares, facilitando a troca de gases já que eles passam por uma pequena quantidade de plasma. Uma hemácia demora aproximadamente 0,75 segundo para passar pelo pulmão através dos capilares. Todos esses fatores fazem com que a troca dos gases através da membrana respiratória seja realizada rapidamente, mas não instantânea. São dois eventos que determinam a taxa de transferência dos gases: a difusão através das membranas e as reações químicas no sangue. 


\subsubsection{Uniformidade dos gases}

O gás presente nos alvéolos não tem composição uniforme. Entretanto, como a taxa de renovação do ar é lenta, as diferenças das pressões parciais dos gases são pequenas. Com isso, para efeitos da difusão pulmonar, a composição do gás pode ser considerada constante em todos os alvéolos.

Já nos capilares pulmonares há uma grande diferença de pressão parcial dos gases no sangue. O sangue entra nos capilares com uma pequena quantidade de $\mathrm{O}_{2}$ e uma grande quantidade de $\mathrm{CO}_{2}$ e, enquanto passa pelos mesmos, é oxigenado e o $\mathrm{CO}_{2}$ eliminado. Como a capacidade de difusão é grande e eficiente, para condições de repouso, o sangue satura quase que totalmente de $\mathrm{O}_{2}$ em $1 / 3$ do trajeto nos capilares pulmonares. Em caso de exercício físico ou falta de oxigênio, o sangue demora mais tempo para saturar de $\mathrm{O}_{2}$. Na Figura 5.3 há uma representação do comportamento da variação das pressões parciais de $\mathrm{O}_{2}$ e $\mathrm{CO}_{2}$ ao longo dos capilares em condições normais.

(a)
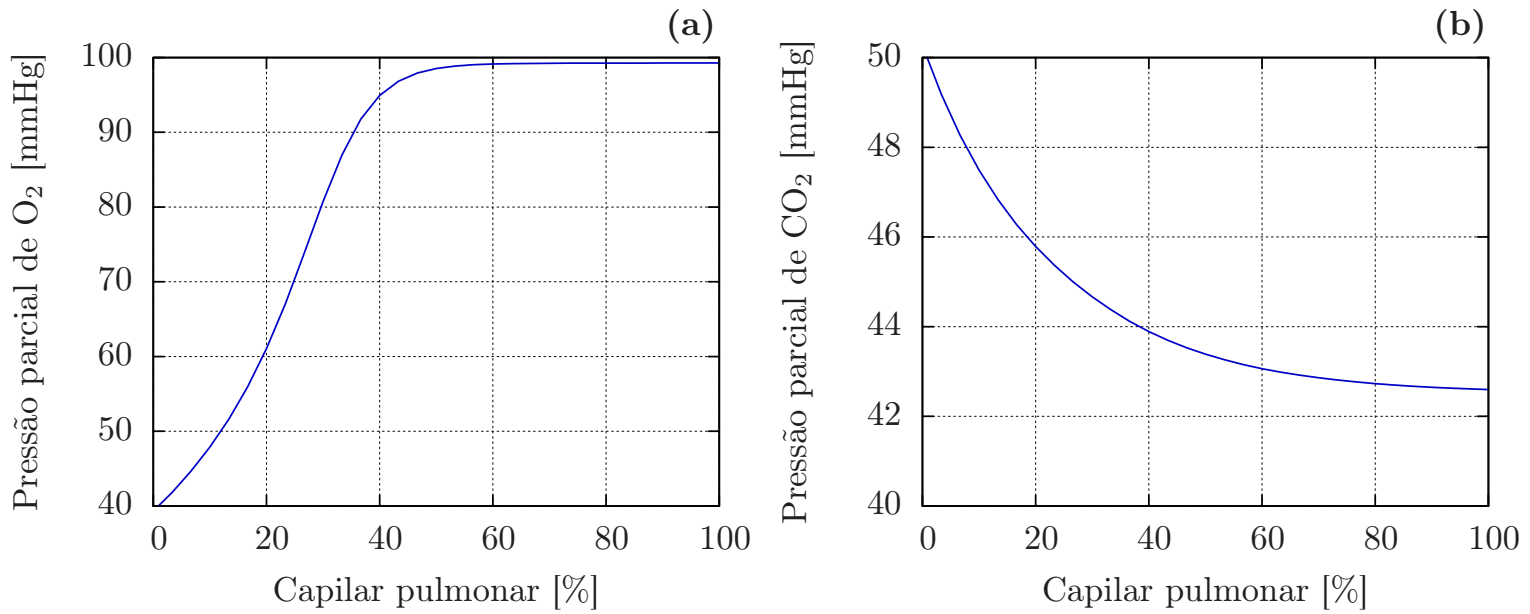

Figura 5.3 - Variação da pressão parcial de $\mathrm{O}_{2}$ (a) e de $\mathrm{CO}_{2}$ (b) ao longo dos capilares pulmonares (ALBUQUERQUE-NETO; YANAGIHARA; TURRI, 2008)

\subsubsection{Capacidade de difusão}

A capacidade de difusão dos gases através da membrana respiratória é conhecida na Fisiologia por $D_{L}$. É definida como o volume de gás que passa pela membrana por minuto para uma diferença de pressão de $1 \mathrm{mmHg}$. Esta variável expressa a relação entre a quantidade de um determinado gás que passa pela membrana respiratória e a diferença entre as pressões parciais do alvéolo e a média dos capilares pulmonares, segundo a seguinte equação:

$$
D_{g, L}=\frac{\dot{V}_{g}}{P_{g, A}-\bar{P}_{g, c p}}
$$


sendo: $D_{g, L}=$ capacidade de difusão do gás $g$ através da membrana respiratória $\left[\mathrm{m}^{3} /(\mathrm{s} . \mathrm{Pa})\right]$

$\dot{V}_{g}=$ vazão do gás $g$ através da membrana respiratória, $\left[\mathrm{m}^{3} / \mathrm{s}\right]$;

$P_{g, A}=$ pressão parcial do gás $g$ nos alvéolos, $[\mathrm{Pa}]$;

$\bar{P}_{g, c p}=$ média da pressão parcial do gás $g$ nos capilares pulmonares $[\mathrm{Pa}]$.

O sentido em que ocorre a difusão dos gases depende da pressão parcial de cada gás. Para o caso do $\mathrm{O}_{2}$, a $P_{\mathrm{O}_{2}}$ nos alvéolos é maior do que no sangue, então o $\mathrm{O}_{2}$ se difunde dos alvéolos para o sangue. Já para o $\mathrm{CO}_{2}$ ocorre o contrário, como a $P_{\mathrm{CO}_{2}}$ é maior no sangue o $\mathrm{CO}_{2}$ se difunde através da membrana respiratória do sangue para os alvéolos.

A representação da capacidade de difusão dos gases na membrana respiratória por um só parâmetro $\left(D_{L}\right)$ é uma simplificação. Inclui tanto a difusão pelas membranas como a velocidade das reações químicas nos glóbulos vermelhos. Esta varia em função da saturação do sangue pelos gases. Existem na literatura alguns trabalhos que consideram a variação da velocidade da reação química separadamente, discutidos na revisão de Hughes e Bates (2003).

Além da diferença de pressão parcial e reação química, existem outros fatores que alteram a velocidade de difusão dos gases: a solubilidade do gás no líquido, a área da seção transversal de troca, a espessura da membrana respiratória, a massa molecular do gás e a temperatura.

Dentre esses fatores, os que variam entre um gás e outro são a solubilidade e a massa molecular. É comum na Fisiologia comparar a velocidade de difusão dos gases os relacionando. Se a velocidade da reação química dos gases no sangue não for considerada, a difusão é proporcional a solubilidade do gás na água e inversamente proporcional a raiz quadrada da massa molecular. Desse modo, a capacidade de difusão do $\mathrm{CO}_{2}$ seria 20,3 vezes maior que a do $\mathrm{O}_{2}$.

Para medir a capacidade de difusão do $\mathrm{O}_{2}$ é necessário determinar a $P_{\mathrm{O}_{2}}$ alveolar e a $P_{\mathrm{O}_{2}}$ média dos capilares pulmonares. Essa última é de difícil medição devido a variação da $P_{\mathrm{O}_{2}}$ ao longo dos capilares pulmonares e da existência de um desvio do sangue do pulmão, que faz com que o sangue no final dos capilares seja diferente do sangue arterial. Turino et al. (1963) a determinaram no valor de $26 \mathrm{ml} /(\mathrm{min} . \mathrm{mmHg})$.

A capacidade de difusão do $\mathrm{CO}_{2}$ também é difícil de ser medida porque o $\mathrm{CO}_{2}$ se difunde rapidamente através da membrana, tornando a diferença entre a $P_{\mathrm{CO}_{2}}$ alveolar e $P_{\mathrm{CO}_{2}}$ dos capilares pulmonares muito pequena. Piiper et al. (1980) chegaram ao valor de $180 \mathrm{ml} /($ min.mmHg). 
Além das dificuldades de medição, a capacidade de difusão varia amplamente em cada indivíduo. Depende de parâmetros fisiológicos como altura, peso, idade, sexo, além da atividade física, da posição do indivíduo e do método utilizado para medição.

Durante o exercício físico há um aumento da capacidade de difusão que, para o caso do $\mathrm{O}_{2}$, pode chegar a $112 \mathrm{ml} / \mathrm{min} / \mathrm{mmHg}$, segundo medições de Turino et al. (1963). Isso ocorre principalmente por um maior recrutamento dos alvéolos e capilares pulmonares e por uma relação entre a ventilação pulmonar e o débito cardíaco mais eficiente. No presente trabalho, será considerado que essa variação está diretamente relacionada com o débito cardíaco. As seguintes equações são usadas para determinar os coeficientes de difusão na membrana pulmonar para o $\mathrm{O}_{2}$ e o $\mathrm{CO}_{2}$, obtidas a partir de interpolações dos dados de Damato, Galante e Smith (1966) - para relacionar o consumo de $\mathrm{O}_{2}$ com o débito cardíaco -, Turino et al. (1963) e Piiper et al. (1980):

$$
\begin{aligned}
D_{O_{2}, L} & =48,6 \dot{V}_{b l}-23,8 \\
D_{C O_{2}, L} & =212 \dot{V}_{b l}-314
\end{aligned}
$$

sendo $D_{\mathrm{O}_{2}, L}=$ coeficiente de difusão do $\mathrm{O}_{2}$ através da membrana respiratória

$$
[\mathrm{ml} /(\mathrm{min} . \mathrm{kPa})]
$$

$D_{C O_{2}, L}=$ coeficiente de difusão do $\mathrm{CO}_{2}$ através da membrana respiratória $[\mathrm{ml} /(\mathrm{min} . \mathrm{kPa})]$;

$\dot{V}_{b l}=$ débito cardíaco $[\mathrm{L} / \mathrm{min}]$. 



\section{Capítulo 6}

\section{Modelagem da Transferência de Calor e Massa}

Neste capítulo será descrito o modelo passivo da transferência de calor, oxigênio e dióxido de carbono no corpo humano. As duas primeiras seções tratam da definição da geometria. A terceira trata da circulação sanguínea dentro de um segmento. Nas últimas seções, cada mecanismo de transferência de calor e massa será modelado matematicamente.

\subsection{Geometria do corpo humano}

A geometria utilizada tem como base a geometria criada por Ferreira e Yanagihara (2009), que oferece uma representação completa e elaborada dos membros e da distribuição de tecidos. O corpo humano foi dividido em 15 segmentos (cabeça, pescoço, tronco, braços, antebraços, mãos, coxas, pernas e pés). São formados por camadas que representam os tecidos e órgãos (pele, gordura, músculo, osso, cérebro, pulmão, coração e vísceras).

Na modelo de Ferreira e Yanagihara (2009), os segmentos foram representados por cilindros com seção transversal elíptica. Optou-se, no presente trabalho, por uma geometria mais simples, considerando os segmentos como cilindros com seção transversal circular ou paralelepípedos (mãos e pés). O motivo desta escolha foi a facilidade de trabalhar com estas geometrias computacionalmente. A Figura 6.1 mostra os segmentos do presente trabalho.

Para a definição do modelo anatômico do corpo humano (dimensão, massa e volume das partes), Ferreira e Yanagihara (2009) usaram os dados levantados por Werner e Buse (1988), para um homem com altura $1,76 \mathrm{~m}$, peso $67 \mathrm{~kg}$, área superficial 1,8 $\mathrm{m}^{2}$, metabolismo basal $47 \mathrm{~W} / \mathrm{m}^{2}$ e porcentagem de gordura $14 \%$.

As dimensões da presente geometria foram obtidas considerando os mesmos comprimentos e volumes dos segmentos de Ferreira e Yanagihara (2009). As áreas superficiais dos segmentos, entretanto, são diferentes. Como a transferência de calor entre a pele 


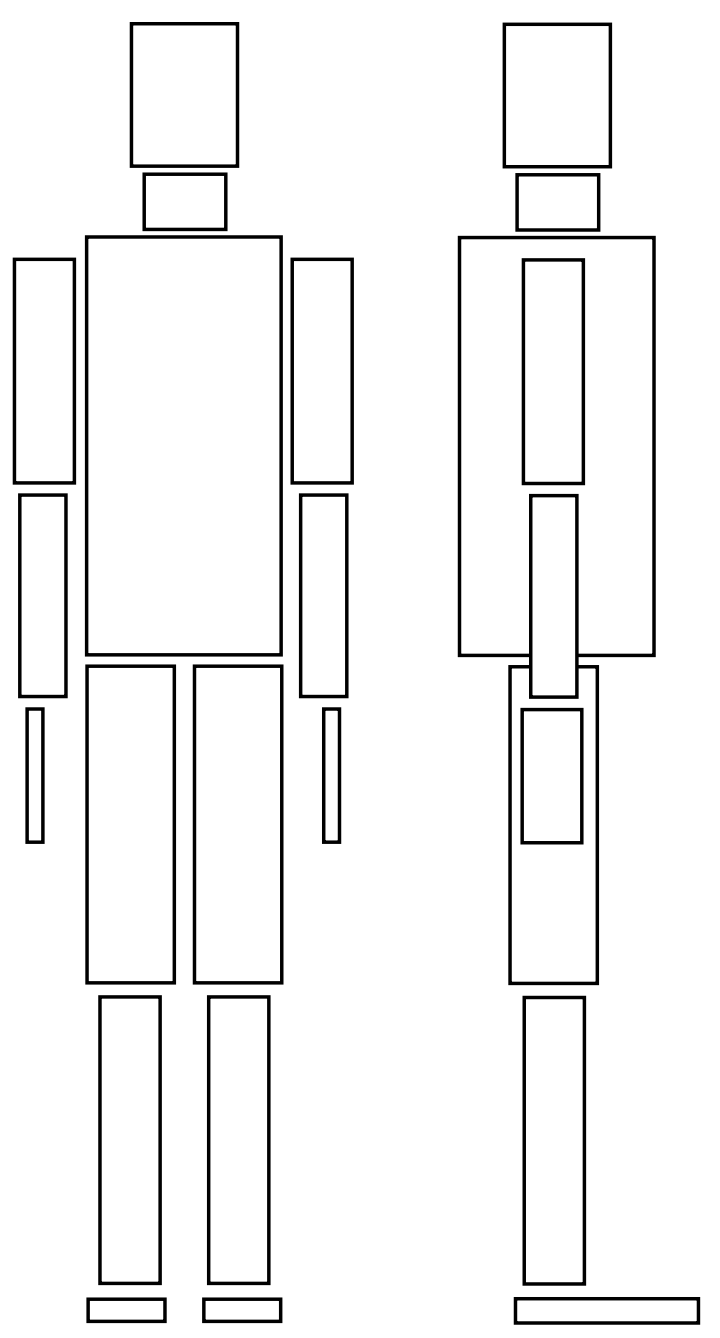

Figura 6.1 - Geometria do corpo humano

e o ambiente depende da área superficial dos segmentos, um fator que relaciona a área superficial de Ferreira e Yanagihara (2009) com a área do presente trabalho será utilizado para corrigir os coeficientes de transferência de calor (descritos na Seção 4.4). Os valores globais dos segmentos do presente modelo, incluindo as dimensões externas, volumes, áreas superficiais, fatores de correção da área e áreas superficiais corrigidas (multiplicadas pelo fator de correção) estão na Tabela 6.1 .

\subsection{Camadas}

A definição e distribuição dos tecidos e órgãos criadas por Ferreira e Yanagihara (2009) serão adotadas no presente trabalho. Os tecidos e órgãos foram agrupados dependendo de suas características particulares. São eles: pele, gordura, músculo, osso, cérebro, vísceras, pulmão e coração. As características descritas por Ferreira e Yanagihara (2009), com o acréscimo das características relacionadas com o sistema respiratório, são as seguintes: 
Tabela 6.1 - Dados da geometria dos segmentos

\begin{tabular}{lccccccc}
\hline Segmento & $\begin{array}{c}\text { Raio ou } \\
\text { largura } \\
\mathrm{cm}\end{array}$ & $\mathrm{cm}$ & $\mathrm{cm}$ & $\mathrm{cm}^{3}$ & $\begin{array}{c}\text { Altura } \\
\text { superficial } \\
\mathrm{cm}^{2}\end{array}$ & $\begin{array}{c}\text { Fator de } \\
\text { correção }\end{array}$ & $\begin{array}{c}\text { Área } \\
\text { corrigida } \\
\mathrm{cm}^{2}\end{array}$ \\
\hline Cabeça & 7,51 & & 20 & 3544 & 944 & 1,20 & 1132 \\
Pescoço & 5,82 & & 8 & 851 & 293 & 1,00 & 292 \\
Tronco & 13,58 & & 60 & 34762 & 5120 & 1,17 & 5989 \\
Braço & 4,26 & & 31 & 1767 & 830 & 1,00 & 829 \\
Antebraço & 3,35 & & 28 & 987 & 589 & 1,00 & 589 \\
Mão & 10,89 & 2,42 & 19 & 501 & 506 & 0,89 & 450 \\
Coxa & 6,15 & & 44 & 5228 & 1700 & 1,00 & 1700 \\
Perna & 4,29 & & 40 & 2313 & 1078 & 1,00 & 1078 \\
Pé & 10,21 & 3,7 & 26 & 982 & 723 & 0,87 & 629 \\
\hline Total & & & & 62714 & 17209 & & 17969 \\
\hline
\end{tabular}

- pele - vazão de sangue controlada; contato com o ambiente;

- gordura - pequena condutividade térmica;

- músculo - vazão de sangue e metabolismo variam durante atividade física e calafrio; armazena $\mathrm{O}_{2}$ quimicamente;

- osso - vazão de sangue desprezível;

- pulmão - vazão de sangue igual ao débito cardíaco; transferência de gases pela membrana respiratória; ventilação;

- coração - alto metabolismo;

- vísceras - inclui fígado, rins, estômago, intestino, pâncreas, baço, bexiga e tecido conjuntivo;

- cérebro - grande vazão de sangue e metabolismo; entrada do sistema de controle.

Como o tecido conjuntivo está presente em vários órgãos e tecidos, não tem limites bem definidos. Ferreira e Yanagihara (2009) o distribuiram entre os demais. O mesmo foi feito com os tecidos dos vasos.

As dimensões das camadas foram determinadas a partir do volume que os tecidos ou órgãos ocupam em cada segmento, com a disposição mais realista possível. A distribuição das camadas de Ferreira e Yanagihara (2009) foi adaptada a fim de representar as formas geométricas do presente trabalho.

Nos segmentos, os tecidos têm a mesma distribuição em uma ou duas dimensões. Por este motivo, somente as dimensões em que ocorrem variações das camadas são consideradas. A Tabela 6.2 mostra a quantidade de dimensões e as coordenadas utilizadas em cada segmento. A distribuição das camadas nos segmentos está representada na Figura 6.2. A figura mostra também a localização das fronteiras adiabáticas e das que estão em contato com o ambiente. Os valores dos limites das camadas em cada segmento estão na Tabela 6.3. 


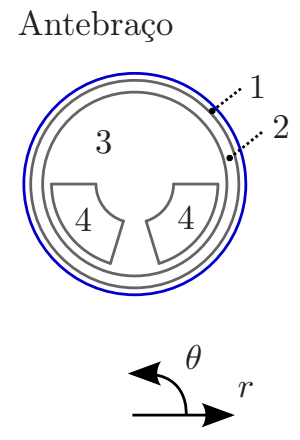

Perna

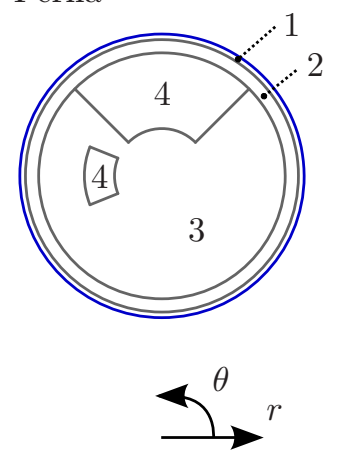

Cabeça
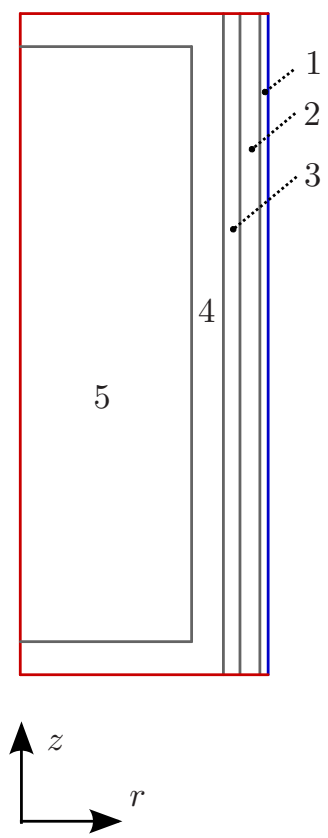

Tronco
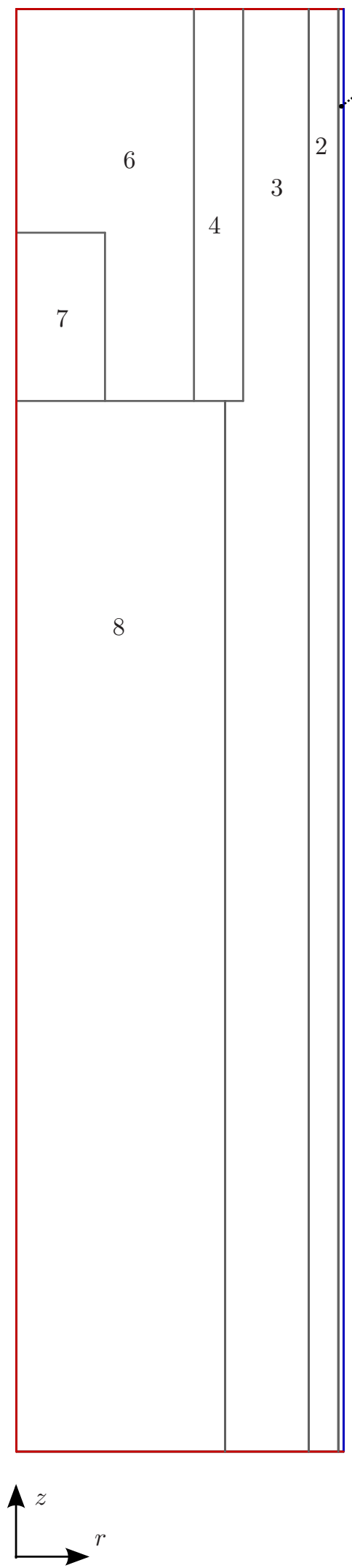

Pescoço

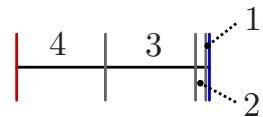

1

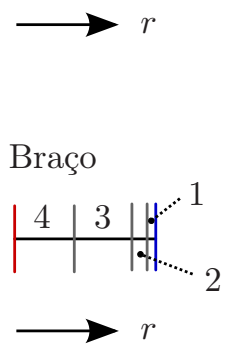

Coxa

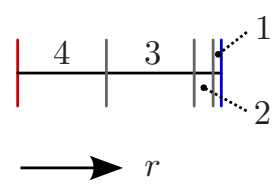

Mão
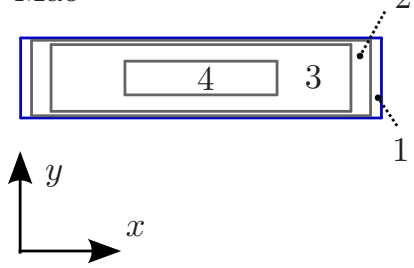

Pé

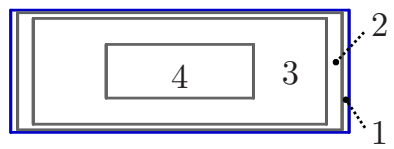

个 $y$

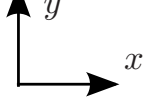

1. Pele

2. Gordura

3. Músculo

4. Osso

5. Cérebro

6. Pulmão

7. Coração

8. Víscera

Limite das camadas

Fronteira adiabática

Contato com o ambiente

Figura 6.2 - Representação das camadas 
Tabela 6.2 - Sistema de coordenadas dos segmentos

\begin{tabular}{llcc}
\hline Segmento & $\begin{array}{l}\text { Sistema de } \\
\text { coordenadas }\end{array}$ & Dimensão & Coordenadas \\
\hline Cabeça & cilíndrico & 2 & $r, z$ \\
Pescoço & cilíndrico & 1 & $r$ \\
Tronco & cilíndrico & 2 & $r, z$ \\
Braço & cilíndrico & 1 & $r$ \\
Antebraço & cilíndrico & 2 & $r, \theta$ \\
Mão & cartesiano & 2 & $x, y$ \\
Coxa & cilíndrico & 1 & $r$ \\
Perna & cilíndrico & 2 & $r, \theta$ \\
Pé & cartesiano & 2 & $x, y$ \\
\hline
\end{tabular}

Tabela 6.3 - Limites das camadas

\begin{tabular}{|c|c|c|}
\hline \multirow[t]{2}{*}{ Segmento } & \multicolumn{2}{|c|}{ Coordenada } \\
\hline & $r[\mathrm{~cm}]$ ou $x[\mathrm{~cm}]$ & $\theta\left[^{\circ}\right], z[\mathrm{~cm}]$ ou $y[\mathrm{~cm}]$ \\
\hline Cabeça & $5,176,156,647,247,51$ & $1,019,020,0$ \\
\hline Pescoço & $2,685,405,715,82$ & \\
\hline Tronco & $3,68 \quad 7,378,66 \quad 9,41 \quad 12,1313,36 \quad 13,58$ & $43,750,760,0$ \\
\hline Braço & $1,803,544,004,26$ & \\
\hline Antebraço & $1,172,512,783,143,35$ & $180,0253,0287,0360,0$ \\
\hline Mão & 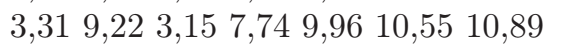 & $\begin{array}{lllllll}0,0736 & 0,205 & 0,699 & 1,72 & 2,21 & 2,34 & 2,42\end{array}$ \\
\hline Coxa & $2,685,335,906,15$ & \\
\hline Perna & $1,43 \quad 3,43 \quad 3,72 \quad 4,124,29$ & $45,0135,0 \quad 158,0202,0$ \\
\hline Pé & $\begin{array}{lllllllllll}0,210 & 0,680 & 2,88 & 7,33 & 9,53 & 10,00 & 10,21\end{array}$ & $0,07600,246 \quad 1,042,653,453,62 \quad 3,70$ \\
\hline
\end{tabular}

\subsection{Circulação}

Neste item será descrito como ocorre a circulação de sangue dentro de um segmento. A circulação é um mecanismo de transporte de calor, $\mathrm{O}_{2}$ e $\mathrm{CO}_{2}$ fundamental para o corpo humano.

Os segmentos estão conectados pela circulação do sangue arterial e venoso. O sangue arterial segue do tronco para os segmentos das extremidades (cabeça, mãos e pés). O sangue venoso, ao contrário, segue dos segmentos das extremidades para o tronco.

A Figura 6.3 mostra a circulação de sangue dentro de um segmento. O volume de sangue está dividido entre os pequenos e os grandes vasos. Os grandes vasos são representados por dois compartimentos: o compartimento arterial e o compartimento venoso. Os pequenos vasos estão conectados com os tecidos.

Sangue arterial proveniente do segmento anterior entra no compartimento arterial. Parte do sangue segue então para os pequenos vasos, trocando calor e gases com os tecidos. Outra parte segue para o próximo segmento (com exceção dos segmentos das extremidades). 


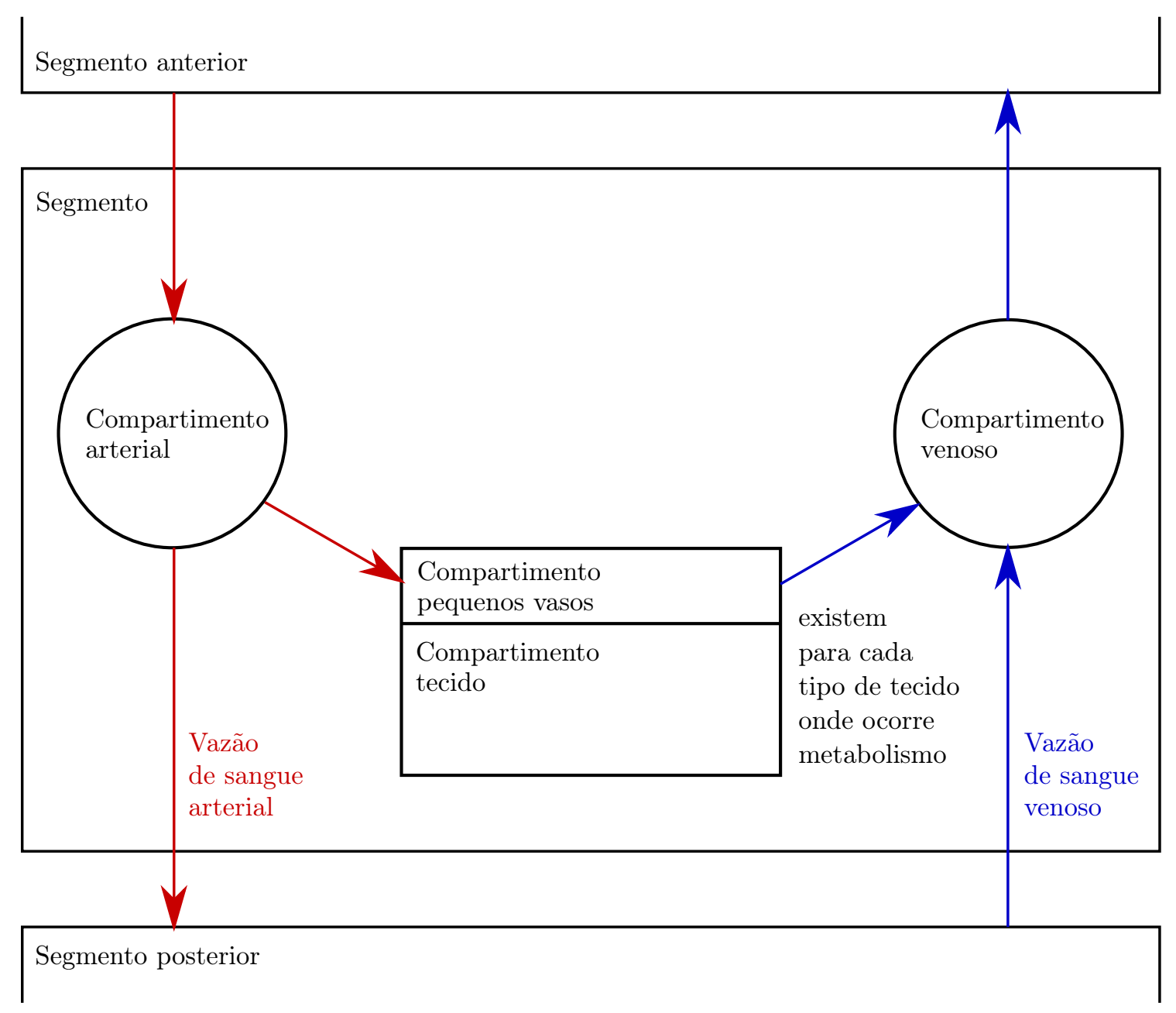

Figura 6.3 - Circulação de sangue em um segmento diferente do tronco

Ao sair dos pequenos vasos, o sangue segue para o compartimento venoso. Este compartimento também recebe sangue venoso do próximo segmento. Saindo do compartimento venoso, o sangue segue para o segmento anterior.

A circulação de sangue no tronco é diferente dos outros segmentos. Neste caso, não existe segmento anterior e existe o pulmão. A Figura 6.4 mostra como ocorre a circulação dentro do tronco. O sangue que sai do compartimento venoso segue para os capilares pulmonares, trocando calor e gases com o compartimento alveolar. Saindo dos capilares pulmonares, o sangue segue para o compartimento arterial.

\subsection{Metodologia de modelagem}

O objetivo do modelo é representar o funcionamento do sistema respiratório e térmico, considerando o transporte dos gases $\mathrm{O}_{2}$ e $\mathrm{CO}_{2}$. O principal método utilizado é a divisão dos diversos reservatórios de sangue e gases do corpo humano em compartimentos. 


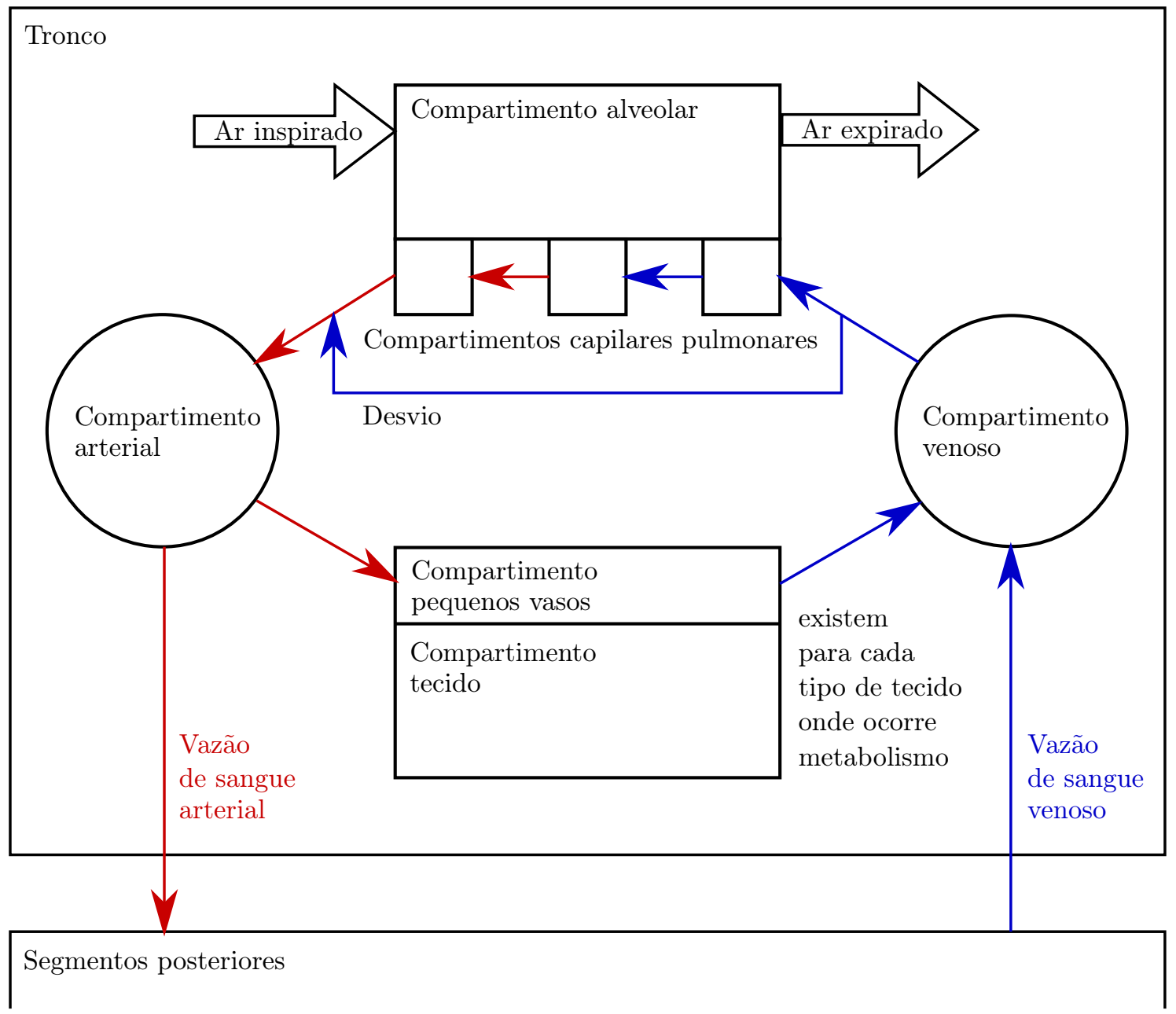

Figura 6.4 - Circulação de sangue no tronco

Os parâmetros utilizados no modelo são conhecidos e encontrados na literatura, sendo volumes, vazões, calores específicos, densidades, coeficientes de difusão de massa e transferência de calor, metabolismo, entre outros. O princípio da modelagem é representar fisicamente o funcionamento do corpo humano, portanto, todos os valores dos parâmetros devem corresponder à realidade.

Os diversos reservatórios de sangue, tecidos e gases de cada membro do corpo humano são divididos em compartimentos. Cada compartimento pode ter entradas e saídas de fluido, carregando $\mathrm{O}_{2}, \mathrm{CO}_{2}$ e calor. Também pode ter difusão de gás com outro compartimento, ou ainda geração de calor e $\mathrm{CO}_{2}$ e consumo de $\mathrm{O}_{2}$.

Os gases, ou líquidos, dentro dos compartimentos são considerados uniformes, ou seja, a composição do fluido no interior do compartimento é igual à composição na saída do mesmo.

Esta metodologia, conhecida por modelagem multicompartimental, só não será utilizada no caso da transferência de calor nos tecidos. Neste caso, a distribuição da temperatura é calculada ao longo da geometria do segmento. 
A concentração dos gases dentro dos compartimentos sanguíneos e teciduais é descrita pela quantidade de mols de gás $\left(\mathrm{O}_{2}\right.$ ou $\left.\mathrm{CO}_{2}\right)$ por volume de sangue ou tecido. Esta opção tem como princípio atender o balanço molar dos gases sem depender dos padrões de temperatura e pressão. A opção de representar o sangue e tecidos por volumes vem do fato destes serem considerados incompressíveis, e seus volumes serem facilmente determinados a partir da geometria do corpo humano ou por medições.

Os gases presentes nos compartimentos sanguíneos ou teciduais podem ainda ser representados por suas pressões parciais. As relações entre as concentrações dos gases com suas pressões parciais são calculadas por uma série de equações apresentadas no Capítulo 3 para o sangue e Capítulo 4 para os tecidos.

Quando os gases estão na forma gasosa, como no caso dos alvéolos pulmonares, são representados por pressões parciais, ou frações molares quando relacionadas com a pressão barométrica.

A concentração dos gases em cada compartimento é descrita por equações diferenciais ordinárias representando a variação no tempo, uma para cada compartimento e uma para cada gás - com exceção do compartimento pequeno vaso e tecidual, que são representados pela mesma equação. A temperatura em cada compartimento, com exceção dos tecidos, também é descrita por equações diferenciais ordinárias representando a variação no tempo, uma para cada compartimento. Nos tecidos, a temperatura é descrita por uma equação diferencial parcial, representando a variação no tempo e no espaço. Deste modo, cada segmento terá 3 equações diferenciais ordinárias para o compartimento arterial, 3 para o venoso, 2 vezes o número de compartimentos teciduais e, no caso do tronco, mais 2 para os alvéolos, 2 vezes o número de compartimentos capilares pulmonares e 7 para o trato respiratório. Concluindo, como são 15 segmentos, com um total de 48 compartimentos teciduais (desprezando o osso), e 10 compartimentos capilares pulmonares, o modelo será descrito por 215 equações diferenciais ordinárias.

Nas próximas seções, balanços de energia e massa serão aplicados para os grandes vasos, pequenos vasos, tecidos e pulmão. O subíndice $g$ será usado para referenciar cada um dos gases, sendo $g$ igual a $\mathrm{O}_{2}$ ou $\mathrm{CO}_{2}$.

\subsection{Modelagem dos grandes vasos}

Os grandes vasos são representados por dois compartimentos sanguíneos em cada segmento: arterial e venoso. A Figura 6.5 mostra estes compartimentos, com suas variáveis e parâmetros. A variação da concentração dos gases e da temperatura nos compartimentos é obtida aplicando balanços de energia e massa. 


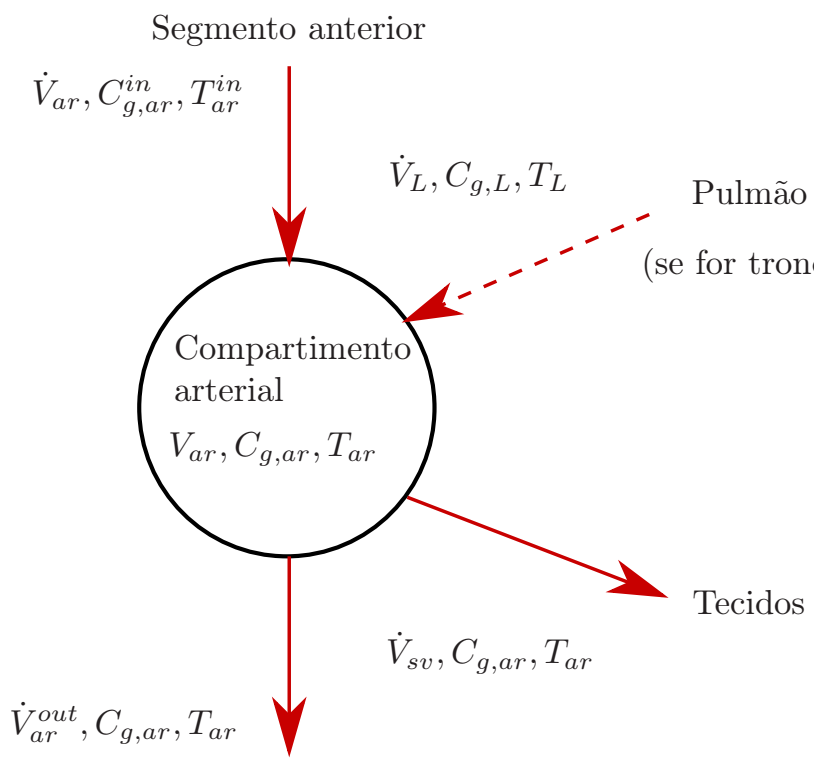

Segmento posterior

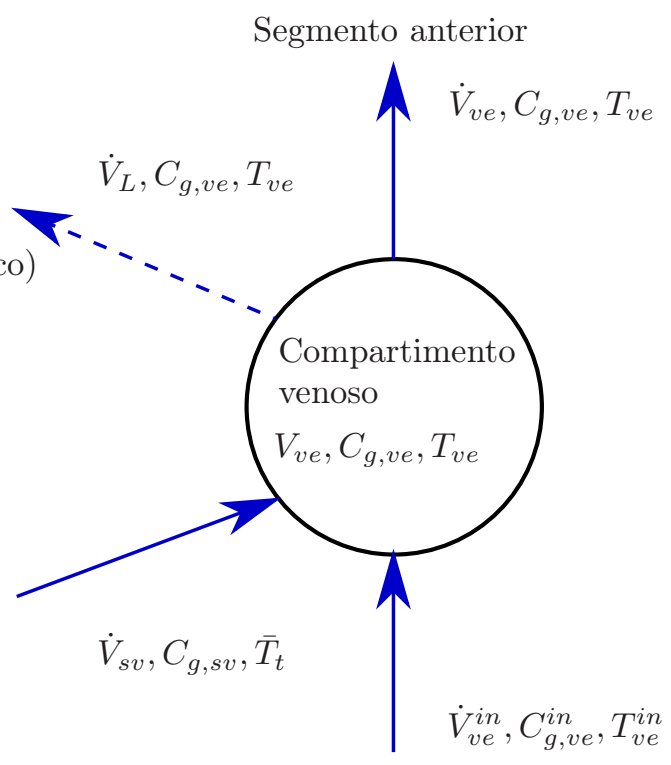

Segmento posterior

Figura 6.5 - Compartimento arterial e compartimento venoso

No compartimento arterial, entra sangue vindo do compartimento arterial do segmento anterior. No caso do tronco, onde não há segmento anterior, entra sangue vindo do pulmão. Saindo do compartimento arterial, o sangue segue para os pequenos vasos conectados com os tecidos. Também segue para o compartimento venoso do segmento posterior (com exceção da cabeça, mãos e pés).

No compartimento venoso, entra sangue vindo do compartimento venoso do segmento posterior (com exceção da cabeça, mãos e pés). Também entra sangue vindo dos pequenos vasos. Saindo do compartimento venoso, o sangue segue para o compartimento venoso do segmento anterior. No caso do tronco, onde não há segmento anterior, o sangue segue para o pulmão.

Ferreira e Yanagihara (2009) determinaram o volume dos reservatórios de sangue arterial e venoso para cada membro, de acordo com o modelo anatômico considerado. O volume total de sangue nos grandes vasos foi dividido entre os segmentos, sendo proporcional ao volume das vísceras e do pulmão no caso do tronco, ao volume do cérebro no caso da cabeça e ao volume de músculo nos demais segmentos (Tabela 6.4).

\subsubsection{Transferência de calor no compartimento arterial}

No compartimento arterial, a temperatura do sangue $\left(T_{a r}\right)$ varia devido a dois processos: a passagem de sangue e a transferência de calor com o compartimento venoso.

O sangue que entra no compartimento arterial vem do compartimento arterial do segmento anterior, com temperatura $T_{a r}^{i n}$ e vazão de sangue $\dot{V}_{a r}$. 
Tabela 6.4 - Volume dos reservatórios de sangue (FERREIRA; YANAGIHARA, 2009)

\begin{tabular}{lrr}
\hline \multirow{2}{*}{ Elemento } & \multicolumn{2}{c}{ Volume, $\mathrm{cm}^{3}$} \\
\cline { 2 - 3 } & Arterial & Venoso \\
\hline Cabeça & 40 & 180 \\
Pescoço & 15 & 66 \\
Vísceras & 335 & 1114 \\
Pulmão & 111 & 370 \\
Mão & 7 & 30 \\
Antebraço & 13 & 60 \\
Braço & 24 & 107 \\
Pé & 15 & 66 \\
Perna & 35 & 155 \\
Coxa & 78 & 349 \\
\hline Total & 846 & 3264 \\
\hline
\end{tabular}

Na saída, como o compartimento arterial é considerado uniforme, o sangue tem a mesma temperatura do compartimento $\left(T_{a r}\right)$. Uma parte do sangue segue para os tecidos. A outra parte, caso não seja um segmento da extremidade, segue para os segmentos posteriores.

A vazão de sangue na entrada do compartimento arterial $\left(\dot{V}_{a r}\right)$ é igual à soma entre a vazão de sangue que vai para os tecidos $\left(\dot{V}_{s v}\right)$ e a vazão de sangue que vai para os segmentos posteriores $\left(\dot{V}_{a r}^{\text {out }}\right)$ :

$$
\dot{V}_{a r}=\dot{V}_{s v}+\dot{V}_{a r}^{o u t}
$$

sendo: $\dot{V}_{a r}=$ vazão de sangue que entra no compartimento arterial $\left[\mathrm{m}^{3} / \mathrm{s}\right]$;

$\dot{V}_{s v}=$ vazão de sangue que passa pelos pequenos vasos $\left[\mathrm{m}^{3} / \mathrm{s}\right]$;

$\dot{V}_{a r}^{\text {out }}=$ vazão de sangue que vai para os segmentos posteriores $\left[\mathrm{m}^{3} / \mathrm{s}\right]$.

A transferência de calor entre o compartimento arterial e venoso é representada por um coeficiente de transferência de calor $\left(H_{a v}\right)$ multiplicado pela diferença entre a temperatura do compartimento arterial $\left(T_{a r}\right)$ e a temperatura do compartimento venoso $\left(T_{v e}\right)$.

A variação da temperatura no compartimento arterial ao longo do tempo é representada pela seguinte equação:

$$
V_{a r} \rho_{b l} c_{b l} \frac{\mathrm{d} T_{a r}}{\mathrm{~d} t}=\dot{V}_{a r} \rho_{b l} c_{b l}\left(T_{a r}^{i n}-T_{a r}\right)+H_{a v}\left(T_{v e}-T_{a r}\right)
$$

sendo: $V_{a r}=$ volume do compartimento arterial $\left[\mathrm{m}^{3}\right]$;

$\rho_{b l}=$ massa específica do sangue $\left[\mathrm{kg} / \mathrm{m}^{3}\right]$;

$c_{b l}=$ calor específico do sangue $\left[\mathrm{J} /\left(\mathrm{kg} .{ }^{\circ} \mathrm{C}\right)\right]$;

$T_{a r}=$ temperatura do sangue no compartimento arterial $\left[{ }^{\circ} \mathrm{C}\right]$;

$t=$ tempo $[\mathrm{s}]$; 
$T_{a r}^{i n}=$ temperatura do sangue que entra no compartimento arterial $\left[{ }^{\circ} \mathrm{C}\right]$;

$H_{a v}=$ coeficiente de transferência de calor entre os compartimentos $\left[\mathrm{W} /{ }^{\circ} \mathrm{C}\right]$;

$T_{v e}=$ temperatura do sangue no compartimento venoso $\left[{ }^{\circ} \mathrm{C}\right]$.

O primeiro membro da equação representa a variação da temperatura no tempo. No segundo membro, o primeiro termo representa a passagem de sangue e o segundo termo a transferência de calor entre compartimento arterial e venoso.

No caso do tronco, o sangue que entra no compartimento arterial vem do pulmão com temperatura $T_{L}$, e não do segmento anterior. A variação da temperatura no compartimento arterial ao longo do tempo, no caso do tronco é:

$$
V_{a r} \rho_{b l} c_{b l} \frac{\mathrm{d} T_{a r}}{\mathrm{~d} t}=\dot{V}_{a r} \rho_{b l} c_{b l}\left(T_{L}-T_{a r}\right)+H_{a v}\left(T_{v e}-T_{a r}\right)
$$

sendo: $T_{L}=$ temperatura do sangue que sai do pulmão $\left[{ }^{\circ} \mathrm{C}\right]$.

O coeficiente de transferência de calor $\left(H_{a v}\right)$ entre artérias e veias foi determinado por Ferreira e Yanagihara (2009), para cada membro, como um problema de condução bidimensional em regime permanente entre dois cilindros (Tabela 6.5).

Tabela 6.5 - Coeficiente de transferência de calor entre grandes vasos (FERREIRA; YANAGIHARA, 2009)

\begin{tabular}{lc}
\hline Elemento & $H_{a v}, \mathrm{~W} /{ }^{\circ} \mathrm{C}$ \\
\hline Cabeça & 0,00 \\
Pescoço & 1,55 \\
Tronco & 0,00 \\
Braço & 2,55 \\
Antebraço & 1,43 \\
Mão & 0,72 \\
Coxa & 8,26 \\
Perna & 3,67 \\
Pé & 1,55 \\
\hline
\end{tabular}

\subsubsection{Transferência de calor no compartimento venoso}

No compartimento venoso ocorre transferência de calor por causa da passagem de sangue e da proximidade com o compartimento arterial.

O sangue que entra no compartimento venoso vem de dois caminhos diferentes. Uma parte vem dos tecidos, com a temperatura média dos tecidos $\left(\bar{T}_{t}\right)$ e a vazão de sangue que passa por todos os pequenos vasos do segmento $\left(\dot{V}_{s v}\right)$. A outra parte vem dos compartimentos venosos dos segmentos posteriores, com temperatura $T_{v e}^{i n}$ e vazão $\dot{V}_{v e}^{i n}$. 
A temperatura do sangue na saída do compartimento venoso é a mesma da temperatura no interior do compartimento $\left(T_{v e}\right)$, já que este é considerado uniforme. Do compartimento venoso, o sangue segue para o segmento anterior ou, no caso do tronco, para o pulmão. A vazão de sangue que sai do compartimento venoso é igual a soma da vazão de sangue que vem dos tecidos com a vazão de sangue que vem dos segmentos posteriores, ou seja,

$$
\dot{V}_{v e}=\dot{V}_{s v}+\dot{V}_{v e}^{i n}
$$

sendo: $\dot{V}_{v e}=$ vazão de sangue que sai do compartimento venoso $\left[\mathrm{m}^{3} / \mathrm{s}\right]$;

$\dot{V}_{v e}^{i n}=$ vazão de sangue que vem dos segmentos posteriores $\left[\mathrm{m}^{3} / \mathrm{s}\right]$.

A transferência de calor entre o compartimento arterial e venoso, assim como na determinação da temperatura do compartimento arterial, é representada por um coeficiente de transferência de calor multiplicado $\left(H_{a v}\right)$ pela diferença entre ambas temperaturas.

A variação da temperatura no compartimento venoso ao longo do tempo é representada pela seguinte equação:

$$
V_{v e} \rho_{b l} c_{b l} \frac{\mathrm{d} T_{v e}}{\mathrm{~d} t}=\rho_{b l} c_{b l}\left(\sum_{i=1}^{N_{t c}} \dot{V}_{s v(i)} \bar{T}_{t(i)}+\dot{V}_{v e}^{i n} T_{v e}^{i n}-\dot{V}_{v e} T_{v e}\right)+H_{a v}\left(T_{a r}-T_{v e}\right)
$$

sendo: $V_{v e}=$ volume do compartimento venoso $\left[\mathrm{m}^{3}\right]$;

$N_{t c}=$ quantidade de compartimentos teciduais em um segmento;

$\dot{V}_{s v(i)}=$ vazão de sangue que passa pelo compartimento pequeno vaso $i\left[\mathrm{~m}^{3} / \mathrm{s}\right]$;

$\bar{T}_{t(i)}=$ temperatura média do compartimento pequeno vaso e tecidual $i\left[{ }^{\circ} \mathrm{C}\right]$;

$T_{v e}^{i n}=$ temperatura do sangue que vem dos segmentos posteriores $\left[{ }^{\circ} \mathrm{C}\right]$.

O primeiro membro da equação representa a variação da temperatura ao longo do tempo. No segundo membro, o primeiro termo representa a passagem de sangue enquanto o segundo termo representa a transferência de calor entre os compartimentos arterial e venoso.

A somatória que aparece no primeiro termo do segundo membro da equação se refere ao sangue que vem dos tecidos. Neste caso, ele vem do compartimento tecidual $i$ com temperatura $\bar{T}_{t(i)}$ - calculada pela eq.(6.22) - e com vazão $\dot{V}_{s v(i)}$ - calculada pela eq.(6.15).

Quando o segmento é o tronco, ele está conectado a vários segmentos posteriores. A temperatura do sangue que entra no compartimento venoso $\left(T_{v e}^{i n}\right)$, vindo dos segmentos posteriores, é uma média ponderada de suas temperaturas. A vazão de sangue $\left(\dot{V}_{v e}^{i n}\right)$ é 
a soma da vazão de sangue destes segmentos. Estas variáveis são determinadas pelas seguintes equações:

$$
\begin{aligned}
\dot{V}_{v e}^{i n} & =\sum_{j=1}^{N_{s p}} \dot{V}_{v e(j)}^{i n} \\
T_{v e}^{i n} & =\frac{1}{\dot{V}_{v e}^{i n}} \sum_{j=1}^{N_{s p}} \dot{V}_{v e(j)}^{i n} T_{v e(j)}^{i n}
\end{aligned}
$$

sendo: $N_{s p}=$ quantidade de segmentos posteriores;

$\dot{V}_{v e(j)}^{i n}=$ vazão de sangue que entra no compartimento venoso vindo do segmento posterior $j\left[\mathrm{~m}^{3} / \mathrm{s}\right]$;

$T_{v e(j)}^{i n}=$ temperatura do sangue que entra no compartimento venoso vindo do segmento posterior $j\left[{ }^{\circ} \mathrm{C}\right]$.

\subsubsection{Transferência de massa no compartimento arterial}

A transferência de massa no compartimento arterial ocorre somente pela passagem de sangue. Ao contrário da transferência de calor, a transferência de massa entre o compartimento arterial e venoso é considerada desprezível.

O sangue entra no compartimento arterial vindo do segmento anterior, com concentração $C_{g, a r}^{\text {in }}$ e vazão $\dot{V}_{a r}$.

Na saída, como o compartimento é considerado uniforme, o sangue tem a mesma concentração do compartimento $\left(C_{g, a r}\right)$. Parte do sangue segue para os tecidos e parte segue para os segmentos posteriores.

A variação da concentração de um gás $g\left(\mathrm{O}_{2}\right.$ ou $\left.\mathrm{CO}_{2}\right)$ no compartimento arterial é igual a:

$$
V_{a r} \frac{\mathrm{d} C_{g, a r}}{\mathrm{~d} t}=\dot{V}_{a r}\left(C_{g, a r}^{i n}-C_{g, a r}\right)
$$

sendo: $g=$ gás $\left[\mathrm{O}_{2}\right.$ ou $\left.\mathrm{CO}_{2}\right]$;

$C_{g, a r}=$ concentração de $g$ no sangue do compartimento arterial $\left[\mathrm{mol} / \mathrm{m}^{3}\right]$;

$C_{g, a r}^{i n}=$ concentração de $g$ no sangue que entra no compartimento arterial $\left[\mathrm{mol} / \mathrm{m}^{3}\right]$.

Nesta equação, o primeiro membro representa a variação no tempo e o segundo membro a passagem de sangue.

O compartimento arterial é um atraso de tempo, com a inércia dada pela vazão de sangue $\left(\dot{V}_{a r}\right)$ e o volume do compartimento $\left(V_{a r}\right)$. 
No caso do tronco, o sangue que entra no compartimento arterial vem do pulmão, com concentração $C_{g, L}$. A variação da concentração de um gás ao longo do tempo no compartimento arterial do tronco é igual a:

$$
V_{a r} \frac{\mathrm{d} C_{g, a r}}{\mathrm{~d} t}=\dot{V}_{a r}\left(C_{g, L}-C_{g, a r}\right)
$$

sendo: $C_{g, L}=$ concentração de $g$ no sangue que sai do pulmão $\left[\mathrm{mol} / \mathrm{m}^{3}\right]$.

\subsubsection{Transferência de massa no compartimento venoso}

No compartimento venoso, a transferência de massa ocorre somente pela passagem de sangue.

Parte do sangue que entra no compartimento venoso vem dos pequenos vasos com concentração $C_{g, s v}$ e vazão $\dot{V}_{s v}$. A outra parte vem dos segmentos posteriores com concentração $C_{g, v e}^{i n}$ e vazão $\dot{V}_{v e}^{i n}$.

O sangue que sai do compartimento venoso segue para o segmento anterior ou, no caso do tronco, para o pulmão, com vazão $\dot{V}_{v e}$. Como o compartimento é considerado uniforme, a concentração na saída é a mesma que a do compartimento $\left(C_{g, v e}\right)$.

Assim como o compartimento arterial, o compartimento venoso funciona como um atraso de tempo no sistema.

A variação da concentração de um gás no compartimento venoso é igual a:

$$
V_{v e} \frac{\mathrm{d} C_{g, v e}}{\mathrm{~d} t}=\dot{V}_{s v} C_{g, s v}+\dot{V}_{v e}^{i n} C_{g, v e}^{i n}-\dot{V}_{v e} C_{g, v e}
$$

sendo: $C_{g, v e}=$ concentração de $g$ no sangue do compartimento venoso $\left[\mathrm{mol} / \mathrm{m}^{3}\right]$;

$C_{g, s v}=$ concentração de $g$ no sangue que sai dos pequenos vasos $\left[\mathrm{mol} / \mathrm{m}^{3}\right]$;

$\dot{V}_{v e}^{i n}=$ vazão de sangue que entra no compartimento venoso $\left[\mathrm{m}^{3} / \mathrm{s}\right]$;

$C_{g, v e}^{i n}=$ concentração de $g$ no sangue que entra no compartimento venoso $\left[\mathrm{mol} / \mathrm{m}^{3}\right]$;

$\dot{V}_{v e}=$ vazão de sangue que sai do compartimento venoso $\left[\mathrm{m}^{3} / \mathrm{s}\right]$.

O primeiro membro da equação representa a variação no tempo, enquanto o segundo a passagem de sangue.

A concentração do sangue que entra no compartimento venoso $\left(C_{g, v e}^{i n}\right)$, vindo dos segmentos posteriores, é uma média ponderada de suas concentrações.

$$
C_{g, v e}^{i n}=\frac{1}{\dot{V}_{v e}^{i n}} \sum_{j=1}^{N_{s p}} \dot{V}_{v e(j)}^{i n} C_{g, v e(j)}^{i n}
$$


sendo: $C_{g, v e(j)}^{i n}=$ concentração de $g$ no sangue que entra no compartimento venoso vindo do segmento posterior $j\left[\mathrm{~mol} / \mathrm{m}^{3}\right]$.

\subsection{Modelagem dos pequenos vasos e tecidos}

A transferência de calor e a transferência de massa nos pequenos vasos são tratadas de forma distintas. No caso da transferência de calor, o sangue presente nos pequenos vasos é considerado parte dos tecidos. A geometria é, neste caso, levada em consideração; a temperatura é determinada ao longo do espaço. No caso da transferência de massa, os tecidos e pequenos vasos são representados por compartimentos.

O sangue que entra nos pequenos vasos vem do compartimento arterial, troca gases e calor com os tecidos, e segue para o compartimento venoso. Nos tecidos ocorre o metabolismo, onde $\mathrm{O}_{2}$ é consumido e $\mathrm{CO}_{2}$ e calor são gerados.

O pulmão é tratado diferente dos outros tecidos. No caso da transferência de calor, a única mudança é que o sangue vem do compartimento venoso, ao invés do arterial. No caso da transferência de massa, ocorre um complexo processo de difusão. A transferência de massa no pulmão será modelada na Seção 6.7.

\subsubsection{Transferência de calor}

A transferência de calor nos tecidos e pequenos vasos considera a geometria do segmento e das camadas. A temperatura é calculada distribuída no espaço. Os segmentos podem ter a forma de um paralelepípedo ou de um cilindro. Serão adotadas coordenadas cartesianas ou cilíndricas. A Figura 6.6 representa um segmento cilíndrico.

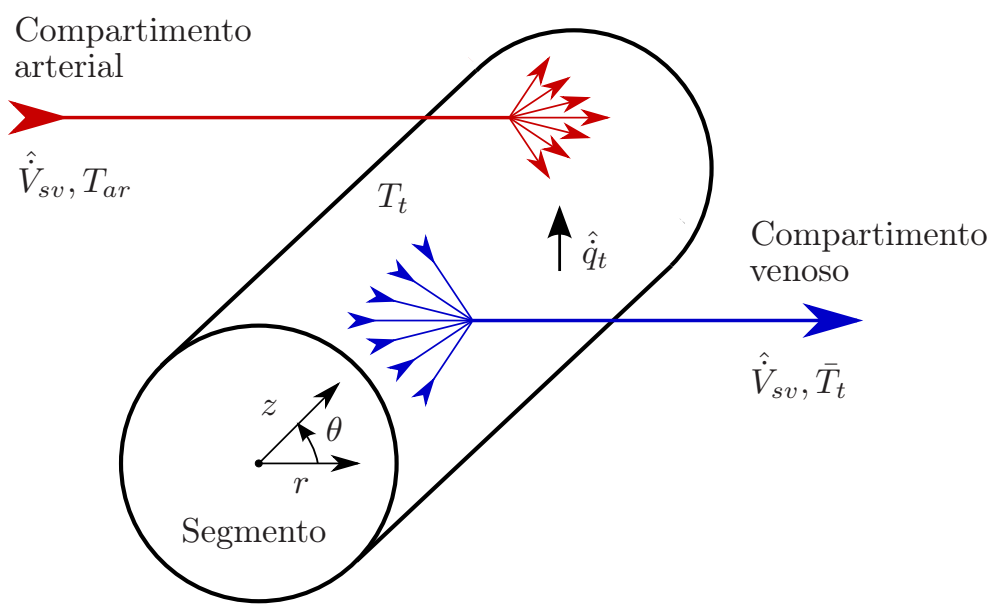

Figura 6.6 - Transferência de calor em um compartimento cilíndrico 
A variação da temperatura nos tecidos depende de quatro mecanismos de transferência de calor: a perfusão de sangue, a condução com os tecidos vizinhos, a geração de calor por metabolismo, e a transferência de calor com o ambiente.

O sangue presente nos pequenos vasos é considerado estar misturado com os tecidos. Ele vem do compartimento arterial de cada segmento com vazão específica (por unidade de volume) $\hat{\dot{V}}_{s v}$ e temperatura $T_{a r}$. Ao sair dos pequenos vasos, o sangue tem a temperatura igual à temperatura dos tecidos $\left(T_{t}\right)$.

A condução de calor depende da geometria adotada; seu equacionamento varia dependendo do sistema de coordenadas. A condutividade térmica $\left(k_{t}\right)$ varia para cada tipo de tecido. A gordura, por exemplo, tem baixa condutividade térmica, determinando sua propriedade isolante.

A geração de calor por metabolismo também varia dependendo do tipo de tecido. A taxa de geração de calor específica (por unidade de volume) é representada por $\hat{\dot{q}}_{t}$.

Nos tecidos superficiais ocorre transferência de calor por convecção, radiação, evaporação e condução. Estes processos são calculados por uma metodologia clássica, abordada por Fanger (1970) e ASHRAE (2005), descrita no Capítulo 4. O corpo humano também realiza transferência de calor com o ambiente pela respiração. Essa transferência é dividida entre os tecidos do pulmão, músculos do pescoço e da cabeça. Sua modelagem é descrita na Seção 6.8.

A equação de condução de calor nos tecidos usada no presente trabalho tem como base o trabalho de Pennes (1948). A variação da temperatura nos tecidos com a forma de um paralelepípedo, em duas dimensões, usando coordenadas cartesianas, é calculada pela seguinte equação:

$$
\rho_{t} c_{t} \frac{\partial T_{t}}{\partial t}=k_{t}\left(\frac{\partial^{2} T_{t}}{\partial x^{2}}+\frac{\partial^{2} T_{t}}{\partial y^{2}}\right)+\hat{\dot{V}}_{s v} \rho_{b l} c_{b l}\left(T_{a r}-T_{t}\right)+\hat{\dot{q}}_{t}
$$

sendo: $\rho_{t}=$ massa específica do tecido $\left[\mathrm{kg} / \mathrm{m}^{3}\right]$;

$c_{t}=$ calor específico do tecido $\left[\mathrm{J} /\left(\mathrm{kg} \cdot{ }^{\circ} \mathrm{C}\right)\right]$;

$T_{t}=$ temperatura do tecido $\left[{ }^{\circ} \mathrm{C}\right]$;

$k_{t}=$ condutividade térmica do tecido $\left[\mathrm{W} /\left(\mathrm{m} .{ }^{\circ} \mathrm{C}\right)\right]$;

$x=$ coordenada cartesiana $[\mathrm{m}]$;

$y=$ coordenada cartesiana $[\mathrm{m}]$;

$\hat{\dot{V}}_{s v}=$ vazão de sangue no tecido $\left[\mathrm{m}^{3} /\left(\mathrm{m}^{3} . \mathrm{s}\right)\right]$;

$\rho_{b l}=$ massa específica do sangue $\left[\mathrm{kg} / \mathrm{m}^{3}\right]$;

$c_{b l}=$ calor específico do sangue $\left[\mathrm{J} /\left(\mathrm{kg} .{ }^{\circ} \mathrm{C}\right)\right]$;

$T_{a r}=$ temperatura do sangue arterial no segmento $\left[{ }^{\circ} \mathrm{C}\right]$;

$\hat{\dot{q}}_{t}=$ geração interna de calor $\left[\mathrm{W} / \mathrm{m}^{3}\right]$. 
A equação contém quatro termos. O primeiro termo do primeiro membro representa a variação da temperatura no tempo. O primeiro termo do segundo membro representa a condução nas duas direções. Este termo depende do sistema de coordenadas adotado. O segundo termo do segundo membro representa a passagem de sangue e o último termo a geração de calor.

Quando o sistema de coordenadas cilíndricas é adotado, a variação da temperatura nos tecidos em um cilindro, nas três dimensões, é calculada pela seguinte equação:

$$
\rho_{t} c_{t} \frac{\partial T_{t}}{\partial t}=k_{t}\left[\frac{1}{r} \frac{\partial}{\partial r}\left(r \frac{\partial T_{t}}{\partial r}\right)+\frac{1}{r^{2}} \frac{\partial^{2} T_{t}}{\partial \theta^{2}}+\frac{\partial^{2} T_{t}}{\partial z^{2}}\right]+\hat{\dot{V}}_{s v} \rho_{b l} c_{b l}\left(T_{a r}-T_{t}\right)+\hat{\dot{q}}_{t}
$$

sendo: $r=$ coordenada cilíndrica $[\mathrm{m}]$;

$\theta=$ coordenada cilíndrica $[\mathrm{rad}]$;

$z=$ coordenada cilíndrica $[\mathrm{m}]$.

No caso do pulmão, o sangue que entra nos tecidos vem do compartimento venoso, e não do arterial, com temperatura $T_{v e}$. Após passar pelos tecidos do pulmão, o sangue segue para o compartimento arterial com a mesma temperatura dos tecidos $\left(T_{t}\right)$. Neste caso, a equação de condução de calor nos tecidos, adotando coordenadas cilíndricas, em duas dimensões, é igual a:

$$
\rho_{t} c_{t} \frac{\partial T_{t}}{\partial t}=k_{t}\left[\frac{1}{r} \frac{\partial}{\partial r}\left(r \frac{\partial T_{t}}{\partial r}\right)+\frac{\partial^{2} T_{t}}{\partial z^{2}}\right]+\hat{\dot{V}}_{s v} \rho_{b l} c_{b l}\left(T_{v e}-T_{t}\right)+\hat{\dot{q}}_{t}
$$

Os valores basais das propriedades dos tecidos relacionadas com o processo de transferência de calor (Tabela 6.6) foram adaptados de Ferreira e Yanagihara (2009). Eles utilizaram como referência os dados de Werner e Buse (1988). No presente trabalho, foram feitas alterações na vazão de sangue e geração de calor de alguns tecidos. Essas têm como objetivos manter a diferença da concentração de $\mathrm{O}_{2}$ entre o sangue arterial e o venoso próxima de 4,98 ml/100 ml (LAMBERTSEN, 1974d), o débito cardíaco igual a 5,0 L/min (URSINO; MAGOSSO; AVANZOLINI, 2001a) e a geração de calor igual a 81,64 W (BROBECK, 1974a) - valor para uma pessoa dormindo. Os valores diferentes dos utilizados por Ferreira e Yanagihara (2009) são:

- geração de calor e vazão de sangue no osso, ambas consideradas nulas;

- vazão de sangue específica da gordura igual a 398,7 $\mathrm{cm}^{3} /\left(\mathrm{m}^{3} . \mathrm{s}\right)$ (LARSEN; LASSEN; QUAADE, 1966) - o valor original leva a concentrações de $\mathrm{O}_{2}$ e $\mathrm{CO}_{2}$ incoerentes;

- vazão de sangue específica do pulmão igual ao débito cardíaco dividido pelo volume do pulmão;

- vazão de sangue específica do coração ajustada para que a diferença artério-venosa seja igual ao valor citado acima; 
Tabela 6.6 - Propriedades dos tecidos e órgãos [adaptado de Ferreira e Yanagihara (2009)]

\begin{tabular}{lrrrrrr}
\hline Tecido & \multicolumn{5}{c}{ Propriedade } \\
\cline { 2 - 7 } & Volume & $\begin{array}{r}\text { Vazão de } \\
\text { sangue basal } \\
\mathrm{cm}^{3} /\left(\mathrm{m}^{3} . \mathrm{s}\right)\end{array}$ & $\begin{array}{r}\text { Massa } \\
\text { específica } \\
\mathrm{kg} / \mathrm{m}^{3}\end{array}$ & $\begin{array}{r}\text { Calor } \\
\text { específico }\end{array}$ & $\begin{array}{r}\text { Condutividade } \\
\text { térmica }\end{array}$ & $\begin{array}{r}\text { Geração de } \\
\text { calor basal }\end{array}$ \\
$\mathrm{W}$ & $\mathrm{\textrm {W }} /\left(\mathrm{m} .{ }^{\circ} \mathrm{C}\right)$ & $\mathrm{W} / \mathrm{m}^{3}$ \\
\hline Pele & 3541 & 362 & 1085 & 3680 & 0,47 & 368 \\
Gordura & 10657 & 3,6 & 920 & 2300 & 0,21 & 4 \\
Músculo & 26330 & 543 & 1085 & 3800 & 0,51 & 684 \\
Osso & 7576 & 0 & 1357 & 1700 & 0,75 & 0 \\
Cérebro & 1514 & 9000 & 1080 & 3850 & 0,49 & 9472 \\
Pulmão & 2481 & 834 & 560 & 3520 & 0,28 & 339 \\
Coração & 298 & 14400 & 1080 & 2550 & 0,47 & 24128 \\
Víscera & 10301 & 5800 & 1080 & 3504 & 0,49 & 3852 \\
\hline
\end{tabular}

- vazão de sangue específica no músculo igual a $483 \mathrm{~cm}^{3} /\left(\mathrm{m}^{3} . \mathrm{s}\right)$ (MOTTRAM, 1955) e geração de calor específica igual a $501 \mathrm{~W} / \mathrm{m}^{3}$ (STOLWIJK; HARDY, 1966a);

- vazão de sangue específica e geração de calor específica nas vísceras ajustadas para que o débito cardíaco e a geração de calor total sejam iguais aos valores citados acima.

\subsubsection{Transferência de massa}

Na transferência de massa, o sangue presente nos pequenos vasos é considerado estar separado dos tecidos. Para cada tipo de tecido presente em um segmento, existe um conjunto formado por um compartimento pequeno vaso e um compartimento tecidual. A Figura 6.7 mostra uma representação desses conjuntos de compartimentos pequeno vaso e tecidual no segmento cabeça. O osso não precisa ser considerado por ter vazão de sangue, consumo de $\mathrm{O}_{2}$ e geração de $\mathrm{CO}_{2}$ desprezíveis.

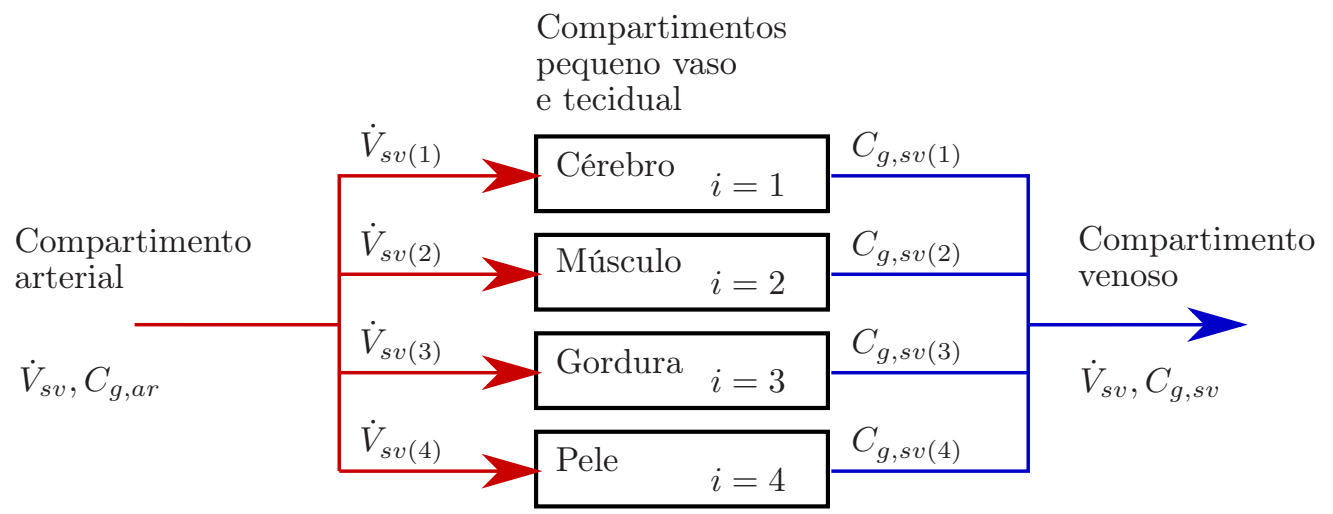

Figura 6.7 - Compartimentos pequenos vasos e tecidos em um segmento

A Figura 6.8 mostra uma representação detalhada de um compartimento pequeno vaso e um compartimento tecidual. O sangue que entra nos pequenos vasos vem do com- 
partimento arterial com concentração $C_{g, a r}$. A vazão total deste sangue é representada por $\dot{V}_{s v}$; já a fração deste sangue que vai para o compartimento pequeno vaso $i$ é representada por $\dot{V}_{s v(i)}$. Essa fração da vazão de sangue é calculada a partir da vazão de sangue específica (por unidade de volume) dos tecidos $\left(\hat{\dot{V}}_{s v}\right)$ que fazem parte do compartimento em questão. A vazão de sangue no compartimento pequeno vaso $i$ é igual a:

$$
\dot{V}_{s v(i)}=\int_{V_{t(i)}} \hat{\dot{V}}_{s v} \mathrm{~d} V_{t(i)}
$$

sendo: $\dot{V}_{s v(i)}=$ vazão de sangue que passa pelo compartimento pequeno vaso $i\left[\mathrm{~m}^{3} / \mathrm{s}\right]$;

$V_{t(i)}=$ volume do compartimento pequeno vaso e tecidual $\left[\mathrm{m}^{3}\right]$.

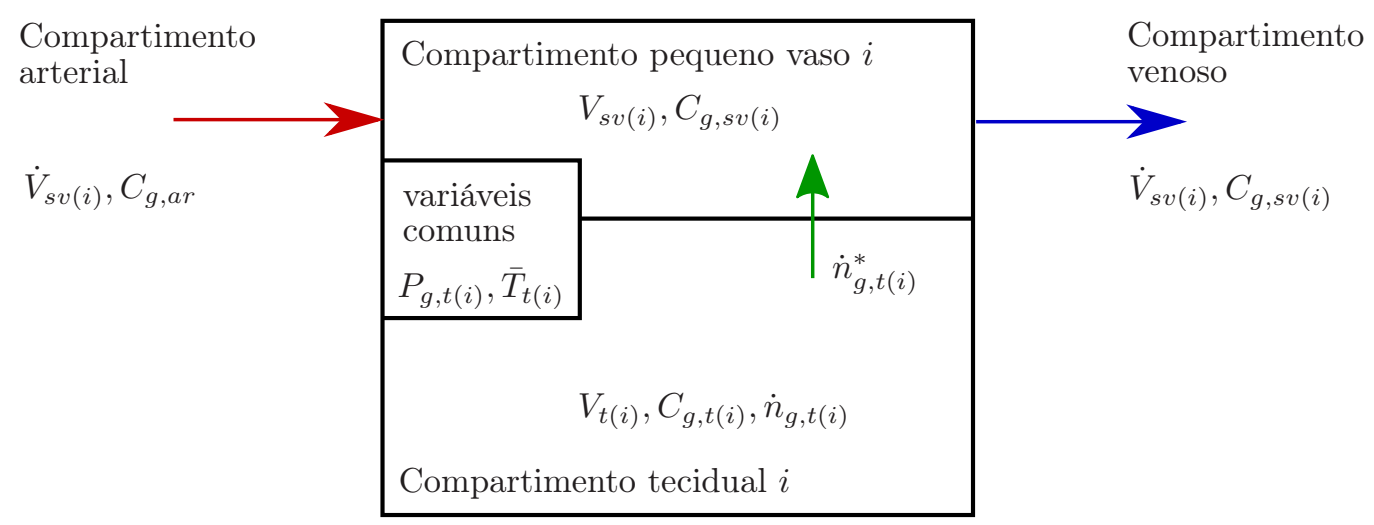

Figura 6.8 - Compartimentos pequeno vaso e tecido

A vazão de sangue que sai do compartimento arterial para os tecidos $\left(\dot{V}_{s v}\right)$, e chega no compartimento venoso, é a soma das vazões de cada compartimento pequeno vaso. É igual a:

$$
\dot{V}_{s v}=\sum_{i=1}^{N_{t c}} \dot{V}_{s v(i)}
$$

sendo: $N_{t c}=$ quantidade de compartimentos teciduais em um segmento.

O sangue no interior do compartimento pequeno vaso $i$ tem concentração do gás $g$ representada por $C_{g, s v(i)}$. Na saída do compartimento, a concentração é a mesma do compartimento, já que este é considerado uniforme. A vazão de sangue na saída é igual a vazão de sangue na entrada.

Saindo do compartimento pequeno vaso, o sangue se mistura com o sangue que sai dos outros compartimentos pequenos vasos e segue para o compartimento venoso. A concentração do gás $g$ no sangue que chega no compartimento venoso $\left(C_{g, s v}\right)$, vindo dos 
compartimentos pequenos vasos, é uma média ponderada da concentração na saída de cada compartimento pequeno vaso $\left(C_{g, s v(i)}\right)$, igual a:

$$
C_{g, s v}=\frac{1}{\dot{V}_{s v}} \sum_{i=1}^{N_{t c}} \dot{V}_{s v(i)} C_{g, s v(i)}
$$

sendo: $C_{g, s v(i)}=$ concentração do gás $g$ que sai do compartimento pequeno vaso $i$ $\left[\mathrm{mol} / \mathrm{m}^{3}\right]$.

Além da vazão de sangue, o compartimento pequeno vaso realiza troca de gases com o compartimento tecidual. A vazão molar dos gases entre os dois compartimentos é representada por $\dot{n}_{g, t}^{*}$. O sentido da vazão no equacionamento segue a vazão de $\mathrm{CO}_{2}$; para o $\mathrm{O}_{2}$, o valor de $\dot{n}_{g, t}^{*}$ é negativo. A seguinte equação expressa a variação da concentração dos gases no compartimento pequeno vaso $i$ :

$$
V_{s v(i)} \frac{\mathrm{d} C_{g, s v(i)}}{\mathrm{d} t}=\dot{V}_{s v(i)}\left(C_{g, a r}-C_{g, s v(i)}\right)+\dot{n}_{g, t}^{*}
$$

sendo: $\dot{n}_{g, t}^{*}=$ vazão do gás $g$ entre os compartimentos tecidual e pequeno vaso $[\mathrm{mol} / \mathrm{s}]$.

O primeiro membro da equação representa a variação da concentração no tempo. No segundo membro, o primeiro termo representa a passagem de sangue e o segundo termo a troca de gás com o compartimento tecidual.

No compartimento tecidual, além da troca de gases com o compartimento pequeno vaso $\left(\dot{n}_{g, t}^{*}\right)$, ocorre o metabolismo. Nos tecidos, o $\mathrm{O}_{2}$ é consumido com taxa $\dot{n}_{O_{2}, t}$ e o $\mathrm{CO}_{2}$ é produzido com taxa $\dot{n}_{\mathrm{CO}_{2}, t}$. No equacionamento, como o sentido seguido é o do $\mathrm{CO}_{2}$, $\dot{n}_{O_{2}, t}$ é negativo. A variação da concentração do gás $g$ no compartimento tecidual ao longo do tempo é representada pela seguinte equação:

$$
V_{t(i)} \frac{\mathrm{d} C_{g, t(i)}}{\mathrm{d} t}=\dot{n}_{g, t}-\dot{n}_{g, t}^{*}
$$

sendo: $V_{t(i)}=$ volume do compartimento tecidual $i\left[\mathrm{~m}^{3}\right]$;

$C_{g, t(i)}=$ concentração do gás $g$ no compartimento tecidual $i\left[\mathrm{~mol} / \mathrm{m}^{3}\right]$;

$\dot{n}_{g, t}=$ taxa de metabolismo do gás $g$ no compartimento tecidual $i[\mathrm{~mol} / \mathrm{s}]$.

O primeiro membro da equação representa a variação da concentração dos gases nos tecidos. O segundo membro representa a diferença entre o gás gerado e o que sai para o compartimento pequeno vaso.

Somando a eq.(6.18) com a eq.(6.19) chega-se a seguinte relação:

$$
V_{s v(i)} \frac{\mathrm{d} C_{g, s v(i)}}{\mathrm{d} t}+V_{t(i)} \frac{\mathrm{d} C_{g, t(i)}}{\mathrm{d} t}=\dot{V}_{s v(i)}\left(C_{g, a r}-C_{g, s v(i)}\right)+\dot{n}_{g, t}
$$


No modelo foi feita uma simplificação quanto à difusão dos gases nos compartimentos pequeno vaso e tecidual. A pressão parcial de cada gás é considerada igual nos compartimentos. Com isso, a expressão acima pode ser rescrita em função da variação da pressão parcial dos gases nos compartimentos $\left(P_{g, t(i)}\right)$, desprezando a segunda derivada da concentração em relação à pressão parcial e a derivada da concentração de um gás em relação a pressão parcial do outro e da temperatura. A variação da pressão parcial do gás $g$ nos pequenos vasos e tecido é igual a:

$$
\left(V_{s v(i)} \frac{\mathrm{d} C_{g, s v(i)}}{\mathrm{d} P_{t(i)}}+V_{t(i)} \frac{\mathrm{d} C_{g, t(i)}}{\mathrm{d} P_{t(i)}}\right) \frac{\mathrm{d} P_{t(i)}}{\mathrm{d} t}=\dot{V}_{s v(i)}\left(C_{g, a r}-C_{g, s v(i)}\right)+\dot{n}_{g, t}
$$

sendo: $P_{t(i)}=$ pressão parcial do gás $g$ nos compartimentos pequeno vaso e tecidual [Pa].

O primeiro membro representa a variação da pressão parcial dos gases no tempo do compartimento pequeno vaso e tecidual. No segundo membro, o primeiro termo representa a passagem de sangue, e o segundo termo representa a produção ou consumo dos gases devido ao metabolismo.

A produção de $\mathrm{CO}_{2}$ e o consumo de $\mathrm{O}_{2}$ são determinados em função da geração de calor metabólica $\left(\hat{\dot{q}}_{t}\right)$ e do quociente respiratório $(R Q)$. Ambos os parâmetros dependem do tipo de tecido. A relação entre estes parâmetros foi descrita no Capítulo 4. Valores da geração de calor nos tecidos foram apresentados na seção anterior. Já para o quociente respiratório, foi considerado o valor de 1,0 para o cérebro, 0,71 para a gordura e 0,85 para os outros tecidos (BROBECK, 1974b). Usando esses valores, chega-se ao quociente respiratório do corpo todo de 0,822 .

As relações entre as concentrações dos gases no sangue e nos tecidos com as suas pressões parciais e temperatura são calculadas a partir de diversas equações apresentadas no Capítulo 3 para o sangue e no Capítulo 4 para os tecidos. Estas relações são também utilizadas para a determinação das derivadas da concentração em relação à pressão parcial.

A temperatura é considerada ser a mesma no compartimento pequeno vaso e tecidual de índice $i$, representada por $\bar{T}_{t(i)}$. É calculada a partir de uma média ponderada das temperaturas dos tecidos representados por estes compartimentos - calculadas a partir da equação de condução de calor nos tecidos, eq.(6.12). Como essas temperaturas representam tecidos com as mesmas características, a temperatura média do compartimento $i$ pode ser calculada pela seguinte equação:

$$
\bar{T}_{t(i)}=\frac{1}{V_{t(i)}} \int_{V_{t(i)}} T_{t} \mathrm{~d} V_{t(i)}
$$

sendo: $\bar{T}_{t(i)}=$ temperatura média do compartimento pequeno vaso e tecidual $i\left[{ }^{\circ} \mathrm{C}\right]$. 


\subsection{Modelagem da transferência de massa no pulmão}

Para representar o transporte dos gases $\mathrm{O}_{2}$ e $\mathrm{CO}_{2}$ no pulmão, que inclui o processo de difusão pulmonar, o espaço alveolar, os capilares pulmonares e os tecidos pulmonares são representados por compartimentos. A Figura 6.9 mostra uma representação do pulmão.

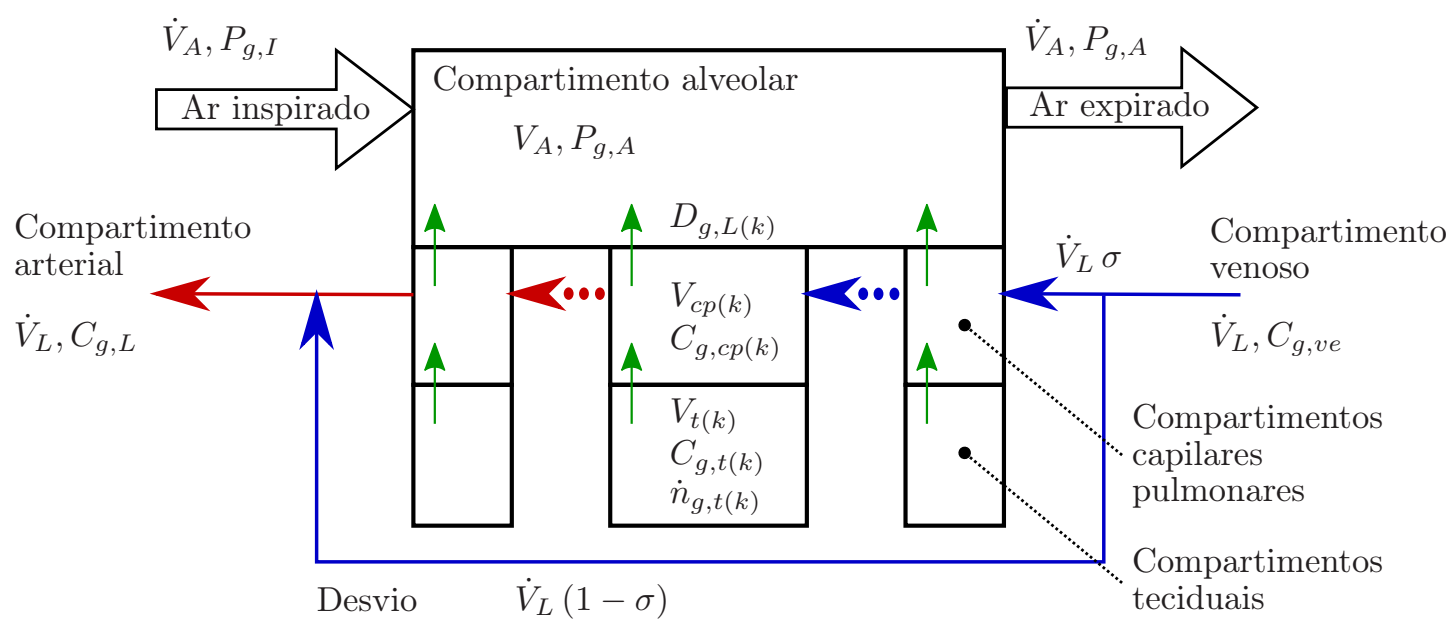

Figura 6.9-Compartimentos alveolar e capilares pulmonares

O compartimento alveolar liga o corpo humano com o ar externo. Representa o gás encontrado nos alvéolos do pulmão. Através do compartimento alveolar passa uma vazão de ar, conhecida por ventilação alveolar. A entrada de ar é resultado da inspiração após ser umidificado pelo espaço morto. O ar expirado representa a saída que, por ser uniforme, possui a mesma composição do ar nos alvéolos. Outro processo existente no compartimento é a transferência de gases por difusão com os compartimentos capilares pulmonares através da membrana respiratória.

O sangue que entra nos capilares pulmonares vem do compartimento venoso. Nem todo o sangue é oxigenado no pulmão (uma parte é desviada fisicamente e outra não realiza trocas gasosas). A parte desviada corresponde a aproximadamente $2 \%$ da vazão de sangue. A parcela da vazão de sangue que passa pelos capilares pulmonares realizando trocas gasosas é representada por $\sigma$, e a parcela desviada por $1-\sigma$.

Os capilares pulmonares são representados por diversos compartimentos em série. Cada compartimento está conectado com um compartimento tecidual, onde o $\mathrm{O}_{2}$ é consumido e o $\mathrm{CO}_{2}$ gerado. A mesma metodologia usada na relação entre pequenos vasos e tecidos, descrita na última seção, será usada entre compartimentos capilares pulmonares e teciduais. Embora a consideração de compartimentos teciduais no pulmão não seja comum em modelos do sistema respiratório, é necessária para que os balanços de energia estejam coerentes com os balanços de massa. 
Por cada compartimento capilar pulmonar percorre o sangue não desviado do pulmão. Sangue venoso entra no primeiro compartimento. Depois, o sangue segue para os próximos capilares pulmonares realizando transferência dos gases com o compartimento alveolar. O motivo de se utilizar diversos compartimentos é a não uniformidade da concentração dos gases conforme passam pelos capilares. Por exemplo, para o caso do $\mathrm{O}_{2}$, em situações normais, o sangue satura totalmente ao passar pelo primeiro terço dos capilares. Já para situações mais críticas, como a falta de $\mathrm{O}_{2}$, o sangue demora mais tempo para ser saturado.

O cálculo da transferência de calor no pulmão segue procedimento similar aos outros tecidos, a partir da equação de condução de calor (Seção 6.6.1).

\subsubsection{Inspiração}

$\mathrm{O}$ ar ao passar pelo espaço morto se umidifica totalmente. Na temperatura corporal de $37^{\circ} \mathrm{C}$ a pressão de vapor-d'água $\left(P_{w}\right)$ é igual a $47 \mathrm{mmHg}(6281 \mathrm{~Pa}$ ) (ASHRAE, 2005). Isto significa que a pressão total dos gases inspirados ao chegar nos alvéolos será igual a pressão barométrica menos $47 \mathrm{mmHg}$. De uma forma geral, pode-se escrever para qualquer gás $g$, fração no ar inspirado $F_{g, I}$ e pressão de vapor-d'água $P_{w}$ :

$$
P_{g, I}=f_{g, I}\left(P_{b a r}-P_{w}\right)
$$

sendo: $P_{g, I}=$ pressão parcial do gás $g$ inspirada $[\mathrm{Pa}]$;

$f_{g, I}=$ fração do gás $g$ no ar inspirado [0-1];

$P_{b a r}=$ pressão barométrica $[\mathrm{Pa}]$;

$P_{w}=$ pressão de vapor-d'água $[\mathrm{Pa}]$.

Para o nível do mar, onde a pressão barométrica $\left(P_{b a r}\right)$ é igual a $760 \mathrm{mmHg}$, a pressão parcial de $\mathrm{O}_{2}$ inspirada é igual a $149 \mathrm{mmHg}$. Em altitudes elevadas a proporção entre os gases continua a mesma, mas como a pressão barométrica diminui a pressão parcial de $\mathrm{O}_{2}$ inspirado também diminui, causando a falta de $\mathrm{O}_{2}$ no sangue e consequentemente nos tecidos. A 63000 pés (19202 m) de altura a pressão barométrica é igual a $47 \mathrm{mmHg}$, ficando o pulmão completamente preenchido de vapor-d'água.

\subsubsection{Compartimento alveolar}

Pelo compartimento alveolar passa uma vazão de ar chamada de ventilação alveolar $\left(\dot{V}_{A}\right)$. A condição do ar na entrada está definida na seção anterior. Na saída, como a composição do compartimento é uniforme, a pressão parcial é igual a própria pressão do compartimento $\left(P_{g, A}\right)$. 
Além da vazão de ar, o compartimento alveolar realiza troca de gases por difusão com os compartimentos capilares pulmonares. Em condições normais, o $\mathrm{O}_{2}$ passa do compartimento alveolar para os capilares pulmonares e o $\mathrm{CO}_{2}$, produzido pelo corpo, vai dos capilares pulmonares ao compartimento alveolar.

A troca dos gases por difusão pela membrana respiratória é representada pelo coeficiente de difusão $\left(D_{g, L}\right)$ vezes a diferença entre as pressões parciais no compartimento alveolar e de cada compartimento capilar pulmonar $\left(P_{g, c p(k)}\right)$.

A variação da pressão parcial dos gases no compartimento alveolar $\left(P_{g, A}\right)$ ao longo do tempo, considerando que todos os volumes estão na norma STPD, é representada pela seguinte equação:

$$
V_{A} \frac{\mathrm{d} P_{g, A}}{\mathrm{~d} t}=\dot{V}_{A} \frac{P_{b a r}}{P_{b a r, 0}}\left(P_{g, I}-P_{g, A}\right)+\beta_{g} P_{b a r} \sum_{k=1}^{N_{c p}} D_{g, L(k)}\left(P_{g, c p(k)}-P_{g, A}\right)
$$

sendo: $V_{A}=$ volume do compartimento alveolar $\left[\mathrm{m}^{3}, \mathrm{STPD}\right]$;

$P_{g, A}=$ pressão parcial do gás $g$ alveolar $[\mathrm{Pa}] ;$

$\dot{V}_{A}=$ ventilação alveolar, $\left[\mathrm{m}^{3} / \mathrm{s}, \mathrm{STPD}\right]$;

$P_{g, I}=$ pressão parcial do gás $g$ inspirada $[\mathrm{Pa}]$;

$\beta_{g}=$ correção do gás $g$ de número de mols para volume (STPD),

$\beta_{\mathrm{O}_{2}}=0,0224 \mathrm{~m}^{3} / \mathrm{mol}$ e $\beta_{C O_{2}}=0,02226 \mathrm{~m}^{3} / \mathrm{mol}$;

$P_{b a r}=$ pressão barométrica $[\mathrm{Pa}]$;

$P_{b a r, 0}=$ pressão barométrica ao nível do mar [Pa];

$k=$ número do compartimento capilar pulmonar $\left[1-N_{c p}\right]$;

$N_{c p}=$ quantidade de compartimentos capilares pulmonares

$D_{g, L(k)}=$ coeficiente de difusão do gás $g$ pela membrana respiratória no compartimento capilar pulmonar $k[\mathrm{~mol} /(\mathrm{s} . \mathrm{Pa})]$;

$P_{g, c p(k)}=$ pressão parcial do gás $g$ no compartimento capilar pulmonar $k[\mathrm{~Pa}]$.

O primeiro membro representa a variação da pressão parcial dos gases no tempo. O primeiro termo do segundo membro representa a ventilação. O último termo da equação representa a difusão dos gases através da membrana respiratória.

O valor do coeficiente de difusão é considerado constante em todos os compartimentos capilares pulmonares. Seu valor entre cada um dos compartimentos capilares pulmonares e o compartimento alveolar $\left(D_{g, L(k)}\right)$ é função do coeficiente de difusão total (detalhado no Capítulo 5):

$$
D_{g, L(k)}=D_{g, L} / N_{c p}
$$

sendo: $D_{g, L}=$ coeficiente de difusão do gás $g$ pela membrana respiratória $[\mathrm{mol} /(\mathrm{s} . \mathrm{Pa})]$. 


\subsubsection{Compartimentos capilares pulmonares}

Cada compartimento capilar pulmonar realiza três processos de troca de gases: passagem de sangue, difusão pela membrana respiratória e difusão com o compartimento tecidual. Os compartimentos estão dispostos em série. As condições do sangue na saída de um compartimento são iguais às condições do sangue na entrada do próximo. A entrada do primeiro compartimento é de sangue venoso $\left(C_{g, c p(0)}=C_{g, v e}\right)$. O sangue passa pelos compartimentos com vazão $\dot{V}_{L} \sigma$, onde $\sigma$ representa a fração de sangue não desviada do pulmão.

A difusão pela membrana respiratória é representada pelo coeficiente de difusão $D_{g, L(k)}$, multiplicado pelo gradiente de pressão parcial do gás entre os alvéolos $\left(P_{g, A}\right)$ e o compartimento capilar pulmonar atual $\left(P_{g, c p(k)}\right)$.

Assim como os outros tipos de tecidos, a pressão parcial de um gás é considerada a mesma nos compartimentos capilares pulmonares e teciduais ligados por difusão $\left(P_{g, c p(k)}\right)$. Nos compartimentos teciduais, ocorre geração de $\mathrm{CO}_{2}$ e consumo de $\mathrm{O}_{2}\left(\dot{n}_{g, t}\right)$.

O volume de cada compartimento capilar pulmonar está relacionado com o volume total destes compartimentos pela seguinte equação:

$$
V_{c p(k)}=V_{c p} / N_{c p}
$$

sendo: $V_{c p(k)}=$ volume do compartimento capilar pulmonar $k\left[\mathrm{~m}^{3}\right]$;

$V_{c p}=$ volume de sangue nos capilares pulmonares $\left[\mathrm{m}^{3}\right]$.

Do mesmo modo, o volume de cada compartimento tecidual é igual a:

$$
V_{t(k)}=V_{t} / N_{c p}
$$

sendo: $V_{t(k)}=$ volume do compartimento tecidual $k\left[\mathrm{~m}^{3}\right]$;

$V_{t}=$ volume de tecido no pulmão $\left[\mathrm{m}^{3}\right]$.

O volume dos tecidos pulmonares é igual a $161 \mathrm{ml}$. Foi calculado a partir do volume total de pulmão de $2481 \mathrm{ml}$ (Tabela 6.6), subtraído do volume alveolar - igual a $2180 \mathrm{ml}$ (LAMBERTSEN, 1974c) - e do volume de sangue nos capilares pulmonares - igual a 140 ml (LAMBERTSEN, 1974a).

A seguinte equação representa a variação da concentração do gás $g$ nos compartimentos capilares pulmonares ao longo do tempo:

$$
\begin{aligned}
& \left(V_{c p(k)} \frac{\mathrm{d} C_{g, c p(k)}}{\mathrm{d} P_{c p(k)}}+V_{t(k)} \frac{\mathrm{d} C_{g, t(k)}}{\mathrm{d} P_{c p(k)}}\right) \frac{\mathrm{d} P_{c p(k)}}{\mathrm{d} t} \\
& =\dot{V}_{L} \sigma\left(C_{g, c p(k-1)}-C_{g, c p(k)}\right)+D_{g, L(k)}\left(P_{g, A}-P_{c p(k)}\right)+\dot{n}_{g, t(k)}
\end{aligned}
$$


sendo: $C_{g, c p(k)}=$ concentração do gás $g$ no compartimento capilar pulmonar $k\left[\mathrm{~mol} / \mathrm{m}^{3}\right]$;

$P_{g, c p(k)}=$ pressão parcial do gás $g$ no compartimento capilar pulmonar $k[\mathrm{~Pa}]$;

$C_{g, t(k)}=$ concentração do gás $g$ no compartimento tecidual $k\left[\mathrm{~mol} / \mathrm{m}^{3}\right]$;

$\sigma=$ fração de sangue que passa pelo pulmão [0-1];

$\dot{n}_{g, t(k)}=$ taxa de metabolismo do gás $g$ no compartimento tecidual $k[\mathrm{~mol} / \mathrm{s}]$.

O primeiro membro representa a variação da pressão parcial no tempo. No segundo membro, o primeiro termo representa a passagem de sangue, o segundo a difusão com o compartimento alveolar e o terceiro a geração ou consumo do gás.

O sangue que sai do último compartimento capilar pulmonar se mistura com a parcela de sangue venoso que foi desviada do pulmão. A concentração do gás $g$ no sangue que chega no compartimento arterial é igual a:

$$
C_{g, L}=C_{g, c p\left(N_{c p}\right)} \sigma+C_{g, v e}(1-\sigma)
$$

\subsection{Modelagem da transferência de calor no trato res- piratório}

A transferência de calor e vapor-d'água na respiração ocorre ao longo do trato respiratório e no pulmão. Para determiná-las, esses locais foram representados por sete compartimentos (Figura 6.10). Os compartimentos são identificados por subíndices (1 a 7). O subíndice 0 é usado para representar o ar ambiente.

O primeiro (subíndice 1) está em contato com o ar ambiente e contém os gases da boca e faringe. O segundo (subíndice 2) contém os gases da traqueia. O terceiro (subíndice 3) contém os gases que estão desde os primeiros brônquios até o fim do espaço morto. Esses três primeiros compartimentos representam o caminho do ar durante a inspiração. Os últimos três compartimentos (subíndices 5, 6 e 7) representam esses mesmos espaços, porém, durante a expiração. Essa separação tem como objetivo simplificar a periodicidade da ventilação. Desta forma, a ventilação pelos compartimentos é contínua e sempre no mesmo sentido. O quarto compartimento (subíndice 4) representa o espaço alveolar.

Os gases presentes nos compartimentos e no ar ambiente são separados em uma parcela de ar seco e outra de vapor-d'água. Foram adotadas as seguintes hipóteses: gases perfeitos; pressão constante e igual a pressão barométrica; volume dos compartimentos constantes; variação de energia cinética e potencial nula.

Os compartimentos estão em contato com tecidos. Entre eles ocorre transferência de calor por convecção e evaporação de água. A adequação destes compartimentos com a 


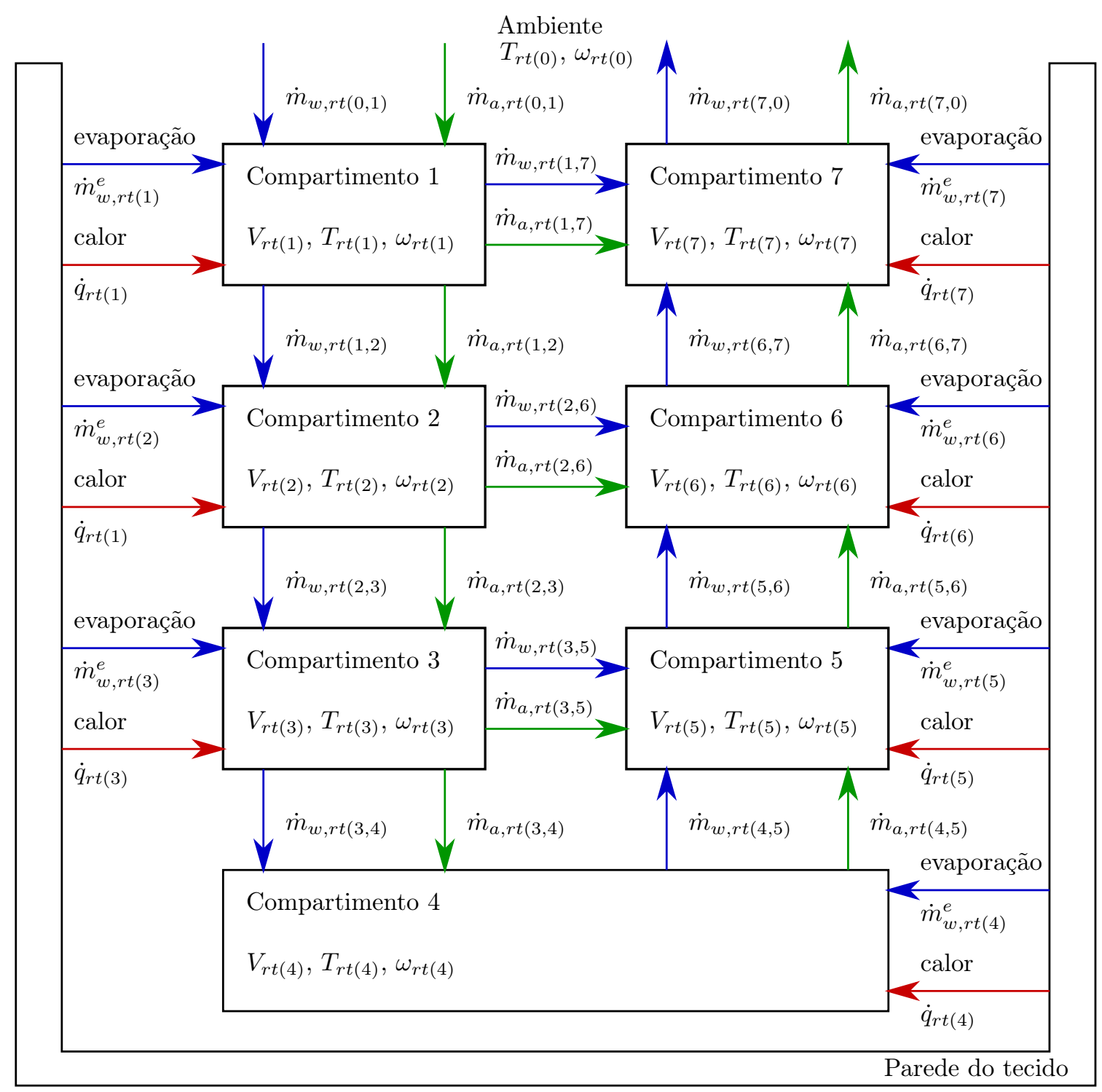

Figura 6.10 - Compartimentos do trato respiratório

geometria do modelo completo do corpo humano é feita ao considerar que o primeiro e o último compartimento (subíndices 1 e 7) estão em contato com o músculo da cabeça; o segundo e o penúltimo (subíndices 2 e 6) com o músculo do pescoço; e o terceiro, quarto e quinto (subíndices 3, 4 e 5) com o pulmão.

A vazão dos gases entre dois compartimentos - ou entre um compartimento e o ar ambiente - é divida em parcelas de ar seco e vapor-d'água. Para identificá-las, recebem os subíndices dos dois compartimentos, no sentido da vazão. Supondo que a vazão ocorra do compartimento $i$ ao $j$, a vazão dos gases é igual a:

$$
\dot{m}_{r t(i, j)}=\dot{m}_{a, r t(i, j)}+\dot{m}_{w, r t(i, j)}
$$

sendo: $\dot{m}_{r t(i, j)}=$ vazão de ar seco e vapor-d'água entre os compartimentos $i$ e $j[\mathrm{~kg} / \mathrm{s}]$; $\dot{m}_{a, r t(i, j)}=$ vazão de ar seco entre os compartimentos $i$ e $j[\mathrm{~kg} / \mathrm{s}]$; 
$\dot{m}_{w, r t(i, j)}=$ vazão de vapor-d'água entre os compartimentos $i$ e $j[\mathrm{~kg} / \mathrm{s}]$.

A determinação da vazão de ar seco entre os compartimentos tem como base a relação entre a ventilação alveolar e o volume minuto respiratório, descrito na Seção 5.5. Seguindo o mesmo princípio, as relações das vazões entre os compartimentos e o volume minuto respiratório são:

$$
\begin{aligned}
& \dot{V}_{a, r t(3,4)}=\dot{V}_{a, r t(4,5)}=\frac{V_{T}-\left(V_{r t(1)}+V_{r t(2)}+V_{r t(3)}\right)}{V_{T}} \dot{V}_{E}=\dot{V}_{A} \\
& \dot{V}_{a, r t(2,3)}=\dot{V}_{a, r t(5,6)}=\frac{V_{T}-\left(V_{r t(1)}+V_{r t(2)}\right)}{V_{T}} \dot{V}_{E} \\
& \dot{V}_{a, r t(1,2)}=\dot{V}_{a, r t(6,7)}=\frac{V_{T}-V_{r t(1)}}{V_{T}} \dot{V}_{E} \\
& \dot{V}_{a, r t(0,1)}=\dot{V}_{a, r t(7,0)}=\dot{V}_{E}
\end{aligned}
$$

sendo: $\dot{V}_{a, r t(i, j)}=$ vazão de ar seco entre os compartimentos $i$ e $j\left[\mathrm{~m}^{3} / \mathrm{s}\right]$;

$V_{T}=$ volume corrente $\left[\mathrm{m}^{3}\right]$;

$V_{r t(i)}=$ volume do compartimento do trato respiratório $i\left[\mathrm{~m}^{3}\right]$;

$\dot{V}_{E}=$ volume minuto respiratório $\left[\mathrm{m}^{3} / \mathrm{s}\right]$.

Os valores da ventilação usados nas equações da transferência de massa no pulmão, descritas na seção anterior, estão em STPD. Para determinar a vazão mássica (em kg/s) a partir da volumétrica (em m³ $/ \mathrm{s}$, STPD), multiplica-se este por $1,275 \times 10^{-5} P_{b a r}$. Já para relacionar a quantidade de ar seco e vapor-d'água na ventilação, considera-se que essa é a ventilação expirada - que é normalmente a medida em experimentos -, e usa-se a umidade absoluta do último compartimento $\left(\omega_{r t(7)}\right)$.

Os volumes e áreas superficiais dos compartimentos foram obtidos a partir de diversos autores. Os valores estão na Tabela 6.7. As áreas superficiais dos compartimentos (com exceção do quarto) foram calculadas a partir dos diâmetros, comprimentos e número de ramos dos dutos. O total da área para cada local foi dividido entre os dois compartimentos que o representam.

Tabela 6.7 - Características dos compartimentos usados para cálculo da transferência de calor no trato respiratório

\begin{tabular}{cccl}
\hline Compartimento & Volume $\left[\mathrm{cm}^{3}\right]$ & Área superficial $\left[\mathrm{m}^{2}\right]$ & Referência \\
\hline 1 e 7 & 22,0 & 0,00440 & Olson, Dart e Filley (1970) \\
2 e 6 & 30,5 & 0,00679 & Olson, Dart e Filley (1970) \\
3 e 4 & 103,5 & 0,595 & Fowler (1948), Olson, Dart e Filley (1970) \\
5 & 2180 & 70 & Lambertsen (1974c) \\
\hline
\end{tabular}

A variação da umidade absoluta nos compartimentos é obtida a partir de balanços de massa do vapor-d'água. Os balanços consideram as vazões de vapor-d'água entre os com- 
partimentos e com o ambiente, e o vapor-d'água proveniente do processo de evaporação nas paredes. Em uma forma geral, a variação da umidade absoluta no compartimento $i$ é igual a:

$$
m_{a, r t(i)} \frac{\mathrm{d} \omega_{r t(i)}}{\mathrm{d} t}=\dot{m}_{w, r t(i)}^{i n}-\dot{m}_{w, r t(i)}^{o u t}+\dot{m}_{w, r t(i)}^{e}
$$

sendo: $m_{a, r t(i)}=$ massa de ar seco no compartimento $i[\mathrm{~kg}]$;

$\omega_{r t(i)}=$ umidade absoluta no compartimento $i[\mathrm{~kg} / \mathrm{kg}] ;$

$\dot{m}_{w, r t(i)}^{i n}=$ vazão de vapor-d'água que entra no compartimento $i[\mathrm{~kg} / \mathrm{s}]$;

$\dot{m}_{w, r t(i)}^{\text {out }}=$ vazão de vapor-d'água que sai do compartimento $i[\mathrm{~kg} / \mathrm{s}]$;

$\dot{m}_{w, r t(i)}^{e}=$ vazão de vapor-d'água da evaporação no compartimento $i[\mathrm{~kg} / \mathrm{s}]$.

A vazão de vapor-d'água que entra no compartimento $i$ é igual a:

$$
\dot{m}_{w, r t(i)}^{i n}= \begin{cases}\dot{m}_{a, r t(i-1, i)} \omega_{r t(i-1)} & \text { se } i \leq \frac{N_{r t}+1}{2} \\ \dot{m}_{a, r t(i-1, i)} \omega_{r t(i-1)}+\dot{m}_{a, r t\left(N_{r t}-i+1, i\right)} \omega_{r t\left(N_{r t}-i+1\right)} & \text { se } i>\frac{N_{r t}+1}{2}\end{cases}
$$

sendo: $N_{r t}=$ quantidade de compartimentos do trato respiratório.

A vazão de vapor-d'água que sai do compartimento $i$ é igual a:

$$
\dot{m}_{w, r t(i)}^{\text {out }}= \begin{cases}\left(\dot{m}_{a, r t(i, i+1)}+\dot{m}_{a, r t\left(i, N_{r t}-i+1\right)}\right) \omega_{r t(i)} & \text { se } i<\frac{N_{r t}+1}{2} \\ \dot{m}_{a, r t(i, i+1)} \omega_{r t(i)} & \text { se } i \geq \frac{N_{r t}+1}{2}\end{cases}
$$

A vazão de vapor-d'água gerada pelo processo de evaporação, dos tecidos para o compartimento, é representada por um processo de difusão proporcional à diferença entre a umidade absoluta com o ar saturado - na temperatura do compartimento - e a umidade absoluta do compartimento:

$$
\dot{m}_{w, r t(i)}^{e}=D_{r t} A_{r t(i)}\left(\omega_{s a t, r t(i)}-\omega_{r t(i)}\right)
$$

sendo: $D_{r t}=$ coeficiente de difusão na parede do trato respiratório $\left[\mathrm{kg} /\left(\mathrm{m}^{2} . \mathrm{s}\right)\right]$;

$A_{r t(i)}=$ área da parede do compartimento $i\left[\mathrm{~m}^{2}\right]$;

$\omega_{\text {sat }, r t(i)}=$ umidade absoluta com o ar saturado no compartimento $i[\mathrm{~kg} / \mathrm{kg}]$.

A determinação da variação de temperatura em cada compartimento é obtida aplicando balanços de energia. Inclui as vazões de ar seco e de vapor-d'água entre compartimentos e com o ambiente, o calor trocado por convecção com os tecidos e o calor da evaporação da água. Para simplificar a equação, os calores específicos do ar seco e do vapor-d'água foram combinados do seguinte modo:

$$
c_{r t(i)}=\omega_{r t(i)} c_{w}+c_{a}
$$


sendo: $c_{r t(i)}=$ calor específico do ar seco e vapor-d'água no compartimento $i\left[\mathrm{~J} /\left(\mathrm{kg} .{ }^{\circ} \mathrm{C}\right)\right]$; $c_{w}=$ calor específico do vapor-d'água $\left[\mathrm{J} /\left(\mathrm{kg} .{ }^{\circ} \mathrm{C}\right)\right]$;

$c_{a}=$ calor específico do ar seco $\left[\mathrm{J} /\left(\mathrm{kg} .{ }^{\circ} \mathrm{C}\right)\right]$.

Os calores específicos são considerados constantes e iguais a 1872,3 J/(kg.K) para o vapor d'água e 1003,5 J/(kg.K) para o ar (VAN WYLEN; SONNTAG; BORGNAKKE, 1998).

A variação da temperatura no compartimento $i$ é obtida pela seguinte equação:

$$
m_{r t(i)} c_{r t(i)} \frac{\mathrm{d} T_{r t(i)}}{\mathrm{d} t}=\dot{E}_{r t(i)}^{i n}-\dot{E}_{r t(i)}^{o u t}-\dot{m}_{w, r t(i)}^{e} h_{l v, r t(i)}+\dot{q}_{r t(i)}
$$

sendo: $m_{r t(i)}=$ massa de ar seco e vapor-d'água no compartimento $i[\mathrm{~kg}]$;

$T_{r t(i)}=$ temperatura no compartimento $i\left[{ }^{\circ} \mathrm{C}\right]$;

$\dot{E}_{r t(i)}^{i n}=$ taxa de energia que entra no compartimento $i[\mathrm{~W}]$;

$\dot{E}_{r t(i)}^{o u t}=$ taxa de energia que sai do compartimento $i[\mathrm{~W}]$;

$h_{l v, r t(i)}=$ entalpia de vaporização da água no compartimento $i[\mathrm{~J} / \mathrm{kg}]$;

$\dot{q}_{r t(i)}=$ transferência de calor com a parede do compartimento $i$ [W].

A taxa de energia que entra com a vazão de ar no compartimento $i$ é igual a:

$$
\dot{E}_{r t(i)}^{i n}= \begin{cases}\dot{m}_{r t(i-1, i)} c_{r t(i-1)} T_{r t(i-1)} & \text { se } i \leq \frac{N_{r t}+1}{2} \\ \dot{m}_{r t(i-1, i)} c_{r t(i-1)} T_{r t(i-1)}+\dot{m}_{r t\left(N_{r t}-i+1, i\right)} c_{r t\left(N_{r t}-i+1\right)} T_{r t\left(N_{r t}-i+1\right)} & \text { se } i>\frac{N_{r t}+1}{2}\end{cases}
$$

A taxa de energia que sai com a vazão de ar do compartimento $i$ é igual a:

$$
\dot{E}_{r t(i)}^{o u t}= \begin{cases}\left(\dot{m}_{r t(i, i+1)}+\dot{m}_{r t\left(i, N_{r t}-i+1\right)}\right) c_{r t(i)} T_{r t(i)} & \text { se } i<\frac{N_{r t}+1}{2} \\ \dot{m}_{r t(i, i+1)} c_{r t(i)} T_{r t(i)} & \text { se } i \geq \frac{N_{r t}+1}{2}\end{cases}
$$

Os mecanismos de transferência de calor entre o tecido e o compartimento são agrupados e representados por:

$$
\dot{q}_{r t(i)}=U_{r t} A_{r t(i)}\left(T_{t(i)}-T_{r t(i)}\right)
$$

sendo: $U_{r t}=$ coeficiente de transferência de calor com a parede do trato respiratório $\left[\mathrm{W} /\left(\mathrm{m}^{2} \cdot{ }^{\circ} \mathrm{C}\right)\right]$

$T_{t(i)}=$ temperatura da parede do compartimento $i\left[{ }^{\circ} \mathrm{C}\right]$.

O valor do coeficiente de transferência de calor $\left(U_{r t}\right)$ foi considerado ser igual a $10 \mathrm{~W} /\left(\mathrm{m}^{2} \cdot{ }^{\circ} \mathrm{C}\right)$. Este valor é próximo dos valores calculados com os dados de Kandjov 
(2001) para diferentes ramos do trato respiratório. Já o valor do coeficiente de difusão nas paredes $\left(D_{r t}\right)$ foi obtido por tentativa e erro a fim de que o valor total de transferência de calor no trato respiratório - com a temperatura ambiente de $30{ }^{\circ} \mathrm{C}$, a interna de $37{ }^{\circ} \mathrm{C}$ e a pressão de vapor-d'água do ambiente de $8 \mathrm{mmHg}$ - seja igual a $14,7 \mathrm{~W}$ (HANSON, 1974). Como resultado, chegou-se ao valor para o coeficiente de difusão $D_{r t}$ de $3 \times 10^{-6} \mathrm{~kg} /\left(\mathrm{m}^{2} . \mathrm{s}\right)$. 



\section{Capítulo 7}

\section{Modelagem do Sistema Regulador}

O corpo humano tem diversos controladores com a função de manter a temperatura e as concentrações de $\mathrm{O}_{2}$ e $\mathrm{CO}_{2}$ em um nível adequado para seu funcionamento. Alguns desses estão diretamente ligados ao sistema respiratório. Outros estão ligados diretamente ao sistema térmico. Outros estão relacionados com os dois sistemas.

O sistema regulador do corpo humano é complexo e depende de várias variáveis. A metodologia utilizada para seu estudo é considerar somente as variáveis mais importantes, que levam a variações significativas no sensoriamento dos sinais e na forma de atuação dos controladores.

Os reguladores do sistema respiratório e térmico podem ser divididos em quatro sistemas de atuação: ventilação, circulação, metabolismo e sudorese. Os três primeiros destes sistemas são divididos em sistemas de controle específicos. A ventilação tem efeitos distintos da parte central do corpo humano e da periférica. A circulação é o sistema mais complexo. Pode ser divida em efeito químico na parte central e na parte periférica, efeito térmico na pele e no músculo e efeito da atividade física no músculo. O metabolismo varia com o calafrio e a atividade física.

A Figura 7.1 mostra um diagrama contendo as principais partes do sistema de regulação considerado neste trabalho. O modelo da transferência de calor e massa foi descrito no capítulo anterior. Como resultados, são obtidas as temperaturas e as concentrações dos gases ao longo do tempo. No corpo humano, essas variáveis são medidas por diferentes sensores. Os sinais destes foram agrupados em térmico, químico e muscular. Os atuadores, que recebem os sinais dos sensores, foram separados em metabolismo, circulação, ventilação e sudorese. O metabolismo e a sudorese foram descritos no Capítulo 4; a circulação no Capítulo 3; e a ventilação no Capítulo 5.

Devido à complexidade dos controladores do corpo humano, a metodologia usual para o desenvolvimento destes é simples. Controladores proporcionais são amplamente utilizados. Consideram como sinal erros (diferença entre uma variável e sua referência) ou ainda combinação de erros. 


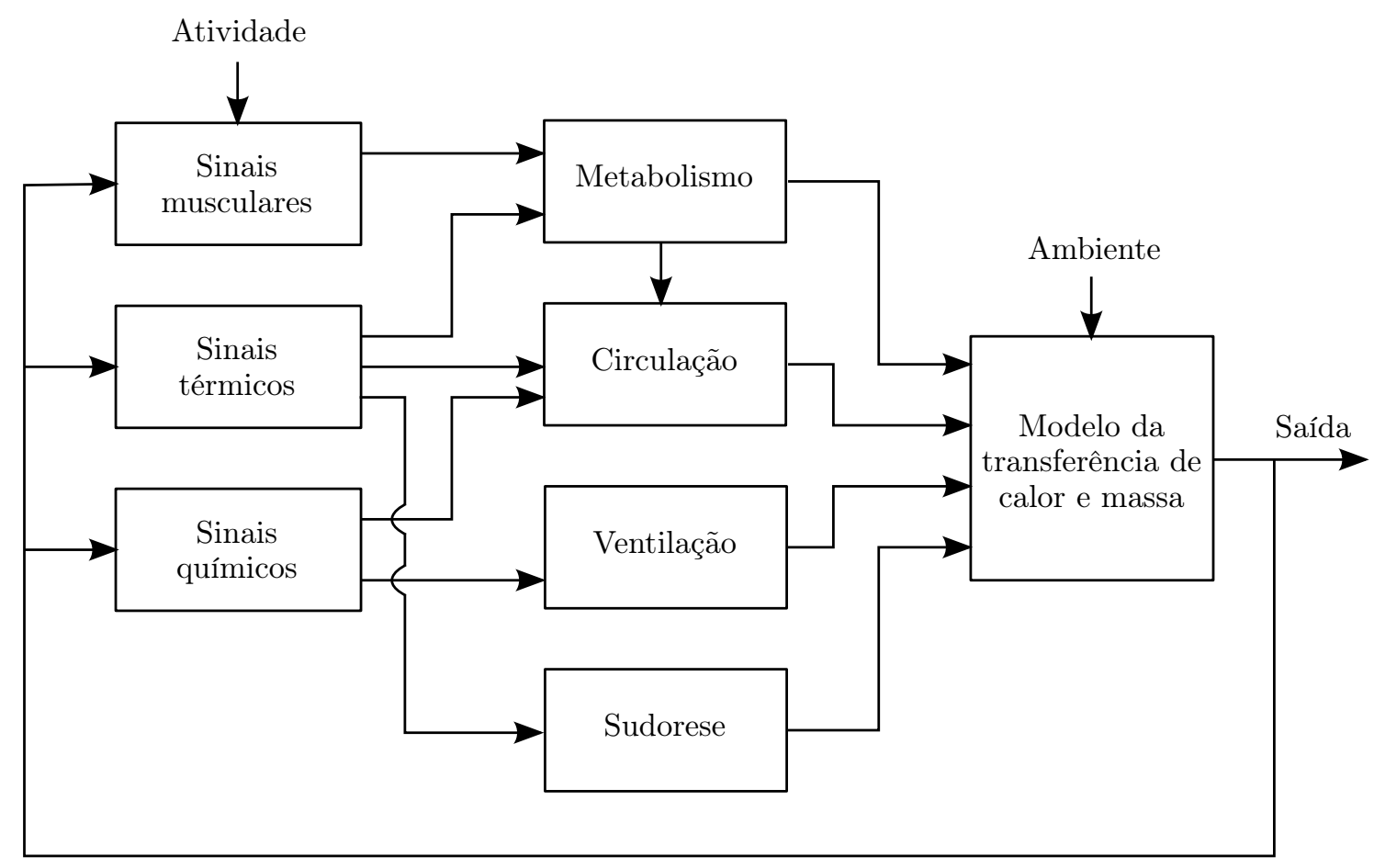

Figura 7.1 - Diagrama mostrando os reguladores e seus sinais

Para representar o sistema regulador do corpo humano, foram usados diversos modelos encontrados na literatura. Estes modelos foram introduzidos no Capítulo 2. Nas seções a seguir, são apresentados com mais detalhes e na forma com que foram usados no presente trabalho.

Na primeira seção, são descritos os sinais entre sensores, controladores e atuadores do sistema regulador. Nas outras seções, são apresentados os modelos de controle do metabolismo, circulação, ventilação e sudorese. Os conceitos fisiológicos do capítulo têm como base o livro de Guyton e Hall (2006) e os capítulos de Hardy e Bard (1974) e Lambertsen (1974b).

\subsection{Sinais}

\subsubsection{Sinais térmicos}

Os controladores do corpo humano estão relacionados com diferentes sensores dependendo de sua função. Quando atuam na regulação da temperatura (vazão de sangue na pele e no músculo, calafrio e sudorese), sensores estão localizados no hipotálamo e na pele. Estes sensores são formados por grupos de neurônios sensíveis à temperatura do sangue. Quando estimulados pela diminuição da temperatura, a vasoconstrição da pele e o tremor muscular são ativados. Além destes, o corpo ainda contém outros meios de elevar 
a temperatura que são desprezados no presente trabalho, como a estimulação simpática do metabolismo, a piloereção e a secreção do hormônio da tireóide. Quando os sensores são estimulados pelo aumento de temperatura, ocorre vasodilatação da pele, sudorese e respiração arfante. Esta última também será desprezada.

Nos modelos de controle do sistema térmico encontrados na literatura, é comum considerar como sensores a temperaturas interna e a temperatura média da pele $\left(\bar{T}_{s k}\right)$. Alguns modelos também incluem o uso da temperatura local da pele $\left(T_{s k(i)}\right)$. Como temperatura interna, utilizam a temperatura do hipotálamo, esôfago, reto ou tímpano. No presente trabalho, a temperatura do cérebro é considerada ser representativa da temperatura do hipotálamo $\left(T_{h y}\right)$. Esta será usada para representar a temperatura interna. Ao invés de utilizar a temperatura média da pele, alguns modelos consideram que os sensores da pele estão em quantidades diferentes em cada segmento (STOLWIJK; HARDY, 1966b; GORDON; ROEMER; HORVATH, 1976). A temperatura média da pele é, neste caso, ponderada em função da quantidade desses sensores. Esta última opção será usada no presente trabalho. Os fatores de ponderação para a cabeça, pescoço, tronco, braço, antebraço, mão, coxa, perna e pé são, respectivamente, iguais a 0,053, 0,0165, 0,4935, 0,02005, 0,01425, 0,09225, 0,04605, 0,0292 e 0,0167. Estes valores foram obtidos de Gordon, Roemer e Horvath (1976). Os valores do braço e do antebraço foram obtidos a partir do braço, ponderados pela área superficial; o da coxa e da perna a partir da perna do mesmo modo.

\subsubsection{Sinais químicos}

O local onde se encontram os quimiorreceptores relacionados com a regulação da ventilação é chamado de centro respiratório. Está localizado na substância reticular do bulbo raquidiano. Os quimiorreceptores são sensíveis à concentração de íons hidrogênio (pH) e ao oxigênio. $\mathrm{O} \mathrm{CO}_{2}$ atua nos sensores ao reagir com a água formando íons bicarbonatos

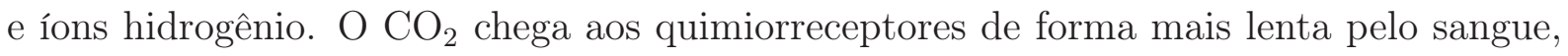
ou de forma mais rápida por difusão no líquido cefalorraquidiano. No caso do $\mathrm{O}_{2}$, as informações chegam aos quimiorreceptores pelo sangue.

Os modelos de controle da ventilação mais recentes separam os efeitos da parte central dos efeitos da parte periférica. A parte central é somente sensível ao $\mathrm{CO}_{2}$, enquanto a parte periférica é sensível ao $\mathrm{CO}_{2}$ e ao $\mathrm{O}_{2}$. É comum alguns modelos incluírem um compartimento para representar o líquido cefalorraquidiano, utilizando os sinais deste como origem do efeito da parte central. Outros ainda usam a quantidade de $\mathrm{CO}_{2}$ no tecido cerebral. Esta será a opção utilizada no presente trabalho. Outra questão é a escolha de qual variável é usada para representar o $\mathrm{CO}_{2}$ e $\mathrm{O}_{2}$. Para o $\mathrm{CO}_{2}$, é comum o uso da $P_{\mathrm{CO}_{2}}$ ou a concentração de íons hidrogênio $\left(\left[H^{+}\right]\right)$. No caso do $\mathrm{O}_{2}$, é comum 
o uso da $P_{\mathrm{O}_{2}}$ ou da saturação de $\mathrm{O}_{2}\left(S_{\mathrm{O}_{2}}\right)$. Neste trabalho, os sinais utilizados como representativos dos sensores são as pressões parciais de $\mathrm{CO}_{2}$ do cérebro $\left(P_{C O_{2}, b r}\right)$ e do sangue arterial $\left(P_{C_{2}, a r}\right)$ e a saturação de $\mathrm{O}_{2}$ do sangue arterial $\left(S_{C O_{2}, a r}\right)$. A composição do sangue arterial é uma média ponderada pelo volume dos compartimentos arteriais de todos os segmentos.

A regulação da vazão de sangue nos tecidos ocorre principalmente pela deficiência de $\mathrm{O}_{2}$. Esta deficiência resulta na variação do diâmetro das arteríolas, assim como ocorre na pele caso ocorra variação de temperatura. A variação da circulação de sangue está relacionada tanto com o sistema respiratório como com o térmico. Sua determinação depende da integração de diversos efeitos, que podem ser separados em: efeito químico, efeito térmico e efeito do metabolismo. O efeito químico pode ainda ser separado em parte central, com atuação no cérebro, e parte periférica, com atuação em todos os outros tecidos. Como sinal para o controle químico da circulação, são também usadas as médias das pressões parciais de $\mathrm{O}_{2}$ e $\mathrm{CO}_{2}$ nos compartimentos arteriais $\left(P_{\mathrm{O}_{2} \text {,ar }}\right.$ e $\left.P_{\mathrm{CO}_{2}, a r}\right)$. Os sinais do efeito térmico são os mesmos apresentados na subseção anterior. O aumento da vazão de sangue nos músculos devido ao aumento do metabolismo (pelo calafrio ou atividade física) é considerado ser proporcional ao aumento da geração de calor.

\subsubsection{Sinais musculares}

A variação do metabolismo nos músculos ocorre devido ao calafrio e às funções motoras do corpo humano. Os sinais do calafrio foram discutidos no início da seção. Os sinais das funções motoras são enviados para a medula espinhal a partir de sensores localizados no músculo. Depois, esses sinais seguem para o cerebelo e para a área motora cerebral, localizados no encéfalo. No encéfalo e na medula, controladores definem os sinais que são enviados para a contração das fibras musculares. O trabalho realizado pela função motora do corpo humano será considerado como sinal de entrada para a variação do metabolismo nos músculos.

\subsection{Metabolismo}

A variação do metabolismo no músculo ocorre por três motivos: o efeito $Q_{10}$, o calafrio e a atividade física. O efeito $Q_{10}$, descrito na Seção 4.1, atua diretamente sobre o valor da geração de calor basal. Nos outros tipos de tecidos, o efeito $Q_{10}$ é a única forma considerada de variação do metabolismo. Descrições de como os efeitos do calafrio e da atividade física foram incluídos no modelo são feitas nas subseções seguintes. Esses efeitos 
são representados pelo segundo e terceiro termo da seguinte equação, que mostra a geração de calor específica no músculo:

$$
\hat{\dot{q}}_{m}=\hat{\dot{q}}_{m, 0} 2^{\left(T_{m}-T_{m, 0}\right) / 10}+\hat{\dot{q}}_{s h}+\hat{\dot{q}}_{a t}
$$

sendo: $\hat{\dot{q}}_{m}=$ geração de calor no músculo $\left[\mathrm{W} / \mathrm{m}^{3}\right]$;

$\hat{\dot{q}}_{m, 0}=$ geração de calor basal no músculo $\left[\mathrm{W} / \mathrm{m}^{3}\right]$;

$T_{m}=$ temperatura do músculo $\left[{ }^{\circ} \mathrm{C}\right]$;

$T_{m, 0}=$ temperatura basal do músculo $\left[{ }^{\circ} \mathrm{C}\right]$;

$\hat{\dot{q}}_{s h}=$ acréscimo na geração de calor devido ao calafrio $\left[\mathrm{W} / \mathrm{m}^{3}\right]$;

$\hat{\dot{q}}_{a t}=$ acréscimo na geração de calor devido à atividade física $\left[\mathrm{W} / \mathrm{m}^{3}\right]$.

As variáveis dessa equação, com exceção dos valores basais, dependem do segmento em que o músculo está presente. Por isto, as gerações de calor nos músculos de cada segmento têm valores distintos.

\subsubsection{Calafrio}

Para determinar a geração total de calor devido ao calafrio, foi utilizado a equação de Tikuisis e Giesbrecht (1999). Foi obtida por interpolação dos dados experimentais de 14 indivíduos imersos em água com temperaturas até $8^{\circ} \mathrm{C}$ por até $1 \mathrm{~h}$. Testaram diversas formas de equações e concluíram que a quadrática mais se adequava aos dados. A equação é a seguinte:

$$
\dot{q}_{s h}^{\prime \prime}=g_{s h(1)}\left(T_{h y}^{r e f}-T_{h y}\right)+g_{s h(2)}\left(T_{s k}^{r e f}-\bar{T}_{s k}\right)-g_{s h(3)}\left(T_{s k}^{r e f}-\bar{T}_{s k}\right)^{2}
$$

sendo: $g_{s h(1)}$ e $g_{s h(2)}=\operatorname{ganhos}\left[\mathrm{W} /\left(\mathrm{m}^{3} . \mathrm{K}\right)\right]$;

$g_{s h(3)}=$ ganho $\left[\mathrm{W} /\left(\mathrm{m}^{3} \cdot \mathrm{K}^{2}\right)\right]$;

$T_{h y}^{\text {ref }}=$ temperatura do hipotálamo de referência $\left[{ }^{\circ} \mathrm{C}\right]$;

$T_{h y}=$ temperatura do hipotálamo $\left[{ }^{\circ} \mathrm{C}\right]$;

$T_{s k}^{r e f}=$ temperatura da pele de referência $\left[{ }^{\circ} \mathrm{C}\right]$;

$\bar{T}_{s k}=$ temperatura média da pele $\left[{ }^{\circ} \mathrm{C}\right]$.

Os ganhos da equação $g_{s h(1)}, g_{\operatorname{sh}(2)}$ e $g_{\operatorname{sh}(3)}$ são iguais a 41,56, 12,56 e -0,42. Os sinais de referência $T_{h y, 0}$ e $T_{s k, 0}$ foram determinados das condições do presente trabalho na situação de neutralidade térmica. São iguais a 36,7 e $34,3^{\circ} \mathrm{C}$.

O calafrio atua com intensidade diferente em cada parte do corpo. O valor da variação do calafrio obtido das equações acimas está relacionado com a área superficial. Para que o efeito do calafrio seja separado nos segmentos, o valor obtido deve primeiro ser 
multiplicado pela área superficial do corpo, que no presente trabalho é igual a $1,8 \mathrm{~m}^{2}$. A variação do calafrio (em W) é então multiplicada pela fração em que o calafrio atua em cada segmento e divida pelo volume de músculo do mesmo. Os valores da fração e dos volumes estão na Tabela 7.1. As frações para o calafrio foram obtidas de Gordon, Roemer e Horvath (1976). Como neste trabalho o braço não estava dividido em braço e antebraço e a perna não estava dividida em perna e coxa, os valores para esses segmentos foram ponderados em função do volume de músculo. Com essas relações, a variação é determinada para cada segmento na forma que é utilizada nas equações de transporte $\left(\hat{\dot{q}}_{s h}, \mathrm{em} \mathrm{W} / \mathrm{m}^{3}\right)$.

Como limites da variação da geração de calor por calafrio, foram usados os mesmos valores de Ferreira e Yanagihara (2009), entre 0 e 429 W.

Tabela 7.1 - Informações para separação do calafrio e da atividade física entre os segmentos

\begin{tabular}{lrrr}
\hline Segmento & $\begin{array}{r}\text { Volume de } \\
\text { músculo }\left[\mathrm{cm}^{3}\right]\end{array}$ & $\begin{array}{r}\text { Fração de atuação } \\
\text { do calafrio }[0-1]\end{array}$ & $\begin{array}{r}\text { Fração de atuação } \\
\text { da atividade }[0-1]\end{array}$ \\
\hline Cabeça & 393,77 & 0,0339 & 0,0 \\
Pescoço & 552,36 & 0,0436 & 0,0 \\
Tronco & 12904,32 & 0,9025 & 0,3 \\
Braço & 817,33 & 0,00235 & 0,025 \\
Antebraço & 503,91 & 0,00145 & 0,015 \\
Mão & 255,26 & 0,0002 & 0,005 \\
Coxa & 2934,14 & 0,004 & 0,21 \\
Perna & 1219,19 & 0,00165 & 0,09 \\
Pé & 550,96 & 0,00035 & 0,005 \\
\hline
\end{tabular}

\subsubsection{Atividade física}

Após o início de uma atividade física, o consumo de $\mathrm{O}_{2}$ não aumenta instantaneamente para o nível necessário para suprir, através da oxidação, toda a energia que está sendo gasta. Esta deficiência no suprimento de $\mathrm{O}_{2}$ é conhecida por "débito de $\mathrm{O}_{2}$ ". O aumento prolongado do consumo de $\mathrm{O}_{2}$ está relacionado com o desenvolvimento da necessidade de $\mathrm{O}_{2}$ pelos tecidos e a preparação destes para aceitar o $\mathrm{O}_{2}$. A realização do trabalho muscular sem a utilização de $\mathrm{O}_{2}$ ocorre a partir de reações anaeróbicas. Durante a recuperação após uma atividade física, o consumo de $\mathrm{O}_{2}$ diminui como uma função logarítmica no tempo. O consumo de $\mathrm{O}_{2}$ maior que o repouso é usado para restaurar os sistemas de alta energia nos músculos Robinson (1974).

Segundo González-Alonso et al. (2000), a elevação da produção de calor nos músculos durante uma atividade física constante é gradual. Observaram, em experimentos com extensor de joelho, que a magnitude e a taxa da elevação da produção de calor deve estar relacionada com o aumento do calor liberado durante a produção de ATP quando o metabolismo aeróbico torna-se o dominante. 
O aumento gradual do consumo de $\mathrm{O}_{2}$, da produção de calor e, consequentemente, da produção de $\mathrm{CO}_{2}$ é considerado, no presente modelo, com a inclusão de uma constante de tempo entre o trabalho realizado pelo corpo humano (que foi transformado em calor pelo metabolismo) e a geração metabólica de calor. Esta constante de tempo também tem como objetivo representar a diminuição gradual do metabolismo aeróbico na fase de recuperação. Deste modo, o parâmetro de entrada do modelo para uma realização constante de atividade física é uma função degrau do trabalho realizado, e não a curva suave da atividade metabólica. O trabalho realizado pelo corpo, neste caso, é o trabalho realizado transformado em calor sem considerar qualquer atividade relacionada com o estado basal. A equação que representa a variação da geração de calor pela atividade física é a seguinte:

$$
\frac{\mathrm{d} \dot{q}_{a t}}{\mathrm{~d} t}=\frac{1}{\tau_{a t}}\left[W-\dot{q}_{a t}\right]
$$

sendo: $\dot{q}_{a t}=$ acréscimo na geração de calor devido à atividade física [W];

$\tau_{a t}=$ constante de tempo da atividade física $[\mathrm{s}]$;

$W=$ trabalho realizado (transformado em calor) $[\mathrm{W}]$.

O valor da constante de tempo da atividade física $\left(\tau_{a t}\right)$ foi determinado por tentativa e erro a partir dos dados experimentais de Cerretelli, Sikand e Farhi (1966), igual a 40 s. Estes dados são comparados com os resultados do modelo na Seção 9.1.8.

Do mesmo modo que o calafrio, a atividade física tem intensidade diferente dependendo do segmento. As frações com que a atividade atua em cada segmento foram obtidas de Stolwijk (1971), estimadas a partir do exercício em bicicleta. Seus valores estão na Tabela 7.1. As frações para o braço, antebraço, coxa e perna foram ponderadas assim como no caso do calafrio. A variação da atividade em cada segmento é obtida pelo valor calculado pela equação acima, multiplicado pela fração, e dividido pelo volume de músculo no segmento. Assim a variação está na forma que é utilizada nas equações de transporte $\left(\hat{\dot{q}}_{a t}, \mathrm{em} \mathrm{W} / \mathrm{m}^{3}\right)$.

\subsection{Circulação}

A regulação da circulação é a mais complexa dentre as modeladas no presente trabalho. Sua atuação ocorre de forma diferente dependendo do tipo de tecido em que estão os pequenos vasos. Seus sinais de entrada vêm do sistema respiratório, térmico e do metabolismo. Os modelos usados para os efeitos do sistema respiratório e do sistema térmico determinam fatores que são multiplicados aos valores basais. Um dos fatores é o efeito químico do $\mathrm{O}_{2}$ e do $\mathrm{CO}_{2}\left(f_{c h}\right)$, que é diferente para os tecidos centrais e periféricos. O fator térmico atua na pele e no músculo $\left(f_{t h}\right)$. No caso do metabolismo, a variação no 
músculo é função da geração de calor. A seguinte equação mostra a vazão de sangue nos pequenos vasos de uma forma generalizada para todos os tipos de tecido.

$$
\hat{\dot{V}}_{s v}=\hat{\dot{V}}_{s v, 0} f_{c h} f_{t h}+\hat{\dot{V}}_{m e t}
$$

sendo: $\hat{\dot{V}}_{s v}=$ vazão de sangue nos pequenos vasos $\left[\mathrm{m}^{3} /\left(\mathrm{m}^{3} . \mathrm{s}\right)\right]$;

$\hat{\dot{V}}_{s v, 0}=$ vazão de sangue basal nos pequenos vasos $\left[\mathrm{m}^{3} /\left(\mathrm{m}^{3} \cdot \mathrm{s}\right)\right]$;

$f_{c h}=$ fator do efeito químico na circulação [adimensional];

$f_{t h}=$ fator do efeito térmico na circulação [adimensional];

$\hat{\dot{V}}_{\text {met }}=$ acréscimo na vazão de sangue pelo metabolismo $\left[\mathrm{m}^{3} /\left(\mathrm{m}^{3} \cdot \mathrm{s}\right)\right]$.

O fator térmico e o efeito do metabolismo dependem de variáveis locais. Como atuam na pele e no músculo, esses tecidos têm vazões de sangue distintas entre segmentos.

\subsubsection{Fator químico}

Para representar a influência do $\mathrm{O}_{2}$ e do $\mathrm{CO}_{2}$ na variação da vazão de sangue nos pequenos vasos, foram utilizadas as relações do modelo do sistema respiratório de Ursino, Magosso e Avanzolini (2001a). O O $\mathrm{O}_{2}$ tem atuação em todos os tipos de tecido, com exceção dos órgãos das vísceras. $\mathrm{O}_{\mathrm{CO}_{2}}$, no entanto, atua somente no cérebro.

$\mathrm{O}$ efeito do $\mathrm{O}_{2}$ na circulação é função da $P_{\mathrm{O}_{2}}$ no sangue arterial, enquanto o efeito do $\mathrm{CO}_{2}$ é função da $P_{\mathrm{CO}_{2}}$ no sangue arterial. Essas pressões foram obtidas pela média volumétrica dos compartimentos arteriais de todos os segmentos.

A seguinte equação estática é utilizada para representar o efeito do $\mathrm{O}_{2}$ :

$$
\psi_{O_{2}, s t a t}=c_{f c(1)}\left[e^{\left(-P_{O_{2}, a r} / c_{f c(2)}\right)}-e^{\left(-P_{O_{2}, a r}^{r e f} / c_{f c(2)}\right)}\right]
$$

sendo: $\psi_{\mathrm{O}_{2}, \text { stat }}=$ efeito estático do $\mathrm{O}_{2}$ na circulação [adimensional];

$c_{f(1)}=$ constante [adimensinal];

$P_{O_{2}, a r}=$ pressão parcial de $\mathrm{O}_{2}$ no sangue arterial $[\mathrm{Pa}]$;

$c_{f c(2)}=$ constante $[\mathrm{Pa}] ;$

$P_{\mathrm{O}_{2}, a r}^{r e f}=$ pressão parcial de $\mathrm{O}_{2}$ no sangue arterial basal $[\mathrm{Pa}]$.

A constante $c_{f(1)}$ é igual a 17 , e a constante $c_{f c(2)}$ igual a $1470 \mathrm{~Pa}(11 \mathrm{mmHg})$.

Para representar o efeito do $\mathrm{CO}_{2}$ no cérebro, utiliza-se a seguinte equação estática:

$$
\psi_{C O_{2}, s t a t}=\frac{c_{f c(3)}+c_{f c(4)} /\left(1+c_{f c(5)} e^{c_{f c(6)} \log \left(P_{C O_{2}, a r}\right)}\right)}{c_{f c(3)}+c_{f c(4)} /\left(1+c_{f c(5)} e^{c_{f c(6)} \log \left(P_{C O_{2}, a r}^{r e f}\right)}\right)}-1
$$


sendo: $\psi_{C_{2}, \text { stat }}=$ efeito estático do $\mathrm{CO}_{2}$ na circulação [adimensional];

$c_{f c(3)}, c_{f c(4)}, c_{f c(5)}$ e $c_{f c(6)}=$ constantes [adimensinal];

$P_{\mathrm{CO}_{2}, a r}=$ pressão parcial de $\mathrm{CO}_{2}$ no sangue arterial $[\mathrm{Pa}]$;

$P_{\mathrm{CO}_{2}, a r}^{r e f}=$ pressão parcial de $\mathrm{CO}_{2}$ no sangue arterial basal $[\mathrm{Pa}]$.

As contantes $c_{f c(3)}, c_{f c(4)}, c_{f c(5)}$ e $c_{f c(6)}$ são, respectivamente, iguais a 20,9, 92,8, 10570 e $-5,251$.

As relações acima dependem de valores de referência (na condição basal) para a $P_{O_{2}}$ e a $P_{\mathrm{CO}_{2}}$ no sangue arterial. Os mesmos valores de Ursino, Magosso e Avanzolini (2001a) foram usados. São iguais a $12,66 \mathrm{kPa}(95 \mathrm{mHg})$ para o $\mathrm{O}_{2}$, e $5,33 \mathrm{kPa}$ (40 mmHg) para o $\mathrm{CO}_{2}$.

Os efeitos dinâmicos do $\mathrm{O}_{2}$ e do $\mathrm{CO}_{2}$ são determinados incluindo um atraso de primeira ordem:

$$
\begin{aligned}
\frac{\mathrm{d} \psi_{\mathrm{O}_{2}}}{\mathrm{~d} t} & =\frac{1}{\tau_{f c, \mathrm{O}_{2}}}\left[\psi_{\mathrm{O}_{2}, \text { stat }}-\psi_{\mathrm{O}_{2}}\right] \\
\frac{\mathrm{d} \psi_{\mathrm{CO}_{2}}}{\mathrm{~d} t} & =\frac{1}{\tau_{f c, \mathrm{CO}_{2}}}\left[\psi_{\mathrm{CO}_{2}, \text { stat }}-\psi_{\mathrm{CO}_{2}}\right]
\end{aligned}
$$

sendo: $\psi_{\mathrm{O}_{2}}=$ efeito do $\mathrm{O}_{2}$ na circulação [adimensional];

$\tau_{f c, O_{2}}=$ constante de tempo do efeito do $\mathrm{O}_{2}$ na circulação $[\mathrm{s}] ;$

$\psi_{\mathrm{CO}_{2}}=$ efeito do $\mathrm{CO}_{2}$ na circulação [adimensional];

$\tau_{f c, C O_{2}}=$ constante de tempo do efeito do $\mathrm{CO}_{2}$ na circulação [s].

As constantes de tempo do efeito do $\mathrm{O}_{2}$ e do $\mathrm{CO}_{2}$ são, respectivamente, iguais a 10 e $20 \mathrm{~s}$.

O efeito químico da vazão de sangue nos pequenos vasos é considerado ao multiplicar um fator pelo valor da vazão basal. Este fator, para os diferentes tipos de tecidos, é igual a:

$$
f_{c h}= \begin{cases}1 & \text { se tecido }=\text { víscera } \\ 1+\psi_{\mathrm{O}_{2}}+\psi_{\mathrm{CO}_{2}} & \text { se tecido }=\text { cérebro } \\ 1+\psi_{\mathrm{O}_{2}} & \text { se tecido } \neq \text { víscera e tecido } \neq \text { cérebro }\end{cases}
$$

O efeito químico não foi considerado na circulação do pulmão, já que a vazão deste é o débito cardíaco.

\subsubsection{Fator térmico}

Para determinar o efeito da variação da temperatura na vazão de sangue nos pequenos vasos da pele e do músculo, são usadas as relações de Wissler (2008). A variação da vazão, 
neste caso, é função de quatro fatores. Representam o efeito da temperatura interna, da temperatura média da pele, da temperatura local da pele e da atividade física. O fator chamado aqui de fator térmico é a multiplicação desses quatro fatores, segundo a seguinte equação:

$$
f_{t h}=f_{i} f_{\overline{s k}} f_{s k} f_{a t}
$$

sendo: $f_{\text {th }}=$ efeito térmico na circulação da pele [adimensional];

$f_{i}=$ efeito da temperatura interna na circulação da pele [adimensional];

$f_{\overline{s k}}=$ efeito da temperatura média da pele na circulação de pele [adimensional];

$f_{s k}=$ efeito da temperatura local da pele na circulação da pele [adimensional];

$f_{a t}=$ efeito da atividade física na circulação da pele [adimensional].

No músculo, o efeito térmico atua somente durante a vasoconstrição $\left(f_{t h} \leq 1\right)$. O efeito da atividade física ocorre principalmente por sua relação com o metabolismo. Por este motivo, a variação do fator da atividade física no músculo não será considerada $\left(f_{a t}=1\right)$.

O efeito da temperatura interna só ocorre quando a temperatura é maior do que a referência. Considerando a temperatura do hipotálamo como representante da temperatura interna, este fator é calculado pela seguinte equação:

$$
f_{i}= \begin{cases}1 & \text { se } T_{h y} \leq T_{h y}^{r e f}+\Delta T_{h y}^{r e f} \\ 1+g_{t h}\left[T_{h y}-\left(T_{h y}^{r e f}+\Delta T_{h y}^{r e f}\right)\right] & \text { se } T_{h y}>T_{h y}^{r e f}+\Delta T_{h y}^{r e f}\end{cases}
$$

sendo: $g_{\text {th }}=$ ganho $\left[{ }^{\circ} \mathrm{C}^{-1}\right]$;

$\Delta T_{h y}^{r e f}=$ variação da temperatura do hipotálamo de referência $\left[{ }^{\circ} \mathrm{C}\right]$.

O valor do ganho $g_{t h}$ não foi informado pelos autores destas relações. Então, foi usado um valor obtido por analogia com o modelo de Savage e Brengelmann (1996), igual a $4,6{ }^{\circ} C^{-1}$. Para o valor da temperatura do hipotálamo de referência $\left(T_{h y}^{r e f}\right)$, foi usado o mesmo que no cálculo da variação do metabolismo pelo calafrio (Seção 7.2.1), igual a 36,7 . Este valor é somado a uma variação $\left(\Delta T_{h y}^{r e f}\right)$, que depende da temperatura média da pele, do exercício e da postura. O efeito do exercício ocorre quando o consumo de $\mathrm{O}_{2}$ é maior que $50 \%$ de sua capacidade máxima e é complexo. Por esses motivos, não é considerado. O efeito da postura também não foi considerado. O efeito da temperatura da pele na variação da temperatura de referência é o seguinte:

$$
\Delta T_{h y}^{r e f}=0,05\left(\bar{T}_{s k}-T_{s k}^{r e f}\right)
$$


O fator que representa o efeito da temperatura média da pele é representado pela seguinte equação:

$$
f_{\overline{s k}}=\frac{1,422+\tanh \left[0,275\left(\bar{T}_{s k}-32\right)\right]}{2,018}
$$

O fator que representa o efeito local da temperatura da pele foi obtido a partir das retas traçadas em um gráfico apresentado pelos autores do modelo, que visam representar alguns dados experimentais. O resultado são as seguintes relações:

$$
f_{s k}= \begin{cases}0,03857 T_{s k}-0,3 & \text { se } T_{s k} \leq 35 \\ 0,56 T_{s k}-18,55 & \text { se } 35<T_{s k} \leq 37 \\ 1,4525 T_{s k}-51,5725 & \text { se } T_{s k}>37\end{cases}
$$

sendo: $T_{s k}=$ temperatura local da pele $\left[{ }^{\circ} \mathrm{C}\right]$.

O fator da atividade física depende do trabalho que está sendo realizado pelo corpo humano. Este será aqui representado pelo acréscimo na geração de calor devido à atividade física (Seção 7.2.2). A seguinte equação representa o fator da atividade física:

$$
f_{a t}=1-\frac{0,071}{110} \dot{q}_{a t}
$$

Os limites da vazão de sangue nos pequenos vasos da pele foram obtidos de Ferreira e Yanagihara (2009). O limite inferior da vazão é 25\% do valor basal. O limite superior é igual a 10 vezes o valor basal. O mesmo limite inferior foi utilizado para os músculos.

\subsubsection{Efeito do metabolismo}

A vazão de sangue nos músculos está relacionada, além dos fatores químicos e térmicos, com o metabolismo. Sua variação foi considerada como sendo diretamente proporcional a variação da geração de calor nos músculos (diferença com o estado basal), segundo a seguinte equação:

$$
\hat{\dot{V}}_{m e t}=c_{m e t} \Delta \hat{\dot{q}}_{m}
$$

sendo: $c_{m e t}=$ constante $\left[\mathrm{m}^{3} / \mathrm{J}\right]$;

$\Delta \hat{\dot{q}}_{m}=$ variação da geração de calor no músculo $\left[\mathrm{W} / \mathrm{m}^{3}\right]$.

A constante $c_{\text {met }}$, igual a $2,914 \times 10^{-7} \mathrm{~m}^{3} / \mathrm{J}$, foi obtida por interpolação dos dados experimentais de Damato, Galante e Smith (1966). Nos experimentos com 24 indivíduos, o consumo de $\mathrm{O}_{2}$ medido variou de 111 até $1411 \mathrm{ml} /\left(\min . \mathrm{m}^{2}\right)$ (STPD). 


\subsection{Ventilação}

A variação da ventilação ocorre principalmente pela variação de $\mathrm{O}_{2}$ e $\mathrm{CO}_{2}$. Para representá-la, será usado o modelo de Longobardo, Evangelisti e Cherniack (2002). O efeito químico na ventilação é separado em duas partes: central e periférica. A parte central é sensível à $P_{\mathrm{CO}_{2}}$ do cérebro. A parte periférica é sensível à saturação de $\mathrm{O}_{2}$ e à $P_{\mathrm{CO}_{2}}$ do sangue arterial. A ventilação determinada pelas relações do modelo é o volume minuto respiratório, em BTPS. É igual a soma do efeito dessas duas partes:

$$
\dot{V}_{E}=\dot{V}_{C}+\dot{V}_{P}
$$

sendo: $\dot{V}_{E}=$ volume minuto respiratório [L/min, BTPS];

$\dot{V}_{C}=$ contribuição da parte central na ventilação [L/min, BTPS];

$\dot{V}_{P}=$ contribuição da parte periférica na ventilação [L/min, BTPS].

O efeito do $\mathrm{CO}_{2}$ em cada uma das partes é dividido em duas regiões. Abaixo de uma $P_{\mathrm{CO}_{2}}$ limite, a ventilação segue proporcional à $P_{\mathrm{CO}_{2}}$ até um ponto em que ambos seriam nulos. O valor estático da parte central é determinado pela seguinte equação:

$$
\dot{V}_{C, s t a t}= \begin{cases}g_{C}\left(P_{C O_{2}, b r}-P_{C O_{2}, b r}^{r e f}\right) & \text { se } P_{C O_{2}, b r} \geq P_{C O_{2}, b r}^{l i m} \\ g_{C}\left(P_{C O_{2}, b r}^{l i m}-P_{C O_{2}, b r}^{r e f}\right) \frac{P_{C O_{2}, b r}}{P_{C O_{2}, b r}^{l i m}} & \text { se } P_{C O_{2}, b r}<P_{C O_{2}, b r}^{l i m}\end{cases}
$$

sendo: $\dot{V}_{C, \text { stat }}=$ contribuição estática da parte central na ventilação [L/min, BTPS];

$g_{C}=$ ganho da parte central $[\mathrm{L} /(\min . \mathrm{mmHg})]$;

$P_{\mathrm{CO}_{2}, b r}=$ pressão parcial de $\mathrm{CO}_{2}$ no cérebro [mmHg];

$P_{\mathrm{CO}_{2}, b r}^{r e f}=$ pressão parcial de $\mathrm{CO}_{2}$ no cérebro de referência $[\mathrm{mmHg}]$;

$P_{\mathrm{CO}_{2}, b r}^{l i m}=$ limite da pressão parcial de $\mathrm{CO}_{2}$ no cérebro [mmHg].

As relações para calcular o valor estático da contribuição da parte periférica na ventilação incluem o efeito do $\mathrm{O}_{2}$ :

$$
\dot{V}_{P, s t a t}= \begin{cases}g_{P}\left(S_{\mathrm{O}_{2}, a r}^{r e f}-S_{\mathrm{O}_{2}, a r}\right)\left(P_{\mathrm{CO}_{2}, a r}-P_{C O_{2}, b r}^{r e f}\right)-c_{P} & \text { se } P_{C O_{2}, a r} \geq P_{C O_{2}, a r}^{l i m} \\ {\left[g_{P}\left(S_{\mathrm{O}_{2}, a r}^{r e f}-S_{\mathrm{O}_{2}, a r}\right)\left(P_{C O_{2}, a r}^{l i m}-P_{C O_{2}, b r}^{r e f}\right)-c_{P}\right] \frac{P_{C O_{2}, a r}}{P_{C O_{2}, a r}^{l i m}}} & \text { se } P_{C O_{2}, a r}<P_{C O_{2}, a r}^{l i m}\end{cases}
$$

sendo: $\dot{V}_{P, \text { stat }}=$ contribuição estática da parte periférica na ventilação [L/min, BTPS];

$g_{P}=$ ganho da parte periférica $[\mathrm{L} /(\min . \mathrm{mmHg})]$;

$S_{\mathrm{O}_{2}, \text { ar }}^{r e f}=$ saturação de $\mathrm{O}_{2}$ arterial de referência [\%];

$S_{O_{2}, a r}=$ saturação de $\mathrm{O}_{2}$ arterial [\%]; 
$P_{\mathrm{CO}_{2}, \text { ar }}=$ pressão parcial de $\mathrm{CO}_{2}$ arterial $[\mathrm{mmHg}]$;

$P_{\mathrm{CO}_{2}, a r}^{r e f}=$ pressão parcial de $\mathrm{CO}_{2}$ arterial de referência $[\mathrm{mmHg}]$;

$P_{\mathrm{CO}_{2}, a r}^{l i m}=$ limite da pressão parcial de $\mathrm{CO}_{2}$ arterial $[\mathrm{mmHg}]$.

Os ganhos $g_{C}$ e $g_{P}$ das equações acima são iguais a 1,573 e $12,4 \mathrm{~L} /(\mathrm{min} . \mathrm{mmHg})$. A constante $c_{P}$ é igual a $1,43 \mathrm{~L} / \mathrm{min}$. Os valores de referência, ao contrário dos outros reguladores, não correspondem ao estado basal. São, para a $P_{\mathrm{CO}_{2}}$ cerebral, $\mathrm{P}_{\mathrm{CO}_{2}}$ arterial e saturação de $\mathrm{O}_{2}$ arterial, iguais a 44,35 mmHg, 31,123 mmHg e 101,72\%. Os limites da $P_{\mathrm{CO}_{2}}$ cerebral e arterial foram considerados iguais a 47,9 e $38,5 \mathrm{mmHg}$.

A inclusão de atrasos de primeira ordem no cálculo da ventilação é comum em modelos do sistema respiratório. A dinâmica da parte central é diferente da periférica. O valor dinâmico da contribuição de ambas na ventilação é determinado pelas seguintes equações:

$$
\begin{aligned}
& \frac{\mathrm{d} \dot{V}_{C}}{\mathrm{~d} t}=\frac{1}{\tau_{C}}\left[\dot{V}_{C, s t a t}-\dot{V}_{C}\right] \\
& \frac{\mathrm{d} \dot{V}_{P}}{\mathrm{~d} t}=\frac{1}{\tau_{P}}\left[\dot{V}_{P, s t a t}-\dot{V}_{P}\right]
\end{aligned}
$$

sendo: $\tau_{C}=$ constante de tempo da parte central $[\mathrm{s}]$;

$\tau_{P}=$ constante de tempo da parte periférica $[\mathrm{s}]$.

Os valores das constantes de tempo $\tau_{C}$ e $\tau_{P}$ foram obtidos de Ursino, Magosso e Avanzolini (2001a). São iguais a 60 e 7 s.

\subsection{Sudorese}

A determinação da sudorese foi feita do mesmo modo que Ferreira e Yanagihara (2009). As equações utilizadas têm como objetivo determinar a fração molhada da superfície de cada segmento. A fração de superfície molhada depende da relação entre a perda de calor por evaporação e a sua capacidade máxima:

$$
\omega=0,06+0,94 \frac{\dot{q}_{e}}{\dot{q}_{e, \max }}
$$

sendo: $\omega=$ fração molhada da superfície $[0-1]$;

$\dot{q}_{e}=$ calor perdido por evaporação $\left[\mathrm{W} / \mathrm{m}^{2}\right]$;

$\dot{q}_{e, \max }=$ capacidade máxima do calor perdido por evaporação $\left[\mathrm{W} / \mathrm{m}^{2}\right]$.

O valor de capacidade máxima da perda de calor por evaporação $\left(\dot{q}_{e, \max }\right)$ é obtido da equação (4.15), considerando que a fração de superfície molhada é igual a 1. 
A relação desenvolvida por Nadel, Bullard e Stolwijk (1971) foi usada para determinar a perda de calor por evaporação. Inclui os efeitos da temperatura interna e das temperaturas média e local da pele. A dependência do valor da temperatura local faz com que a sudorese seja diferente entre os segmentos. A seguinte equação representa a perda de calor por evaporação:

$$
\dot{q}_{e}=g_{e(1)}\left(T_{h y}-T_{h y}^{r e f}\right)+g_{e(2)}\left(\bar{T}_{s k}-T_{s k}^{r e f}\right) e^{\left(T_{s k}-T_{s k}^{r e f}\right) / 10}
$$

sendo: $g_{e(1)}$ e $g_{e(2)}=\operatorname{ganhos}\left[\mathrm{W} /\left(\mathrm{m}^{2} \cdot{ }^{\circ} \mathrm{C}\right)\right]$.

Os ganhos $g_{e(1)}$ e $g_{e(2)}$ são iguais a 197 e $23 \mathrm{~W} /\left(\mathrm{m}^{2} .{ }^{\circ} \mathrm{C}\right)$. Os valores usados como referência foram os mesmos usados no calafrio, quando o corpo está na condição basal. São iguais a $36,7{ }^{\circ} \mathrm{C}$ para a temperatura interna e $34,3{ }^{\circ} \mathrm{C}$ para a pele. 


\section{Capítulo 8}

\section{Solução do Modelo}

O resultado da modelagem realizada nos últimos capítulos são diversas equações diferenciais ordinárias (EDO), equações diferenciais parciais (EDP) e equações algébricas. Neste capítulo, as metodologias utilizadas para solucionar as equações do modelo serão descritas.

Casos de equações algébricas que necessitam o uso de métodos numéricos para serem solucionadas encontram-se no transporte dos gases no sangue (Capítulo 3) e na transferência de calor na superfície da pele (Capítulo 4). Estas equações formam sistemas de equações não-lineares. Para a solução destes sistemas, é utilizado o método das aproximações sucessivas. Divergências na solução são evitadas com o uso de sub-relaxação.

Para a solução das equações diferenciais, são usados métodos totalmente implícitos. A solução implícita tem vantagens em relação à explícita quanto a estabilidade da solução, porém, necessita um processo iterativo para cada instante de tempo, já que dependem dos valores das variáveis naquele instante. As não-linearidades do modelo também exigem processo iterativo para solucioná-las em cada instante de tempo. Métodos que usam valores antigos e atuais, como o conhecido por Crank-Nicolson, que considera a média da variável anterior e atual, podem gerar soluções não realistas (PATANKAR, 1980). Os motivos citados sugerem que a formulação totalmente implícita é adequada para solucionar as equações diferenciais do modelo desenvolvido no presente trabalho.

Equações diferenciais ordinárias são usadas para representar a variação da temperatura e quantidade dos gases nos compartimentos ao longo do tempo. Também são usadas na representação do sistema regulador. Para solucionar as equações diferenciais ordinárias, é usado o método de Euler implícito. A simplicidade deste método permite que estas equações sejam reescritas de modo que a variável que está sendo calculada fique isolada. Esta manipulação, junto com sub-relaxação, garante a convergência da solução.

As equações diferenciais parciais do modelo representam a transferência de calor nos tecidos. A discretização das equações foi realizada usando o método dos volumes fini- 
tos (MVF). A aplicação deste método nas equações diferenciais parciais do modelo será detalhada na próxima seção.

Outra etapa realizada para solucionar o modelo é a implementação computacional. Uma breve apresentação desta será feita na última seção do capítulo.

\subsection{Discretização da equação de condução de calor}

A equação de condução de calor nos tecidos é uma equação diferencial parcial, com variação no espaço e no tempo (Capítulo 6, eq.(6.12) e eq.(6.13)). Os segmentos do corpo humano são, no presente trabalho, representados por duas formas geométricas distintas: paralelepípedos (mãos e pés) e cilindros (outros membros). Sistemas de coordenadas cartesiano e cilíndrico são usados dependendo da forma do segmento. Como os segmentos têm a distribuição de camadas uniforme em alguma direção, somente a variação da temperatura em algumas coordenadas precisa ser considerada. A combinação do sistema de coordenadas com as coordenadas consideradas leva a quatro configurações diferentes, aqui denominadas retangular, radial, polar e axial-radial. A Tabela 8.1 mostra as informações de cada configuração. Seus nomes serão usados ao longo desta seção.

Tabela 8.1 - Configurações dos segmentos

\begin{tabular}{lcccl}
\hline Segmento & $\begin{array}{c}\text { Sistema de } \\
\text { coordenadas }\end{array}$ & $\begin{array}{c}\text { Número de } \\
\text { dimensões }\end{array}$ & Coordenadas & Membros \\
\hline Retangular & cartesiano & 2 & $x$ e $y$ & mãos e pés \\
Radial & cilíndrico & 1 & $r$ & pescoço, braços e coxas \\
Polar & cilíndrico & 2 & $r$ e $\theta$ & antebraços e pernas \\
Axial-radial & cilíndrico & 2 & $r$ e $z$ & cabeça e tronco \\
\hline
\end{tabular}

O método dos volumes finitos (MVF) foi escolhido para a discretização por dois motivos principais. O primeiro é porque este método satisfaz os balanços de conservação para cada volume, mesmo com malhas menos refinadas. O outro motivo é a facilidade de aplicação em malhas estruturadas e sistemas de coordenadas ortogonais.

No método dos volumes finitos, a equação diferencial parcial é integrada no volume da célula e no tempo. Dessa forma, a equação discretizada é obtida, sendo que a temperatura de cada célula em um determinado instante está relacionada com a temperatura das células vizinhas e a do instante anterior.

Como referência foram usados os livros de Patankar (1980) e Maliska (2004) e a tese de Ferreira (2001). 


\subsubsection{Geração da malha}

No método dos volumes finitos, a malha deve definir o posicionamento das células e das faces. A equação na forma discretizada é resolvida para cada célula. As faces contêm as características relativas ao transporte de calor entre células vizinhas. Podem ser internas, entre duas células, ou externas, entre uma célula e o ambiente. As malhas são geradas respeitando os dois sistemas de coordenadas considerados no modelo, cartesiano ou cilíndrico, ambos ortogonais.

Como os segmentos que representam os membros do corpo humano são divididos em camadas, uma premissa da malha é que os limites das camadas devem sempre coincidir com faces. Cada camada pode então ser divida em um número inteiro de células, em cada direção, igualmente espaçados. Esse método permite que cada camada da malha possa ser refinada diferente uma da outra, já que as camadas têm tamanhos diferentes.

\subsubsection{Forma da equação discretizada}

A direção das células vizinhas acompanha o sentido dos eixos do sistema de coordenadas (cartesiano ou cilíndrico). São denominadas leste (E) e oeste (W) para os eixos $x$ ou $r$, e sul (S) e norte (N) para os eixos $y, \theta$ ou $z$.

A equação discretizada pelo método dos volumes finitos na formulação totalmente implícita, em duas dimensões, costuma ser escrita na seguinte forma:

$$
a_{P} T_{P}=a_{W} T_{W}+a_{E} T_{E}+a_{S} T_{S}+a_{N} T_{N}+b
$$

sendo: $a_{P}=$ coeficiente da equação discretizada da célula atual $\left[\mathrm{W} /{ }^{\circ} \mathrm{C}\right]$;

$T_{P}=$ temperatura no centro da célula atual $\left[{ }^{\circ} \mathrm{C}\right]$;

$a_{W}=$ coeficiente da equação discretizada da célula vizinha na direção $\mathrm{W}\left[\mathrm{W} /{ }^{\circ} \mathrm{C}\right]$;

$T_{W}=$ temperatura no centro da célula vizinha na direção $\mathrm{W}\left[{ }^{\circ} \mathrm{C}\right]$;

$a_{E}=$ coeficiente da equação discretizada da célula vizinha na direção $\mathrm{E}\left[\mathrm{W} /{ }^{\circ} \mathrm{C}\right]$;

$T_{E}=$ temperatura no centro da célula vizinha na direção $\mathrm{E}\left[{ }^{\circ} \mathrm{C}\right]$;

$a_{S}=$ coeficiente da equação discretizada da célula vizinha na direção $\mathrm{S}\left[\mathrm{W} /{ }^{\circ} \mathrm{C}\right]$;

$T_{S}=$ temperatura no centro da célula vizinha na direção $\mathrm{S}\left[{ }^{\circ} \mathrm{C}\right]$;

$a_{N}=$ coeficiente da equação discretizada da célula vizinha na direção $\mathrm{N}\left[\mathrm{W} /{ }^{\circ} \mathrm{C}\right]$;

$T_{N}=$ temperatura no centro da célula vizinha na direção $\mathrm{N}\left[{ }^{\circ} \mathrm{C}\right]$;

$b=$ fonte da equação discretizada [W].

Durante a determinação dos coeficientes da equação discretizada, o sub-índice usado para representar um tecido $(t)$ não será usado. No lugar, serão usados sub-índices que representam as direções. 


\subsubsection{Fonte}

Na equação de condução de calor nos tecidos, os dois últimos termos representam a fonte da equação. O primeiro destes é a perfusão de sangue pelos tecidos, sendo função da própria temperatura do tecido. O segundo é a geração metabólica de calor. Agrupando ambos mecanismos, as seguintes equações representam a fonte, na forma usual no método dos volumes finitos (FERREIRA, 2001):

$$
\begin{aligned}
S & =S_{C}+S_{P} T_{P} \\
S_{C} & =\hat{\dot{V}}_{s v} \rho_{b l} c_{b l} T_{a r}+\hat{\dot{q}} \\
S_{P} & =-\hat{\dot{V}}_{s v} \rho_{b l} c_{b l}
\end{aligned}
$$

sendo: $S=$ fonte linearizada $\left[\mathrm{W} / \mathrm{m}^{3}\right]$;

$S_{C}=$ parâmetro da equação da fonte linearizada $\left[\mathrm{W} / \mathrm{m}^{3}\right]$;

$S_{P}=$ parâmetro da equação da fonte linearizada $\left[\mathrm{W} /\left(\mathrm{m}^{3} .{ }^{\circ} \mathrm{C}\right)\right]$;

$\hat{\dot{V}}_{s v}=$ vazão de sangue no tecido $\left[\mathrm{m}^{3} /\left(\mathrm{m}^{3} \cdot \mathrm{s}\right)\right]$;

$\rho_{b l}=$ massa específica do sangue $\left[\mathrm{kg} / \mathrm{m}^{3}\right]$;

$c_{b l}=$ calor específico do sangue $\left[\mathrm{J} /\left(\mathrm{kg} .{ }^{\circ} \mathrm{C}\right)\right]$;

$T_{a r}=$ temperatura do sangue arterial no segmento $\left[{ }^{\circ} \mathrm{C}\right]$;

$\hat{\dot{q}}=$ geração interna de calor $\left[\mathrm{W} / \mathrm{m}^{3}\right]$.

Para evitar instabilidades e soluções não realísticas, é importante que o $S_{P}$ seja negativo (PATANKAR, 1980; MALISKA, 2004).

\subsubsection{Propriedades geométricas}

As propriedades no ponto central de uma célula são representadas pelo sub-índice $P$. Quando se trata de uma propriedade do ponto central de uma célula vizinha, serão letras maiúsculas $(E, W, S, N)$. Já quando tratar de uma propriedade da face, serão letras minúsculas $(e, w, s, n)$.

As dimensões de uma célula são iguais a $\Delta x$ e $\Delta y$ no sistema cartesiano e $\Delta r, \Delta \theta$ e $\Delta z$ no sistema cilíndrico. Para representar a distância entre o centro da célula em questão e o centro da célula vizinha, usa-se o mesmo símbolo das dimensões da célula acrescentando o sub-índice da face entre as células. A Figura 8.1 mostra essas dimensões e distâncias para o sistema de coordenas cartesiano, com duas dimensões. As outras coordenadas são equivalentes.

Para o cálculo do volume da célula, usado nos coeficientes da equação discretizada, adota-se que as direções não consideradas têm dimensão unitária ou, no caso do $\theta$, igual 


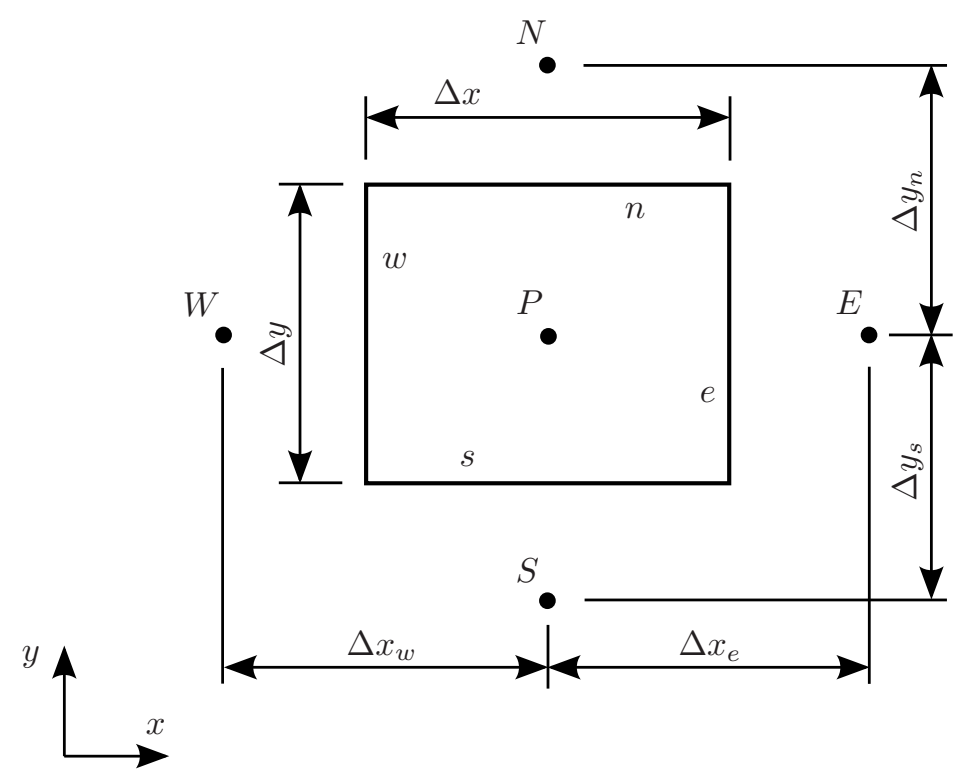

Figura 8.1 - Dimensões e distâncias das células e faces

a $2 \pi$. A Tabela 8.2 mostra as equações usadas para calcular o volume das células de cada tipo de segmento.

Tabela 8.2 - Volume das células $(\Delta V)$ para cada tipo de segmento

\begin{tabular}{lc}
\hline Retangular & $\Delta x \Delta y L$ \\
Radial & $\pi\left(r_{e}^{2}-r_{w}^{2}\right) L$ \\
Polar & $\left(r_{e}^{2}-r_{w}^{2}\right) \Delta \theta L / 2$ \\
Axial-radial & $\pi\left(r_{e}^{2}-r_{w}^{2}\right) \Delta z$ \\
\hline
\end{tabular}

\subsubsection{Fronteira}

Os volumes na fronteira devem considerar a transferência de calor entre a superfície da pele e o ambiente. Esta transferência ocorre por convecção, radiação, evaporação e condução. O calor trocado pela união destes mecanismos é representado por $q_{f}^{\prime \prime}$.

A Figura 8.2 mostra, para o tipo de segmento retangular, a distribuição das células com os índices utilizados para representá-las nas duas dimensões. As fronteiras estão, na figura, em contato com o ambiente. Quando o tipo do segmento é radial, a fronteira W é adiabática. Quando é axial-radial, as fronteiras N, W e S são adiabáticas.

\subsubsection{Coeficientes da equação discretizada}

Os coeficientes da equação de condução de calor nos tecidos discretizada, eq.(8.1), são obtidos a partir dos resultados da integração da equação no espaço e no tempo. Quando o sistema de coordenadas cilíndrico é adotado, os termos da equação de condução de calor 


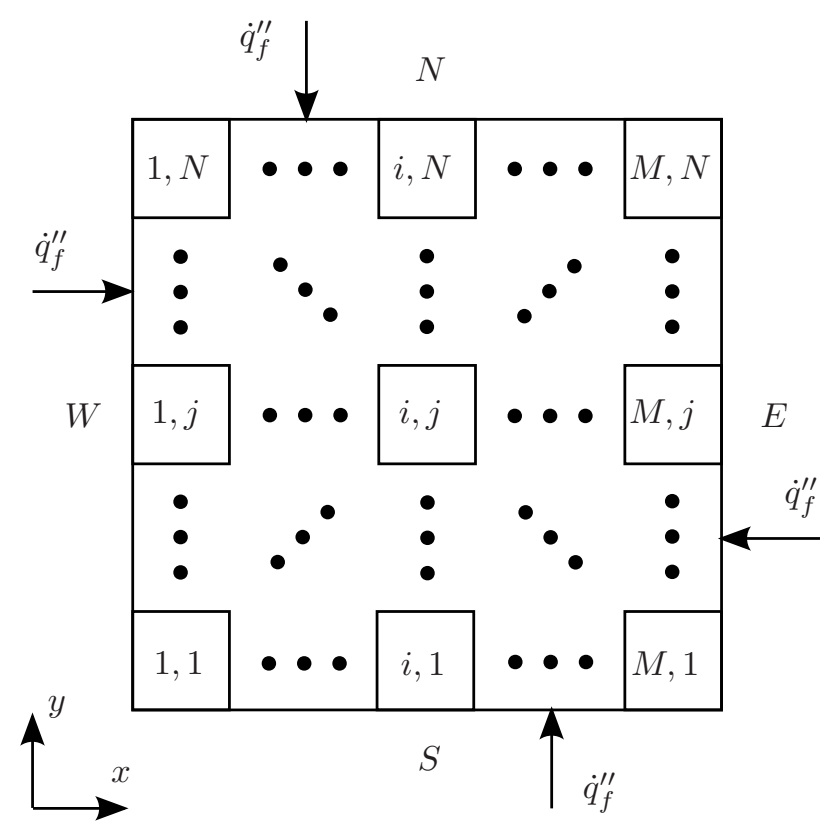

Figura 8.2 - Representação da distribuição de células em um segmento

são multiplicados pelo raio $(r)$ antes de a equação ser integrada. Assim como na definição dos volumes das células, as direções não consideradas são unitárias ou, quando se trata do $\theta$, igual a $2 \pi$.

Alguns coeficientes da equação discretizada podem ser generalizados para qualquer tipo de segmento:

$$
\begin{aligned}
a_{P}^{0} & =\frac{\rho_{t} c_{t} \Delta V}{\Delta t} \\
b & =S_{C} \Delta V+a_{P}^{0} T_{P}^{0} \\
a_{P} & =a_{W}+a_{E}+a_{S}+a_{N}+a_{P}^{0}-S_{P} \Delta V
\end{aligned}
$$

sendo: $a_{P}^{0}=$ coeficiente da célula no instante anterior $\left[\mathrm{W} /{ }^{\circ} \mathrm{C}\right]$;

$\rho_{t}=$ massa específica do tecido $\left[\mathrm{kg} / \mathrm{m}^{3}\right]$;

$c_{t}=$ calor específico do tecido $\left[\mathrm{J} /\left(\mathrm{kg} .{ }^{\circ} \mathrm{C}\right)\right]$;

$\Delta V=$ volume da célula $\left[\mathrm{m}^{3}\right]$;

$\Delta t=$ passo de tempo $[\mathrm{s}]$.

Outros coeficientes dependem do tipo do segmento. Estes coeficientes estão descritos na Tabela 8.3. Além da dependência do tipo do segmento, são diferentes nas células internas e externas. As células externas também dependem do tipo de fronteira: adiabática ou ambiente. No último caso, um termo contendo a transferência de calor com o ambiente é somado ao coeficiente $b$, definido na eq.(8.6). 
Tabela 8.3 - Coeficientes da equação discretizada que dependem do tipo do segmento

\begin{tabular}{|c|c|c|c|c|c|c|c|c|}
\hline \multirow[t]{2}{*}{ Segmento } & \multicolumn{4}{|c|}{ Coordenada $x$ ou $r$} & \multicolumn{4}{|c|}{ Coordenada $y, \theta$ ou $z$} \\
\hline & Posição & $a_{W}$ & $a_{E}$ & $b$ & Posição & $a_{S}$ & $a_{N}$ & $b$ \\
\hline Retangular & $\begin{array}{l}i=1 \\
1<i<M \\
i=M\end{array}$ & $\begin{array}{c}0 \\
k_{w} \Delta y / \Delta x_{w} \\
k_{w} \Delta y / \Delta x_{w}\end{array}$ & $\begin{array}{c}k_{e} \Delta y / \Delta x_{e} \\
k_{e} \Delta y / \Delta x_{e} \\
0\end{array}$ & $\begin{array}{l}+\dot{q}_{f}^{\prime \prime} \Delta y \\
+\dot{q}_{f}^{\prime \prime} \Delta y\end{array}$ & $\begin{array}{l}j=1 \\
1<j<N \\
j=N\end{array}$ & $\begin{array}{c}0 \\
k_{s} \Delta x / \Delta y_{s} \\
k_{s} \Delta x / \Delta y_{s}\end{array}$ & $\begin{array}{c}k_{n} \Delta x / \Delta y_{n} \\
k_{n} \Delta x / \Delta y_{n} \\
0\end{array}$ & $\begin{array}{l}+\dot{q}_{f}^{\prime \prime} \Delta x \\
+\dot{q}_{f}^{\prime \prime} \Delta x\end{array}$ \\
\hline Radial & $\begin{array}{l}i=1 \\
1<i<M \\
i=M\end{array}$ & $\begin{array}{c}0 \\
2 \pi k_{w} r_{w} / \Delta r_{w} \\
2 \pi k_{w} r_{w} / \Delta r_{w} \\
\end{array}$ & $\begin{array}{l}4 \pi k_{e} r_{e} / \Delta r_{e} \\
2 \pi k_{e} r_{e} / \Delta r_{e} \\
0\end{array}$ & $+2 \pi \dot{q}_{f}^{\prime \prime} r_{e}$ & & & & \\
\hline Polar & $\begin{array}{l}i=1 \\
1<i<M \\
i=M\end{array}$ & $\begin{array}{c}0 \\
k_{w} r_{w} \Delta \theta / \Delta r_{w} \\
k_{w} r_{w} \Delta \theta / \Delta r_{w}\end{array}$ & $\begin{array}{c}k_{e} r_{e} \Delta \theta / \Delta r_{e} \\
k_{e} r_{e} \Delta \theta / \Delta r_{e} \\
0\end{array}$ & $+\dot{q}_{f}^{\prime \prime} r_{e} \Delta \theta$ & $\begin{array}{l}1 \leq j \leq N \\
\text { cíclico: se } j\end{array}$ & $\begin{array}{c}k_{s} \Delta r /\left(r_{s} \Delta \theta_{s}\right) \\
=N+1 \Rightarrow j=1 ; \text { se } j\end{array}$ & $\begin{aligned} & k_{n} \Delta r /\left(r_{n} \Delta \theta_{n}\right) \\
= & 0 \Rightarrow j=N\end{aligned}$ & \\
\hline Axial & $\begin{array}{l}i=1 \\
1<i<M \\
i=M\end{array}$ & $\begin{array}{c}0 \\
2 \pi k_{w} r_{w} \Delta z / \Delta r_{w} \\
2 \pi k_{w} r_{w} \Delta z / \Delta r_{w}\end{array}$ & $\begin{array}{c}4 \pi k_{e} r_{e} \Delta z / \Delta r_{e} \\
2 \pi k_{e} r_{e} \Delta z / \Delta r_{e} \\
0\end{array}$ & $+2 \pi \dot{q}_{f}^{\prime \prime} r_{e} \Delta z$ & $\begin{array}{l}j=1 \\
1<j<N \\
j=N\end{array}$ & $\begin{array}{c}0 \\
\pi k_{s}\left(r_{e}^{2}-r_{w}^{2}\right) / \Delta z_{s} \\
2 \pi k_{s}\left(r_{e}^{2}-r_{w}^{2}\right) / \Delta z_{s}\end{array}$ & $\begin{array}{c}2 \pi k_{n}\left(r_{e}^{2}-r_{w}^{2}\right) / \Delta z_{n} \\
\pi k_{n}\left(r_{e}^{2}-r_{w}^{2}\right) / \Delta z_{n} \\
0\end{array}$ & \\
\hline
\end{tabular}




\subsubsection{Condutividade na interface}

A condutividade térmica nas interfaces não homogêneas é determinada com base em metodologia proposta por Patankar (1980). Considerando que a interface está entre os pontos $P$ e $E$, faz-se um balanço da transferência de calor entre esses dois pontos, com condutividade $k_{e}$, e entre a interface e os pontos, com condutividades $k_{P}$ e $k_{E}$. A condutividade térmica entre os pontos $P$ e $E$ é igual a:

$$
k_{e}=\frac{2 \Delta x_{e}}{\frac{\Delta x}{k_{P}}+\frac{2 \Delta x_{e}-\Delta x}{k_{E}}}
$$

sendo: $k_{P}=$ condutividade térmica na célula atual $[\mathrm{W} /(\mathrm{m} . \mathrm{K})]$;

$k_{E}=$ condutividade térmica na célula vizinha na direção $\mathrm{E}[\mathrm{W} /(\mathrm{m} . \mathrm{K})]$.

\subsection{Implementação computacional}

Para solucionar o modelo, foi desenvolvido um programa de computador usando a linguagem de programação $\mathrm{C}++$. Esta linguagem é adequada para a simulação do modelo desenvolvido pelos seguintes motivos:

- é uma linguagem orientada a objetos, o que facilita a implementação dos diversos segmentos e compartimentos;

- a Standard Template Library (STL) traz soluções otimizadas e práticas para estruturas de dados;

- é adequada para simulação por ter alta velocidade de execução e compilação;

- tem compilador confiável e gratuito.

Como opção de compilador, foi usado o GCC, produzido pelo projeto GNU. Este compilador tem a vantagem de ser livre e ter o código aberto. Optou-se por utilizar o padrão ANSI, para que assim o programa tenha portabilidade em outros compiladores.

A paralelização e otimização do programa desenvolvido foi tema do trabalho de formatura de Chaves e Moraes (2009), no Instituto de Matemática e Estatística da Universidade de São Paulo. 


\subsubsection{Modelagem de objetos}

O programa foi desenvolvido usando conceitos de orientação a objetos. As principais classes criadas estão representadas no diagrama UML simplificado da Figura 8.3.

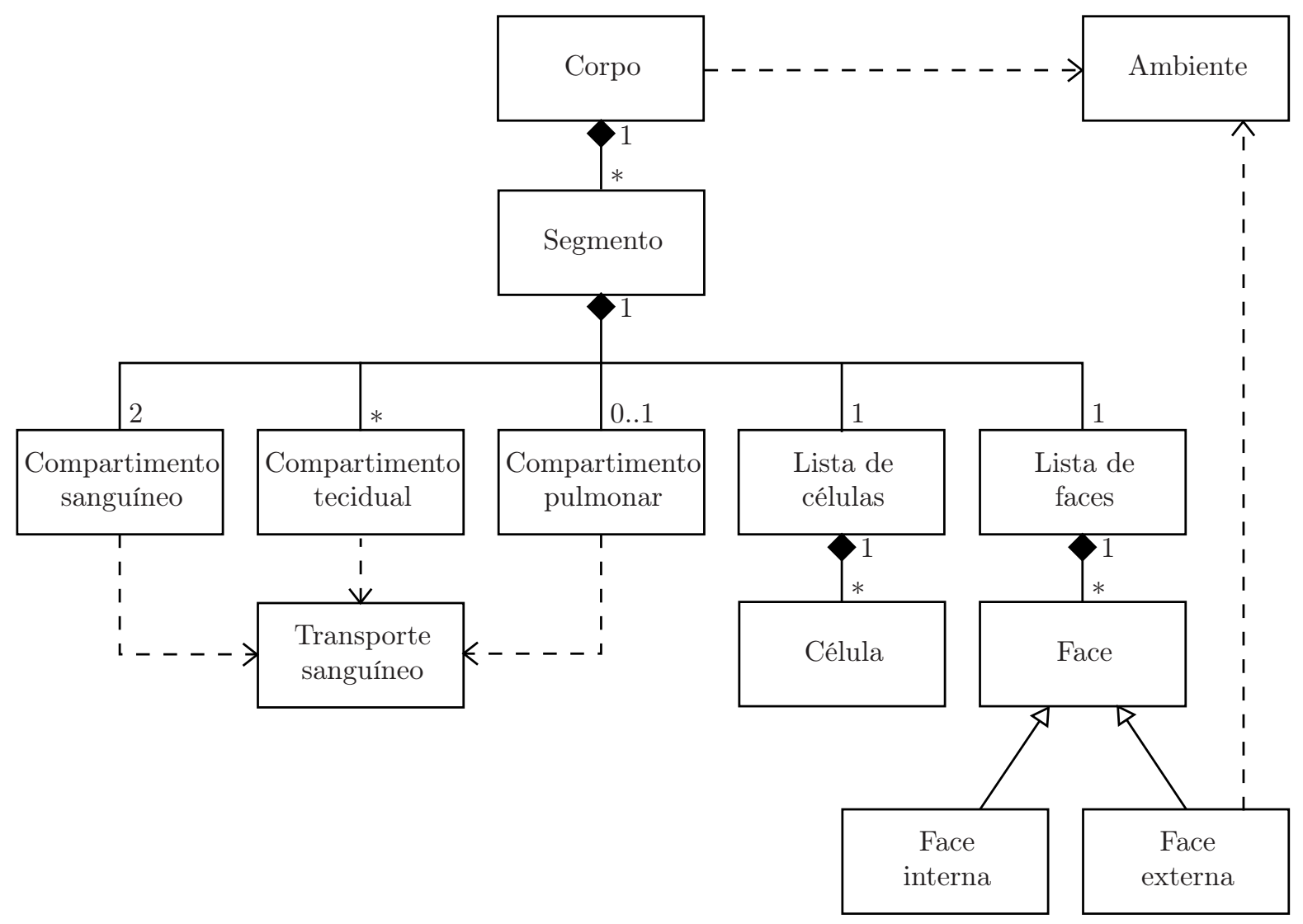

Figura 8.3 - Modelo de classes simplificado da implementação computacional (notação UML)

A classe "Corpo" contém os segmentos e as propriedades dos tecidos. Tem métodos para criação dos segmentos e para realização do cálculo. A classe "Ambiente" contém as condições ambientais e seus métodos de cálculo. A classe "Segmento" pode ser considerada a classe principal do modelo. Contém a lista de células e faces e os compartimentos sanguíneos e teciduais. Também contém informações sobre sua geometria, vazões de sangue e resistências de troca com o ambiente. No caso do tronco, contém também o compartimento pulmonar. Tem os principais métodos de cálculo.

A classe "Lista de faces" tem os métodos para criar as faces, representadas pela classe abstrata "Face", base para as classes "Face Interna" e "Face Externa". Estas classes contêm o endereço das células vizinhas e, no caso da "Face Externa", ligação com o ambiente. Na classe "Lista de células" estão os métodos para criar as células, que são representadas pela classe "Célula", que contém informações para o cálculo da temperatura nos tecidos e os endereços das faces vizinhas. 
Três classes são utilizadas para representar os compartimentos. A classe "Compartimento sanguíneo" contém informações dos compartimentos usados para representar os grandes vasos (arterial e venoso), como a temperatura, concentrações e pressões parciais dos gases. A classe "Compartimento tecidual" contém informações dos tecidos e pequenos vasos usadas para o cálculo da transferência de massa, como as concentrações e pressões parciais. Também contém as propriedades dos tecidos. A classe "Compartimento pulmonar" contém um conjunto de compartimentos que representam o transporte de massa no pulmão. São estes os compartimentos capilares pulmonares e o compartimento alveolar. Estas três classes utilizam a classe "Transporte sanguíneo", que contém métodos para calcular as relações de transporte dos gases no sangue. 


\section{Capítulo 9}

\section{Resultados}

Este capítulo mostra diversas simulações em situações distintas do modelo integrado dos sistemas respiratório e térmico do corpo humano. A primeira seção do capítulo tem como principal objetivo mostrar que o modelo representa corretamente o funcionamento desses sistemas. Isto é feito ao comparar as simulações com resultados experimentais encontrados na literatura. Foram selecionados trabalhos que representem situações de exposição a variações climáticas, baixas concentrações de $\mathrm{O}_{2}$, altas concentrações de $\mathrm{CO}_{2}$ e exercício físico.

As outras seções do capítulo têm como objetivo mostrar e discutir as relações que ocorrem entre o sistema respiratório e o sistema térmico. Na segunda seção, é discutido o efeito da variação da temperatura ambiente nas diversas partes do corpo em regime permanente. Os resultados desta seção mostram a distribuição de variáveis importantes do modelo, tornando possível uma análise detalhada de seu comportamento. A terceira seção mostra como o comportamento do corpo em acidentes de descompressão pode ser alterado quando ocorre, ao mesmo tempo, diminuição da temperatura ambiente. A quarta e a quinta seção mostram, para três temperaturas ambientes, como o corpo humano se comporta durante uma exposição ao $\mathrm{CO}_{2}$ e durante a realização de exercício físico.

Uma observação deve ser feita quanto o significado da temperatura ambiente usada nos resultados. Em todas as situações, foi considerado que a temperatura radiante média é igual a temperatura do ar. Deste modo, o valor da temperatura do ambiente é o mesmo da temperatura operativa.

As atividade físicas usadas nos resultados foram obtidas da Tabela 4.3, a não ser quando se trata de alguma comparação com um experimento em que seu valor foi informado. 


\subsection{Comparação com dados experimentais da literatura}

Nesta seção, os resultados das simulações do modelo são comparados com dados experimentais encontrados na literatura. As duas primeiras subseções mostram comparações em regime permanente, uma com valores de referência da respiração e outra com variações da temperatura ambiente. As outras seções mostram comparações em regime transitório durante exposição a ambiente frio, a ambiente quente, a falta de $\mathrm{O}_{2}$ (altitude e concentração baixa no ambiente), ao $\mathrm{CO}_{2}$, e durante exercício físico (respiração e termorregulação). Um trabalho experimental foi selecionado para cada uma dessas situações.

$\mathrm{Na}$ comparação com resultados experimentais existem algumas dificuldades. Uma delas ocorre porque os trabalhos experimentais disponibilizam somente os dados usados para cumprir seus objetivos. Outra dificuldade é a diferença existente entre indivíduos. O presente modelo foi desenvolvido para representar uma pessoa padrão, o que não ocorre nos experimentos. As diferenças fisiológicas e antropométricas podem fazer com que as respostas do corpo sejam diferentes.

Os dados de entrada usados nas simulações (como atividade física, vestimentas e condições do ambiente), quando não informados pelos autores dos experimentos, foram escolhidos com o objetivo de representar a situação do experimento.

Não foram feitas mudanças no modelo para representar os dados experimentais. A mudança de parâmetros do modelo poderia fazer com que os resultados das simulações coincidissem com os experimentais. Entretanto, essas mudanças teriam que ser feitas para cada experimento. Neste trabalho, foi decidido pela manutenção dos parâmetros do modelo nos valores padrões e, no caso do sistema regulador, pelos valores usados nas referências.

Mesmo com essas dificuldades e escolhas, é possível observar, nas comparações a seguir, coerência entre as simulações e os dados experimentais, assim como uma grande semelhança na forma com que as variáveis são alteradas.

\subsubsection{Respiração em situação normal}

A Tabela 9.1 mostra valores de referência de variáveis relacionadas ao sistema respiratório em uma situação normal. Estas variáveis caracterizam o estado do $\mathrm{O}_{2}$ e do $\mathrm{CO}_{2}$ no pulmão e no sangue. Os dados do modelo apresentados na tabela foram obtidos considerando que o indivíduo estava em uma situação próxima do conforto térmico (nu, com temperatura operativa de $30{ }^{\circ} \mathrm{C}$, e umidade relativa de $50 \%$ ), com atividade de uma pessoa sentada e quieta $(108 \mathrm{~W})$. Os resultados teóricos estão dentro da faixa dos valores de referência (com exceção da $P_{O_{2}}$ alveolar, que é 0,5\% maior que o limite). 
Tabela 9.1 - Comparação de valores de referência da respiração com resultados do modelo

\begin{tabular}{lrrl}
\hline Variável & Referência & Modelo & Unidade \\
\hline Alveolar & & & \\
Pressão parcial de $\mathrm{O}_{2}$ & $96,6-104,2^{c}$ & 104,7 & $\mathrm{mmHg}$ \\
$\quad$ Pressão parcial de $\mathrm{CO}_{2}$ & $38,6-40,7^{c}$ & 39,0 & $\mathrm{mmHg}$ \\
Sangue arterial & $97^{a}$ & 97,4 & $\%$ \\
$\quad$ Saturação de $\mathrm{O}_{2}$ & $80-100^{a}$ & 95,0 & $\mathrm{mmHg}$ \\
Pressão parcial de $\mathrm{O}_{2}$ & $35-45^{a}$ & 39,3 & $\mathrm{mmHg}$ \\
Pressão parcial de $\mathrm{CO}_{2}$ & $7,38-7,44^{a}$ & 7,40 & \\
pH & & & \\
Sangue venoso & $60-85^{a}$ & 63,8 & $\%$ \\
Saturação de $\mathrm{O}_{2}$ & $29,5-48,5^{b}$ & 33,6 & $\mathrm{mmHg}$ \\
Pressão parcial de $\mathrm{O}_{2}$ & $46,9-54,3^{b}$ & 47,2 & $\mathrm{mmHg}$ \\
Pressão parcial de $\mathrm{CO}_{2}$ & $7,32-7,40^{b}$ & 7,37 & \\
pH &
\end{tabular}

${ }^{a}$ Kratz et al. (2005); ${ }^{b}$ Altman, Gibson Jr. e Wang (1958); ${ }^{c}$ Lambertsen (1974a)

\subsubsection{Variações da temperatura ambiente}

Werner e Reents (1980) realizaram 86 experimentos com 6 indivíduos em uma câmara climática com $16 \mathrm{~m}^{3}$ de capacidade. Os indivíduos tinham entre 21 e 27 anos, com peso médio igual a 74,2 kg e altura média igual a 1,806 m. Usavam apenas shorts e estavam deitados em uma rede. No início do experimento, os indivíduos permaneciam deitados durante 1 hora a $30^{\circ} \mathrm{C}$. Depois, eram expostos uma temperatura constante do ar entre 20 e $50{ }^{\circ} \mathrm{C}$ por $120 \mathrm{~min}$, ou a $10{ }^{\circ} \mathrm{C}$ por $90 \mathrm{~min}$. As flutuações da temperatura eram menores que $0,2{ }^{\circ} \mathrm{C}$. A umidade relativa do ar foi mantida a $40 \pm 5 \%$. A velocidade do ar era menor do que $0,2 \mathrm{~m} / \mathrm{s}$. A diferença entre a temperatura das paredes e do ar era no máximo de $1{ }^{\circ} \mathrm{C}$.

Foram medidas a temperatura da pele em 12 locais diferentes, a temperatura do reto e a temperatura do tímpano com o uso de termopares. A evaporação foi medida em 6 locais diferentes com condensadores de umidade. Outra medição realizada foi da vazão de sangue, usando o método fluviográfico. Este método, segundo os autores do experimento, tem um erro que pode ser maior do que $10 \%$.

A Figura 9.1 mostra gráficos que comparam os resultados experimentais de Werner e Reents (1980) com resultados teóricos gerados pelo presente modelo. Os dois primeiros gráficos mostram a temperatura em diversas partes do corpo. Nas temperaturas internas, a do tímpano experimental foi comparada com a do cérebro teórica e a do reto com a das vísceras. Nas temperaturas da pele, a da testa experimental foi comparada com a da cabeça teórica, a do dedo da mão com a da mão, a do peito com a do tronco, e a do dedão do pé com a do pé. As outras temperaturas da pele comparadas foram as do braço, do antebraço, da coxa e da perna. Todas essas temperaturas foram medidas em 5 temperaturas do ambiente: 10, 20, 30, 40 e $50{ }^{\circ} \mathrm{C}$. Comparações similares foram feitas nos 
outros gráficos, entre medições da evaporação e da vazão de sangue em alguns membros do corpo e resultados teóricos dos segmentos. Estas duas variáveis foram medidas com as temperaturas do ambiente iguais a: 10, 20, 30, 35, 40 e $45^{\circ} \mathrm{C}$.

As simulações para obter os dados teóricos foram feitas considerando que o indivíduo estava sem vestimentas, no nível do mar, com a velocidade do vento nula e com a atividade física de uma pessoa repousando na cama (90 W). Para obter os valores das variáveis usadas na comparação, foram realizadas simulações seguindo o mesmo procedimento do experimento $-1 \mathrm{~h}$ a $30{ }^{\circ} \mathrm{C}$ e mais 90 ou $120 \mathrm{~min}$ na temperatura final -. Os gráficos mostram os valores finais dessas simulações, para as exposições a 10, 20, 30, 35, 40, 45 e $50{ }^{\circ} \mathrm{C}$.

A Figura 9.1a e a Figura 9.1b mostram comparações da temperatura interna e diversas temperaturas da pele dos resultados experimentais com os resultados teóricos. Uma conclusão importante, que foi discutida pelos autores do experimento, é a grande faixa de variação da temperatura dos membros periféricos no ambiente frio. Segundo eles, isto é uma consequência da diminuição do fluxo sanguíneo periférico com o objetivo de proteger o núcleo do corpo, prejudicando as áreas periféricas. Já durante a exposição a altas temperaturas do ambiente, a faixa de variação das temperaturas é pequena. As temperaturas da pele se aproximam das temperaturas internas. As temperaturas internas permanecem quase constantes durante as exposições de 10 a $45{ }^{\circ} \mathrm{C}$. Quando a temperatura do ar é igual a $50^{\circ} \mathrm{C}$, seu valor é significadamente maior que os outros. Isto ocorre porque, nesta temperatura, os dois mecanismos termorreguladores relacionados com ambientes quentes - a sudorese e a vasodilatação - estão eu seus limites máximos de atuação. As variações das temperaturas obtidas com as simulações são próximas das temperaturas experimentais. Diferenças entre os resultados ocorrem principalmente a $40{ }^{\circ} \mathrm{C}$, em que todas as temperaturas experimentais estão entre as temperaturas internas e as da pele do modelo. Outras diferenças significativas ocorrem nos ambientes mais frios $\left(10\right.$ e $\left.20{ }^{\circ} \mathrm{C}\right)$. Nestes, as temperaturas experimentais estão próximas das teóricas na cabeça, no tronco e na coxa e são inferiores nos outros locais. Os únicos locais em que é possível notar uma grande diferença são a mão e o pé, que foram comparados com medições em pontos mais extremos (dedos).

Na Figura 9.1c e na Figura 9.1d, estão os resultados teóricos e experimentais da perda de calor por evaporação em diversos pontos da pele. A evaporação permanece baixa e constante enquanto a temperatura do ar é inferior a $30{ }^{\circ} \mathrm{C}$. Nesta faixa, ela representa a difusão de água entre a pele e o ar, sem a ação das glândulas sudoríparas. Os resultados teóricos são, neste caso, um pouco superiores aos resultados experimentais. Acima de $30{ }^{\circ} \mathrm{C}$, a evaporação aumenta quase que linearmente até os $45^{\circ} \mathrm{C}$. A pequena diferença na variação da evaporação entre 45 e $50{ }^{\circ} \mathrm{C}$ ocorre porque a superfície da pele 
(a)

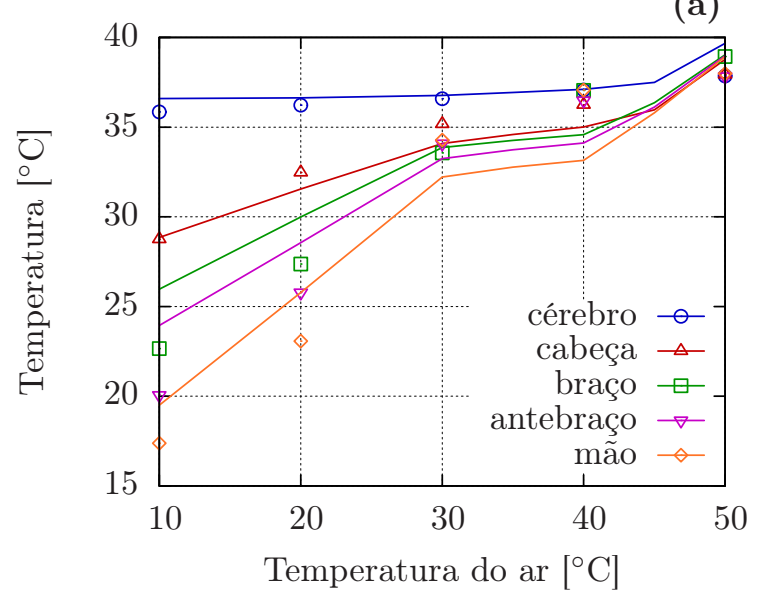

(c)

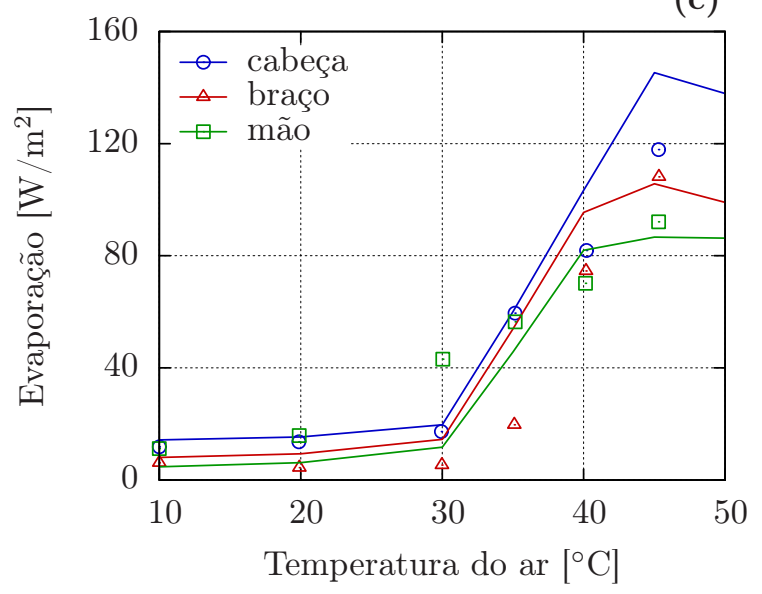

(e)

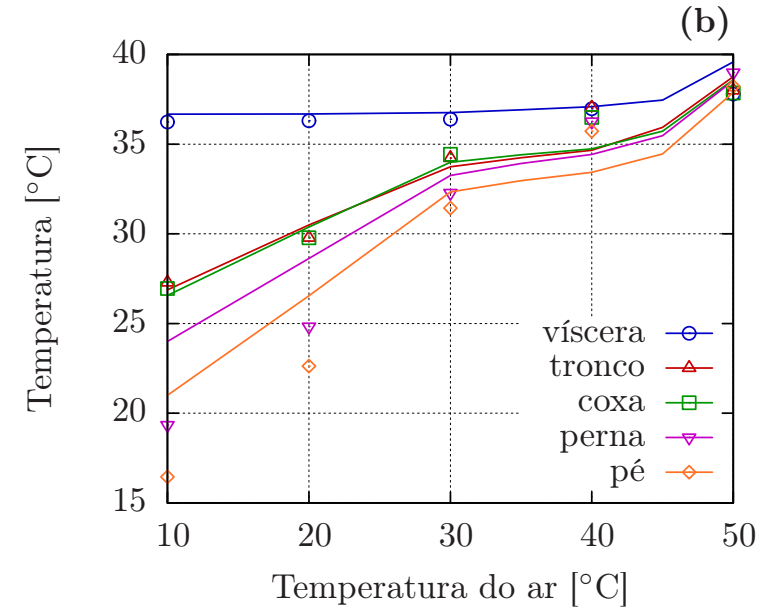

(d)

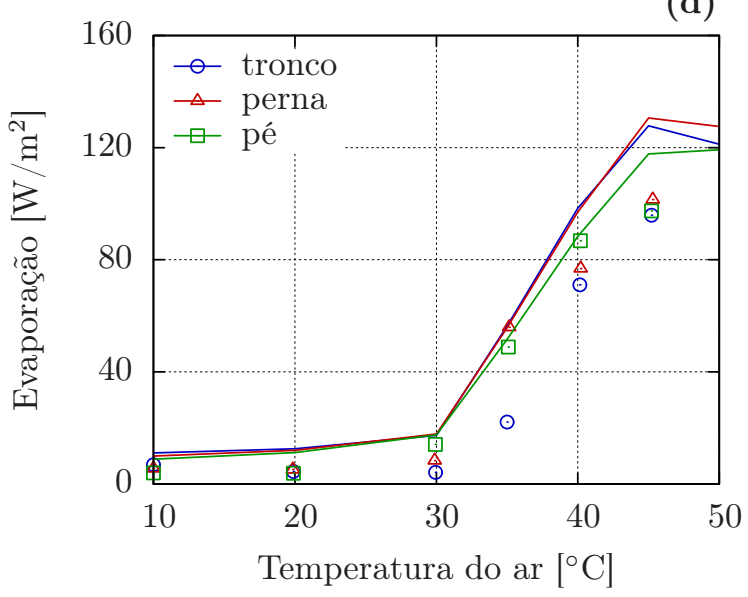

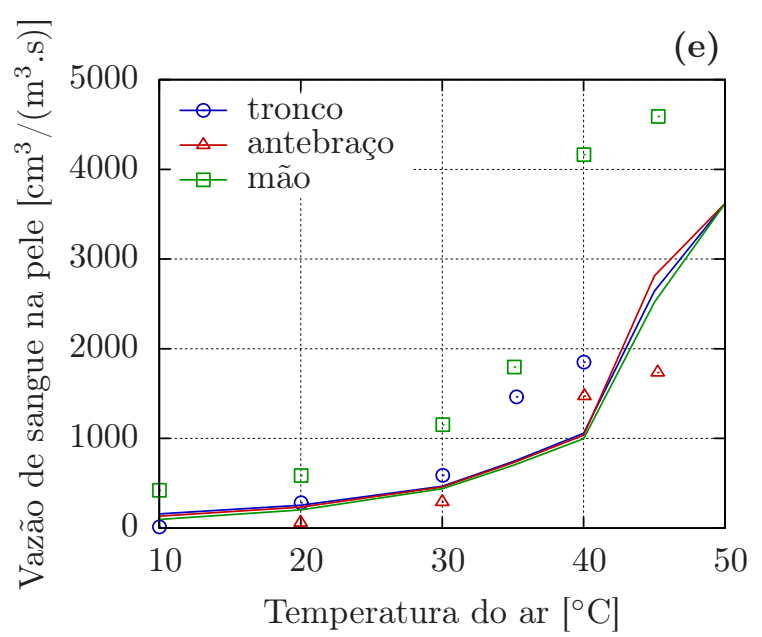

Figura 9.1 - Comparação das temperaturas internas e da pele (a, b), da evaporação (c, d) e da vazão de sangue na pele (e) de alguns segmentos (linhas) com dados experimentais de Werner e Reents (1980) (pontos) para variação da temperatura ambiente 
fica completamente molhada, limitando assim a capacidade da transferência de calor por evaporação.

O último gráfico (Figura 9.1e) mostra a variação da vazão de sangue na pele para o tronco, o antebraço e a mão. A vazão de sangue aumenta conforme aumenta a temperatura do ambiente. A variação é menor nos ambientes frios do que nos quentes. Assim como no caso da evaporação, os resultados teóricos mostram a saturação do sistema de regulação na temperatura de $50{ }^{\circ} \mathrm{C}$. Os resultados teóricos variam pouco entre membros diferentes. Já nos resultados experimentais, a diferença entra as vazões de sangue para uma mesma temperatura do ar são maiores.

\subsubsection{Exposição a ambiente frio}

Raven e Horvath (1970) e Raven et al. (1970) realizaram experimentos de exposição ao frio com 11 indivíduos. A média da área superficial dos indivíduos (ponderada dependendo do número de exposições) era de $1,87 \mathrm{~m}^{2}$. Vestiam somente shorts atlético. Ficaram primeiro em descanso durante uma hora em posição de supino em uma cama de tiras de nylon. As condições ambientais eram de $28 \pm 1{ }^{\circ} \mathrm{C}$ com umidade relativa igual a $45 \pm 2 \%$ e velocidade do ar menor que $0,4 \mathrm{~m} / \mathrm{min}$. As medições iniciaram na metade do tempo de descanso. Após este período, o indivíduo era coberto e transferido para uma câmara vizinha. Nesta as condições eram de $5 \pm 1^{\circ} \mathrm{C}$, umidade relativa de $70 \pm 2 \%$ e velocidade do ar $<0,4 \mathrm{~m} / \mathrm{min}$. Depois de 10 minutos - tempo em que os instrumentos eram ligados aos monitores -, o cobertor era retirado e as medições inciavam.

As medições eram feitas de 10 em 10 minutos. O débito cardíaco e a geração de calor foram determinados a partir de medições da ventilação, da quantidade de $\mathrm{O}_{2}$ e $\mathrm{CO}_{2}$ do ar expirado e do consumo de $\mathrm{O}_{2}$. Foram também medidas as temperaturas em diversos pontos da pele (coxa, dedão do pé, um dedo da mão, peito e testa) e a temperatura retal. Esses resultados experimentais foram usados por Gordon, Roemer e Horvath (1976) para calibrar e validar seu modelo do sistema térmico.

Os gráficos da Figura 9.2 comparam esses dados experimentais com resultados do presente modelo para um degrau nas condições ambientais. Os pontos experimentais das temperaturas foram obtidos de Raven e Horvath (1970). Os outros pontos foram obtidos de Raven et al. (1970). Barras de erro mostrando o desvio padrão das medições então presentes nos gráficos, exceto para as temperaturas locais da pele.

Na simulação, foi considerado que o indivíduo estava sem vestimentas, no nível do mar, com a velocidade do ar nula e atividade física de uma pessoa repousando na cama $(90 \mathrm{~W})$. 

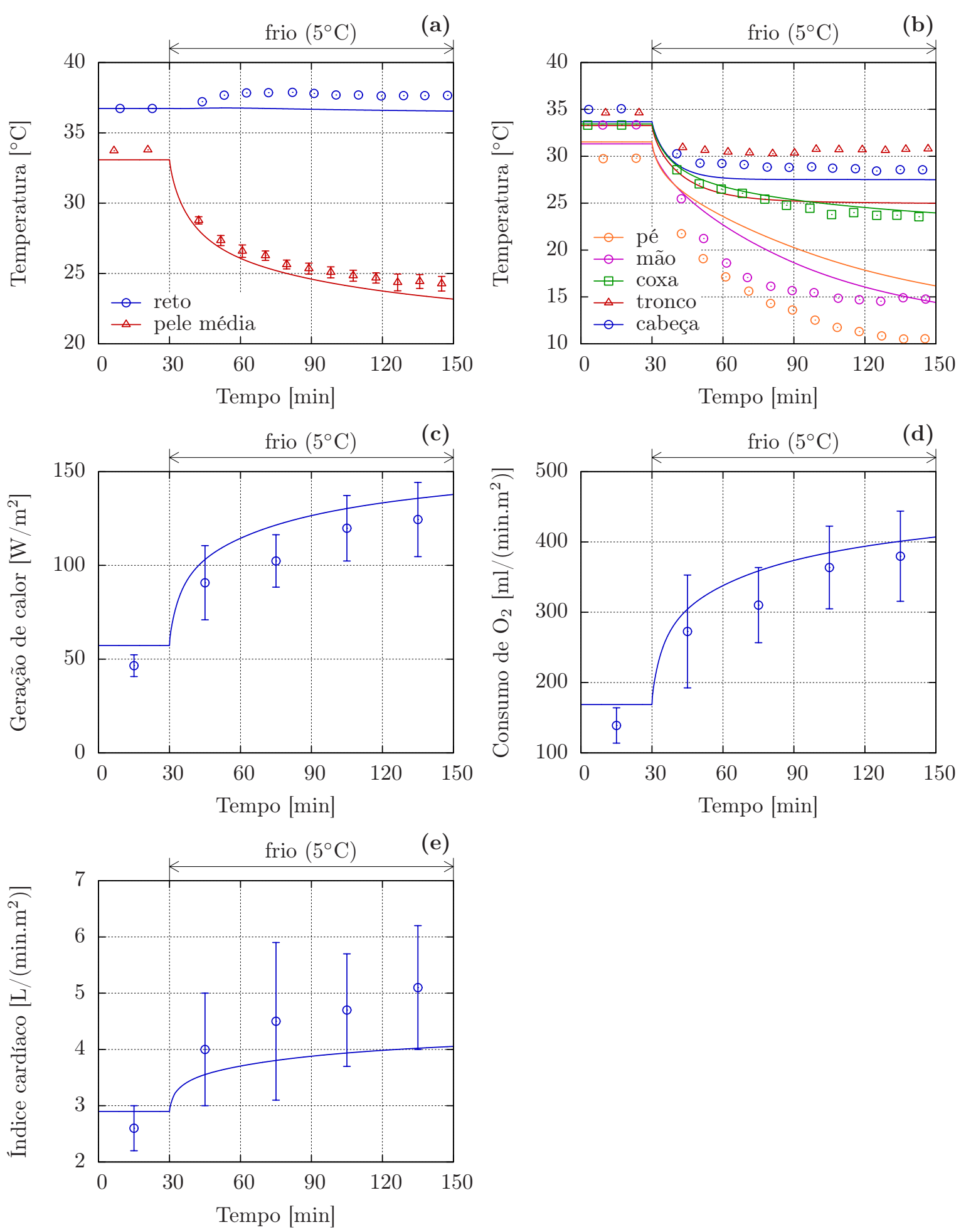

Figura 9.2 - Comparação da temperatura retal, da pele média (a) e de diversos pontos da pele (b), da geração de calor (c), do consumo de $\mathrm{O}_{2}$ (d) e do índice cardíaco (e) do presente modelo (linha contínua) com dados experimentais de Raven e Horvath (1970) e Raven et al. (1970) (pontos) para variação do ambiente de $28^{\circ} \mathrm{C}$ para $5{ }^{\circ} \mathrm{C}$ 
Na Figura 9.2a as temperaturas retal e média da pele são comparadas com resultados teóricos. A temperatura retal aumentou um pouco durante a exposição ao frio. Este aumento ocorre devido ao efeito de dois mecanismos reguladores: o calafrio e a vasoconstrição. O resultado teórico também aumentou após o início da exposição, porém, menos que o experimental. Já no caso da temperatura da pele média, a diminuição ocorre por causa da proximidade com o ambiente. A temperatura da pele média obtida pelo modelo é um pouco inferior aos resultados experimentais em todos os momentos.

A Figura 9.2b mostra comparações entre resultados teóricos e experimentais para diversos pontos da pele. As temperaturas diminuem durante a exposição ao frio. Nos dados experimentais, o peito é o local que menos diminui. No gráfico, foi comparado com a temperatura da pele média do segmento que representa todo o tronco. Esta temperatura teórica é inferior à experimental em toda a duração do experimento. O segundo local em que a temperatura menos diminuiu foi a testa. Esta foi comparada com a temperatura da pele média do segmento da cabeça. O resultado teórico, neste caso, é um pouco inferior ao experimental. Tantos os resultados teóricos como os experimentais, da cabeça e do tronco, chegaram a patamares onde as temperaturas são quase constantes. Este não foi o caso dos outros três locais medidos, em que as temperaturas continuaram diminuindo durante toda a exposição ao frio. Para a coxa, o resultado teórico é praticamente igual ao experimental. O dedão do pé e o dedo da mão são os locais que mais esfriam durante a exposição. Foram comparados respectivamente com os resultados teóricos médio da pele dos segmentos do pé e da mão.

A Figura 9.2c mostra o aumento da geração de calor que ocorre durante a exposição ao ambiente frio. O principal motivo deste aumento é o calafrio. Os resultados teóricos estão próximos dos resultados experimentais. A forma das curvas dos resultados, porém, difere um pouco. Nos resultados experimentais, a geração de calor parece aumentar mais suavemente que os resultados teóricos, no entanto, ambas têm seus valores muito próximos no final. Na Figura 9.2d, que mostra o aumento do consumo de $\mathrm{O}_{2}$, os resultados experimentais e teóricos variam de forma muito similar à geração de calor.

A Figura 9.2e mostra o índice cardíaco, que é a relação entre o débito cardíaco e a área superficial. O índice cardíaco aumenta durante a exposição ao frio. Este aumento ocorre principalmente por causa do aumento da vazão de sangue nos músculos, que está diretamente relacionado com a geração de calor. O resultado teórico durante a exposição é inferior ao resultado experimental. Este último tem grande variação entre os indivíduos que participaram do experimento, fato que pode ser notado pela amplitude do desvio padrão. 


\subsubsection{Exposição a ambiente quente}

Stolwijk e Hardy (1966b) realizaram experimentos com três indivíduos com o objetivo de estudar a resposta do corpo humano durante a exposição a um ambiente quente. Os indivíduos eram estudantes de uma escola profissional com boa saúde. Dois deles eram altos e magros e o outro tinha altura média e era obeso. A área superficial média dos três indivíduos era de $2,14 \mathrm{~m}^{2}$.

Foram usadas duas câmaras com a temperatura e umidade do ar controladas. Uma câmara estava com a temperatura próxima de $28{ }^{\circ} \mathrm{C}$, enquanto a outra estava com as condições do ambiente quente. A diferença entre a temperatura do ar e das paredes era controlada para ser menor do $1{ }^{\circ} \mathrm{C}$ durante o experimento. A umidade na câmara neutra era controlada de forma passiva para permanecer próxima de 35\%. Na câmara quente, foram usados secadores. O movimento do ar nas salas era menor que $10 \mathrm{~cm} / \mathrm{s}$.

Os indivíduos foram conectados aos termopares para a medição logo que chegaram no laboratório. Permaneceram então quietos por duas horas com a temperatura do ambiente neutra. Cada uma das cinco sequências de experimentos foi feita duas vezes em cada indivíduo. A primeira não será usada para as comparações com o modelo porque nela os indivíduos permaneceram a $28{ }^{\circ} \mathrm{C}$ durante todo o experimento. Nas outras, após o início das medições, permaneceram por uma hora na câmara com as condições neutras, depois duas horas no ambiente quente, depois voltaram para o ambiente neutro por mais uma hora. Em uma delas, a temperatura no início era de $27,8{ }^{\circ} \mathrm{C}$ e a umidade igual a $37 \%$; no ambiente quente, a temperatura era de $33,3{ }^{\circ} \mathrm{C}$ e a umidade $34 \%$; no final, a temperatura era de $28,0 \%$ e a umidade $37 \%$. Em outra sequência, as condições no início eram de $28,5^{\circ} \mathrm{C}$ e $40 \%$, no meio $37,5^{\circ} \mathrm{C}$ e $33 \%$ e no final $28,5^{\circ} \mathrm{C}$ e $41 \%$. Outra tinha as condições no início de $28,0{ }^{\circ} \mathrm{C}$ e $37 \%$, no meio $42,5{ }^{\circ} \mathrm{C}$ e $28 \%$ e no final $28,1{ }^{\circ} \mathrm{C}$ e $33 \%$. A última tinha no início $28,1{ }^{\circ} \mathrm{C}$ e $43 \%$, no meio $47,8{ }^{\circ} \mathrm{C}$ e $27 \%$ e no final $28,3{ }^{\circ} \mathrm{C}$ e $44 \%$. No presente trabalho, serão chamadas pelo valor da temperatura do ambiente quente, ou seja, $33,3,37,5,42,5$ e $47,8{ }^{\circ} \mathrm{C}$.

Com o uso de termopares, foram medidas as temperaturas timpânica, retal e da pele em 10 locais diferentes. O metabolismo foi calculado a partir de medições da quantidade de $\mathrm{O}_{2}$ no ar expirado. A perda de calor por evaporação na pele foi determinada pela medição contínua da variação da massa corpórea, após subtrair desta a diferença de massa entre o $\mathrm{CO}_{2}$ expirado e o $\mathrm{O}_{2}$ inspirado e a perda de água pela respiração.

Os gráficos da Figura 9.3 mostram comparações dos resultados experimentais de Stolwijk e Hardy (1966b) com resultados obtidos com o presente modelo das temperaturas, evaporação, metabolismo e ganho de calor. Para as simulações, considerou-se que o indivíduo estava sem vestimentas e repousando na cama $\left(50 \mathrm{~W} / \mathrm{m}^{2}\right.$ ou $\left.90 \mathrm{~W}\right)$. Para 
o ambiente, foram usadas as condições de temperatura e umidade do experimento, com velocidade do vento nula ao nível do mar.

A Figura 9.3a e a Figura 9.3b mostram respectivamente a temperatura retal e a temperatura do esôfago. Os resultados teóricos mostram as temperaturas dos modelos que são consideradas como representativas dessas. São elas a temperatura das vísceras e a temperatura do pulmão. Essas duas temperaturas internas do corpo aumentam durante a exposição ao ambiente quente, sendo maiores quanto maior for a temperatura do ambiente. Os valores iniciais das temperaturas experimentais são superiores aos valores teóricos. Esta diferença pode ser justificada por dois fatores: a diferença antropométrica dos indivíduos - a área superficial do presente trabalho é $1,8 \mathrm{~m}^{2}$, enquanto a do experimento é superior a $2 \mathrm{~m}^{2}$-, e diferenças nas condições inicias de atividade física entre simulação e experimento. O aumento das temperaturas durante a exposição ocorre tanto nos resultados teóricos como nos experimentais, porém, os valores teóricos também são inferiores aos experimentais.

A temperatura da pele (Figura 9.3c) também aumenta durante a exposição ao ambiente quente. Assim como a temperatura interna, o aumento é maior para temperaturas do ambiente mais elevadas. Os valores teóricos também são inferiores que os experimentais.

A Figura 9.3d mostra o calor perdido por evaporação na pele. Os resultados teóricos variam de forma muito parecida com os experimentais, porém, chegam a valores superiores conforme aumenta a temperatura do ambiente.

A Figura 9.3e mostra a geração de calor pelo metabolismo. Os resultados experimentais não apresentam variações significativas durante todo o experimento. Isto não acontece com os resultados teóricos, onde as gerações de calor antes e depois da exposição são superiores. Este aumento é resultado do calafrio. Nessas fases, a temperatura do ar é de aproximadamente $28{ }^{\circ} \mathrm{C}$ e a umidade relativa aproximadamente $40 \%$. Esta condição é considerada como neutra durante o experimento. Para o presente modelo, a situação de neutralidade térmica ocorre com a temperatura de $30{ }^{\circ} \mathrm{C}$ e a umidade relativa de $50 \%$. Assim como no caso da temperatura interna, diferenças antropométricas podem justificar uma maior capacidade de resistência ao frio pelos indivíduos. Outro motivo seria a possibilidade do corpo estar em uma zona neutra, em que o principal regulador da temperatura é o aparelho vasomotor. Segundo Savage e Brengelmann (1996), essa zona ocorre quando a temperatura da pele está entre 33 e $35^{\circ} \mathrm{C}$.

A Figura 9.3f mostra o ganho de calor do corpo - diferença entre o calor gerado pelo metabolismo e a perda total de calor -. Em uma situação de regime permanente, esse valor deve ser nulo, conforme ocorre no resultado teórico. Nos resultados experimentais, o corpo humano tem um certo débito de calor no início do experimento. Segundo os autores do experimento, este débito é resultado dos indivíduos estarem perdendo calor lentamente 

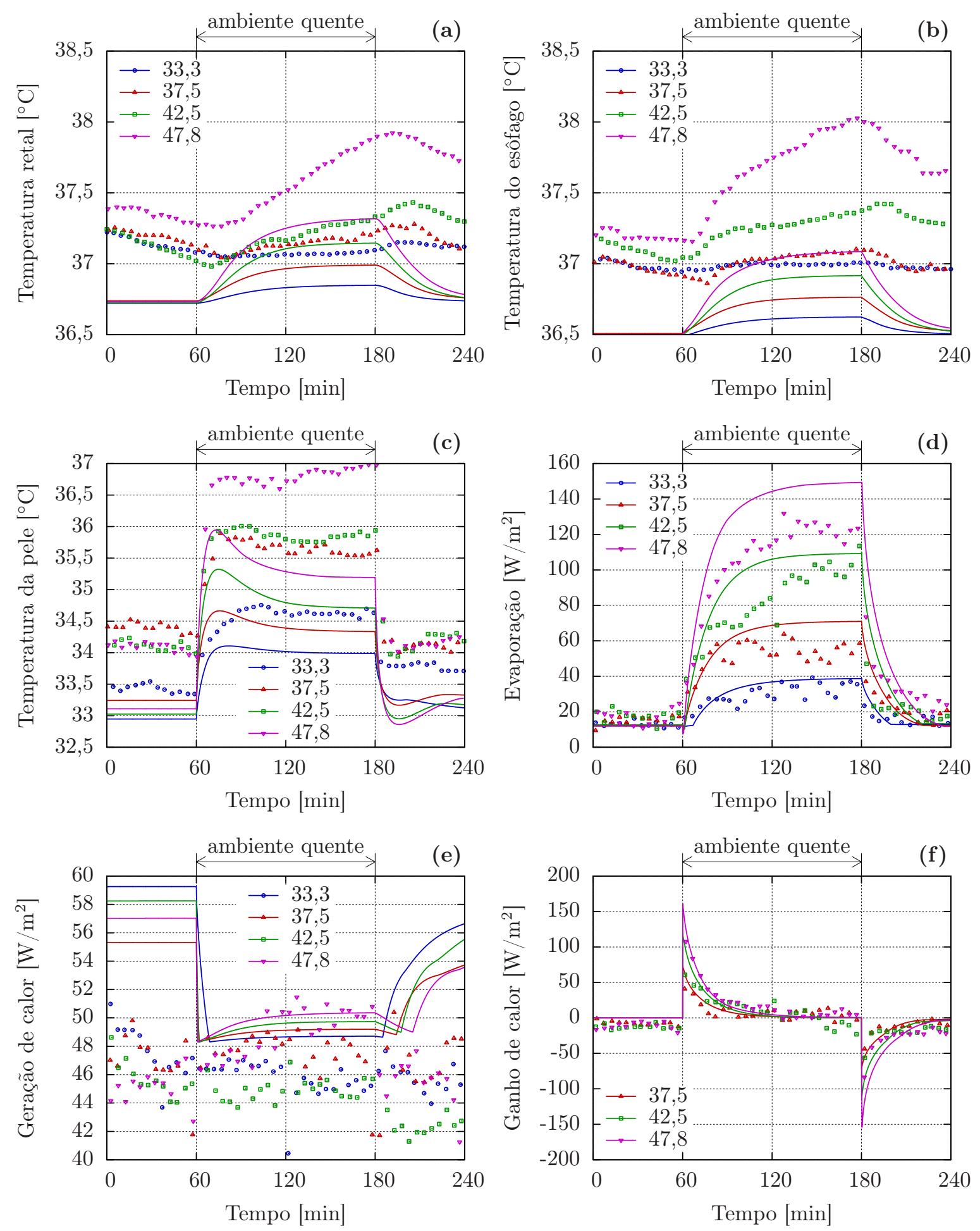

Figura 9.3 - Comparação da temperatura retal (a), da temperatura do esôfago (b), da temperatura média da pele (c), do calor perdido por evaporação pela pele (d), da geração de calor (e) e do ganho de calor (f) do presente modelo (linhas contínuas) com resultados experimentais de Stolwijk e Hardy (1966b) para exposição a ambientes quentes de $33,3,37,5,42,5$ e $47,8^{\circ} \mathrm{C}$ 
a $28{ }^{\circ} \mathrm{C}$, o que pode vir do fato desta temperatura não ser exatamente a neutralidade térmica de um indivíduo nu. Os resultados teóricos e experimentais são próximos durante a exposição ao calor. Na recuperação, os resultados experimentais voltam mais rápido para o valor inicial.

\subsubsection{Exposição a grandes altitudes}

Os experimentos de Rahn e Otis (1947) tiveram como objetivo obter dados do comportamento do corpo durante exposição aguda a grandes altitudes. Oito indivíduos saudáveis participaram do experimento, que foi conduzido em uma câmara hipobárica. Durante os testes, permaneceram sentados respirando por uma máscara. As altitudes simuladas foram de 12000, 16000, 18000, 20000 e 22000 pés.

As medições iniciaram 20 minutos antes da exposição da despressurização, para obter as condições iniciais. Neste momento, a altitude era de 540 pés (nível do solo). A subida para a altitude simulada ocorreu a uma taxa de $4500 \mathrm{ft} / \mathrm{min}$. Assim que a altitude final era atingida, as medições reiniciavam. As exposições às altitudes duraram uma hora para 12000, 16000 e 18000 pés, 45 minutos para 20000 pés e 30 minutos para 22000 pés. Nenhum indivíduo fez mais do que um experimento por dia.

Durante o experimento, foram medidas a $P_{\mathrm{O}_{2}}$ alveolar, a $P_{\mathrm{CO}_{2}}$ alveolar, a ventilação, a frequência respiratória, a saturação de $\mathrm{O}_{2}$ arterial e a frequência cardíaca. A partir desses dados, foram também calculados o quociente respiratório alveolar (relação entre $\mathrm{CO}_{2}$ expirado e $\mathrm{O}_{2}$ inspirado) e o consumo de $\mathrm{O}_{2}$.

A Figura 9.4 mostra seis gráficos comparando os resultados teóricos do presente modelo com os resultados experimentais de Rahn e Otis (1947). Das variáveis medidas e calculadas que foram citadas, somente a frequência cardíaca não foi usada por não ser uma variável do modelo. A frequência respiratória e a ventilação foram combinadas para a determinação da ventilação alveolar. Nas simulações, foi considerado que o indivíduo estava sem vestimentas, em um ambiente neutro (temperatura operativa de $30{ }^{\circ} \mathrm{C}$ e umidade relativa de $50 \%$ ) e com a atividade obtida a partir do consumo de $\mathrm{O}_{2}$ medido na fase inicial do experimento $(102,5 \mathrm{~W})$.

Na comparação entre os resultados teóricos e experimentais da $P_{\mathrm{O}_{2}}$ alveolar na Figura 9.4a, é possível observar grande semelhança entre as formas das curvas. Incluem uma queda brusca no inicio da descompressão, seguidas de uma redução suave. Os valores iniciais dos resultados experimentais coincidem com os resultados teóricos, enquanto os valores finais dos experimentais são inferiores aos teóricos. Embora ocorra esta última diferença, a diferença entre os valores finais do experimento são similares às diferenças entre os valores finais teóricos. 

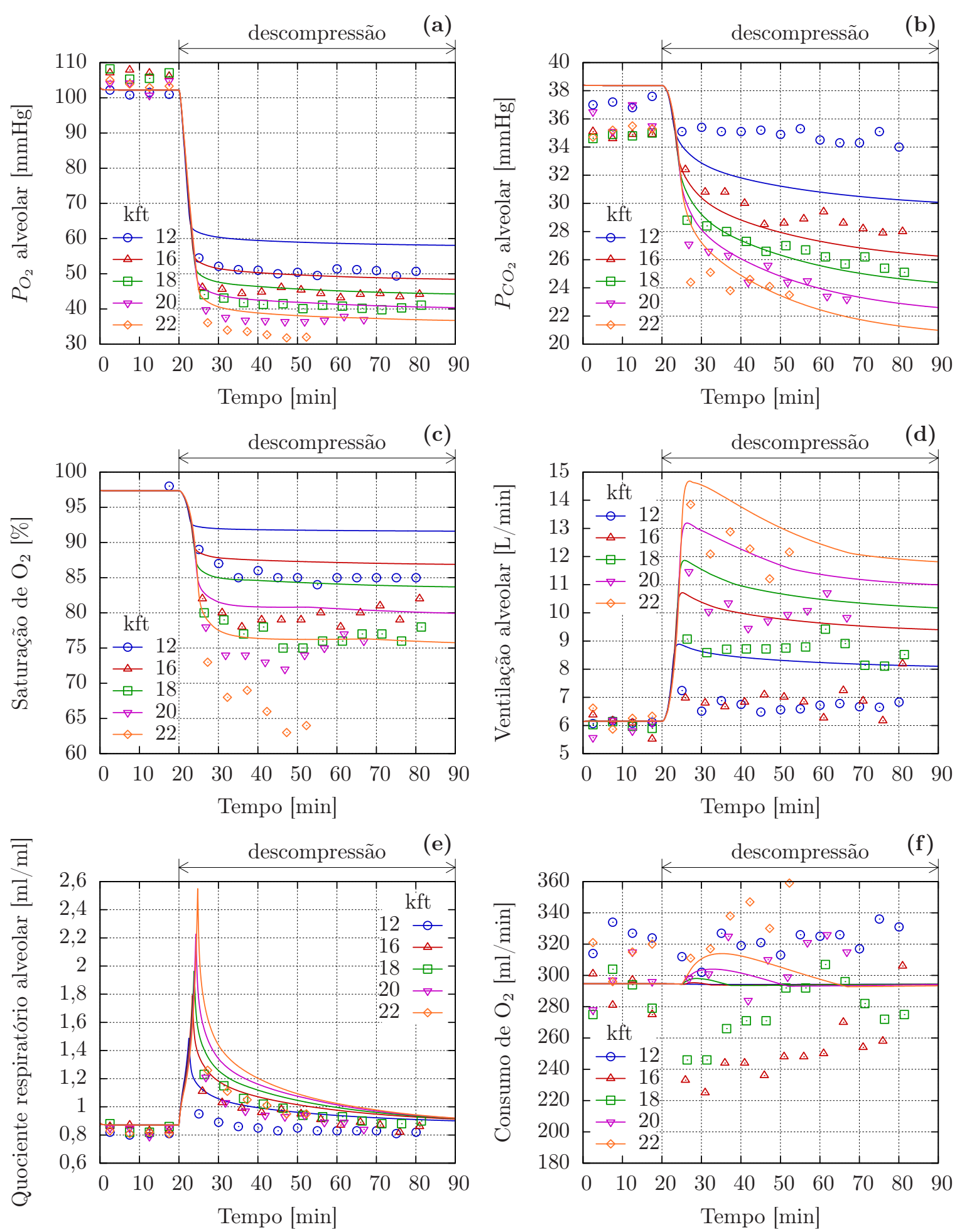

Figura 9.4 - Comparação da $P_{\mathrm{O}_{2}}$ alveolar (a), da $P_{\mathrm{CO}_{2}}$ alveolar (b), da saturação de $\mathrm{O}_{2}$ arterial (c), da ventilação alveolar (d), do quociente respiratório alveolar (e) e do consumo de $\mathrm{O}_{2}$ (f) do presente modelo (linhas contínuas) com resultados experimentais de Rahn e Otis (1947) para exposição a altitudes de 12000, 16000, 18000, 20000 e 22000 pés 
A Figura 9.4b mostra uma grande semelhança entre a $P_{\mathrm{CO}_{2}}$ alveolar teórica e experimental durante a descompressão, exceto quando a altitude é de 12000 pés. A diminuição da $P_{\mathrm{CO}_{2}}$ alveolar é mais suave que a $P_{\mathrm{O}_{2}}$ alveolar. O principal motivo disto é a maior capacidade dos tecidos de armazenar $\mathrm{CO}_{2}$. Nas condições iniciais, a $P_{\mathrm{CO}_{2}}$ teórica é superior a experimental. Entretanto, o valor teórico é coerente segundo dados apresentados por Lambertsen (1974a) de diversos autores, em repouso ao nível do mar, em que a $P_{\mathrm{CO}_{2}}$ alveolar varia de 38,6 a $40,7 \mathrm{mmHg}$.

Os resultados teóricos da saturação de $\mathrm{O}_{2}$ no sangue arterial (Figura 9.4c) chegam a patamares superiores aos experimentais, assim ocorre com a $P_{\mathrm{O}_{2}}$ alveolar.

A Figura 9.4d mostra a comparação dos resultados teóricos e experimentais para a ventilação alveolar (em BTPS). Os resultados teóricos são inferiores aos resultados experimentais. No entanto, observa-se que as formas das curvas são bem similares. Os resultados teóricos representam inclusive o sobressinal que ocorre no início da descompressão. A diminuição da ventilação depois deste momento, ocorre principalmente porque, no modelo do regulador, a ventilação é proporcional ao $\mathrm{CO}_{2}$ no sangue arterial e no cérebro. O fato da $P_{\mathrm{O}_{2}}$ alveolar e da saturação de $\mathrm{O}_{2}$ teóricas (Figuras 9.4a e 9.4c) serem maiores que as experimentais está relacionado com o fato da ventilação teórica ser maior que a experimental. O aumento da ventilação resulta em maior disponibilidade de $\mathrm{O}_{2}$.

A Figura 9.4e mostra o quociente respiratório alveolar teórico e experimental. No início da descompressão, o quociente respiratório teórico forma um pico com a amplitude dependendo do nível da descompressão. Após o pico, os resultados teóricos diminuem suavemente, fazendo uma curva com a forma próxima dos resultados experimentais. O pico pode ser explicado pela diminuição brusca da quantidade de $\mathrm{O}_{2}$ e a diminuição suave da quantidade de $\mathrm{CO}_{2}$. Como o quociente respiratório é a relação entre o $\mathrm{CO}_{2}$ e o $\mathrm{O}_{2}$, voltará ao valor inicial somente quando o $\mathrm{CO}_{2}$ chegar a um patamar final.

A Figura 9.4f mostra a comparação do consumo de $\mathrm{O}_{2}$ dos resultados teóricos com os experimentais. Estes últimos não parecem estar relacionados com a variação do nível de descompressão. Para as altitudes de 12000 e 20000 pés, os pontos parecem oscilar em torno de um valor praticamente constante. Para as altitudes de 18000 e 20000 pés, o consumo de $\mathrm{O}_{2}$ diminui logo após a descompressão, e depois volta para um valor próximo do inicial. Na altitude de 22000 pés, o consumo de $\mathrm{O}_{2}$ aumenta após o início da descompressão. Os resultados teóricos variam dentro de uma faixa inferior aos experimentais. O principal motivo do aumento do consumo de $\mathrm{O}_{2}$ na simulação após o início da descompressão é o aumento do calafrio. A atuação dos mecanismos termorreguladores durante a descompressão é discutida na Seção 9.3. 


\subsubsection{Exposição a baixa concentração de $\mathrm{O}_{2}$}

Reynolds e Milhorn Jr. (1973) fizeram duas séries de experimentos com exposições a 9, 8 e $7 \%$ de $\mathrm{O}_{2}$. Tinham como objetivo analisar a resposta transitória da ventilação, da $P_{\mathrm{O}_{2}}$ alveolar e da $P_{\mathrm{CO}_{2}}$ alveolar. Na primeira das séries, os indivíduos respiravam livremente; enquanto que na segunda, o $\mathrm{CO}_{2}$ inspirado era controlado para manter a $P_{\mathrm{CO}_{2}}$ alveolar constante. Os resultados das duas séries foram usados para determinar a inibição da ventilação causada pela diminuição do $\mathrm{CO}_{2}$ na hipoxia. A primeira série representa uma situação bem mais comum; portanto, será a única usada na comparação com os resultados do modelo.

Participaram do experimento dez indivíduos do sexo masculino, entre 22 e 29 anos de idade, sem problemas pulmonares ou cardíacos. Todos nasceram e viveram em baixas altitudes. Fumantes também realizaram o experimento, entretanto, ficaram pelo menos uma hora antes do teste sem fumar. Os indivíduos participaram no máximo de um experimento por dia.

Para as medições, foi utilizado um circuito onde o ar respirado pelo indivíduo era coletado. A ventilação, frequência respiratória, volume corrente, $P_{\mathrm{O}_{2}}$ alveolar e $P_{\mathrm{CO}_{2}}$ alveolar eram medidos continuamente, e depois agrupados em médias a cada 2 minutos. A exposição a frações baixas de $\mathrm{O}_{2}$ (em nitrogênio) durava 10 minutos. Os indivíduos permaneceram em uma cadeira reclinada confortável durante o experimento.

A Figura 9.5 mostra comparações dos resultados teóricos do modelo com os dados experimentais de Reynolds e Milhorn Jr. (1973), para a $P_{\mathrm{O}_{2}}$ alveolar, a $P_{\mathrm{CO}_{2}}$ alveolar e a ventilação.

A ventilação do experimento foi corrigida pelos autores para BTPS e para uma área superficial de $1,73 \mathrm{~m}^{2}$. Na comparação da Figura 9.5c, a ventilação experimental foi corrigida para a área superficial do presente trabalho (multiplicada por 1,8/1,73). A ventilação teórica está apresentada em BTPS.

$\mathrm{Na}$ simulação, foi suposto um ambiente neutro (temperatura operativa de $30{ }^{\circ} \mathrm{C}$ e umidade relativa de 50\%), no nível do mar e com velocidade do vento nula; com o indivíduo sem vestimentas, sentado e quieto (metabolismo de $60 \mathrm{~W} / \mathrm{m}^{2}$ ou $108 \mathrm{~W}$ ).

Na Figura 9.5a, a queda da $P_{\mathrm{O}_{2}}$ alveolar dos resultados teóricos são semelhantes aos resultados experimentais para os três níveis de hipoxia. Embora os valores atingidos no final dos resultados teóricos sejam um pouco inferiores, as formas são muito parecidas. Na recuperação após a hipoxia, a $P_{O_{2}}$ alveolar teórica retorna ao valor inicial mais rápido que a experimental. 

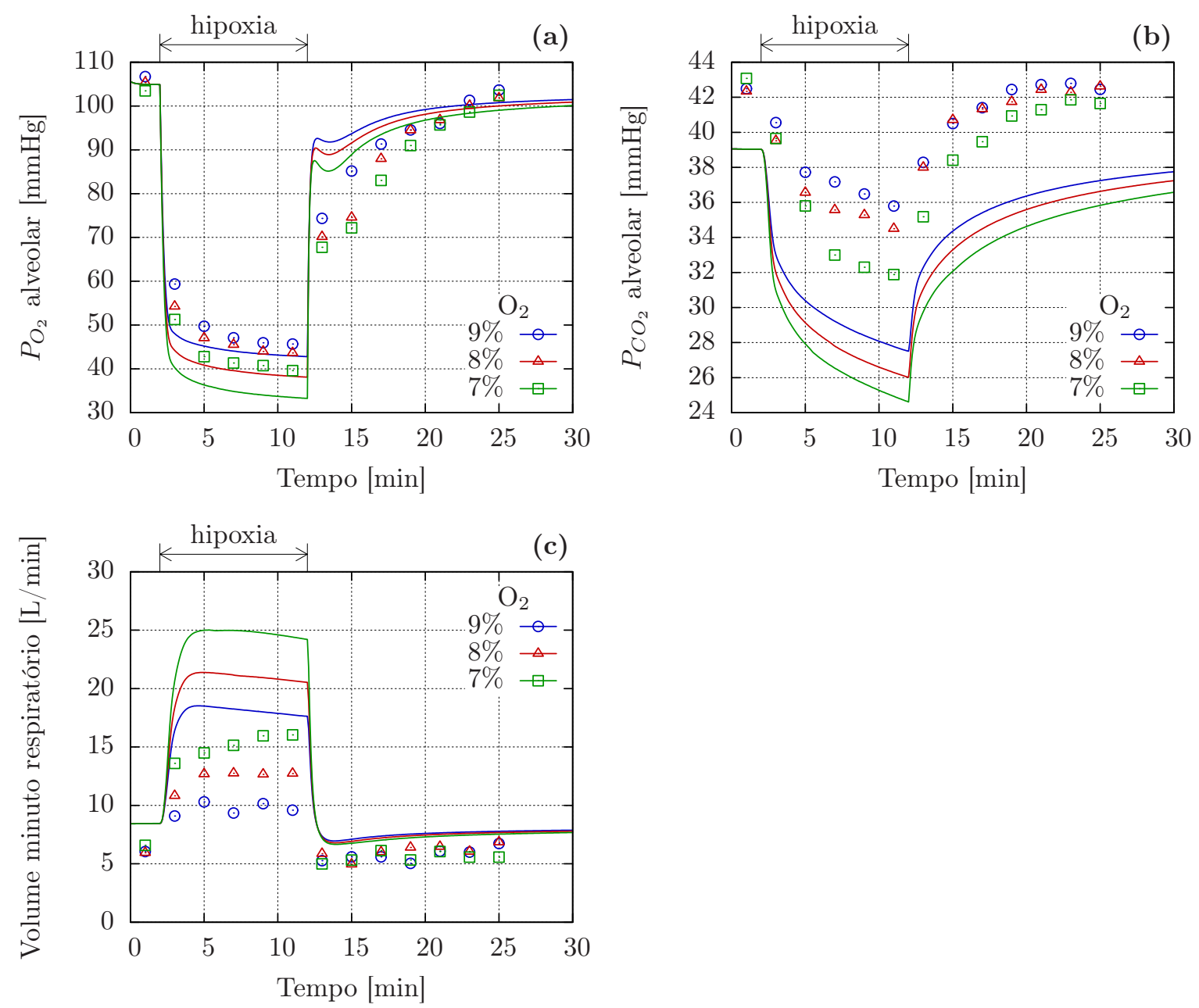

Figura 9.5 - Comparação da $P_{\mathrm{O}_{2}}$ alveolar (a), da $P_{\mathrm{CO}_{2}}$ alveolar (b) e do volume minuto respiratório (c) do presente modelo (linhas contínuas) com resultados experimentais de Reynolds e Milhorn Jr. (1973) para exposição a concentrações de $\mathrm{O}_{2}$ de 9,8 e $7 \%$

A forma da curvas da $P_{\mathrm{CO}_{2}}$ alveolar teóricas e experimentais da Figura 9.5b são muito parecidas, para todos os níveis de hipoxia. Entretanto, os valores teóricos são inferiores aos experimentais em todos os momentos. Assim como discutido na seção anterior, o valor inicial teórico está em uma faixa coerente, segundo valores apresentados por Lambertsen (1974a) de diversos autores. A queda da $P_{\mathrm{CO}_{2}}$ alveolar durante a hipoxia ocorre principalmente devido ao aumento da ventilação. Este ocorre para que o corpo aumente sua capacidade de captação de $\mathrm{O}_{2}$. Como consequência, o corpo acaba também aumentando sua capacidade de eliminação do $\mathrm{CO}_{2}$.

Na Figura 9.5c, os patamares atingidos pelas ventilações dos resultados teóricos são bem superiores aos experimentais. As formas das curvas, no entanto, são parecidas. Esta grande diferença entre a ventilação teórica e experimental também foi observada por Wolf e Garner (2007), ao compararem seu modelo do sistema respiratório com os mesmos dados experimentais. Justificaram que os autores do experimento padronizaram os resultados. 


\subsubsection{Exposição ao $\mathrm{CO}_{2}$}

Reynolds, Milhorn Jr. e Holloman Jr. (1972) realizaram experimentos com dez indivíduos do sexo masculino para analisar o comportamento da ventilação e das pressões parciais de $\mathrm{O}_{2}$ e $\mathrm{CO}_{2}$ alveolar durante hipercapnia. Os indivíduos respiraram uma mistura de ar com 3, 5, 6 e $7 \%$ de $\mathrm{CO}_{2}$ durante 25 minutos. O experimento foi realizado com o mesmo aparato experimental e os mesmos indivíduos do experimento realizado por Reynolds e Milhorn Jr. (1973). A metodologia do experimento também foi a mesma. Está descrita na Seção 9.1.6.

A Figura 9.6 mostra a comparação dos resultados teóricos do presente modelo com os resultados experimentais de Reynolds, Milhorn Jr. e Holloman Jr. (1972). Do mesmo modo que a comparação durante a hipoxia (Seção 9.1.6), a ventilação foi corrigida para a área superficial de 1,8 $\mathrm{m}^{2}$ e está em BTPS. A mesma situação dos indivíduos foi considerada para a simulação, ou seja, temperatura operativa de $30{ }^{\circ} \mathrm{C}$, umidade relativa de $50 \%$, sem vestimentas, nível do mar, atividade de uma pessoa sentada e quieta (108 W), velocidade do vento nula.

Na Figura 9.6a, a forma com que ocorre o aumento e a recuperação da $P_{\mathrm{O}_{2}}$ alveolar é parecida com a dos dados experimentais. Os valores durante a hipercapnia são muito próximos para 3 e $7 \%$ de $\mathrm{CO}_{2}$. O principal motivo pelo qual ocorre o aumento da quantidade de $\mathrm{O}_{2}$ é o aumento da ventilação para eliminar o $\mathrm{CO}_{2}$, que faz com que mais $\mathrm{O}_{2}$ seja captado pelo pulmão.

Os resultados da $P_{\mathrm{CO}_{2}}$ alveolar teórica (Figura 9.6b) são próximos dos experimentais durante a hipercapnia. Os dados experimentais apresentam um sobressinal nas exposições a 3 e $5 \%$ de $\mathrm{CO}_{2}$. Este sobressinal ocorreu na exposição a $3 \%$ de $\mathrm{CO}_{2}$ nos dados teóricos. Segundo Reynolds, Milhorn Jr. e Holloman Jr. (1972), os sobressinais nas exposições mais leves indicam que a ventilação foi suficiente para diminuir a $P_{\mathrm{CO}_{2}}$ alveolar. Já nas exposições mais críticas, a ventilação não é estimulada a um nível suficiente para eliminar o $\mathrm{CO}_{2}$ adicionado. Na fase de recuperação, os resultados teóricos apresentam um subsinal. Este sub-sinal ocorre porque a ventilação do presente modelo tem uma queda mais suave que a $P_{\mathrm{CO}_{2}}$ alveolar, ou seja, o pulmão permanece com uma capacidade elevada de eliminar $\mathrm{o}_{\mathrm{CO}_{2}}$ por mais tempo. Apesar de não aparecerem nos pontos experimentais do gráfico, seus autores discutiram que sub-sinais após a hipercapnia existiram para as exposições a 5, 6 e 7\% de $\mathrm{CO}_{2}$, quando os resultados são observados de forma contínua e não com valores médios.

A Figura 9.6c mostra formas muito semelhantes no aumento da ventilação teórica e experimental, tanto na fase de exposição ao $\mathrm{CO}_{2}$ como na fase de recuperação. Os valores teóricos são um pouco superiores aos experimentais, exceto na exposição mais crítica. 

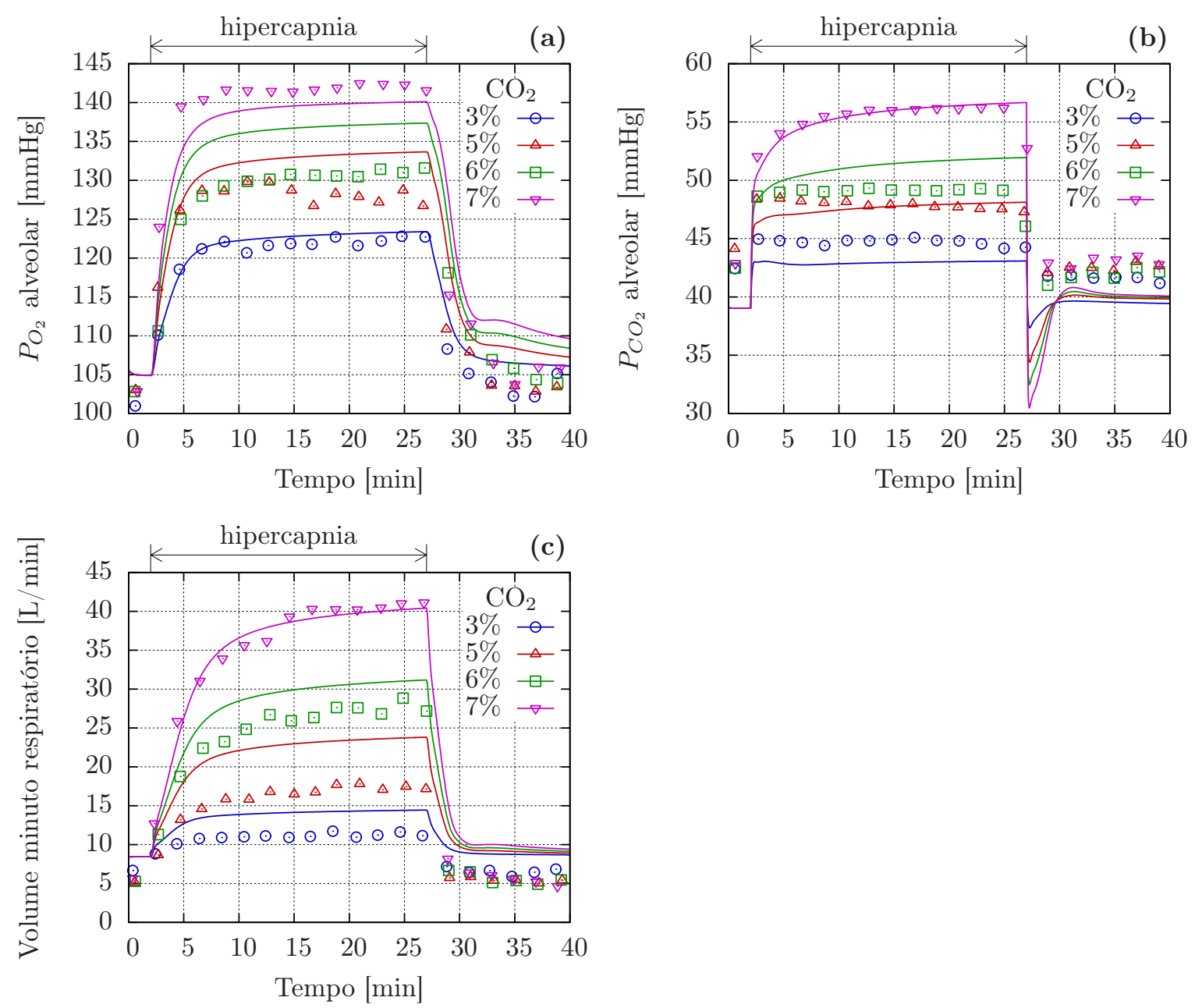

Figura 9.6 - Comparação da $P_{\mathrm{O}_{2}}$ alveolar (a), da $P_{\mathrm{CO}_{2}}$ alveolar (b) e do volume minuto respiratório (c) do presente modelo (linhas contínuas) com resultados experimentais de Reynolds, Milhorn Jr. e Holloman Jr. (1972) para exposição a concentrações de $\mathrm{CO}_{2}$ de 3, 5, 6 e $7 \%$

\subsubsection{Respiração durante exercício físico}

Os experimentos realizados por Cerretelli, Sikand e Farhi (1966) tiveram como objetivo estudar as relações entre o aumento do consumo de $\mathrm{O}_{2}$, da geração de $\mathrm{CO}_{2}$, da ventilação e do débito cardíaco durante o exercício físico e a fase de recuperação. O exercício foi realizado em uma esteira por dois indivíduos, andando em três velocidades diferentes $(3,2 \mathrm{~km} / \mathrm{h}, 4,9 \mathrm{~km} / \mathrm{h}$ e $6,8 \mathrm{~km} / \mathrm{h})$, com inclinação de $8 \%$. Esses três níveis de exercícios podem ser considerados como leve, moderado e pesado. Cada indivíduo realizou pelo menos duas vezes cada um dos níveis de exercícios; e somente um experimento por dia.

Antes de serem conectados ao circuíto de medição, os indivíduos permaneceram por 10 minutos sentados em uma cadeira. Depois de serem conectados, permaneceram mais 10 minutos em pé, ao lado da esteira. Logo após, subiram na esteira, que já estava com a velocidade e a inclinação ajustadas. 
O circuito utilizado para medição incluía um espirômetro e um espectrômetro de massa. Assim eram obtidos os níveis de $\mathrm{O}_{2}$ e $\mathrm{CO}_{2}$ do ar expirado e a ventilação. A partir desses dados e algumas relações fisiológicas, o consumo de $\mathrm{O}_{2}$, a geração de $\mathrm{CO}_{2}$, o débito cardíaco e as pressões parciais de $\mathrm{O}_{2}$ e $\mathrm{CO}_{2}$ no sangue foram calculados.

Nas Figuras 9.7 e 9.8, os dados obtidos por Cerretelli, Sikand e Farhi (1966) são comparados com os resultados obtidos pelo presente modelo para as mesmas condições do experimento. A legenda das figuras mostra as três velocidades da esteira. A Figura 9.7 mostra quatro gráficos: o consumo de $\mathrm{O}_{2}$, a geração de $\mathrm{CO}_{2}$, o volume minuto respiratório e o débito cardíaco. Os gráficos da Figura 9.8 mostram as pressões parciais de $\mathrm{CO}_{2}$ no sangue arterial e venoso, e a pressão parcial de $\mathrm{O}_{2}$ no sangue arterial.
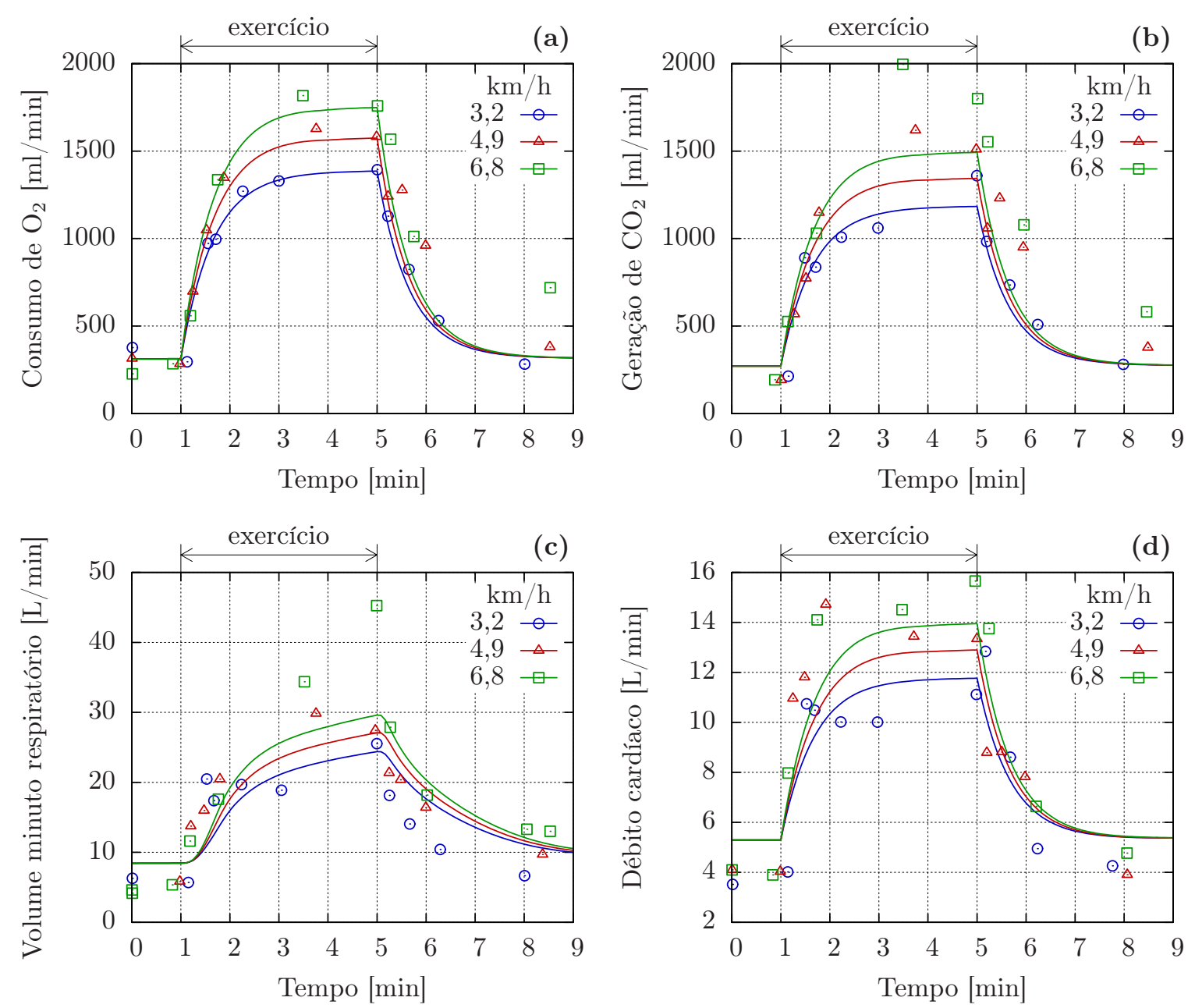

Figura 9.7 - Comparação do consumo de $\mathrm{O}_{2}$ (a), da geração de $\mathrm{CO}_{2}$ (b), do volume minuto respiratório (c) e do débito cardíaco (d) do presente modelo (linhas) com dados experimentais de Cerretelli, Sikand e Farhi (1966) (pontos) durante exercício físico e recuperação com três intensidades diferentes

As seguintes características foram consideradas para a simulação: temperatura operativa de $30{ }^{\circ} \mathrm{C}$, umidade relativa igual a $50 \%$, nível do mar, velocidade do ar nula, ar puro, vestimenta típica de verão (tênis, shorts e camiseta). 

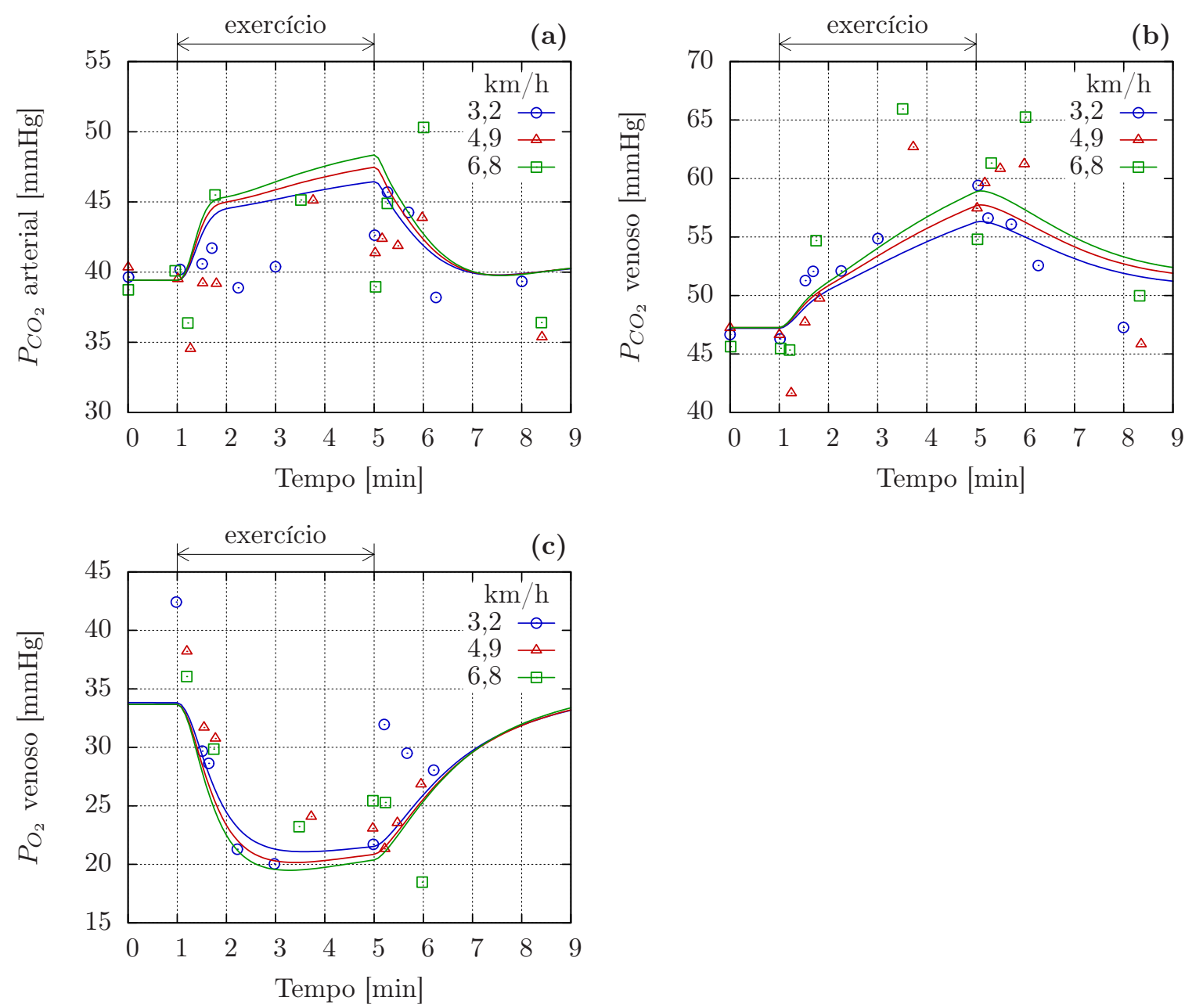

Figura 9.8 - Comparação da $P_{\mathrm{CO}_{2}}$ no sangue arterial (a), da $P_{\mathrm{CO}_{2}}$ no sangue venoso (b) e da $P_{\mathrm{O}_{2}}$ no sangue venoso (c) do presente modelo (linhas) com dados experimentais de Cerretelli, Sikand e Farhi (1966) (pontos) durante exercício físico e recuperação com três intensidades diferentes

As medições durante o período de descanso foram feitas logo após os indivíduos permanecerem 10 minutos sentados. Por isso, a atividade de um indivíduo sentado e quieto $\left(60 \mathrm{~W} / \mathrm{m}^{2}\right.$ ou $\left.108 \mathrm{~W}\right)$ é considerada na fase anterior e posterior ao exercício. Durante o exercício, os metabolismos usados como dados de entrada nas simulações para os três níveis de atividade foram obtidos a partir dos dados experimentais do consumo de $\mathrm{O}_{2}$. São iguais a 471, 535 e 594 W.

A variação do consumo de $\mathrm{O}_{2}$ deste experimento (Figura 9.7a) foi utilizada na determinação da constante de tempo do metabolismo em relação a um degrau de entrada na atividade (Seção 7.2.2).

Ao comparar a geração de $\mathrm{CO}_{2}$ teórica com a experimental (Figura 9.7b) observa-se que, para os níveis leve e moderado de exercício físico, os resultados estão próximos. Já para o exercício pesado, o resultado teórico ficou inferior ao experimental. Esta diferença vem do fato de que o modelo foi desenvolvido para funcionar até atividades moderadas. 
Em atividades pesadas, ocorrem diversas mudanças no corpo humano que não foram incluídas no modelo. Muitas dessas mudanças estão relacionadas com os reguladores. Outras ainda estão relacionadas com o metabolismo, que incluem a acidose causada pelo aumento da produção de ácido láctico, que resulta em aumento do quociente respiratório, ou seja, aumento da relação entre $\mathrm{CO}_{2}$ produzido e $\mathrm{O}_{2}$ consumido (BROBECK, 1974b).

A acidose causada durante o exercício pesado é um dos fatores que justifica a diferença da ventilação teórica e experimental da Figura 9.7c. Isso porque o íon $\left[\mathrm{H}^{+}\right]$é um dos principais estimuladores da ventilação. Durante os exercício leve e moderado, os resultados teóricos estão próximos dos experimentais.

Ao comparar o débito cardíaco teórico e experimental da Figura 9.7d, verifica-se que, no final do exercício, os resultados estão próximos. Já durante o início do exercício físico, o débito cardíaco dos resultados experimentais aumentam mais rápido que os teóricos, apresentando inclusive um sobressinal nos casos do exercício leve e moderado. O débito cardíaco teórico, no entanto, aumenta de forma suave.

$\mathrm{Na}$ fase de recuperação - após o exercício -, o consumo de $\mathrm{O}_{2}$ e a geração de $\mathrm{CO}_{2}$ teóricos só não estão próximos dos experimentais quando o exercício é pesado. Já para a ventilação e o débito cardíaco, os dados estão próximos em todos os níveis de exercício.

Quando se trata das comparações entre dados teóricos e experimentais das pressões parciais de $\mathrm{O}_{2}$ e $\mathrm{CO}_{2}$ no sangue (Figura 9.8), os resultados não são tão próximos como nos casos até então discutidos. Os dados experimentais da $P_{\mathrm{CO}_{2}}$ arterial (Figura 9.8a) apresentam uma tendência que não parece estar relacionada diretamente com o exercício físico. Para o exercício leve, a $\mathrm{P}_{\mathrm{CO}_{2}}$ arterial permanece praticamente constante durante todo o experimento. Para o exercício moderado e pesado, a $P_{\mathrm{CO}_{2}}$ arterial tem uma queda no início do exercício que, segundo Cerretelli, Sikand e Farhi (1966), ocorre devido a um excesso da resposta ventilatória ao trabalho. Nos resultados teóricos, a $\mathrm{P}_{\mathrm{CO}_{2}}$ arterial aumenta para todos os níveis de exercício. A amplitude deste aumento é apenas um pouco superior à amplitude da variação dos dados experimentais.

A $P_{\mathrm{CO}_{2}}$ do sangue venoso (Figura 9.8b), assim como a do sangue arterial, aumenta durante o exercício físico, porém, de forma mais lenta. Os resultados teóricos se aproximam dos resultados teóricos neste caso, com exceção da fase de recuperação. Nesta fase, as curvas teóricas retornam mais lentamente ao valor inicial.

Durante o exercício físico, a $P_{\mathrm{O}_{2}}$ do sangue venoso (Figura 9.8c) diminui rapidamente, tanto nos resultados teóricos como nos experimentais. A diferença observada entre os patamares alcançados para os três níveis de exercício físico é insignificante. O principal motivo desta diferença ser tão pequena é a atuação mais intensa dos reguladores conforme a intensidade do exercício. 


\subsubsection{Termorregulação durante exercício físico}

Saltin, Gagge e Stolwijk (1970) realizaram experimentos com o objetivo de estudar o efeito de transientes térmicos na termorregulação durante diferentes níveis de exercícios periódicos. Os experimentos foram realizados em três temperaturas diferentes do ambiente: 10, 20 e $30^{\circ} \mathrm{C}$. O exercício foi feito em uma bicicleta ergométrica. Três indivíduos participaram dos experimentos, porém, só um deles os fez nas três temperaturas ambiente. Os dados deste indivíduo também são os únicos apresentados com a duração de todo o experimento. Por esses motivos, só os dados deste são usados nas comparações a seguir.

No experimento, foram medidos as temperaturas intramuscular, retal, do esôfago e da pele, o metabolismo e a evaporação na pele. Para a medição das temperaturas, foram usados termopares. A temperatura da pele foi medida em 10 locais diferentes para obtenção da temperatura média. O metabolismo foi determinado a partir do consumo de $\mathrm{O}_{2}$. A evaporação foi determinada a partir da perda de peso, subtraindo a parcela perdida pela respiração.

Na câmara usada para o experimento, a umidade relativa era igual a 40\%, nas três temperaturas do ambiente. Os indivíduos vestiam shorts e tênis. Antes do início do exercício, os indivíduos ficavam de 20 a 30 min expostos ao ambiente. Depois, fizeram exercício em três períodos com durações próximas de meia hora, com consumos de $\mathrm{O}_{2}$ iguais a 25, 47 e $73 \%$ da capacidade máxima. O exercício do primeiro período na temperatura de $30{ }^{\circ} \mathrm{C}$ teve maior duração.

A Figura 9.9 mostra comparações das temperaturas do esôfago, reto, músculo e pele, da geração de calor e da perda de calor por evaporação na pele do modelo com os resultados experimentais de Saltin, Gagge e Stolwijk (1970), para um indivíduo.

As Figuras 9.9a e 9.9b mostram que as duas temperaturas internas (esôfago e reto) obtidas com o modelo são próximas das experimentais, para os níveis leves e moderados de atividade física. Quando a atividade é pesada, os valores das temperaturas internas do modelo são superiores aos experimentais. As temperaturas teóricas e experimentais dos músculos (Figura 9.9c) são próximas em quase todos os casos, com exceção do primeiro período a $10{ }^{\circ} \mathrm{C}$. As variações das temperaturas da pele (Figura 9.9d) estão principalmente relacionadas com a temperatura ambiente. O efeito do exercício é pequeno, tanto nos resultados experimentais como nos teóricos.

A Figura 9.9e mostra a variação da geração de calor pelo metabolismo. Os dados teóricos e experimentais estão próximos para todas as temperaturas ambientes. Quando o ambiente está frio, nota-se que a geração de calor diminui durante o exercício físico. Esta diminuição está relacionada com o efeito do calafrio, que diminui conforme a temperatura 
(a)
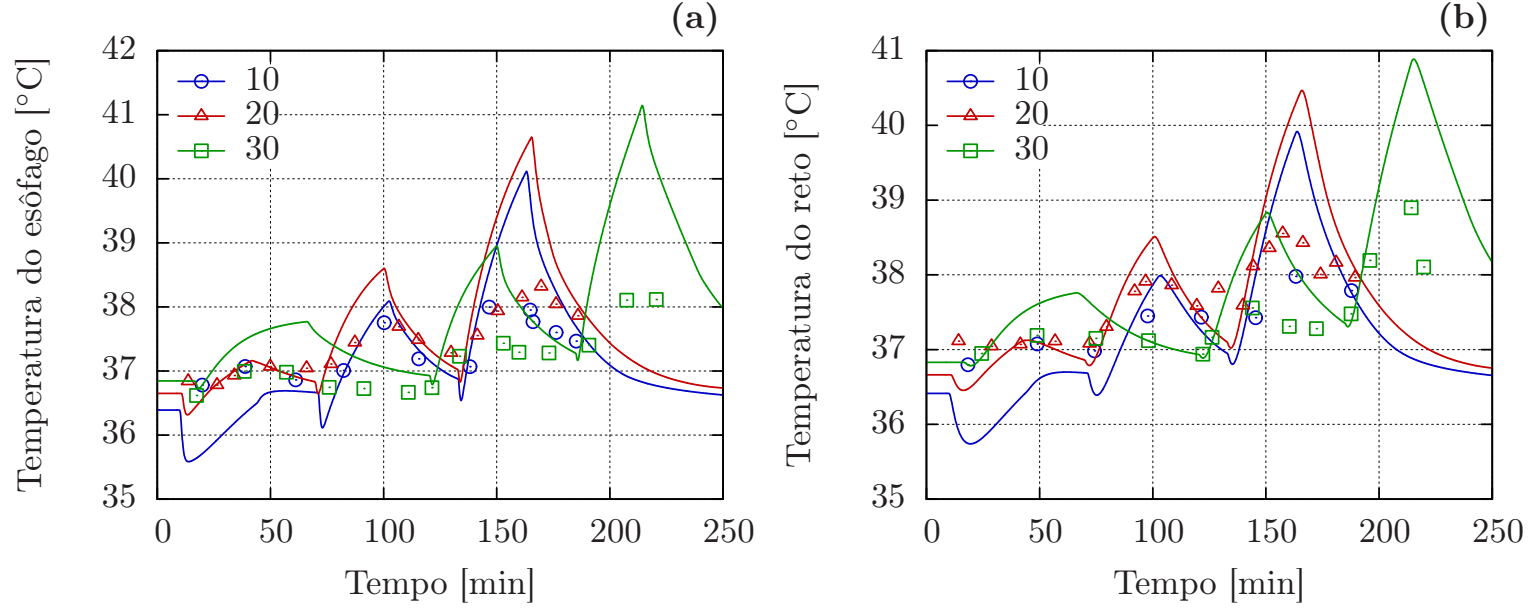

(c)
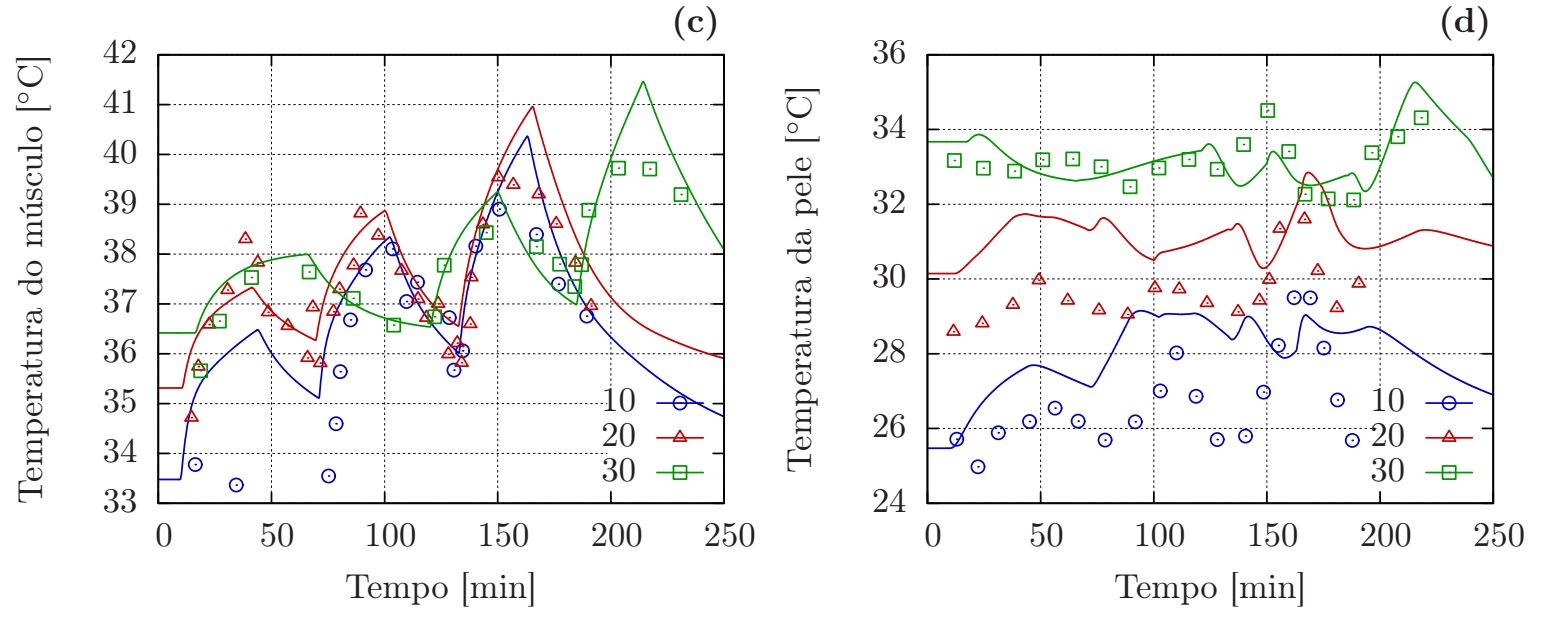

(e)
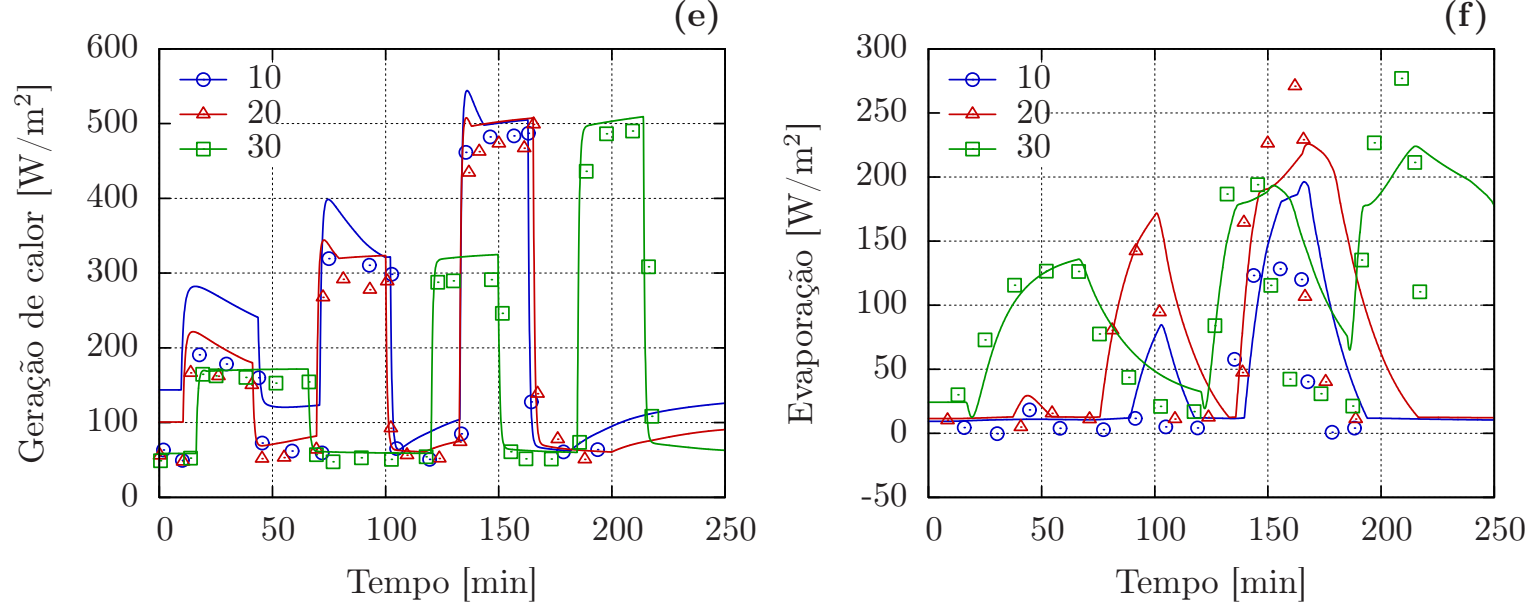

Figura 9.9 - Comparação da temperatura do esôfago (a), da temperatura retal (b), da temperatura do músculo (c), da temperatura média da pele (d), da geração de calor (e) e do calor perdido por evaporação pela pele (f) do presente modelo (linhas contínuas) com resultados experimentais de Saltin, Gagge e Stolwijk (1970) durante exercício físico em três temperaturas ambientes 
do corpo aumenta. Quando o ambiente está quente, a geração de calor permanece em um patamar já que o calor gerado pelo calafrio é nulo.

As variações das perdas de calor por evaporação na pele estão na Figura 9.9f. Os resultados mostram o efeito da sudorese quando o corpo está realizando exercício físico. Quando o ambiente está frio e a atividade é leve, a sudorese não chega a atuar. O aumento da atuação da sudorese ocorre para temperaturas do ambiente e para níveis de exercício maiores.

Uma análise detalhada do efeito da variação da temperatura do ambiente no exercício físico é feita na Seção 9.5, no final deste capítulo.

\subsection{Alterações no corpo humano em diferentes tempe- raturas ambientes}

Os resultados desta seção tem como objetivo mostrar as alterações no corpo humano, em regime permanente, para três temperaturas operativas diferentes: 20,30 e $40{ }^{\circ} \mathrm{C}$. Os resultados mostram a distribuição de temperatura em todos os segmentos, assim como as distribuições de $P_{\mathrm{O}_{2}}$ e de $P_{\mathrm{CO}_{2}}$ nos tecidos, grandes vasos e pulmão.

Em todos os casos, foi considerado que a umidade relativa é igual a 50\%; e que o corpo está no estado basal (82 W), sem vestimentas e ao nível do mar.

As simulações do modelo foram feitas considerando que o corpo é simétrico. Desta forma, o estado de um membro do lado esquerdo é igual ao mesmo membro do lado direito. Nos resultados a seguir, somente o lado esquerdo é representado.

A Figura 9.10 mostra a distribuição da temperatura em três segmentos que são representados por cilindros unidimensionais, em que só a coordenada radial é considerada. Esses são o pescoço, o braço esquerdo e a coxa esquerda. A figura mostra a variação da temperatura do centro do cilindro (raio igual a $0 \mathrm{~cm}$ ) até a fronteira. Quando o ambiente é frio, as temperaturas da pele são as que mais diminuem. A temperatura interna do pescoço se mantém quase constante em todas as temperaturas ambientes. Já o braço e a coxa têm temperaturas internas inferiores em ambientes mais frios.

A Figura 9.11 mostra a distribuição da temperatura na cabeça e no tronco. Cada um destes membros é representado por um cilindro bidimensional. São consideradas as coordenadas $r$, do centro (esquerda) até a fronteira (direita), e z. Observa-se, nas figuras, a alta temperatura do cérebro e do coração, que são justificadas pela alta geração de calor. Como estes dois membros contém órgãos importantes para o corpo, suas temperaturas internas são mantidas praticamente constantes, independente da temperatura ambiente. 

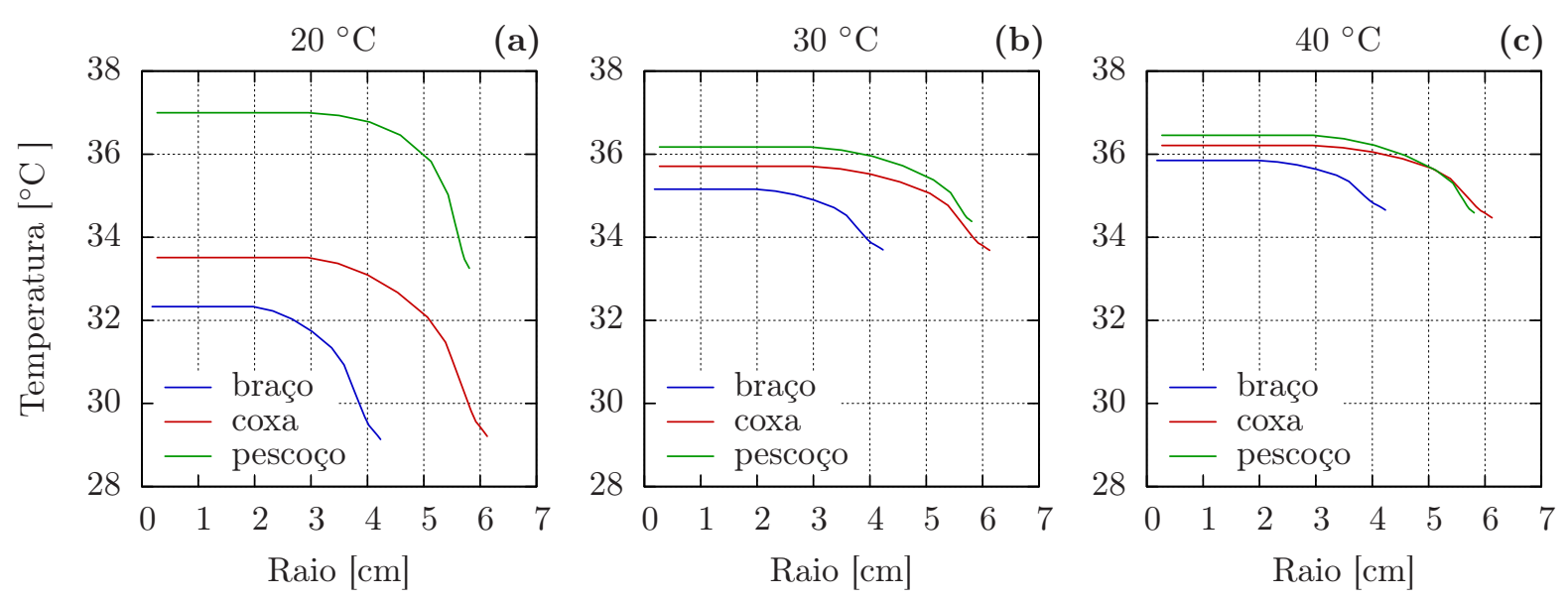

Figura 9.10 - Distribuição de temperatura no braço esquerdo, na coxa esquerda e no pescoço a 20, 30 e $40{ }^{\circ} \mathrm{C}$

A Figura 9.12 mostra a distribuição da temperatura no antebraço esquerdo e na perna esquerda. Estes segmentos são representados por cilindros bidimensionais. As coordenadas $r$ e $\theta$ são consideradas. Nas figuras, observa-se que, para a mesma distância do centro, a temperatura é inferior na região do osso em comparação com o músculo. Isso ocorre porque o osso tem vazão de sangue e geração de calor desprezíveis. O antebraço e a perna, por estarem mais próximos da extremidade, sofrem maiores variações de temperatura em função da temperatura do ambiente.

A Figura 9.13 mostra a distribuição da temperatura na mão esquerda e no pé esquerdo. Estes segmentos são representados por paralelepípedos, entretanto, somente a variação da temperatura nas coordenadas $x$ (largura) e $y$ (altura) são consideradas. Estes segmentos, como são os mais extremos do corpo, são os que têm menores temperatura, e os que mais são alterados pela variação da temperatura ambiente.

A Figura 9.14 mostra a média de temperatura de cada tipo de tecido e as temperaturas do sangue arterial e venoso em cada segmento. O sangue arterial tem pequena variação porque é muito influenciado pela temperatura do tronco. O sangue venoso é influenciado diretamente pela temperatura dos tecidos. As temperaturas do sangue arterial e venoso no tronco e do pulmão são praticamente as mesmas, como resultado da vazão de sangue pela circulação pulmonar. As temperaturas do cérebro e do pulmão são praticamente iguais nos três ambientes.

As Figuras 9.15 e 9.16 mostram as pressões parciais de $\mathrm{O}_{2}$ e $\mathrm{CO}_{2}$ nos compartimentos arterial e venoso e nos tecidos de cada segmento. As variações das pressões parciais ocorrem principalmente por dois motivos. Um é que, para a mesma temperatura operativa, a queda da pressão parcial do tronco até as extremidades é reflexo da variação da temperatura nas curvas de dissociação do sangue. Como os grandes vasos são considerados impermeáveis, a concentração do sangue arterial é igual em todos os segmentos em regime 
Cabeça
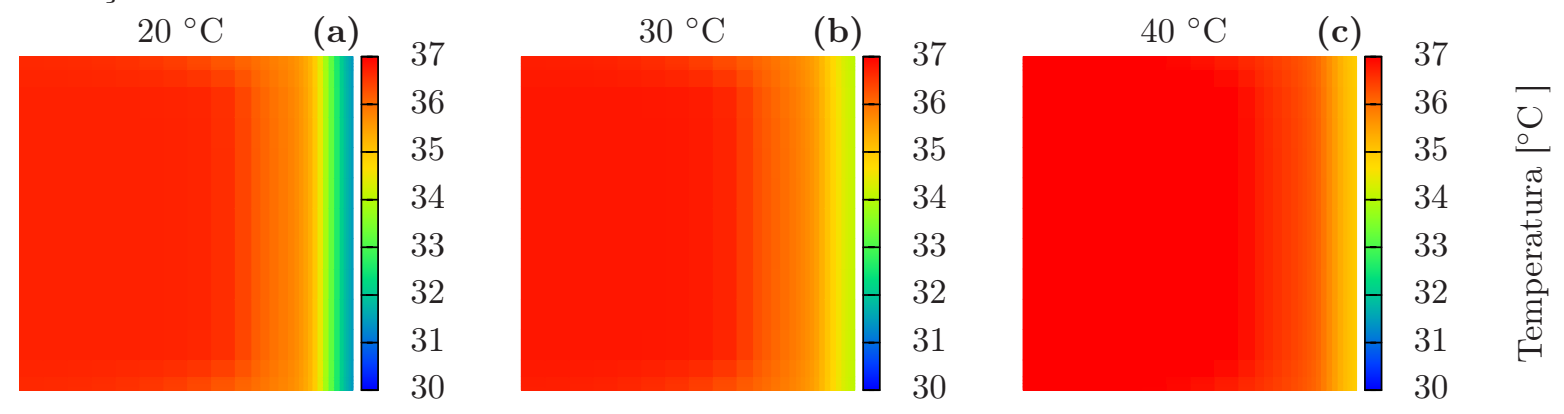

Tronco
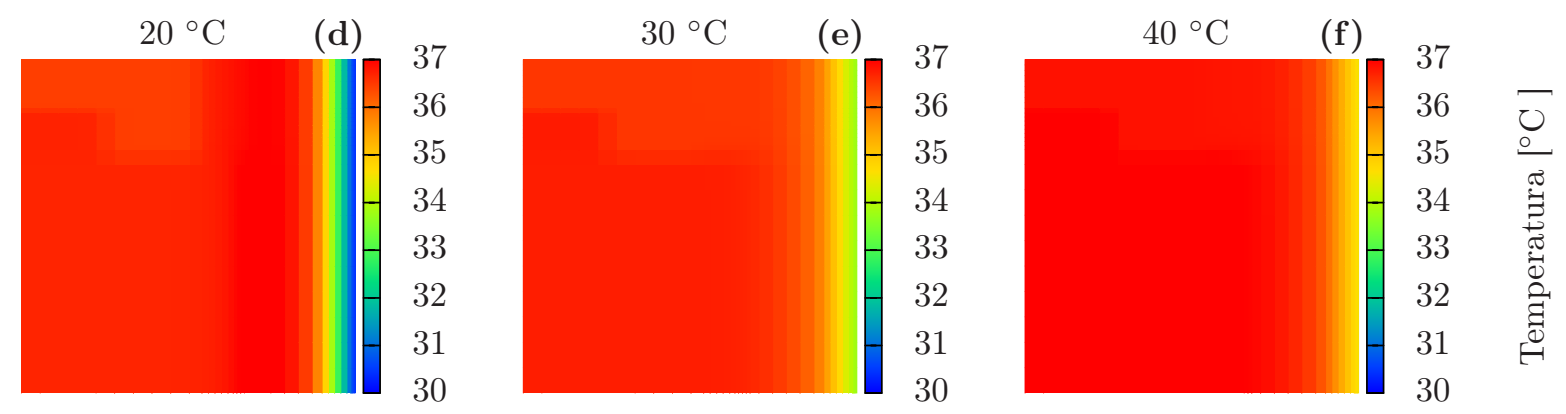

Figura 9.11 - Distribuição de temperatura na cabeça e no tronco ( $r$ no eixo das abcissas e $z$ no eixo das ordenadas) a 20,30 e $40{ }^{\circ} \mathrm{C}$

Antebraço

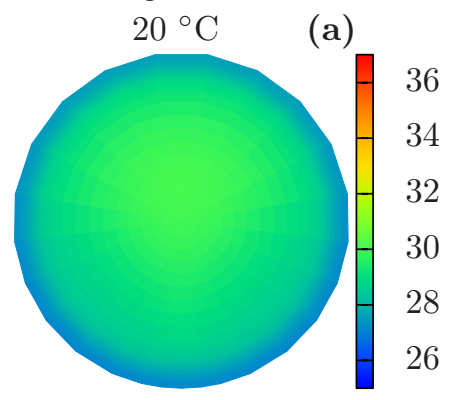

Perna

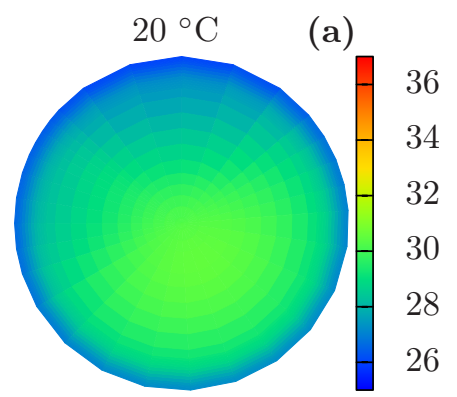

$30{ }^{\circ} \mathrm{C}$

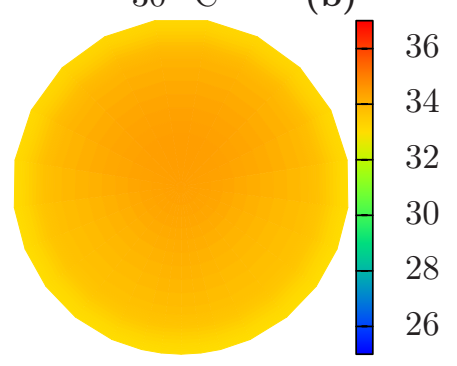

$30{ }^{\circ} \mathrm{C}$

(b)

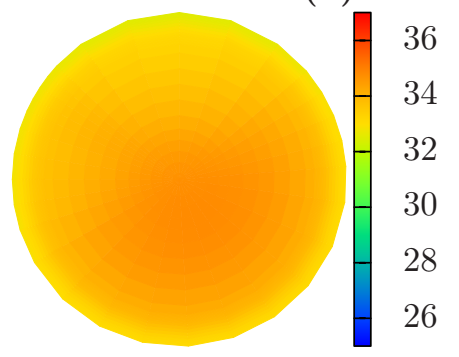

$40{ }^{\circ} \mathrm{C}$

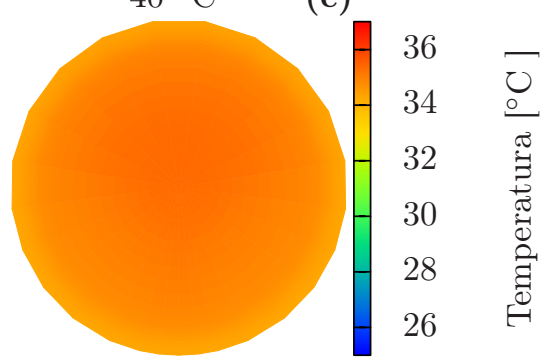

$40{ }^{\circ} \mathrm{C}$

(c)

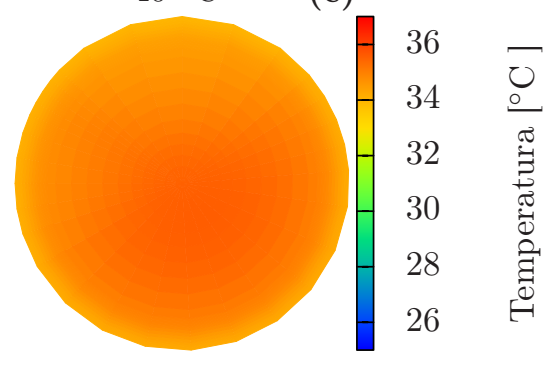

Figura 9.12 - Distribuição de temperatura no antebraço esquerdo e na perna esquerda (gráfico polar) a 20,30 e $40{ }^{\circ} \mathrm{C}$ 
Mão

$20{ }^{\circ} \mathrm{C} \quad(\mathbf{a})$

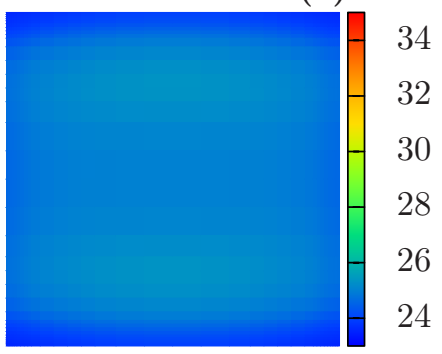

Pé

$20^{\circ} \mathrm{C}$

(d)

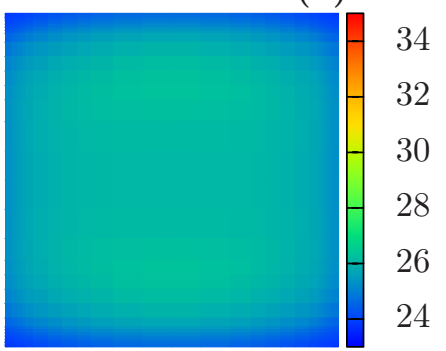

$30{ }^{\circ} \mathrm{C}$

(b)

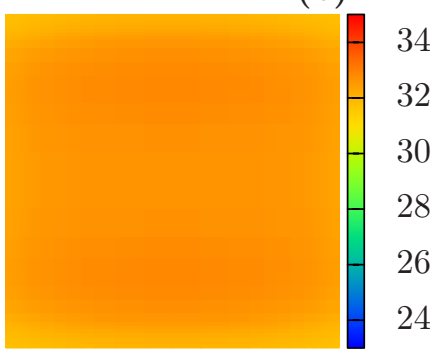

$30{ }^{\circ} \mathrm{C}$

(e)

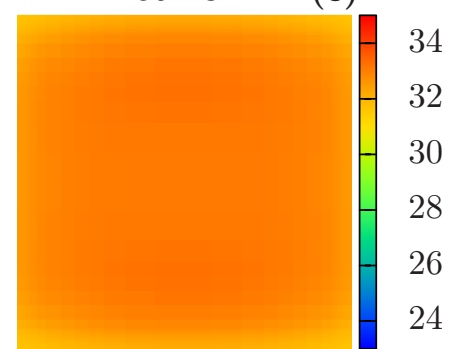

$40{ }^{\circ} \mathrm{C}$

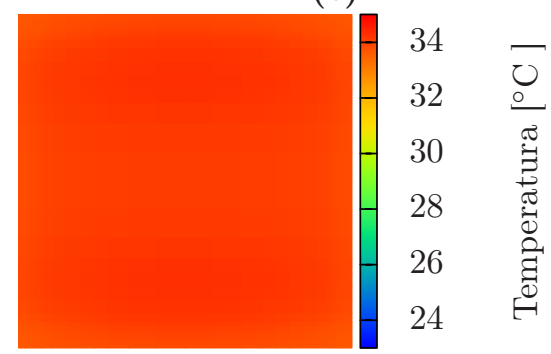

$40{ }^{\circ} \mathrm{C}$

(f)

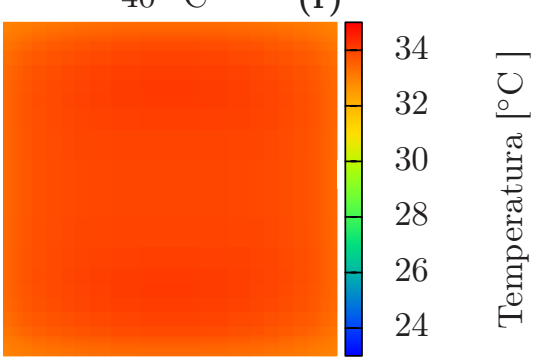

Figura 9.13 - Distribuição de temperatura na mão esquerda e no pé esquerdo ( $x$ no eixo das abcissas e $y$ no eixo das ordenadas) a 20,30 e $40^{\circ} \mathrm{C}$

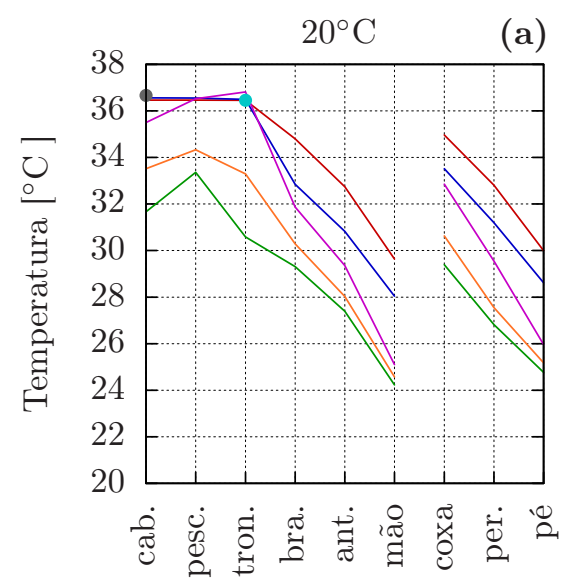

- arterial - venoso - pele
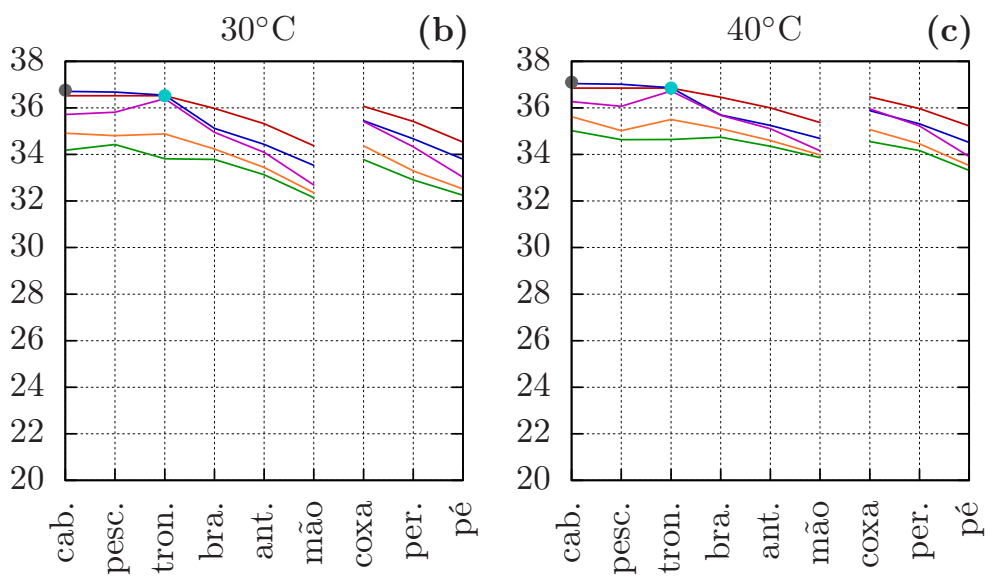

Figura 9.14 - Temperatura do sangue arterial e venoso e dos tecidos nos segmentos a 20,30 e $40{ }^{\circ} \mathrm{C}$ 
permanente. O outro motivo é o calafrio, que resulta no aumento do consumo de $\mathrm{O}_{2}$ e da produção de $\mathrm{CO}_{2}$. Sua atuação fica em evidência com a diminuição da $P_{\mathrm{O}_{2}}$ e o aumento da $P_{\mathrm{CO}_{2}}$ nos músculos do tronco, pescoço e cabeça, que são os membros mais afetados pelo calafrio. A $P_{\mathrm{O}_{2}}$ no cérebro e nos tecidos do pulmão varia muito pouco com a temperatura ambiente. A $P_{\mathrm{CO}_{2}}$ nos tecidos do pulmão também tem pequena variação. No cérebro, a $\mathrm{P}_{\mathrm{CO}_{2}}$ aumenta com o frio.
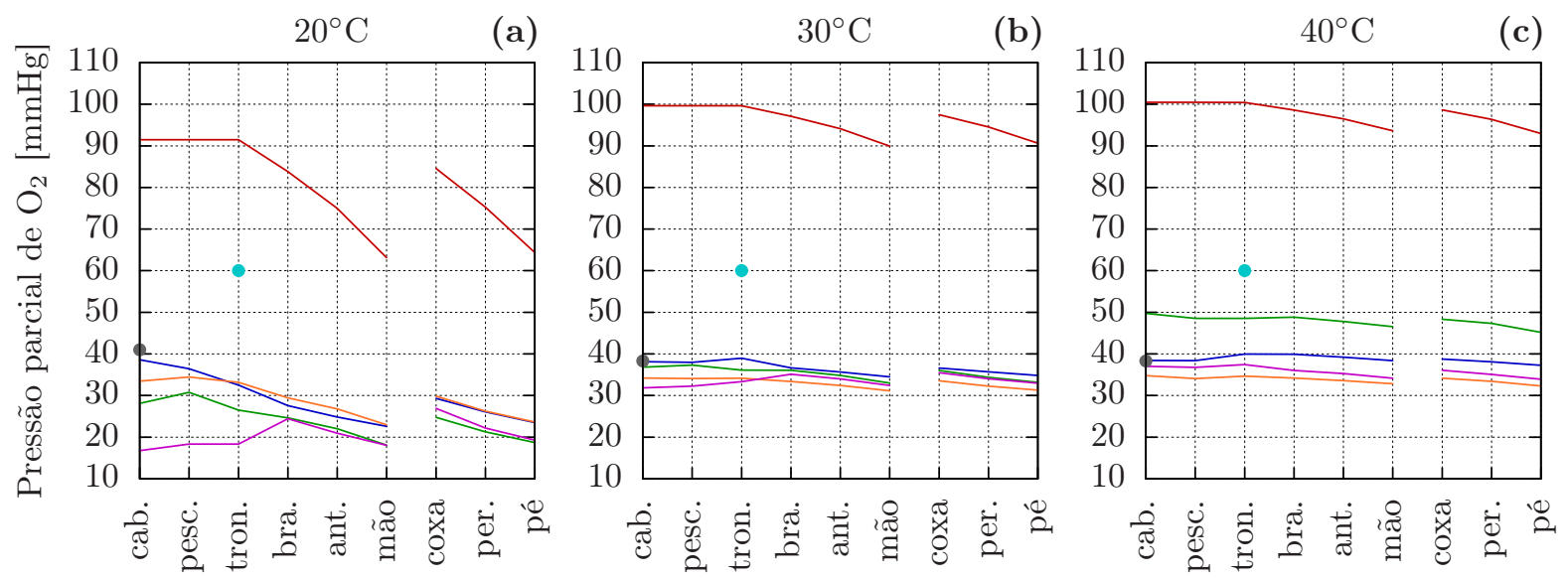

— arterial — venoso — pele

- gordura - músculo

- cérebro • pulmão

Figura 9.15 - Pressão parcial de $\mathrm{O}_{2}$ no sangue arterial e venoso e nos tecidos a 20,30 e $40{ }^{\circ} \mathrm{C}$
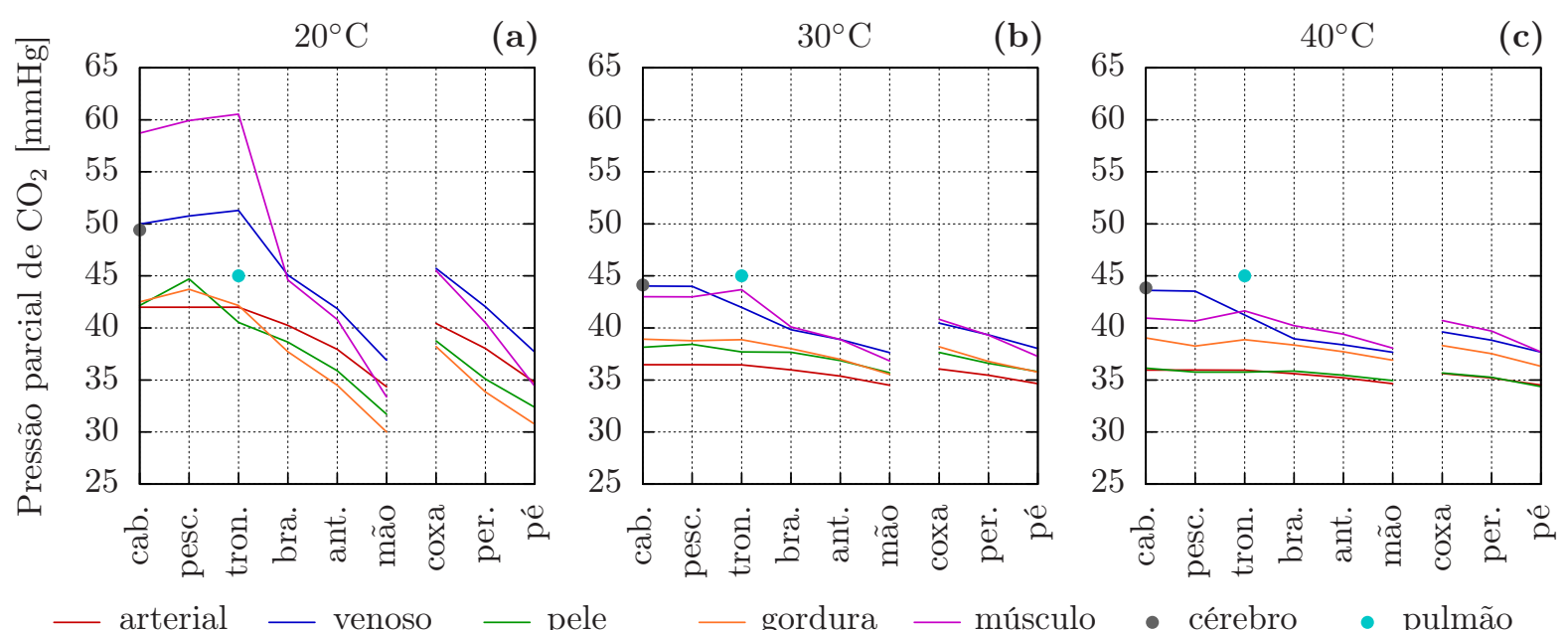

— arterial — venoso — pele

— gordura - músculo

cérebro - pulmão

Figura 9.16 - Pressão parcial de $\mathrm{CO}_{2}$ no sangue arterial e venoso e nos tecidos a 20,30 e $40{ }^{\circ} \mathrm{C}$

A Figura 9.17 mostra a variação da pressão parcial dos gases ao longo dos capilares pulmonares. Os inícios das linhas representam a condição do sangue venoso que entra no pulmão. As variações das pressões parciais dos gases conforme passam pelos capilares pulmonares também dependem da temperatura. O sangue venoso chega no pulmão com diferentes composições. Diferenças significativas ocorrem quando o ambiente é frio, devido ao aumento da produção de $\mathrm{CO}_{2}$ e do consumo de $\mathrm{O}_{2}$ pelo calafrio. Mesmo assim, o $\mathrm{O}_{2}$ e o $\mathrm{CO}_{2}$ têm transferência efetiva com o espaço alveolar. As pressões parciais dos capilares 
pulmonares chegam a valores próximos das alveolares. A $P_{O_{2}}$ alveolar é igual a 101,6, 108,5 e 109,0 para as temperaturas ambientes de 20,30 e $40{ }^{\circ}$ Crespectivamente. A $P_{\mathrm{CO}_{2}}$ alveolar é igual a 41,4, 35,9 e 35,4 para essas três temperaturas ambientes.

(a)

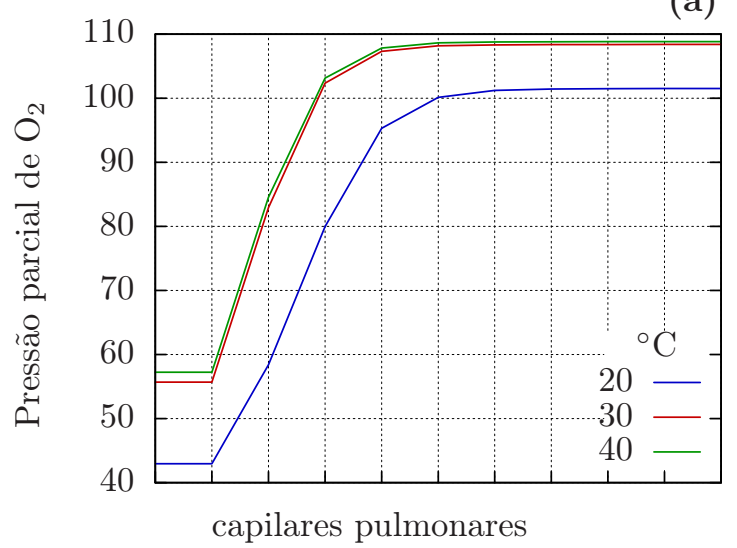

(b)

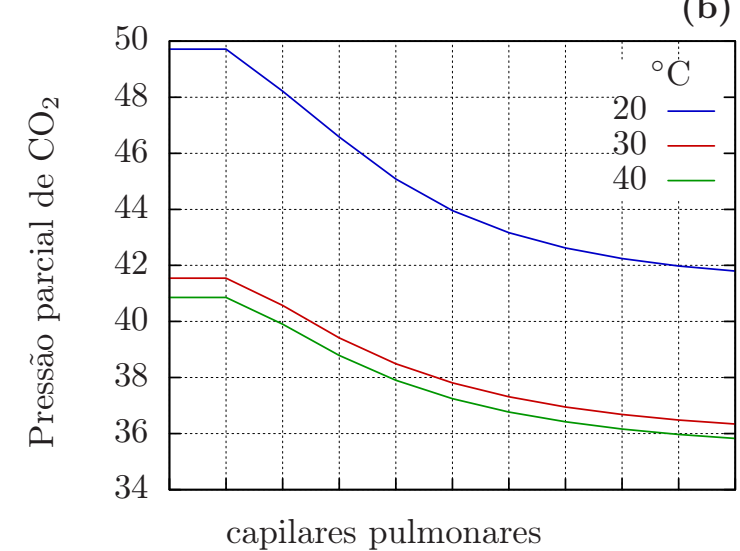

Figura 9.17 - Pressão parcial dos gases ao longo dos capilares pulmonares a 20 , 30 e $40{ }^{\circ} \mathrm{C}$

\subsection{Acidentes de descompressão}

Acidentes aéreos devido à descompressão da cabine são comuns e podem ser fatais. Podem ocorrer pelo mal funcionamento do sistema de pressurização ou por dano estrutural da aeronave. A intensidade da descompressão depende de diversos fatores como tipo da falha, diferença de pressão, volume da cabine. Os principais efeitos fisiológicos de uma descompressão rápida são (UNITED STATES AIR FORCE, 1991):

- possibilidade de rompimento dos tecidos pulmonares ou dos capilares, se a saída de ar dos pulmões estiver bloqueada;

- dor no ouvido médio e no seio paranasal;

- expansão dos gases no trato gastrointestinal causando deslocamento do diafragma e dos órgãos abdominais;

- hipoxia;

- doença de descompressão;

- possibilidade de ocorrência de enregelamento e hipotermia (quando a temperatura cai na descompressão). 
Os resultados desta seção mostram o comportamento do corpo humano durante uma despressurização da cabine de avião em duas situações: com a temperatura do ambiente constante e igual a $20{ }^{\circ} \mathrm{C}$ e com a queda da temperatura ambiente após o início de descompressão. Em todos os casos, foi considerado que o indivíduo estava vestindo terno; sentado e quieto; sem máscara de $\mathrm{O}_{2}$; e que a umidade relativa era de $50 \%$.

A curva hipotética da altitude de cabine utilizada como dado de entrada na simulação está na Figura 9.18a, junto com uma curva mostrando a altitude do avião ${ }^{1}$. Nesta situação, o avião estava voando a 41000 pés de altitude quando ocorre a despressurização causada por um furo na fuselagem com diâmetro de 15 in. O avião iniciou a descida, com taxa de $5000 \mathrm{ft} / \mathrm{min}$, após $17 \mathrm{~s}$ - tempo em que o piloto percebe a falha e inicia o procedimento de descida. A altitude final é de 10000 pés, atingida após 389 s. A altitude de cabine antes da despressurização é de 8000 pés; no final, é igual a altitude do avião.

(a)
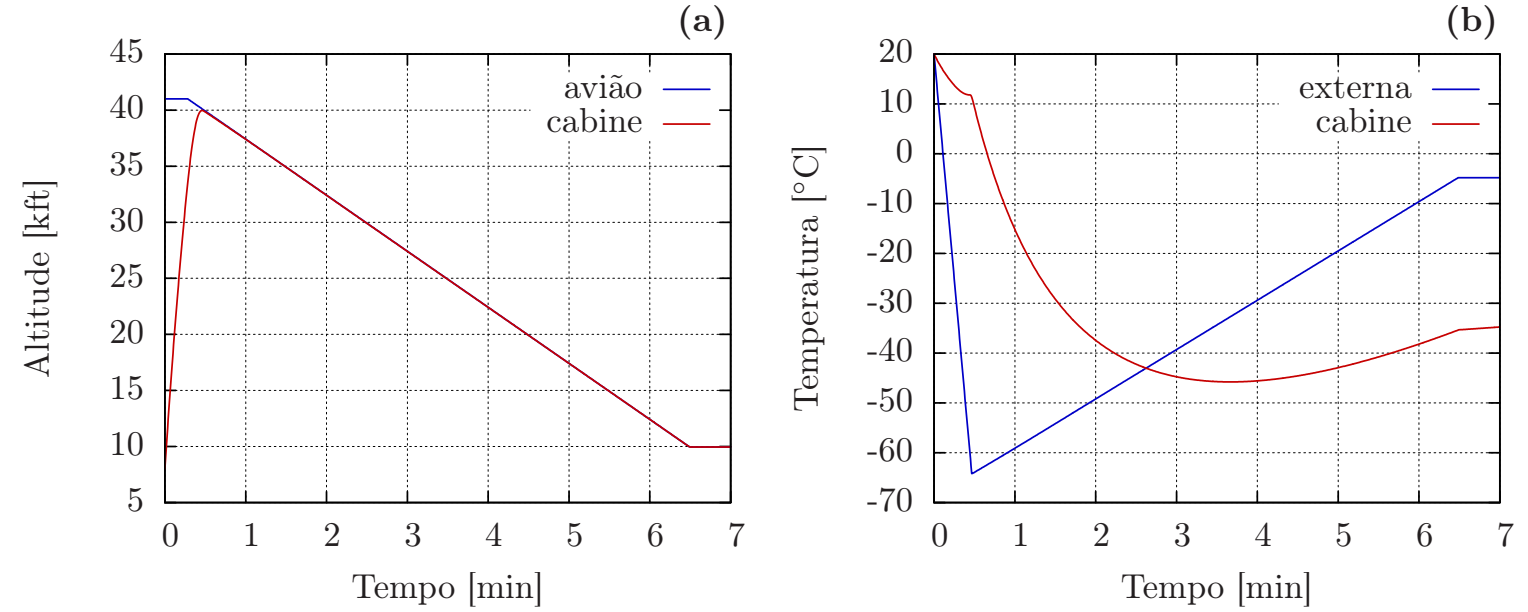

Figura 9.18 - Altitude da cabine e do avião (a) e temperatura do ar externo e da cabine (b)

A queda da temperatura operativa na cabine incluída em um dos casos simulados foi considerada como sendo extremamente crítica. A Figura 9.18b mostra duas curvas: a variação da temperatura externa e a curva criada para representar a variação crítica da temperatura da cabine. Esta última foi obtida a partir de equações geradas por balanços de massa e energia em regime transitório. Antes do início da descompressão, foi considerada que a temperatura da cabine era igual a $20^{\circ} \mathrm{C}$. Três fases diferentes são observadas na curva da variação da temperatura. Na primeira (até 28 s), sua queda ocorre devido à expansão dos gases no interior da cabine. Nesta fase ocorre vazão de massa da cabine para o ambiente externo. Na segunda fase (após $28 \mathrm{~s}$ e até o fim da descida do avião), a vazão de massa ocorre do ar externo para o interior da cabine. A entrada de ar externo é o principal motivo pelo qual ocorre primeiro uma queda da temperatura, e na sequência o seu aumento. Na última fase, após a estabilização da aeronave, continua

\footnotetext{
${ }^{1}$ As curvas foram cedidas pela Empresa Brasileira de Aeronáutica (EMBRAER).
} 
ocorrendo uma pequena vazão do ar externo para a cabine, que resulta no aumento da temperatura interna.

A Figura 9.19 mostra os resultados da simulação. As linhas contínuas dos gráficos são os resultados quando a temperatura do ambiente é mantida constante. As linhas tracejadas são os resultados com a queda da temperatura na descompressão.

As Figuras 9.19a e 9.19b mostram, respectivamente, a $P_{\mathrm{O}_{2}}$ e a $P_{\mathrm{CO}_{2}}$ do sangue arterial, venoso e do cérebro. As pressões parciais de ambos os gases caem após o início da descompressão. A variação da $P_{\mathrm{O}_{2}}$ nos três locais é mais rápida que a da $P_{\mathrm{CO}_{2}}$. O principal motivo desta diferença é que o corpo tem uma quantidade de $\mathrm{CO}_{2}$ armazenada nos tecidos muito superior à quantidade de $\mathrm{O}_{2}$ - são $12 \mathrm{~L}$ de $\mathrm{CO}_{2}$ (sem contar o osso) e 0,3 L de $\mathrm{O}_{2}$ (CHERNIACK; LONGOBARDO, 1970). A queda da $P_{\mathrm{CO}_{2}}$ está relacionada com o aumento da ventilação. Este, por conseguinte, ocorre principalmente devido à diminuição da $P_{O_{2}}$ no sangue arterial.

Comparando as diferenças entre as pressões parciais dos gases no sangue arterial e venoso é possível observar uma queda mais rápida da primeira. A quantidade de sangue venoso no corpo humano é quase quatro vazes maior que a quantidade de sangue arterial. Por isso, o sangue venoso tem uma inércia maior que faz com que sofra menos os efeitos da descompressão. Outro motivo ainda é que o sangue arterial é composto em sua maior parte pelo sangue que passou pelos capilares pulmonares e realizou trocas dos gases por difusão com o espaço alveolar do pulmão. No caso do $\mathrm{O}_{2}$, sua quantidade no pulmão diminui como resultado da diminuição da $P_{O_{2}}$ inspirada. Já a concentração de $\mathrm{CO}_{2}$ nos alvéolos diminui devido ao aumento da ventilação.

A Figura 9.19c mostra a variação da temperatura média da pele, do pulmão e do cérebro. A temperatura da pele permanece praticamente constante quando não há variação da temperatura ambiente. Já quando esta cai, a temperatura da pele diminui. As temperaturas do pulmão e do cérebro são temperaturas internas do corpo humano. A primeira representa a temperatura do sangue arterial e do sangue venoso do tronco, já que a circulação pulmonar tem vazão praticamente igual ao débito cardíaco. A temperatura do cérebro é importante por ser entrada do sistema de controle. Logo no início da descompressão, as duas temperaturas internas diminuem. O principal motivo desta diminuição é o aumento da perda de calor pela respiração, que é provocado pelo aumento da ventilação e pelo aumento da diferença entre a umidade absoluta do ambiente e do trato respiratório na altitude. A variação da perda de calor pela respiração está na Figura 9.19d. Este gráfico mostra também a variação da geração de calor pelo metabolismo, que aumenta durante a descompressão. A principal explicação deste aumento é a ocorrência de calafrio (devido a diminuição da temperatura interna pela respiração). Seu aumento faz com que ambas as temperaturas internas tendam a retornar para seus valores iniciais 
(a)
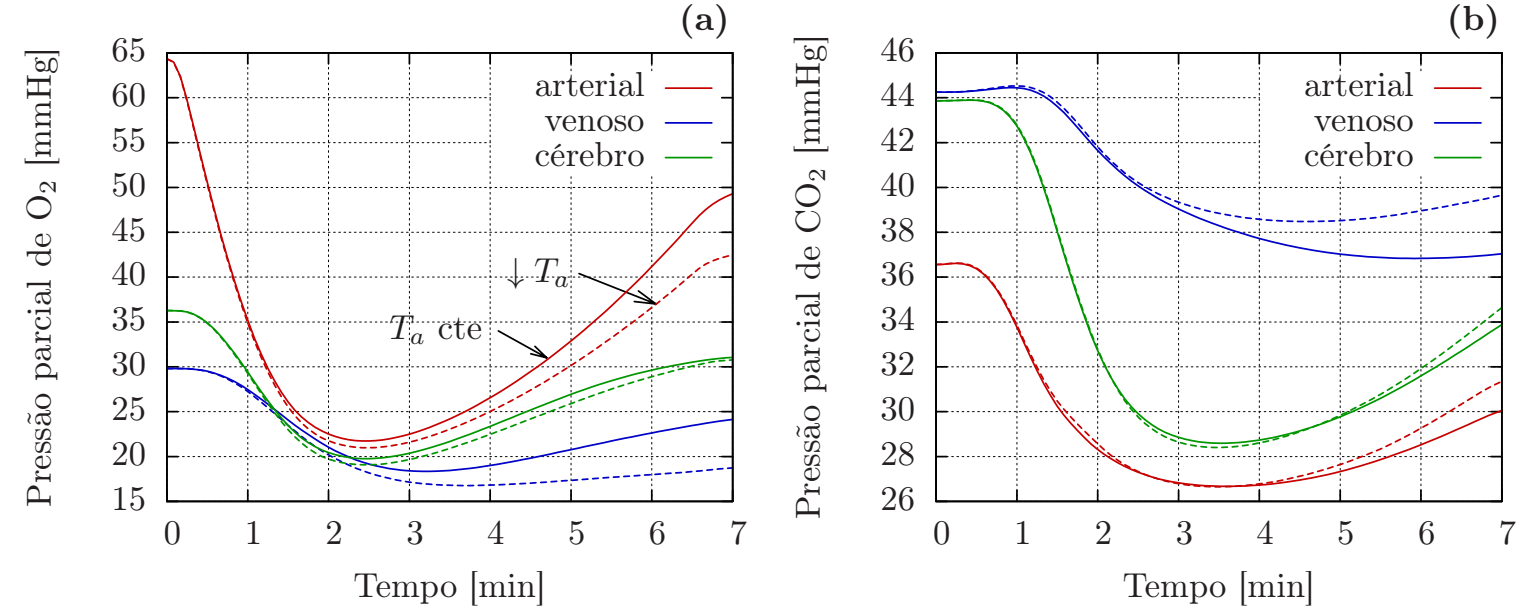

(c)
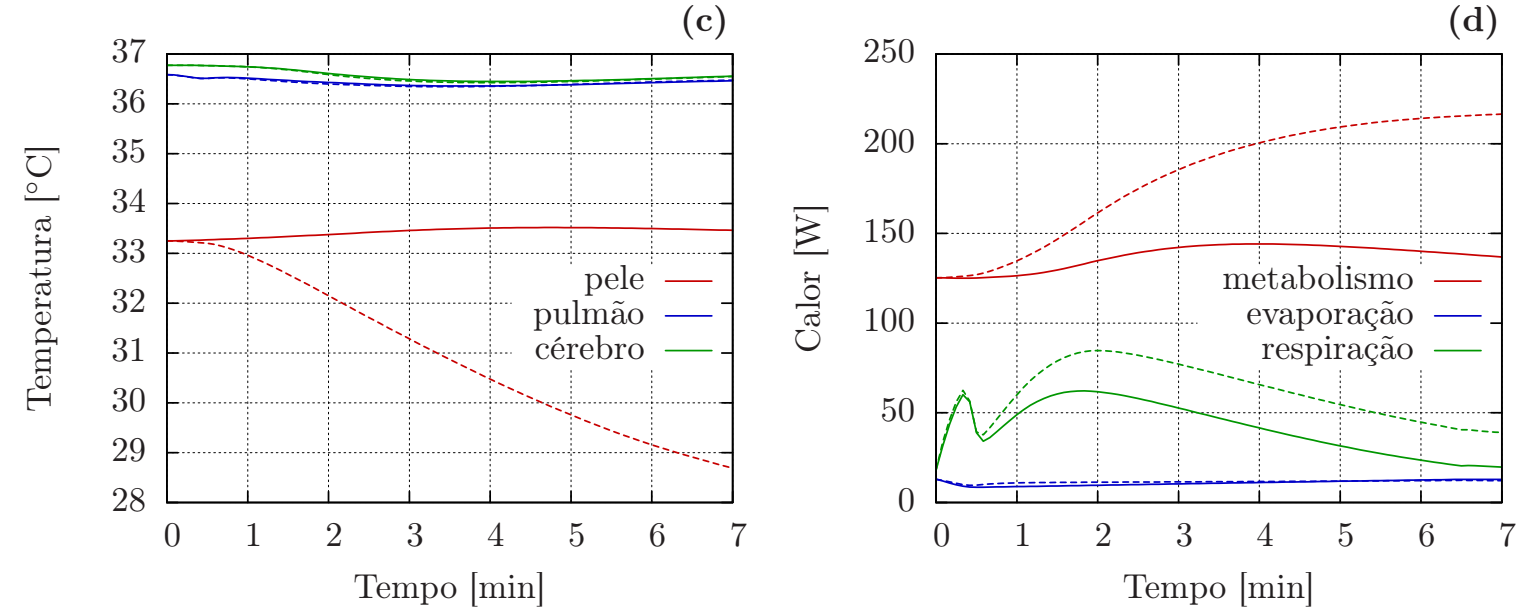

(e)

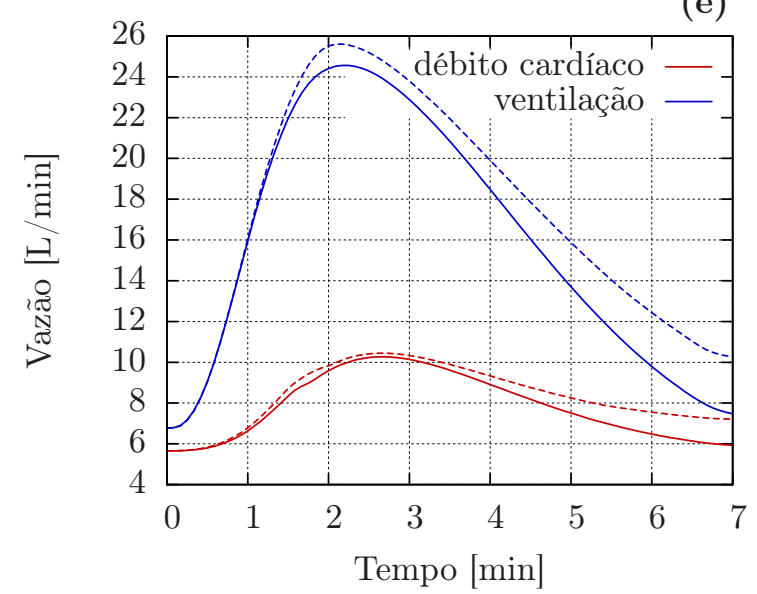

(f)

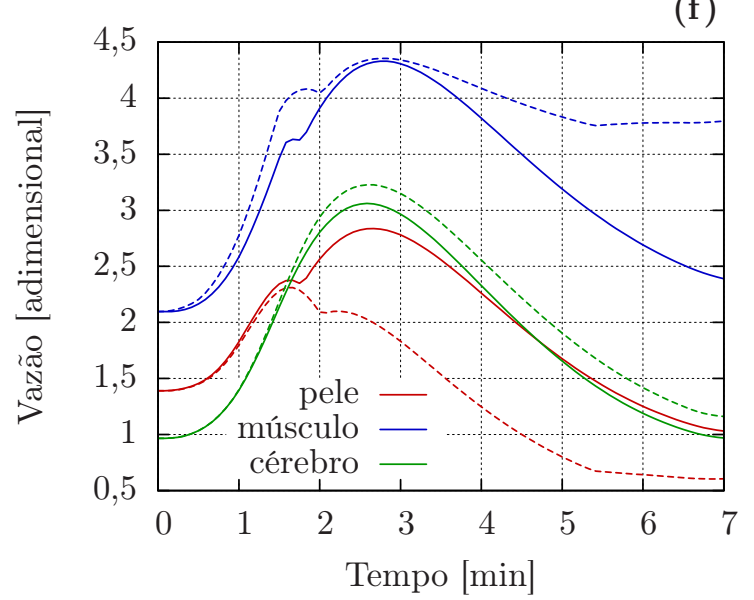

Figura $9.19-P_{\mathrm{O}_{2}}$ no sangue arterial, venoso e no cérebro (a), $P_{\mathrm{CO}_{2}}$ no sangue arterial, venoso e no cérebro (b), temperatura da pele, pulmão e cérebro (c), calor gerado pelo metabolismo e perdido pela evaporação na pele e pela respiração (d), ventilação alveolar e débito cardíaco (e) e vazões de sangue na pele, músculo e cérebro (f) durante um acidente de descompressão com temperatura do ambiente constante (linhas contínuas) e com diminuição da temperatura ambiente (linhas tracejadas) 
na segunda metade da simulação. O aumento da geração de calor por calafrio é superior no caso em que a temperatura do ambiente cai. No caso da perda de calor pela respiração, o aumento também é superior já que a temperatura do ar inspirado é menor.

A Figura 9.19d também mostra o calor perdido pela evaporação. Este permanece praticamente constante representando a parcela de água que segue para o ar por difusão através da pele.

As Figuras 9.19e e 9.19f mostram a variação de vazões que são alteradas pelos sistemas reguladores do corpo humano. A Figura 9.19e mostra o débito cardíaco e a ventilação alveolar (em STPD). Os valores destas vazões são absolutos. A Figura 9.19f mostra a vazão de sangue na pele, músculo e cérebro. Nestes casos os valores são adimensionais, sendo unitários quando iguais aos seus valores basais. A vazão na pele e no músculo são as médias ponderadas pelo volume de todos os segmentos.

Tanto o débito cardíaco como a ventilação aumentam após o início da descompressão e depois voltam para valores próximos dos iniciais. O principal fator que faz com que estas duas vazões aumentem, neste caso, é a diminuição da $P_{O_{2}}$ arterial. O débito cardíaco também é influenciado pelos mecanismos termorreguladores.

Quando ocorre a descompressão com a queda da temperatura ambiente, essas vazões são superiores do que quando a temperatura ambiente é mantida constante. Essa diferença pode ser explicada em conjunto com outras variáveis discutidas anteriormente, mostrando um bom exemplo de interações entre o funcionamento do sistema térmico e respiratório. A exposição ao ambiente frio reduz a temperatura do corpo, tanto pela superfície da pele como pela respiração. Como resultado, o corpo aumenta o metabolismo. Este aumento resulta em maior consumo de $\mathrm{O}_{2}$ e produção de $\mathrm{CO}_{2}$, que resultam em uma diminuição da $P_{\mathrm{O}_{2}}$ e aumento da $P_{\mathrm{CO}_{2}}$ maior do que se a temperatura fosse constante. A diminuição da $P_{\mathrm{O}_{2}}$ arterial resulta no aumento da ventilação e do débito cardíaco. Este aumento, portanto, é maior quando ocorre a exposição ao frio.

Na Figura 9.19f, o aumento da vazão de sangue no músculo está ligado com o aumento da geração de calor por calafrio. No caso da pele, quando a temperatura do ambiente é constante, a vazão de sangue aumenta para suprir as necessidades de $\mathrm{O}_{2}$. Já no ambiente frio, a vazão de sangue aumenta um pouco devido à diminuição do $\mathrm{O}_{2}$ e, logo depois, diminui como resposta à diminuição da temperatura do corpo. O aumento da vazão de sangue no cérebro também ocorre para suprir as necessidades de $\mathrm{O}_{2}$.

Um dos principais efeitos que acontece no corpo humano em acidentes de descompressão é a perda de consciência. A disponibilidade de $\mathrm{O}_{2}$ no cérebro está relacionada com este efeito. Deste modo, a pequena redução da $P_{\mathrm{O}_{2}}$ cerebral durante a descompressão acompanhada de queda da temperatura ambiente (em relação a situação em que a temperatura é mantida constante), pode vir a ser um fator importante. 


\subsection{Intoxicação por $\mathrm{CO}_{2}$}

$\mathrm{O} \mathrm{CO}_{2}$ é usado na indústria na preservação de alimentos, em bebidas gasosas, em gelo seco e em extintores de incêndio. A exposição a quantidades elevadas deste gás pode causar intoxicação. A inspiração de 1 a $3 \%$ de $\mathrm{CO}_{2}$ no nível do mar em indivíduos normais não provoca desconforto respiratório. A estimulação respiratória é nítida em inspirações entre 4 e $6 \%$ de $\mathrm{CO}_{2}$. Entre 7 e $10 \%$ de $\mathrm{CO}_{2}$, ocorre dispneia e deterioração do desempenho mental. Acima de 15\%, a perda de consciência é rápida e acompanhada de espasmos neuromusculares. (LAMBERTSEN, 1974d)

Os resultados desta seção tem como objetivo mostrar como a temperatura ambiente afeta a intoxicação por $\mathrm{CO}_{2}$. O caso mais crítico dos experimentos realizados por Reynolds, Milhorn Jr. e Holloman Jr. (1972) foi selecionado para a análise. Neste caso, o corpo humano foi exposto a uma concentração de $7 \%$ de $\mathrm{CO}_{2}$ durante 20 min. Os resultados dos experimentos são comparados com simulações do presente modelo na Seção 9.1.7. As condições do corpo humano e do ambiente usadas nas comparações são diferentes das usadas na presente seção. O objetivo daquela seção era a reprodução do experimento. Nesta seção, o objetivo é representar uma situação de trabalho. Deste modo, nas simulações a seguir, foi considerado que o indivíduo estava vestindo um macacão industrial e estava realizando trabalho com máquinas leves (metabolismo de $230 \mathrm{~W}$ ). Foram consideradas três temperaturas ambientes $\left(10,20\right.$ e $\left.30{ }^{\circ} \mathrm{C}\right)$, com umidade relativa de $50 \%$.

A Figura 9.20 mostra os resultados das simulações. As variáveis dos gráficos são as mesmas usadas na análise da seção anterior. As linhas pontilhadas mostram os resultados quando a temperatura do ambiente é igual a $10{ }^{\circ} \mathrm{C}$; as linhas tracejadas quando a temperatura é igual a $20^{\circ} \mathrm{C}$; e as linhas contínuas quando a temperatura é igual a $30{ }^{\circ} \mathrm{C}$.

As pressões parciais de $\mathrm{O}_{2}$ e de $\mathrm{CO}_{2}$ aumentam durante a exposição ao $\mathrm{CO}_{2}$ (Figuras 9.20a e 9.20b). Para os dois gases, a variação do sangue arterial é mais brusca que a do sangue venoso.

A principal razão do aumento da $P_{\mathrm{CO}_{2}}$ é a inspiração do ar com alta concentração de $\mathrm{CO}_{2}$. Conforme pode ser observado na Figura 9.20b, quando a temperatura do ambiente é igual a $10{ }^{\circ} \mathrm{C}$, a $P_{\mathrm{CO}_{2}}$ é maior do que nos outros casos. O motivo disto é que no frio ocorre o aumento do metabolismo devido ao calafrio (Figura 9.20d), que aumenta a produção de $\mathrm{CO}_{2}$. Uma atenção especial deve ser dada para esse aumento, que mostra que uma intoxicação no frio pode ser mais severa. Na $P_{\mathrm{O}_{2}}$ o efeito é contrário. A $P_{\mathrm{O}_{2}}$ é menor quando a temperatura ambiente é igual a $10^{\circ} \mathrm{C}$ (no sangue arterial e venoso), devido ao maior consumo de $\mathrm{O}_{2}$ pelo calafrio. 

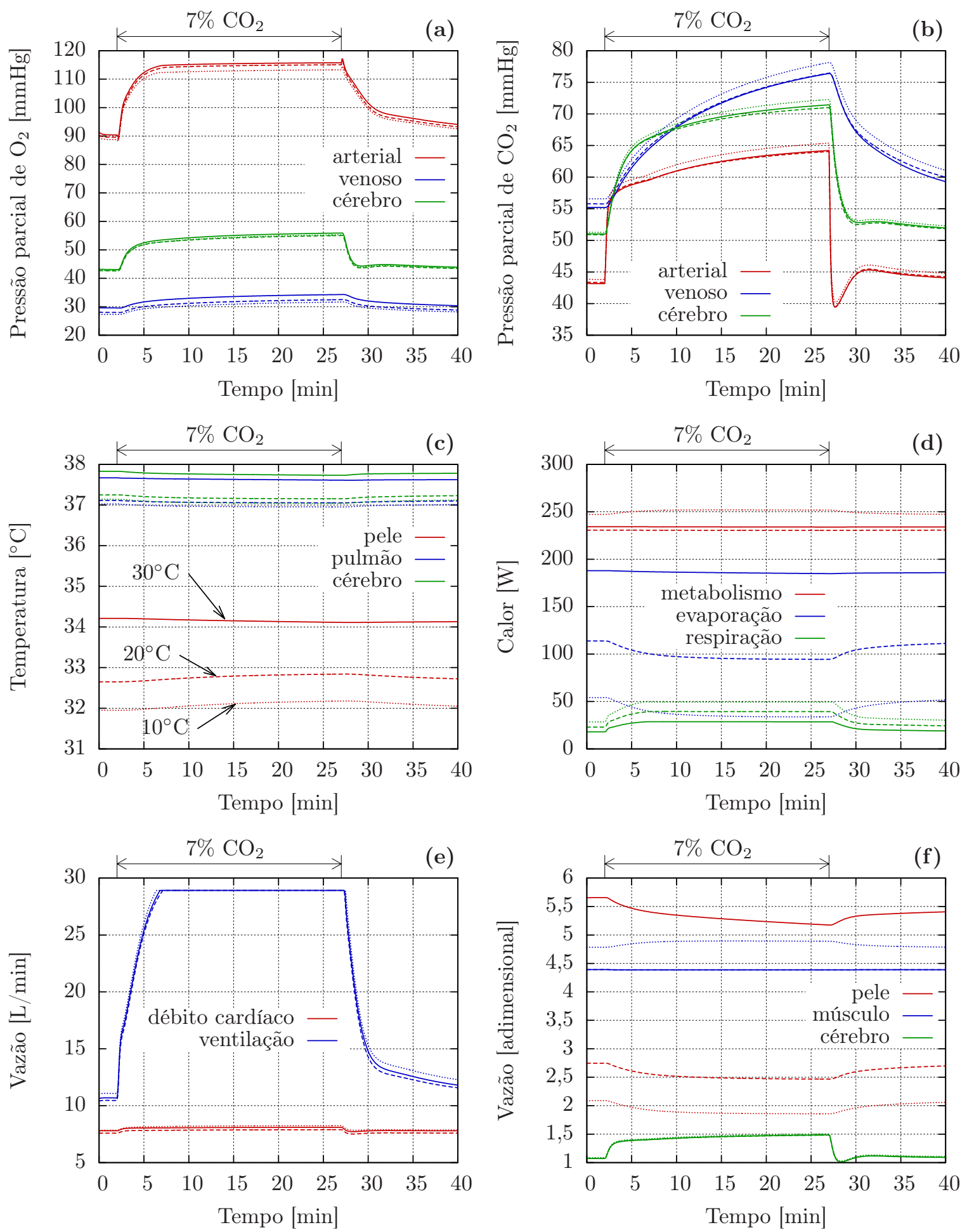

Figura $9.20-P_{\mathrm{O}_{2}}$ no sangue arterial, venoso e no cérebro (a), $P_{\mathrm{CO}_{2}}$ no sangue arterial, venoso e no cérebro (b), temperatura da pele, pulmão e cérebro (c), calor gerado pelo metabolismo e perdido pela evaporação na pele e pela respiração (d), ventilação alveolar e débito cardíaco (e) e vazões de sangue na pele, músculo e cérebro (f) durante intoxicação por $\mathrm{CO}_{2}$ com temperaturas do ambiente iguais a $10{ }^{\circ} \mathrm{C}$ (linhas pontilhadas), $20{ }^{\circ} \mathrm{C}$ (linhas tracejadas) e $30{ }^{\circ} \mathrm{C}$ (linhas contínuas) 
A principal razão pela qual a $P_{\mathrm{O}_{2}}$ aumenta durante a intoxicação por $\mathrm{CO}_{2}$ é o aumento da ventilação. Este, por sua vez, ocorre como resultado do aumento da $P_{\mathrm{CO}_{2}}$ arterial e cerebral. A resposta do corpo para aumentar a eliminação do $\mathrm{CO}_{2}$ torna o sistema respiratório mais efetivo e, consequentemente, aumenta a disponibilidade de $\mathrm{O}_{2}$.

O aumento da ventilação resulta ainda no aumento da perda de calor pela respiração, conforme pode ser observado na Figura 9.20d. Essa perda é maior para menores temperaturas do ambiente. Junto com a perda de calor através da pele, é responsável pela diminuição das temperaturas interna do corpo (Figura 9.20c). A Figura 9.20d mostra ainda uma variação grande do calor perdido por evaporação através da pele entre as diferentes temperaturas do ambiente, resultado da atuação da sudorese.

A aumento do débito cardíaco é muito pequeno quando comparado com o aumento da ventilação (Figura 9.20e). Isto ocorre porque a circulação periférica do corpo não é diretamente afetada pelo efeito químico do $\mathrm{CO}_{2}$. O principal órgão que tem sua vazão de sangue influenciada pelo efeito químico do $\mathrm{CO}_{2}$ é o cérebro. Conforme pode ser observado na Figura 9.20f, a vazão de sangue no cérebro aumenta aproximadamente 50\% na intoxicação. A vazão de sangue na pele varia principalmente com o objetivo de regular a temperatura do corpo. Sua diminuição durante a intoxicação está principalmente relacionada com a diminuição da temperatura interna. A vazão do músculo permanece praticamente constante, sendo maior quando a temperatura do ambiente é baixa devido ao calafrio. O valor elevado das vazões de sangue no músculo, mais que quatro vezes o valor basal, é uma consequência do metabolismo muscular, que é alto para a atividade realizada.

\subsection{Exercício físico}

Tanto o sistema respiratório como o sistema térmico do corpo humano estão intensamente envolvidos nos processos decorrentes da atividade física. O aumento do trabalho muscular exige uma maior disponibilidade de $\mathrm{O}_{2}$. Este, quando consumido, aumenta a produção de $\mathrm{CO}_{2}$ e calor. O transporte de $\mathrm{O}_{2}$ do ar externo aos músculos e de $\mathrm{CO}_{2}$ dos músculos ao ar externo é feito pelo sistema respiratório. A manutenção da temperatura do corpo em níveis aceitáveis é feita pelo sistema térmico.

Algumas variáveis do corpo humano foram comparadas com dados experimentais na Seção 9.1.8, quando estão relacionadas com o sistema respiratório, e na Seção 9.1.9, quando relacionadas com o sistema térmico. Nos resultados da presente seção, será feita uma análise conjunta das variáveis relacionadas aos dois sistemas. 
A Figura 9.21 mostra as varições das mesmas variáveis usadas nas análises das duas últimas seções, em uma situação em que o indivíduo realizou 30 min de atividade moderada, andando em superfície plana a $6,4 \mathrm{~km} / \mathrm{h}$ (metabolismo igual a $396 \mathrm{~W}$ ). No início e final da atividade física, o indivíduo estava em pé relaxado (metabolismo igual a $126 \mathrm{~W}$ ). Usava uma vestimenta típica de verão (camiseta, shorts, meias e tênis). Os resultados mostram as simulações das atividades realizadas em três temperaturas operativas diferentes $\left(10,20\right.$ e $\left.30{ }^{\circ} \mathrm{C}\right)$, com umidade relativa igual a $50 \%$. As linhas pontilhadas mostram os resultados quando a temperatura do ambiente é igual a $10{ }^{\circ} \mathrm{C}$; as linhas tracejadas quando a temperatura é igual a $20^{\circ} \mathrm{C}$; e as linhas contínuas quando a temperatura é igual a $30{ }^{\circ} \mathrm{C}$.

Um dos mais importantes efeitos do corpo humano durante a realização de atividade física é o aumento das atividades metabólicas nos músculos. A geração de calor pelo metabolismo está representada na Figura 9.21d. Ela aumenta logo após o início da atividade, e retorna ao valor inicial na fase de recuperação. No ambiente frio, a geração de calor é maior nas condições iniciais e no início da atividade. Este acréscimo é devido ao calafrio. Como o corpo esquenta no decorrer do execício, o calafrio diminui até não ter mais efeito. O aumento das temperatura internas (pulmão e cérebro) é demonstrado na Figura 9.21c. Quanto maior é a temperatura do ambiente, maior é a temperatura interna. Já no caso da temperatura da pele, que costuma sofrer maiores variações por estar em contato com o ambiente, a variação é pequena durante o exercício físico. A variação da temperatura da pele está principalmente relacionada com a variação da temperatura do ambiente.

$\mathrm{O}$ aumento do metabolismo resulta ainda no aumento do consumo de $\mathrm{O}_{2}$ e da produção de $\mathrm{CO}_{2}$. A $P_{\mathrm{O}_{2}}$ do sangue arterial e venoso diminui no início do exercício (Figura 9.21a). Ao longo do exercício, esses valores se aproximam de seus valores iniciais, principalmente pelas atuações da ventilação e do débito cardíaco. A $P_{\mathrm{O}_{2}}$ é menor para menores temperaturas do ambiente por culpa do aumento do consumo de $\mathrm{O}_{2}$ pelo calafrio. A $P_{\mathrm{O}_{2}}$ no cérebro permanece praticamente constante. A maior produção de $\mathrm{CO}_{2}$ durante o exercício resulta no aumento da $P_{\mathrm{CO}_{2}}$ arterial, venosa e cerebral, conforme a Figura 9.21b. Em ambientes frios, a $P_{\mathrm{CO}_{2}}$ é ainda maior devido ao calafrio.

A variação na temperatura ambiente reflete também em alterações nas vazões de sangue. O calafrio faz com que o aumento da ventilação alveolar e do débito cardíaco sejam maiores em ambientes frios (Figura 9.21e). A variação do débito cardíaco ocorre principalmente como uma consequência da variação da vazão de sangue nos músculos, conforme pode ser observado na Figura 9.21f. Este mesmo gráfico mostra que a vazão de sangue no cérebro é pouco influenciada pelo exercício físico. Já a vazão na pele, que responde principalmente ao sistema termorregulador, é maior para as temperaturas do ambiente mais elevada. 

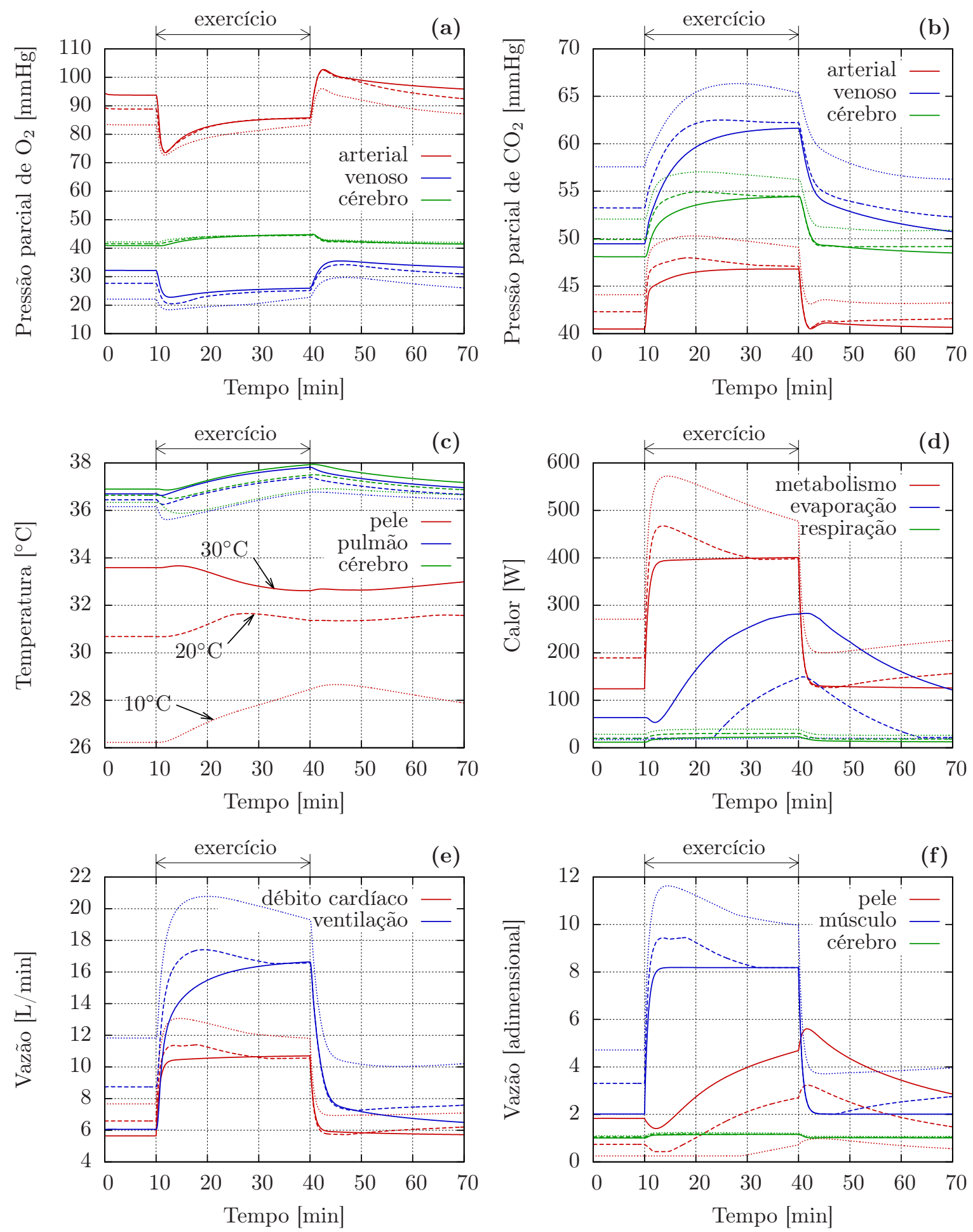

Figura $9.21-P_{\mathrm{O}_{2}}$ no sangue arterial, venoso e no cérebro (a), $P_{\mathrm{CO}_{2}}$ no sangue arterial, venoso e no cérebro (b), temperatura da pele, pulmão e cérebro (c), calor gerado pelo metabolismo e perdido pela evaporação na pele e pela respiração (d), ventilação alveolar e débito cardíaco (e) e vazões de sangue na pele, músculo e cérebro (f) durante a realização de exercício físico com temperaturas do ambiente iguais a $10{ }^{\circ} \mathrm{C}$ (linhas pontilhadas), $20{ }^{\circ} \mathrm{C}$ (linhas tracejadas) e $30{ }^{\circ} \mathrm{C}$ (linhas contínuas) 
Outro mecanismo ligado diretamente com o sistema termorregulador é a sudorese, representada pelo perda de calor pela evaporação através da pele na Figura 9.21d. Nas condições iniciais, a sudorese está atuando somente na temperatura ambiente mais elevada. Após o início do exercício, o resfriamento do corpo pelo suor também ocorre quando a temperatura do ambiente é igual a $20^{\circ} \mathrm{C}$. A atuação da sudorese na temperatura ambiente mais fria é praticamente nula, mesmo quando o corpo está realizando o exercício.

A Figura 9.21d mostra também a perda de calor pela respiração. Ela aumenta um pouco durante o exercício físico, principalmente pelo aumento da ventilação. A perda de calor pela respiração aumenta com a diminuição da temperatura do ambiente. A principal razão desse aumento é a diferença de temperatura entre o ar externo e o pulmão, que também aumenta.

As análises dos gráficos apresentados nesta seção mostram como as complexas mudanças do corpo humano durante o exercício físico estão relacionas com os sistemas respiratório e térmico. Todas essas interações entre os mecanismos mostram que a realização de atividades físicas pode ser bem representada por um modelo matemático destes dois sistemas. 



\section{Capítulo 10}

\section{Conclusão}

Neste trabalho foi desenvolvido um modelo matemático completo dos sistemas respiratório e térmico do corpo humano. O modelo permite a representação dos processos de transferência de calor, $\mathrm{O}_{2}$ e $\mathrm{CO}_{2}$. $\mathrm{O}$ corpo humano foi dividido em quinze segmentos. Os segmentos têm camadas representando os tecidos e órgãos. Os grandes vasos são representados por compartimentos sanguíneos. Os pequenos vasos são considerados juntos com os tecidos, onde calor e $\mathrm{CO}_{2}$ são produzidos e $\mathrm{O}_{2}$ é consumido. Entre a pele e o ambiente ocorre condução, conveç̧ão, radiação e evaporação. O sistema regulador inclui o metabolismo, a circulação, a ventilação e a sudorese.

As comparações com os dados experimentais revelam que o modelo representa corretamente o funcionamento do corpo humano em diversas situações. Nestas, podem tanto ocorrer variações das condições térmicas - exposições a ambientes frios e quentes -, como exposições a ambientes com variações nas quantidades de $\mathrm{O}_{2}$ ou $\mathrm{CO}_{2}$, ou ainda a realização de exercício físico. Mesmo com uma grande variabilidade dos dados experimentais, comum na área da Fisiologia, o comportamento dos resultados teóricos é semelhante ao comportamento dos dados experimentais. Na maioria das situações, as curvas têm formas parecidas, embora alguns resultados tenham valores absolutos distintos. Variações entre os resultados são normalmente justificadas por diferenças entre as características dos participantes dos experimentos e as de um indivíduo padrão; pela comparação de variáveis distintas com significados semelhantes; ou pela simplificação de mecanismos complexos, como durante atividades físicas pesadas ou termorregulação na zona neutra.

A primeira análise do modelo mostra, para três temperaturas ambientes, a distribuição da temperatura e das pressões parciais de $\mathrm{O}_{2}$ e $\mathrm{CO}_{2}$ nos tecidos e no sangue. A variação da temperatura é pequena nos órgãos internos e grande nos membros extremos e na pele. As pressões parciais dos gases diminuem no caminho do tronco até as extremidades, pelo efeito da temperatura nas curvas de dissociação. No frio, o aumento do consumo de $\mathrm{O}_{2}$ e da produção de $\mathrm{CO}_{2}$, devido ao calafrio, resultam na diminuição da $P_{\mathrm{O}_{2}}$ e no aumento da $P_{\mathrm{CO}_{2}}$, principalmente nos músculos do tronco, cabeça e pescoço. 
Duas outras análises mostram que a exposição a ambientes frios podem tornar casos de descompressão da cabine de avião e de intoxicação ao $\mathrm{CO}_{2}$ mais críticos. Em acidentes de descompressão, a baixa disponibilidade de $\mathrm{O}_{2}$ faz com que o corpo aumente a ventilação e a circulação sanguínea. O aumento da ventilação é maior quando a descompressão é acompanhada de diminuição da temperatura ambiente. Este aumento resulta em maior perda de calor pela respiração que, junto com a transferência de calor entre o ambiente e a pele, aumenta a queda da temperatura e, consequentemente, a atuação do calafrio. $\mathrm{O}$ aumento do calafrio junto com a descompressão faz com que mais $\mathrm{O}_{2}$ seja consumido, podendo tornar um acidente ainda mais severo.

Durante a intoxicação por $\mathrm{CO}_{2}$, o corpo humano hiperventila para eliminar seu excesso. Este aumento também resulta em maior perda de calor pela respiração que, junto com o contato da pele com o ambiente, contribui para a diminuição da temperatura do corpo. O calafrio então atua aumentando a geração de $\mathrm{CO}_{2}$, podendo tornar um caso de intoxicação mais crítico.

A realização de exercício físico está diretamente relacionada com os mecanismos do sistema respiratório e térmico do corpo humano. Em ambientes frios, o consumo de $\mathrm{O}_{2}$ e a geração de $\mathrm{CO}_{2}$ são maiores durante o início do exercício devido ao calafrio, resultando em diminuição da $P_{\mathrm{O}_{2}}$ arterial e aumento da $P_{\mathrm{CO}_{2}}$ arterial e cerebral. Essas, por conseguinte, aumentam a ventilação e o débito cardíaco. O calafrio diminui durante o exercício, conforme a temperatura do corpo aumenta. A atuação da sudorese durante o exercício ocorre em ambientes neutros e quentes. No ambiente frio, pode ter atuação nula.

As análises do modelo mostram a importância da integração entre os sistemas térmico e respiratório do corpo humano em determinadas situações. Com algumas modificações, o presente modelo pode ser útil também em outras aplicações, como tratamento com hipotermia ou ambientes hiperbáricos. 


\section{Referências}

ADAIR, G. S. The hemoglobin system VI. The oxygen dissociation curve of hemoglobin. Journal of Biological Chemistry, v. 63, n. 2, p. 529-545, 1925.

AL-OTHMANI, M.; GHADDAR, N.; GHALI, K. A multi-segmented human bioheat model for transient and asymmetric radiative environments. International Journal of Heat and Mass Transfer, v. 51, n. 23-24, p. 5522-5533, 2008.

ALBUQUERQUE-NETO, C. Um modelo do transporte de monóxido de carbono no sistema respiratório do corpo humano. Dissertação (Mestrado) - Escola Politécnica, Universidade de São Paulo, São Paulo, 2005.

ALBUQUERQUE-NETO, C.; YANAGIHARA, J. I.; TURRI, F. A carbon monoxide transport model of the human respiratory system applied to urban atmosphere exposure analysis. Journal of the Brazilian Society of Mechanical Sciences and Engineering, v. 30, n. 3, p. 253-260, 2008.

ALTMAN, P. L.; GIBSON JR., J. F.; WANG, C. C. Handbook of respiration. Bethesda: WB Saunders Co., 1958.

ARKIN, H.; XU, L. X.; HOLMES, K. R. Recent developments in modeling heat transfer in blood perfused tissues. IEEE Transactions on Biomedical Engineering, v. 41, n. 2, p. 97-107, 1994.

ASHRAE. American Society of Heating, Refrigerating and Air-Conditioning Engineers. Thermal comfort. In: Handbook, Fundamentals. Atlanta: [s.n.], 2005. cap. 8.

BATZEL, J. J.; TRAN, H. T. Modeling instability in the control system for human respiration: applications to infant non-rem sleep. Applied Mathematics and Computation, v. 110, n. 1, p. 1-52, 2000.

BROBECK, J. R. Energy balance and food intake. In: MOUNTCASTLE, V. B. (Ed.). Medical Physiology. 13. ed. St. Louis: C.V. Mosby Company, 1974a. v. 2, cap. 54, p. $1253-1272$.

BROBECK, J. R. Energy exchange. In: MOUNTCASTLE, V. B. (Ed.). Medical Physiology. 13. ed. St. Louis: C.V. Mosby Company, 1974b. v. 2, cap. 53, p. 1237-1252.

BRUCE, E.; BRUCE, M. A multicompartment model of carboxyhemoglobin and carboxymyoglobin responses to inhalation of carbon monoxide. Journal of Applied Physiology, v. 95, n. 3, p. 1235-1247, 2003. 
BYLUnD-FELLENIUS, A. C.; WALKER, P. M.; ELANDER, A.; HOLM, S.; HOLM, J.; SCHERSTEN, T. Energy metabolism in relation to oxygen partial pressure in human skeletal muscle during exercise. Biochemical Journal, v. 200, n. 2, p. 247-255, 1981.

CABANAC, M. Adjustable set point: to honor Harold T. Hammel. Journal Applied Physiology, v. 100, n. 4, p. 1338-1346, 2006.

CERRETELLI, P.; SIKAND, R.; FARHI, L. E. Readjustments in cardiac output and gas exchange during onset of exercise and recovery. Journal of Applied Physiology, v. 21, n. 4, p. 1345-1350, 1966.

CHARNY, C. K.; HAGMANN, M. J.; LAVIN, R. L. A whole body thermal model of man during hyperthermia. IEEE Transactions on Biomedical Engineering, v. 34, n. 5, p. 375-387, 1987.

CHAVES, F. F.; MORAES, L. Paralelização de um modelo integrado dos sistemas térmico e respiratório do corpo humano. Trabalho de Formatura - Instituto de Matemática e Estatística, Universidade de São Paulo, São Paulo, 2009.

CHEN, M. M.; HOLMES, K. R. Microvascular contributions in tissue heat transfer. Annals of the New York Academy of Sciences, v. 335, n. 1, p. 137-150, 1980.

CHERNIACK, N. S.; LONGOBARDO, G. S. Oxygen and carbon dioxide gas stores of the body. Physiological Reviews, v. 50, n. 2, p. 196-243, 1970.

CHIARI, L.; AVANZOLINI, G.; URSINO, M. A comprehensive simulator of the human respiratory system: validation with experimental and simulated data. Annals of biomedical engineering, v. 25, n. 6, p. 985-999, 1997.

COBURN, R. F.; MAYERS, L. B. Myoglobin $\mathrm{O}_{2}$ tension determined from measurements of carboxymyoglobin in skeletal muscle. American Journal of Physiology, v. 220, n. 1, p. 66-74, 1971.

DAMATO, A. N.; GALANTE, J. G.; SMITH, W. M. Hemodynamic response to treadmill exercise in normal subjects. Journal of Applied Physiology, v. 21, n. 3, p. 959-966, 1966.

DAVENPORT, H. W. ABC da química ácido básica do sangue. São Paulo: Atheneu, 1973.

DEAR, R. J. de; ARENS, E.; HUI, Z.; OGURO, M. Convective and radiative heat transfer coefficients for individual human body segments. International Journal of Biometeorology, v. 40, n. 3, p. 141-156, 1997.

DOUGLAS, A. R.; JONES, N. L.; REED, J. W. Calculation of the whole blood $\mathrm{CO}_{2}$ content. Journal of Applied Physiology, v. 65, n. 1, p. 473-477, 1988.

DOWNEY, D.; SEAGRAVE, R. C. Mathematical modeling of the human body during water replacement and dehydration: body water changes. Annals of Biomedical Engineering, v. 28, n. 3, p. 278-290, 2000.

DUBOIS, D.; DUBOIS, E. F. A formula to estimate the approximate surface area if height and weight be known. Archives of Internal Medicine, v. 17, p. 863-871, 1916. 
DUFFIN, J. Role of acid-base balance in the chemoreflex control of breathing. Jounal of Applied Physiology, v. 99, n. 6, p. 2255-2265, 2005.

FANGER, P. O. Thermal comfort analysis and application in environmental engineering. New York: McGraw-Hill, 1970.

FARHI, L. E.; RAHN, H. Dynamics of changes in carbon dioxide stores. Anesthesiology, v. 21, n. 6 , p. 604-14, 1960.

FERREIRA, M. S. Um modelo do sistema termorregulador do corpo humano: exposição a ambientes quentes. Dissertação (Mestrado) - Escola Politécnica, Universidade de São Paulo, São Paulo, 1997.

FERREIRA, M. S. Um modelo do sistema térmico do corpo humano. Tese (Doutorado) — Escola Politécnica, Universidade de São Paulo, São Paulo, 2001.

FERREIRA, M. S.; YANAGIHARA, J. Y. A transient three-dimensional heat transfer model of the human body. International Communications in Heat and Mass Transfer, v. 36, n. 7, p. 718-724, 2009.

FIALA, D.; LOMAS, K. J.; STOHRER, M. A computer model of human thermoregulation for a wide range of environmental conditions: the passive system. Journal of Applied Physiology, v. 87, n. 5, p. 1957-1972, 1999.

FIALA, D.; LOMAS, K. J.; STOHRER, M. Computer prediction of human thermoregulatory and temperature responses to a wide range of environmental conditions. International Journal of Biometeorology, v. 45, n. 3, p. 143-159, 2001.

FINCHAM, W.; TEHRANI, F. T. On the regulation of cardiac output and cerebral blood flow. Journal of biomedical engineering, v. 5, n. 1, p. 73-75, 1983.

FOWLER, W. S. Lung function studies. II. The respiratory dead space. American Journal of Physiology, v. 154, n. 3, p. 405-416, 1948.

GAGGE, A. P.; STOLWIJK, J. A. J.; NISHI, Y. An effective temperature scale based upon a simple model of human physiological temperature response. ASHRAE Transactions, v. 77, p. 247-262, 1971.

GAOHUA, L.; KIMURA, H. A mathematical model of respiratory and biothermal dynamics in brain hypothermia treatment. IEEE Transactions on Biomedical Engineering, v. 55, n. 4, p. 1266-1278, 2008.

GARDNER, G. G.; MARTIN, C. J. The mathematical modelling of thermal responses of normal subjects and burned patients. Physiological Measurement, v. 15, n. 4, p. 381-400, 1994.

GONZÁLEZ-ALONSO, J.; QUISTORFF, B.; KRUSTRUP, P.; BANGSBO, J.; SALTIN, $B$. Heat production in human skeletal muscle at the onset of intense dynamic exercise. The Journal of Physiology, v. 524, n. 2, p. 603-615, 2000.

GORDON, R. G.; ROEMER, R. B.; HORVATH, S. M. A mathematical model of the human temperature regulatory system - transient cold exposure response. IEEE Transactions on Biomedical Engineering, n. 6, p. 434-444, 1976. 
GRAY, H. Anatomy of the human body. 20. ed. Philadelphia: Lea and Febiger, 1918.

GRAY, J. S. The multiple factor theory of the control of respiratory ventilation. Science, v. 103, n. 2687, p. 739-744, 1946.

GRODINS, F. S.; BUELL, J.; BART, A. J. Mathematical analysis and digital simulation of the respiratory control system. Journal of Applied Physiology, v. 22, n. 2, p. 260-276, 1967.

GRODINS, F. S.; GRAY, J. S.; SCHROEDER, K. R.; NORINS, A. L.; JONES, R. W. Respiratory responses to $\mathrm{CO}_{2}$ inhalation. A theoretical study of a nonlinear biological regulator. Journal of Applied Physiology, v. 7, n. 3, p. 283-308, 1954.

GUYTON, A. C.; HALL, J. E. Textbook of medical physiology. 11. ed. Philadelphia: Saunders, 2006.

HALDANE, J. S.; PRIESTLEY, J. G. The regulation of the lung-ventilation. Journal of Physiology, v. 32, p. 225-266, 1905.

HALLIBURTON, W. D. Handbook of physiology. 11. ed. Philadelphia: P. Blakiston's Son Co., 1914.

HAMMEL, H. T.; JACKSON, D. C.; STOLWIJK, J. A. J.; HARDY, J. D.; STROMME, S. B. Temperature regulation by hypothalamic proportional control with an adjustable set point. Journal of Applied Physiology, v. 18, n. 6, p. 1146-1154, 1963.

HANCOCK, P. A. Simulated and experimental temperature responses in man during exercise in varying environments. Computers in Biology and Medicine, v. 10, p. 19, 1980.

HANSON, R. Respiratory heat loss at increased core temperature. Journal of Applied Physiology, v. 37, n. 1, p. 103-107, 1974.

HARDY, J. D.; BARD, P. Body temperature regulation. In: MOUNTCASTLE, V. B. (Ed.). Medical Physiology. 13. ed. St. Louis: C.V. Mosby Company, 1974. v. 2, cap. 56, p. 1305-1342.

HAYWARD, J. S.; ECKERSON, J. D.; COLLIS, M. L. Thermoregulatory heat production in man: prediction equation based on skin and core temperatures. Journal of Applied Physiology, v. 42, n. 3, p. 377-384, 1977.

HEDLEY-WHYTE, J.; LAVER, M. B. $\mathrm{O}_{2}$ solubility in blood and temperature correction factors for $P_{\mathrm{O}_{2}}$. Journal of Applied Physiology, v. 19, n. 5, p. 901-906, 1964.

HILL, A. V. The possible effects of the aggregation of the molecules of haemoglobin on its dissociation curves. Journal of Physiology, v. 40, p. 4-7, 1910.

HORGAN, J. D.; LANGE, R. L. Digital computer simulation of respiratory response to cerebrospinal fluid $P_{\mathrm{CO}_{2}}$ in the cat. Biophysical Journal, v. 5, n. 6, p. 935-945, 1965.

HSU, F. T.; HWANG, C. L.; FAN, L. T. Steady-state optimization of an integrated human thermal system. Computers in biology and medicine, v. 3, n. 4, p. 407-425, 1973. 
HUGHES, J. M. B.; BATES, D. V. Historical review: the carbon monoxide diffusing capacity $\left(D_{L C O}\right)$ and its membrane $\left(D_{M}\right)$ and red cell $\left(\Theta . V_{c}\right)$ components. Respiratory Physiology \& Neurobiology, v. 138, n. 2-3, p. 115-142, 2003.

HUIZENGA, C.; ZHANG, H.; ARENS, E. A model of human physiology and comfort for assessing complex thermal environments. Building and Environment, v. 36, n. 6, p. 691-699, 2001.

JI, Y.; LIU, J. Numerical studies on the effect of lowering temperature on the oxygen transport during brain hypothermia resuscitation. Computers in Biology and Medicine, v. 32, n. 6, p. 495-514, 2002.

KANDJOV, I. M. Heat and water rate transfer processes in the human respiratory tract at various altitudes. Journal of Theoretical Biology, v. 208, n. 3, p. 287-293, 2001.

KAPPEL, F.; BATZEL, J. J. Survey of research in modeling the human respiratory and cardiovascular systems. In: SMITH, R. C.; DEMETRIOU, M. (Ed.). Research directions in distributed parameter systems. Natick: Society for Industrial Mathematics, 2003. cap. 8, p. 187-218.

KELMAN, G. R. Digital computer subroutine for the conversion of oxygen tension into saturation. Journal of Applied Physiology, v. 21, n. 4, p. 1375-1376, 1966.

KELMAN, G. R. Computer program for the production of $\mathrm{O}_{2}-\mathrm{CO}_{2}$ diagrams. Respiration physiology, v. 4, n. 2, p. 260-269, 1968.

KHOO, M. C.; YAMASHIRO, S. M. Models of control of breathing. In: CHANG, H. K.; PAIVA, M. (Ed.). Respiratory physiology: an analytical approach. New York: Dekker, 1989. cap. 18, p. 799-829.

KHOO, M. C. K.; KRONAUER, R. E.; STROHL, K. P.; SLUTSKY, A. S. Factors inducing periodic breathing in humans: a general model. Journal of Applied Physiology, v. 53, n. 3, p. 644-659, 1982.

KONZ, S.; HWANG, C.; DHIMAN, B.; DUNCAN, J.; MASUD, A. An experimental validation of mathematical simulation of human thermoregulation. Computers in Biology and Medicine, v. 7, n. 1, p. 71-82, 1977.

KRATZ, A.; SLUSS, P. M.; JANUZZI JR., J. L.; LEWANDROWSKI, K. B. Laboratory values of clinical importance. In: KASPER, D. L.; FAUCI, A. S.; LONGO, D. L.; BRAUNWALD, E.; HAUSER, S. L.; JAMESON, J. L. (Ed.). Harrison's principles of internal medicine. 16. ed. New York: McGraw-Hill, 2005. p. A1-A15.

KRONEnBERG, R.; HAMILTON, F. N.; GABEL, R.; HICKEY, R.; READ, D. J.; SEVERINGHAUS, J. Comparison of three methods for quantitating respiratory response to hypoxia in man. Respiration physiology, v. 16, n. 1, p. 109-125, 1972.

LAMBERTSEN, C. J. The atmosphere and gas exchanges with the lungs and blood. In: MOUntCASTle, V. B. (Ed.). Medical Physiology. 13. ed. St. Louis: C.V. Mosby Company, 1974a. v. 2, cap. 59, p. 1372-1398. 
LAMBERTSEN, C. J. Chemical control of respiration at rest. In: MOUNTCASTLE, V. B. (Ed.). Medical Physiology. 13. ed. St. Louis: C.V. Mosby Company, 1974b. v. 2, cap. 62 , p. 1447-1495.

LAMBERTSEN, C. J. Physical and mechanical aspects of respiration. In: MOUNTCASTLE, V. B. (Ed.). Medical Physiology. 13. ed. St. Louis: C.V. Mosby Company, 1974c. v. 2, cap. 58, p. 1361-1371.

LAMBERTSEN, C. J. Transport of oxygen and carbon dioxide by the blood. In: MOUNTCASTLE, V. B. (Ed.). Medical Physiology. 13. ed. St. Louis: C.V. Mosby Company, 1974d. v. 2, cap. 60, p. 1399-1422.

LARSEN, O. A.; LASSEN, N. A.; QUAADE, F. Blood flow through human adipose tissue determined with radioactive xenon. Acta Physiologica Scandinavica, v. 66, n. 3, p. 337-345, 1966.

LIANG, P. J.; BASCOM, D. A.; ROBBINS, P. A. Extended models of the ventilatory response to sustained isocapnic hypoxia in humans. Journal of Applied Physiology, v. 82, n. 2, p. 667-677, 1997.

LLOYD, B. B.; JUKES, M. G. M.; CUNNINGHAM, D. J. C. The relation between alveolar oxygen pressure and the respiratory response to carbon dioxide in man. Experimental Physiology, v. 43, n. 2, p. 214-227, 1958.

LONGOBARDO, G.; EVANGELISTI, C. J.; CHERNIACK, N. S. Effects of neural drives on breathing in the awake state in humans. Respiration physiology, v. 129, n. 3, p. 317-333, 2002.

LONGOBARDO, G. S.; CHERNIACK, N. S.; FISHMAN, A. P. Cheyne-Stokes breathing produced by a model of the human respiratory system. Journal of Applied Physiology, v. 21, n. 6, p. 1839-1846, 1966.

LU, K.; CLARK, J. W. J.; GHORBEL, F. H.; WARE, D. L.; ZWISCHENBERGER, J. B.; BIDANI, A. Whole-body gas exchange in human predicted by a cardiopulmonary model. Cardiovascular Engineering, v. 3, n. 1, p. 1-19, 2002.

MALISKA, C. R. Transferência de calor e mecânica dos fluidos computacional. 2. ed. Rio de Janeiro: LTC, 2004.

MCCUllOUGH, E. A.; JONES, B. W.; HUCK, J. A comprehensive data base for estimating clothing insulation. ASHRAE Transactions, v. 91, n. 2, p. 795-802, 1985.

MCCUlLOUGH, E. A.; JONES, B. W.; TAMURA, T. A data base for determining the evaporative resistance of clothing. ASHRAE Transactions, v. 95, n. 2, p. 316-328, 1989.

MILHORN JR., H. T.; BENTON, R.; ROSS, R.; GUYTON, A. C. A mathematical model of the human respiratory control system. Biophysical Journal, v. 5, n. 1, p. 27-46, 1965.

MILlER, N. C.; SEAGRAVE, R. C. A model of human thermoregulation during water immersion. Computers in biology and medicine, v. 4, n. 2, p. 165, 1974. 
MOTTRAM, R. F. The oxygen consumption of human skeletal muscle in vivo. Journal of Physiology, v. 128, n. 2, p. 268-276, 1955.

NADEL, E. R.; BULLARD, R. W.; STOLWIJK, J. A. Importance of skin temperature in the regulation of sweating. Journal of applied physiology, v. 31, n. 1, p. 80-87, 1971.

NADEL, E. R.; HORVATH, S. M.; DAWSON, C. A.; TUCKER, A. Sensitivity to central and peripheral thermal stimulation in man. Journal of Applied Physiology, v. 29, n. 5, p. 603-609, 1970.

OLSON, D. E.; DART, G. A.; FILLEY, G. F. Pressure drop and fluid flow regime of air inspired into the human lung. Journal of Applied Physiology, v. 28, n. 4, p. 482-494, 1970.

PATANKAR, S. V. Numerical heat transfer and fluid flow. New York: Hemisphere, 1980.

PENNES, H. H. Analysis of tissue and arterial blood temperatures in the resting human forearm. Journal of Applied Physiology, v. 1, n. 2, p. 93-122, 1948.

PIIPER, J.; MEYER, M.; MARCONI, C.; SCHEID, P. Alveolar-capillary equilibration kinetics of ${ }^{13} \mathrm{CO}_{2}$ in human lungs studied by rebreathing. Respiration Physiology, v. 42, n. 1 , p. 29-41, 1980.

QIU, A.; BAI, J. Multiple modeling in the study of interaction of hemodynamics and gas exchange. Computers in biology and medicine, v. 31, n. 1, p. 59-72, 2001.

RAHN, H.; OTIS, A. B. Alveolar air during simulated flights to high altitudes. American Journal of Physiology, v. 150, n. 1, p. 202-221, 1947.

RAVEN, P. B.; NIKI, I.; DAHMS, T. E.; HORVATH, S. M. Compensatory cardiovascular responses during an environmental cold stress, $5{ }^{\circ} \mathrm{C}$. Journal of Applied Physiology, v. 29, n. 4, p. 417-421, 1970.

RAVEN, P. R.; HORVATH, S. M. Variability of physiological parameters of unacclimatized males during a two-hour cold stress of $5{ }^{\circ} \mathrm{C}$. International Journal of Biometeorology, v. 14, n. 3, p. 309-320, 1970.

REBUCK, A. S.; WOODLEY, W. E. Ventilatory effects of hypoxia and their dependence on $\mathrm{p}_{\mathrm{CO}_{2}}$. Journal of Applied Physiology, v. 38, n. 1, p. 16-19, 1975.

REYNOLDS, W. J.; MILHORN JR., H. T. Transient ventilatory response to hypoxia with and without controlled alveolar $\mathrm{P}_{\mathrm{CO}_{2}}$. Journal of Applied Physiology, v. 35, n. 2, p. 187, 1973.

REYNOLDS, W. J.; MILHORN JR., H. T.; HOLLOMAN JR., G. H. Transient ventilatory response to graded hypercapnia in man. Journal of Applied Physiology, v. 33, n. 1, p. 47-54, 1972.

ROBINSON, S. Physiology of muscular exercise. In: MOUNTCASTLE, V. B. (Ed.). Medical Physiology. 13. ed. St. Louis: C.V. Mosby Company, 1974. v. 2, cap. 55, p. $1273-1304$. 
ROUGHTON, F. J. W. Transport of oxygen and carbon dioxide. In: Handbook of Physiology. Respiration. Washington: American Physiological Society, 1964. v. 1, cap. 31.

SALLOUM, M.; GHADDAR, N.; GHALI, K. A new transient bioheat model of the human body and its integration to clothing models. International Journal of Thermal Sciences, v. 46, n. 4, p. 371-384, 2007.

SALTIN, B.; GAGGE, A. P.; STOLWIJK, J. A. Body temperatures and sweating during thermal transients caused by exercise. Journal of Applied Physiology, v. 28, n. 3, p. 318-327, 1970.

SAVAGE, M. V.; BRENGELMANN, G. L. Control of skin blood flow in the neutral zone of human body temperature regulation. Journal of Applied Physiology, v. 80, n. 4, p. 1249-1257, 1996.

SCHENKMAN, K. A.; MARBLE, D. R.; BURNS, D. H.; FEIGL, E. O. Myoglobin oxygen dissociation by multiwavelength spectroscopy. Journal of Applied Physiology, v. 82, n. 1, p. 86-92, 1997.

SEVERENS, N. M. W.; LICHTENBELT, W. D. van M.; FRIJNS, A. J. H.; STEENHOVEN, A. A. V.; MOL, B. A. J. M. de; SESSLER, D. I. A model to predict patient temperature during cardiac surgery. Physics in medicine and biology, v. 52, n. 17, p. 5131-5145, 2007.

SEVERINGHAUS, J. Proposed Standard Determination of Ventilatory. Chest, v. 70, n. 1, p. 129-131, 1976.

SEVERINGHAUS, J. W. Blood gas calculator. Journal of Applied Physiology, v. 21, n. 3, p. 1108-1116, 1966.

SHARAN, M.; SELVAKUMAR, S. A mathematical model for the simultaneous transport of gases to compute blood carboxyhaemoglobin build-up due to CO exposures: application to the end-expired breath technique. Environmental Pollution, v. 105, n. 2, p. 231-242, 1999.

SIGGAARD-ANDERSEN, O. Titratable acid or base of body fluids. Annals of the New York Academy of Sciences, v. 133, n. 1, p. 41-58, 1966.

SMITH, P.; TWIZELL, E. H. The extrapolation of padé approximants in the closed-loop simulation of human thermoregulation. Applied Mathematical Modelling, v. 6, n. 2, p. 81-91, 1982 .

STOLWIJK, J. A. J. A mathematical model of physiological temperature regulation in man. Washington, 1971. NASA Report CR-1855.

STOLWIJK, J. A. J.; HARDY, J. D. Temperature regulation in man - a theoretical study. Pflügers Archiv European Journal of Physiology, v. 291, n. 2, p. 129-162, 1966a.

STOLWIJK, J. A. J.; HARDY, J. D. Partitional calorimetric studies of responses of man to thermal transients. Journal of Applied Physiology, v. 21, n. 3, p. 967-977, 1966b. 
STUHMILLER, J. H.; STUHMILLER, L. M. A mathematical model of ventilation response to inhaled carbon monoxide. Journal of Applied Physiology, v. 98, n. 6, p. 2033-2044, 2005.

THOMAS, L. J. Algorithms for selected blood acid-base and blood gas calculations. Journal of Applied Physiology, v. 33, n. 1, p. 154-158, 1972.

TIKUISIS, P.; GIESBRECHT, G. G. Prediction of shivering heat production from core and mean skin temperatures. European journal of applied physiology and occupational physiology, v. 79, n. 3, p. 221-229, 1999.

TIKUISIS, P.; GONZALEZ, R. R.; PANDOLF, K. B. Thermoregulatory model for immersion of humans in cold water. Journal of Applied Physiology, v. 64, n. 2, p. 719-727, 1988.

TODD, R. B.; BOWMAN, W. The physiological anatomy and physiology of man. Philadelphia: Lea and Blanchard, 1850.

TOPOR, Z. L.; PAWLICKI, M.; REMMERS, J. E. A computational model of the human respiratory control system: responses to hypoxia and hypercapnia. Annals of biomedical engineering, v. 32, n. 11, p. 1530-1545, 2004.

TURinO, G. M.; BERGOFSKY, E. H.; GOLDRING, R. M.; FISHMAN, A. P. Effect of exercise on pulmonary diffusing capacity. Journal of Applied Physiology, v. 18, n. 3, p. $447-456,1963$.

TURRI, F. Análise teórico-experimental do transporte de oxigênio e gás carbônico em oxigenadores de sangue. Tese (Doutorado) — Escola Politécnica, Universidade de São Paulo, São Paulo, 2006.

UNITED STATES AIR FORCE. United States Naval Flight Surgeon's Manual. 3. ed. United States of America, 1991.

URSINO, M.; MAGOSSO, E. A theoretical analysis of the carotid body chemoreceptor response to $\mathrm{O}_{2}$ and $\mathrm{CO}_{2}$ pressure changes. Respiratory physiology \& neurobiology, v. 130, n. 1, p. 99-110, 2002.

URSINO, M.; MAGOSSO, E.; AVANZOLINI, G. An integrated model of the human ventilatory control system: the response to hypercapnia. Clinical Physiology, v. 21, n. 4, p. 447-464, 2001a.

URSINO, M.; MAGOSSO, E.; AVANZOLINI, G. An integrated model of the human ventilatory control system: the response to hypoxia. Clinical Physiology, v. 21, n. 4, p. $465-477,2001 b$.

VAN WYLEN, G. J.; SONNTAG, R. E.; BORGNAKKE, C. Fundamentals of thermodynamics. 5. ed. New Jersey: John Wiley \& Sons, 1998.

WARNER, H. R.; SEAGRAVE, R. C. A distributed-lumped parameter model of mass transfer in the respiratory system. In: Chemical Engineering Progress Symposium Series. [S.l.: s.n.], 1970. v. 66, n. 99, p. 12-21. 
WERNER, J.; BUSE, M. Temperature profiles with respect to inhomogeneity and geometry of the human body. Journal of Applied Physiology, v. 65, n. 3, p. 1110-1118, 1988.

WERNER, J.; REENTS, T. A contribution to the topography of temperature regulation in man. European Journal of Applied Physiology, v. 45, n. 1, p. 87-94, 1980.

WISSLER, E. H. Steady-state temperature distribution in man. Journal of Applied Physiology, v. 16, n. 4, p. 734-740, 1961.

WISSLER, E. H. A mathematical model of the human thermal system. Bulletin of Mathematical Biology, v. 26, n. 2, p. 147-166, 1964.

WISSLER, E. H. Pennes' 1948 paper revisited. Journal of Applied Physiology, v. 85, n. 1, p. 35-41, 1998.

WISSLER, E. H. A quantitative assessment of skin blood flow in humans. European Journal of Applied Physiology, v. 104, n. 2, p. 145-157, 2008.

WOLF, M. B.; GARNER, R. P. A mathematical model of human respiration at altitude. Annals of biomedical engineering, v. 35, n. 11, p. 2003-2022, 2007.

WYSS, C. R.; BRENGELMANN, G. L.; JOHNSON, J. M.; ROWELL, L. B.; NIEDERBERGER, M. Control of skin blood flow, sweating, and heart rate: role of skin vs. core temperature. Journal of Applied Physiology, v. 36, n. 6, p. 726-733, 1974.

YAMASHIRO, S. M. Non-linear dynamics of human periodic breathing and implications for sleep apnea therapy. Medical \& biological engineering \& computing, v. 45, n. 4, p. 345-356, 2007.

YI, L.; FENGZHI, L.; YINGXI, L.; ZHONGXUAN, L. An integrated model for simulating interactive thermal processes in human-clothing system. Journal of Thermal Biology, v. 29 , n. $7-8$, p. $567-575,2004$.

YING, B. A.; KWOK, Y. L.; LI, Y.; YEUNG, C. Y.; LI, F. Z.; LI, S. Mathematical modeling of thermal physiological responses of clothed infants. Journal of Thermal Biology, v. 29, n. 7-8, p. 559-565, 2004.

ZHOU, H.; SAIDEL, G. M.; CABRERA, M. E. Multi-organ system model of $\mathrm{O}_{2}$ and $\mathrm{CO}_{2}$ transport during isocapnic and poikilocapnic hypoxia. Respiratory physiology \& neurobiology, v. 156, n. 3, p. 320-330, 2007. 